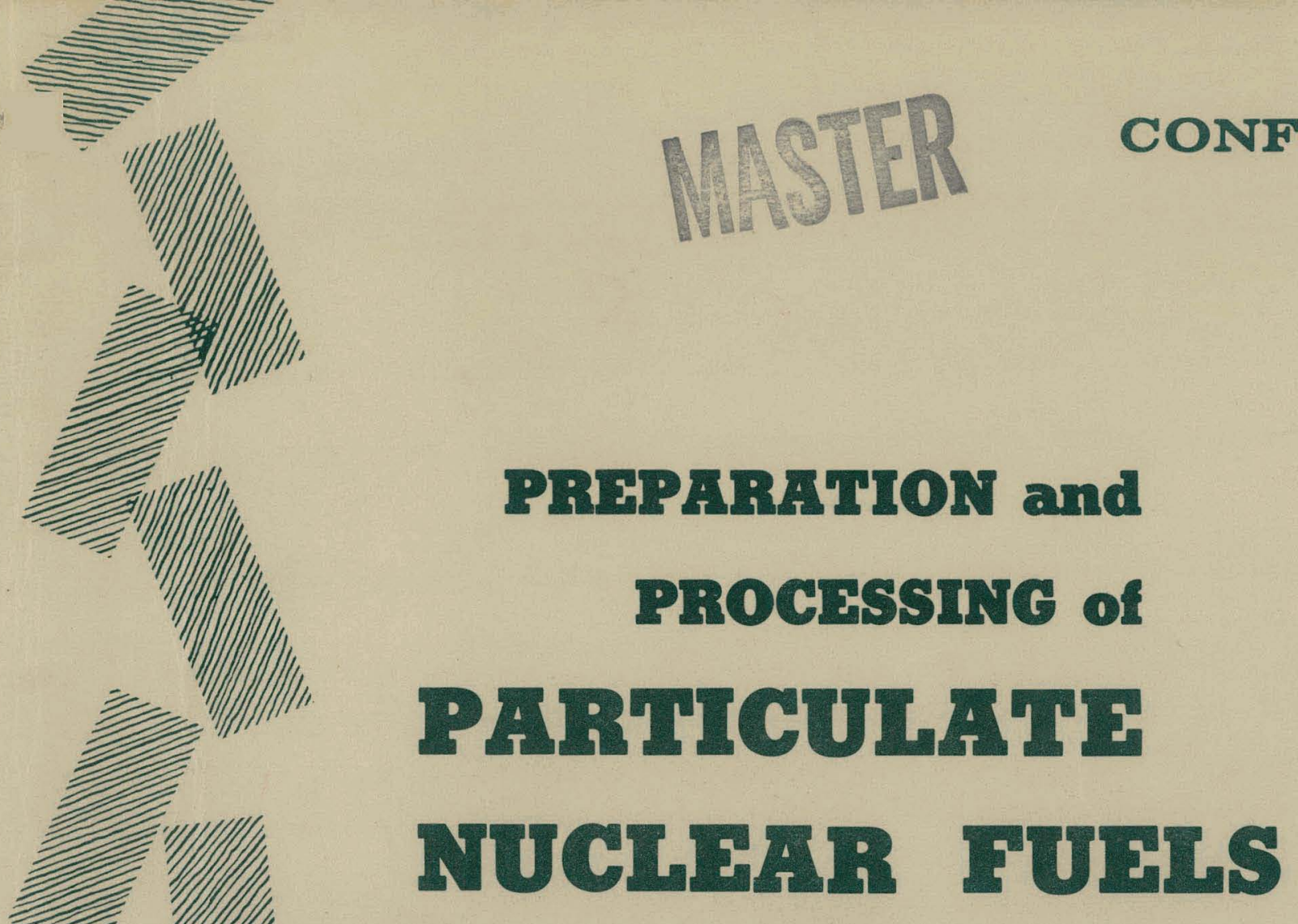

Proceedings of a Symposium held at New York

September 9, 1963

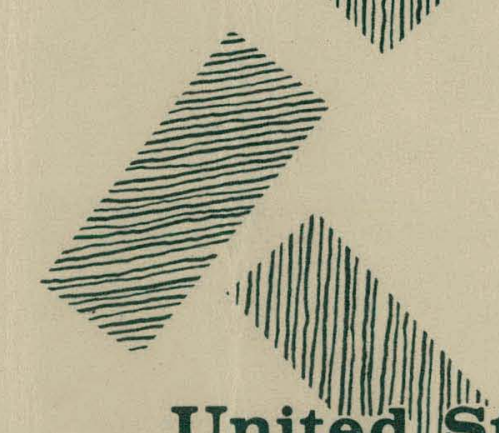

United States Atomic Energy Commission (n) 


\section{DISCLAIMER}

This report was prepared as an account of work sponsored by an agency of the United States Government. Neither the United States Government nor any agency Thereof, nor any of their employees, makes any warranty, express or implied, or assumes any legal liability or responsibility for the accuracy, completeness, or usefulness of any information, apparatus, product, or process disclosed, or represents that its use would not infringe privately owned rights. Reference herein to any specific commercial product, process, or service by trade name, trademark, manufacturer, or otherwise does not necessarily constitute or imply its endorsement, recommendation, or favoring by the United States Government or any agency thereof. The views and opinions of authors expressed herein do not necessarily state or reflect those of the United States Government or any agency thereof. 


\section{DISCLAIMER}

Portions of this document may be illegible in electronic image products. Images are produced from the best available original document. 


\section{LEGAL NOTICE}

This report was prepared as an account of Government sponsored work. Neither the United States, nor the Commission, nor any person acting on behalf of the Commission:

A. Makes any warranty or representation, expressed or implied, with respect to the accuracy, completeness, or usefulness of the information contained in this report, or that the use of any information, apparatus, method, or process disclosed in this report may not infringe privately owned rights; or

B. Assumes any liabilities with respect to the use of, or for damages resulting from the use of any information, apparatus, method, or process disclosed in this report.

As used in the above, "person acting on behalf of the Commission" includes any employee or contractor of the Commission, or employee of such contractor, to the extent that such employee or contractor of the Commission, or employee of such contractor prepares, disseminates, or provides access to, any information pursuant to his employment or contract with the Commission, or his employment with such contractor.

This report has been reproduced directly from the best available copy.

Printed in USA. Price $\$ 2.00$. Available from the Clearinghouse for Federal Scientific and Technical Information, National Bureau of Standards, U. S. Department of Commerce, Springfield, Va. 
PRÉPARATION AND PROCESSING

of

PARTICULATE NUCLEAR FUELS

Proceedings of a symposium sponsored by

The American Chemical Society, Division of Nuclear Chemistry and Technology, New York, September 9, 1963 


\section{THIS PAGE WAS INTENTIONALLY LEFT BLANK}


FOREWORD

The symposium at which the papers in this volume were presented was organized by the Nuclear Chemistry and Technology Division of the American Chemical Society as part of the 145th National. Meeting in New York, September 8-13, 1963. The topic was chosen to cover those particulate nuclear fuels whose particle size, shape, distribution, or possession of a coating is a significant design factor in their end use. Among these are cermet-type elements with dispersed uncoated fuel particles, particles for fissiochemical reactors, and particles coated individually for use in dispersion elements or in fluidized-bed or settled-bed nuclear reactors. Papers were presented on the requirements for particulate fuels, their fabrication, coating and reprociessing.

Appreciation is due the authors for making this information available.

John M. Blocher, Jr. Battelle Memorial Institute Symposium Chairman and Editor 
THIS PAGE

WAS INTENTIONALLY

LEFT BLANK 
TABLE OF CONTENTS

Page

1. COATED PARTICLES IN THE CIVILIAN GAS-COOLED REACTOR PROGRAM -

R. E. Pahler .

2. THE PREPARATION AND PROPERTIES OF PARTICULATE OXIDE FUELS -

R. E. Latta and C. C. Browne

3. THE SOL-GEL PROCESS FOR PREPARING SPHEROIDAL PARTICLES OF THE

DICARBIDES OF THORIUM AND THORIUM-URANIUM MIXTURES - James L. Kelley,

A. Todd Kleinsteuber, Sam D. Clinton, and Orlen C. Dean . . • 21

4. PREPARATION OF DENSE URANIUM DIOXIDE PARTICLES FROM URANIUM

HEXAFLUORIDE IN A FLUIDIZED BED - Irving E. Knudsen, Norman Levitz,

and Albert A. -Jonke

5. FUEL REQUIREMENTS FOR FISSIOCHEMICAL PRODUCTION - R. I. Pearson,

J. H. Cusack, and D. E. Deutsch .

6. THE PREPARATION AND PROCESSING OF FUEL FOR FISSIOCHEMICAL REACTORS -

R. L. Pearson.

7. PREPARATION AND PROPERTIES OF PLUTONIUM-BEARING OXIDE PARTICULATES -

Lerroy V. Jones, Donald, Ofte, Kenneth D. Phipps, and

Philip A. Tucker

8. PREPARATION AND PROPERTIES OF SPHERICAL PARTICULATE NUCLEAR FUELS FOR

PLUTONIUM-FUELED REACTORS - R. J. Atkins, E. M. Benson, C. S. Ca1dwell,

R. S. Swain, and M. J. Zambernard.

9. THE PROCESSING, PHYSICAL PROPERTIES AND PERFORMANCE OF PYROLYTIC

GRAPHITE COATED $\mathrm{UC}_{2}$ - R. L. Finicle and S. A. Taylor • • • • • 127

10. PREPARATION AND EVALUATION OF CARBON-COATED FUEL PARTICLES -

M. F. Browning, A. C. Secrest, V. M. Secrest, R. B. Landrigan,

and J. M. Blocher, Jr.

11. PROCESSING OF GRAPHITE REACTOR FUELS CONTAINING COA'IED PARTICLES AND

CERAMICS - R. E: Blanco, G. I. Cathers, L. M. Ferris, T. A. Gens,

R. W. Horton, and E. L. Nicholson.

RECOVERY OF URANIUM FROM PYROLYTIC CARBON - COATED UC 2 SPHEROIDS -

H. Katz and J. Wagner 


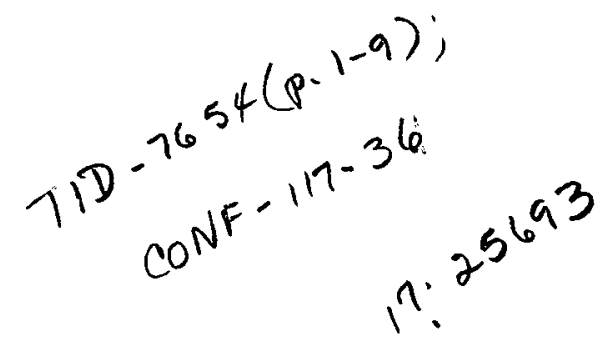

\section{COATED PARTICLES IN THE CIVILIAN \\ GAS-COOLED REACTOR PROGRAM.}

By R. E. Pahler, U.S. Atomic Energy Commission, Washington, D.C. (Presented by R. F. Kirkpatrick)

\section{ABSTRACT}

Ceramic coated fuel particles have been developed primarily for gas-cooled, graphite-moderated reactors. Coated particles are uniquely suited for this application because they permit high operating temperatures, good neutron economy and high fuel burnup. The graphite. moderator provides a matrix for the. coated particles that is easily fabricated, conducts heat effectively and is economical. The helium coolant is compatible with all coated-particle concepts.

Most gas-cooled reactors currently being developed; Peach Bottom, Dragon and AVR, utilize pyrographite-coated. $\mathrm{UC}_{2}$ because it is chemically stable to very high temperatures. However, other coated-particle designs including $\mathrm{Al}_{2} \mathrm{O}_{3}$-coated $\mathrm{UO}_{2}$ have also shown promise at temperatures of interest. Other possible coated-particle desings include pyrographite:coated $\mathrm{UO}_{2}$, $\mathrm{BeO}$ and $\mathrm{UO}_{2}$, various metal carbides on $\mathrm{UC}_{2}$, and combinations of the above coating materials. Much work remains to be accomplished. to fully evaluate these various possible coated-particle fuels for gascooled reactors. 


\section{INTRODUCTION}

A brief history of ceramic-coated-particle development is of intérest because it illustrates the reasons why coated particles have become an almost universal fuel for advanced civilian gas cooled reactors. It also shows the requirements and limitations of high-performance coated particles.

In the initial investigations of the pebble bed reactor, plain graphite balls containing $\mathrm{UO}_{2}$ or $\mathrm{UC}_{2}$ were irradiated. These in-pile tests showed that this fuel concept had excellent irradiation stability and met all of the requirements of a high-neutron-economy, hi.gh-temperature fuel. However, excessive quantities of fission products were released. Therefore, efforts were made to apply a coating around the outside of the balls to retain fission products. Silicon carbide and pyrolytic graphite were the principal ball coatings investigated because they had good nuclear properties and the required high temperature stability. In-pile tests of these materials usually showed excellent fission-product retention during initial operation, but later failure with sudden release of fission products, usually during a thermal cycle. This showed that ceramic coatings could retain fission products but even in a perfect shape, the sphere, they were highly sensitive to thermally produced or other mechanical stresses. Next, metal-coated fuel particles were tested in a graphite ball, but none of the available metal coatings were stable in graphite at the required temperatures. This led directly to use of the ceramic coatings on fuel particles. It was reasoned that with the smaller fuel particle, 200 microns compared to $1-1 / 2^{\prime \prime}$ ball, the ceramic coating would be stronger. Also a thicker coating, relative to 
the particle diameter, could be used. The early tests of ceramic-coated particles, first $\mathrm{Al}_{2} \mathrm{O}_{3}$-coated $\mathrm{UO}_{2}$ and later pyrographite-coated $\mathrm{UC}_{2}$ showed real promise.

The Peach Bottom project was also being started about this time and was having trouble with the highly reactive characteristics of $(\mathrm{U}-\mathrm{Th}) \mathrm{C}_{2}$. This project used a vent system to trap fission products and so did not require high fission product retention within the fuel. Therefore, this project began to investigate pyrographite-coated UC ${ }_{2}$ just to protect the carbides from air prior to loading into the reactor. The ability of these coatings to also retain fission products has permitted substantial simplifications of the Peach Bottom fuel design.

With this background, the requirements of a fuel element for advanced civilian gas-cooled reactors will be reviewed.

\section{Fue1 Requ1rements}

The requirements for a gas-cooled reactor fuel are:

(1) High temperature

(2) Good neutron economy

(3) High burnup

(4) Chemical stability

(5) Ease of fabrication and reprocessing.

One of the prime advantages of gas-cooled reactors is their ability to achieve modern steam conditions in the power-recovery circuit. This requires $1200 \mathrm{~F}$ to $1400 \mathrm{~F}$ outlet gas temperatures to achieve $1050 \mathrm{~F}$ steam with high heat-transfer rates in the steam generator. Beyond 
this, there is the potential for gas-turbine topping of the steam system which can result in net plant efficiency of over $50 \%$. Gas temperatures in the $1600-1800 \mathrm{~F}$ range could ultimately be required for such cycles. On the assumption that the peak fuel temperature is at least $800 \mathrm{~F}$ above the outlet gas temperature, coated particles must be capable of at least $2000 \mathrm{~F}$ and ultimately $3000 \mathrm{~F}$ operation will be desirable.

The next two characteristics, good neutron economy and high burnup, are closely interrelated. Gas-cooled reactors have the basic characteristics of a high conversion-ratio system because its graphite moderator is very efficient and helium coolant absorbs no neutrons. These high conversion characteristics are enhanced by the-use of the thorium fuel cycle. If low cross-section cladding can be used, the resulting high internal fuel-conversion ratio will maintain reactivity for high burnups. Ceramic coated-particle fuel meets both of these tests; it has very low crossfisection and is capable of sustaining high burnup. The most outstanding test has been an ORNL irradiation of loose coated particles to $280,000 \mathrm{MWD} /$ ton at $600 \mathrm{~F}$ to $1700 \mathrm{~F}$. The nuclear - characteristics of this fuel are so good that break-even breeders appear achievable, especially if some $\mathrm{BeO}$ is used for its $n-2 n$ contribution. When one is striving for such high conversion ratios, even the slightest nuclear poison is important. Therefore, PyC particle coating has definite advantages over $\mathrm{Al}_{2} \mathrm{O}_{3}$ coating. 
Chemical stability is important even in a helium-cooled reactor. The fuel must exist in normal atmosphere after it is fabricated and before it is charged into the reactor. As pointed out before, this can be a serious problem where mixed uranium-thorium carbides are involved. During exposure in the reactor, the helium is normally very pure. However, there is always the possibility of temporary steam leaks and the fuel may therefore be exposed to moisture for short periods. Unprotected carbides would quickly oxidize, and the resulting swelling could ruin the fuel. The coated particles should be capable of sustaining such short-term exposures to moisture without failing.

The final requirements are ease of fabricating and reprocessing. The fabrication processes used to date involve many steps, are rather cumbersome, and result in high fabrication costs. The fuel must first be sized and formed into spheroids which is generally accomplished by melting. This fuel is then coated and finally formed into fuel bodies generally using a graphite matrix. Potential areas of simplification will be touched on later in this paper and covered more extensively in the following papers.

Reprocessing presents the usual enigma. The more effective we are in fabricating a fuel that will withstand the rigors of reactor operation, the more difficult it is to reprocess. In this area, coated particles definitely present greater problems than unprotected graphite fuel. The coating must be removed before the fuel can be reprocessed. of the various possible coatings, pyrographite appears the best from 
a reprocessing viewpoint. Whereas it will withstand short exposures to oxidants because of its slow oxidization, it can be completely removed by controlled burning. There is no convenient way to remove the other potential coating materials such as $\mathrm{Al}_{2} \mathrm{O}_{3}$ or $\mathrm{SiC}$ except mechanical grinding which involves more severe technical difficulties.

\section{AEC Development Program on Coated Particles}

The following R\&D programs are underway to develop this fuel:

(1) Basic development - BMI

(2) AVR Fuel - ORNL

- Commercial Supplier

(3) Peach Botton - GA

(4) TARGET - GA

- ORNL

(5) Oxide-coated particles - GE Lockland

(6) Fue1 Recycle - ORNL

As an outgrowth of their initial work on ceramic-coated fuel particles, BMI has been conducting a basic investigation of both oxideand carbide-coated particles. This includes coating studies using $\mathrm{Al}_{2} \mathrm{O}_{3}$, BeO and pyrographite, out-of-pile characterization, and irradiation studies. Matrix studies have included both oxide and graphite matrices. A portion of this program will be described in a later paper.

We have been discussing a cooperative fuel-test program with the AVR pebble bed reactor being built by BBC-Krupp at Julich, Germany. This cooperation contemplates the testing of a U. S.-developed and fabricated 
coated-particle core in this reactor. ORNL is conducting the development and fuel design work and the fuel will be fabricated by a commercial supplier. ORNL is utilizing the extensive irradiation facilities which were built for gas-cooled fuel testing. These include inexpensive static capsules for loose-párticle testing in the LITR, high-flux sweep capsules in the ORR, and capsules for testing complete fuel balls in the core and reflector of the ORR. In addition, the ORR-2 loop is being used to test fuel balls at coolant flow conditions closely approximating reactor conditions. This loop will provide fission-product plateout data on graphite fuels.

The Peach Bottom reactor will use coated particles in a vented, graphite fuel element. Under the development program for this reactor, GA develioped production techniques for this fuel and is currently producing the Peach Bottom first core. Full-diameter, but shortened fuel elements have been tested under full reactor conditions in the GAIL loop. The element currently under test has achieved about 30,000 MWD/ton and the fission product release rate is currently about $1 / 100$ of design conditions. The objective of the TARGET fuel program is to develop an economical fuel system with breeding or near-breeding characteristics on recycle fuel. This will require reduced fuel-fabrication costs so that reduced exposure levels can be used. In addition; BeO will probably be incorporated to gain the benefit of the $n-2 n$ reaction. GA is designing and analyzing the fuel as part of their over-all system responsibilities and ORNL will perform irradiation tests utilizing the facilities described previous ly. 
GE-Lockland is conducting fabrication and analysis tests on

oxide-coated particles. This program will be described in a later paper.

ORNL is conducting a comprehensive program directed at

developing technology related to recycling graphite-based thorium fuels.

This includes development of the sol-gel process for remote fabrication

of microspheres and reprocessing development for graphite fuel. A

complete demonstration of recycling thorium-based graphite fuels will

be conducted in the Thorium Utilization Facility which is being constructed

at ORNL. These programs will be discussed in other papers.

Limitations of Coated Particle Fuels,

Since ceramic coated particles have found such wide

acceptance in gas-cooled reactors, one might wonder why they have not been applied.to other systems. Ceramic coated particles are not a "universal fuel" such as $\mathrm{UO}_{2}$ has proven to be. They have definite limitations :

(1) Low fuel loading $20 \% \max$.

(2) Requirement of matrix

(3) Difficulties with oxidizing coolants.

The first limitation results from the relatively thick coating required for good performance. With pyrographite coating, a coating thickness of about 100 microns appears desirable. If this thickness of coating is used on a 300 micron particle, the fuel fraction of the coated particle is about $20 \%$. This presents no' great problem in homogeneous graphite-moderated reactors because the carbon-to-fuelvolume ratio is in the range of 100-1. However, in many other types of 
reactors, especially low-enrichment water-cooled and moderated

reactors, a high fuel density is required. This same problem would exist in applying ceramic coated particles to fast reactors which also require a high fuel loading.

The second limitation is the requirement for a matrix to hold the coated particles and serve as a structural and heat-transfer medium. Graphite has proven to be an ideal matrix because it is cheap, has excellent thermal properties, and can be easily fabricated by a variety of techniques. Other matrix materials such as oxides, have proven to be very difficult to fabricate with coated particles and these other materials generally have inferior thermal properties.

The final limitation is difficulty with oxidizing coolants. Even $\mathrm{UO}_{-2}$, coated with oxide ceramics such as $\mathrm{Al}_{2} \mathrm{O}_{3}$, have shown sensitivity to oxidizing coolants, and generally perform better in a helium coolant.

Work has been conducted on other applications, and compatibility tests have been performed with water, air, organics, steam, molten salts and impure helium. However, this work has yet to point to a really attractive application other than gas-cooled reactors.

\section{$\underline{\text { Summary }}$}

We may summarize the major conclusions of our work on ceramic coated particles for gas-cooled reactors:

(1) Advantages - Temperature, neutron economy, burnup, chemical stability

(2) Best coating-Pyrographite, on basis of cost, neutron absorption, reprocessing

(3) Limitation - Fue1 loading, matrix requirements, coolant 
compatibility.

It is not meant to convey the impression that coated particles are well understood and completely evaluated. We have developed products which we feel confident are acceptable for current applications. However, our current understanding has resulted in large part from in-pile trial and error.

We definitely need a better understanding of the basic properties of these materials and the effects of reactor operation on each component of the coated particle. 


\title{
THE PREPARATION AND PROPERTIES OF
}

PARTICULATE OXIDE FUELS

\author{
By R.E. Latta and C.C. Browne
}

Nuclear Materials and Propulsion Operation

General Electric Company, Cincinnat1 15, Oh1o

\section{ABSTRACT}

Uranium dioxide is dimensionally unstable in oxidizing atmospheres at elevated temperaturés, but it can be partially stabilized against oxidation by the addition of certain other oxides such as $\mathrm{La}_{2} \mathrm{O}_{3}$ or $\mathrm{Y}_{2} \mathrm{O}_{3}$. Solid solution powders of $\mathrm{UO}_{2}$ with $\mathrm{Y}_{2} \mathrm{O}_{3}$ or with $\mathrm{Y}_{2} \mathrm{O}_{3}$ and $\mathrm{ZrO}_{2}$ were prepared and spheroidized in a direct current plasma flame. Some fractional volatilization of $\mathrm{UO}_{2}$ occurred during spheroldization, and starting compositions were adjusted to compensate for this fuel loss. X-ray examination of the fuel spheres indicated a single phase face-centered-cubic material. Potential applications of spherical oxide fuels are discussed.

\section{INTRODUCTION}

Particulate oxide fuels in the 30- to 50-micron size range offer the advantages of (1) high temperature capability, (2) high burnup capacity, and (3) possibility for use in a ceramic matrix without serious decrease in the strength of the matrix.

The properties and nuclear applications of one of the oxide fuels, uranium dioxide, have been reviewed in a publication of the United States Atomic Energy Commission ${ }^{1}$. Uranlum dioxide has a high melting polnt $\left(\sim 2800^{\circ} \mathrm{C}\right)$, but it is chemically and dimensionally unstable in 
oxldizing atmospheres at high temperatures. If the dioxide, which. has a fluorite structure, is heated in a1r, conversion to orthorhomblc $\mathrm{U}_{3} \mathrm{O}_{8}$ and a volume expansion of approximately 30 percent occur near $250^{\circ} \mathrm{C}^{1}$. In the same atmosphere and at temperatures above $1200^{\circ} \mathrm{C}$ the $\mathrm{U}_{3} \mathrm{O}_{8}$ exhibits appreciable vapor pressure because of oxidation to $\mathrm{UO}_{3}(\mathrm{~g})$. Uranium dioxide can be combined with certaln other oxides, such as $\mathrm{Ia}_{2} \mathrm{O}_{3}$ or $\mathrm{Y}_{2} \mathrm{O}_{3}$, to yield solid solutions in which the loss of nuclear fuel as $\mathrm{UO}_{3}(g)$ is inhibited ${ }^{2}$. The stability of the solid solutions appears to be associated with the fluorite structure, which persists at additions of $\mathrm{R}_{2} \mathrm{O}_{3}$ of approximately 50 mole percent, and probably depends on valence compensation of the $\mathrm{U}^{+6}$ lons by the more stable $\mathrm{R}^{+3}$ ions. Fuel retention and the face-centered-cubic structure can be maintained even when $\mathrm{ZrO}_{2}$ Is substituted for a part of the $\mathrm{Y}_{2} \mathrm{O}_{3}$ to yleld a ternary solution. The work reported here was concerned with the $\mathrm{UO}_{2}-\mathrm{Y}_{2} \mathrm{O}_{3}-\mathrm{ZrO}_{2}$ ternary.

\section{EXPERIMENTAL}

- The objective of the experimental work was the preparation of dense single phase $\mathrm{UO}_{2}-\mathrm{Y}_{2} \mathrm{O}_{3}-\mathrm{ZrO}_{2}$ spheres less than 50 microns in diameter. The procedure involved the preparation of solid solutions of the desired composition by reacting an isostatically pressed blend of the three powders for one hour in air at $1850^{\circ} \mathrm{C}$, pulverizing the reacted pressing, and, spheroldizing the powder in a plasma flame.

The three starting powders $\left(\mathrm{UO}_{2}, \mathrm{Y}_{2} \mathrm{O}_{3}\right.$, and $\left.\mathrm{ZrO}_{2}\right)$ in the -325 mesh size range were blended in an impact mill blender. The blend was heated to $800^{\circ} \mathrm{C}$ in air for one hour to convert the $\mathrm{UO}_{2}$ to $\mathrm{U}_{3} \mathrm{O}_{8}$, was 1 sostatically pressed at $2800 \mathrm{kilograms}$ per 
square centimeter, and was then heated to $1850^{\circ} \mathrm{C}$ and maintained at that temperature in air for one hour to convert the blend to a single phase face-centered-cubic material. The ternary achieved about 99 percent of theoretical density during the reaction step.

To obtain spheres in the 30- to 50-micron size range, ternary powder in the 35- to 55-micron size is required. The reacted ternary pressing is quite friable, and impact methods of comminution of the pressing resulted in up to 90 percent fines, that is, particles less than 35 microns in diameter. Even with careful hand grinding between two ceramic plates, the yield of powder in the proper size range is only about 40 percent of the starting material. The fines can be repressed and fired again at $1850^{\circ} \mathrm{C}$ to sinter the compact, but each recycle results in the loss of one or two percent of the fuel. Comminution of the reacted pressing remains a problem only partly solved.

Spheroldization of the fuel powders was carried out in the plasma flame produced in a direct-current plasma gun shown in Figure 1. Electrical energy was supplied to the plasma gun at the rate of approximately $20 \mathrm{kllowatts.} \mathrm{The} \mathrm{plasma} \mathrm{was} \mathrm{maintained} \mathrm{in} \mathrm{helium}$ flowing at a rate' of 2830 liters per hour. The powder particles were transported from the feed chamber by a flow of approximately 57 I1ters per hour of argon and were introduced to the plasma gas through two small openings located opposite to each other near the exit of the plasma gun. The temperature of the plasma was not measured, but under the conditions of the spheroldization experiments 1 t $1 \mathrm{~s}$ of the order of $20,000^{\circ} \mathrm{K}$.

A photomicrograph of powders used in some spheroidization experiments is shown in Figure 2. As is shown in Figure 3, the $\mathrm{UO}_{2}-\mathrm{Y}_{2} \mathrm{O}_{3}-$ $\mathrm{ZrO}_{2}$ powders were essentially completely spheroldized in the plasma 
flame, but some porosity remained in approximately 50 percent of the spheres. Spheres containing very large voids were removed by air elutriation in the apparatus shown in Figure 4. A photomicrograph of the spheres removed by air elutriation is shown. In Pigure 5.

The $\mathrm{UO}_{2}$ is the most volatile member of the $\mathrm{UO}_{2}-\mathrm{Y}_{2} \mathrm{O}_{3}-\mathrm{ZrO}_{2}$ ternary, and up to 25 percent of the fuel in the solid solution powders was lost by volatilization as, the powders were spheroldized in the plasma flame. As may be expected, when particles with a size range of several microns are spheroldized simultaneously, fuel loss is most severe with the smaller particles. Although the fuel loss for a given set of operating conditions was determined with sufficient accuracy to permit adjustment of the starting composition to compensate for the loss, variation in composition from sphere to sphere remains a problem.

$\mathrm{X}$-ray examination of the elutriated spheres indicated a single phase face-centered-cubic material. Ceramographic examination of the solid solution powders before spheroldization revealed considerable porosity in the powder particles, as shown In Figure 2; however, the fact that pycnometer density was 99. percent of theoretical density indicates that the pores were open. Similar examination of the resulting spheres revealed the high density of some particles and the coalescence of porosity in others, as shown in Figure 3 .

POTENTIAL APPLICATIONS OF SPHERICAL OXIDE FUELS

The potential applications of the spherical mixed oxide fuels discussed in this report arise from the size of the particles (35 to 50 microns), their spherical shape, and their stability toward oxidation. The small size would permit use of the spheres 
In fuel elements with fairly thin walls (high surface-to-volume ratios) without serious loss of fuel element strength. The spherical shape would permit pressing or extruding the fuel in a matrix with reduced possibility of damage to the spheres. The stability of the mixed oxide spheres toward oxidation at high temperatures would permit use of the fuel in a high temperature air-cooled reactor.

\section{LITERATURE CITED}

1. J. Belle, ed., Uranium Dioxide - Properties and Nuclear Applications, Naval Reactors, Division of Reactor Development, United States Atomic Energy Commission, July, 1961.

2. W.B. Wilson, C.A. Alexander, and A.F. Gerds, "Stabilization of $\mathrm{UO}_{2}$," J. Inorg. Nucl. Chem. 20, 242-251 (1961). 


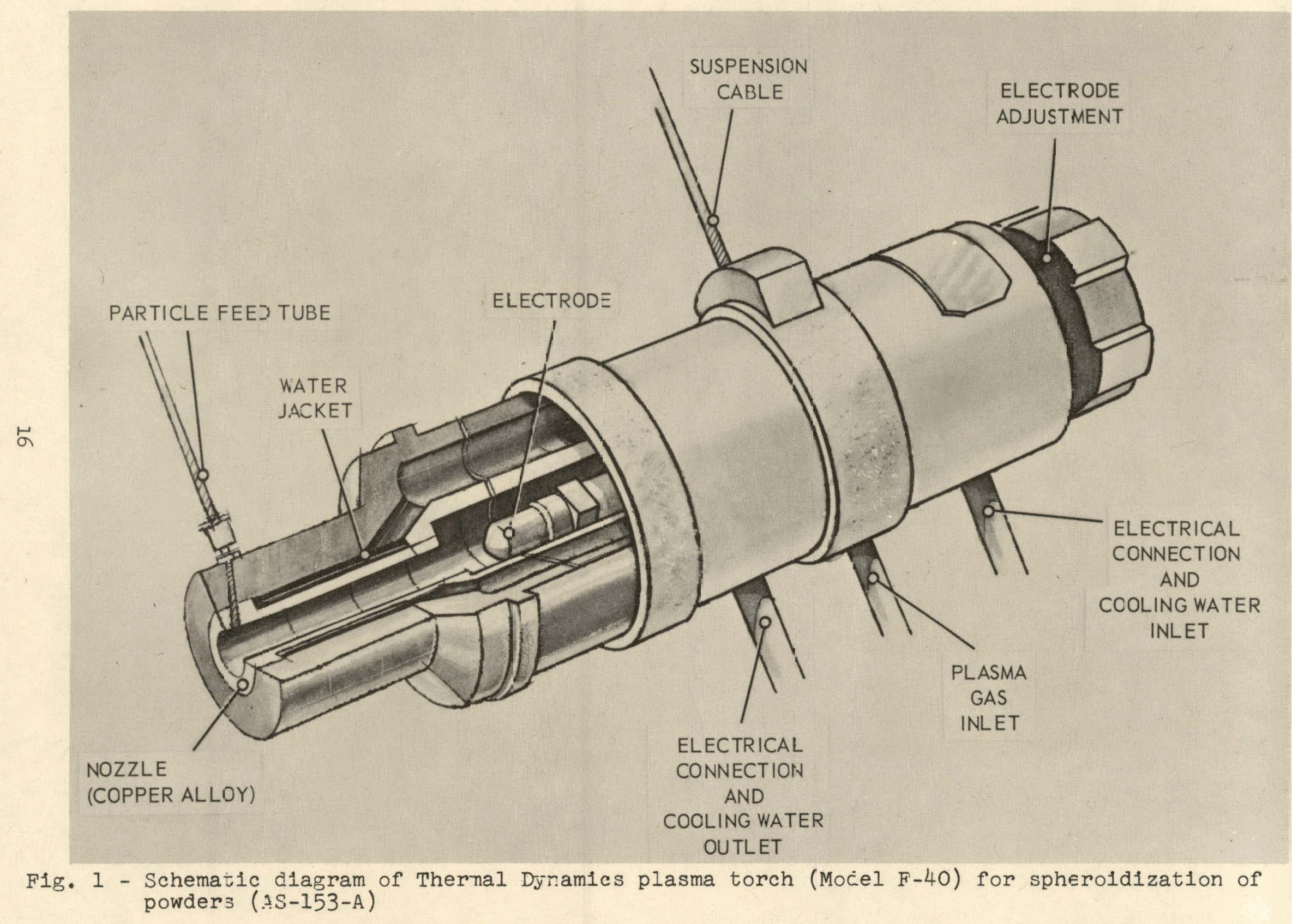




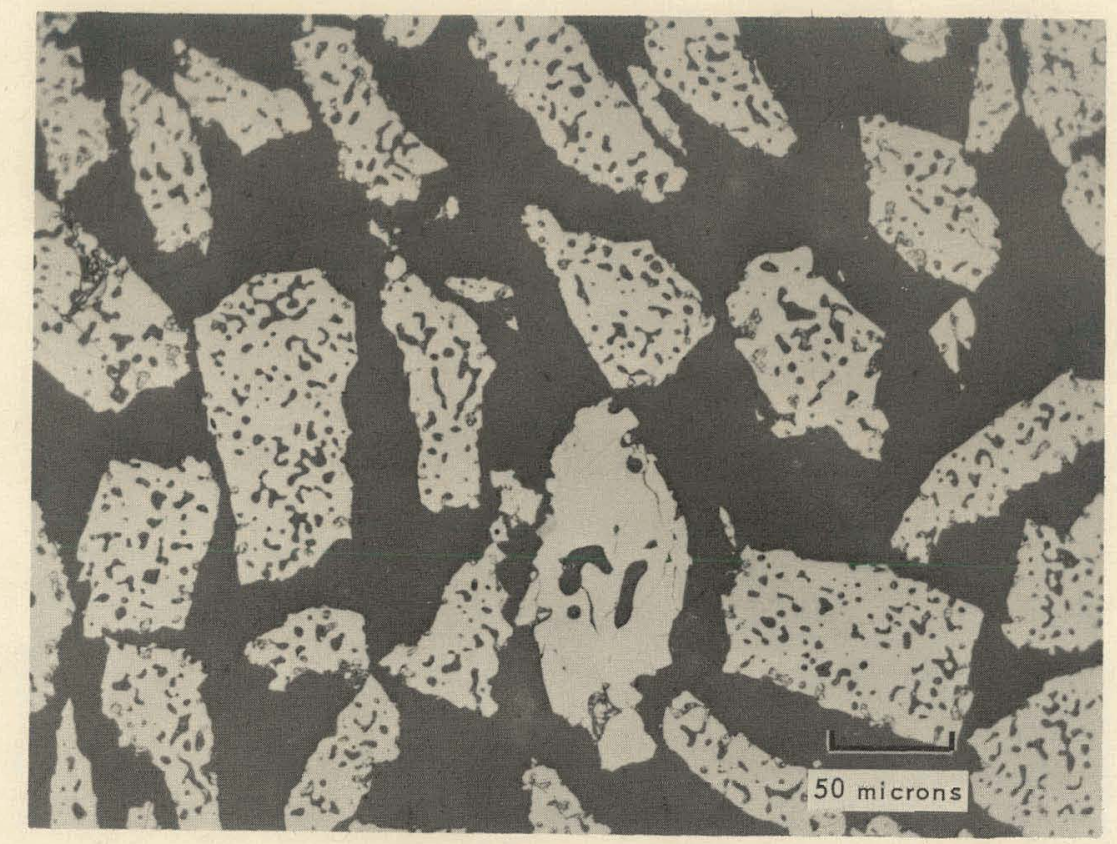

Negative 3417

Unetched

Figure 2 - Fuel Powders Before Spheroldization

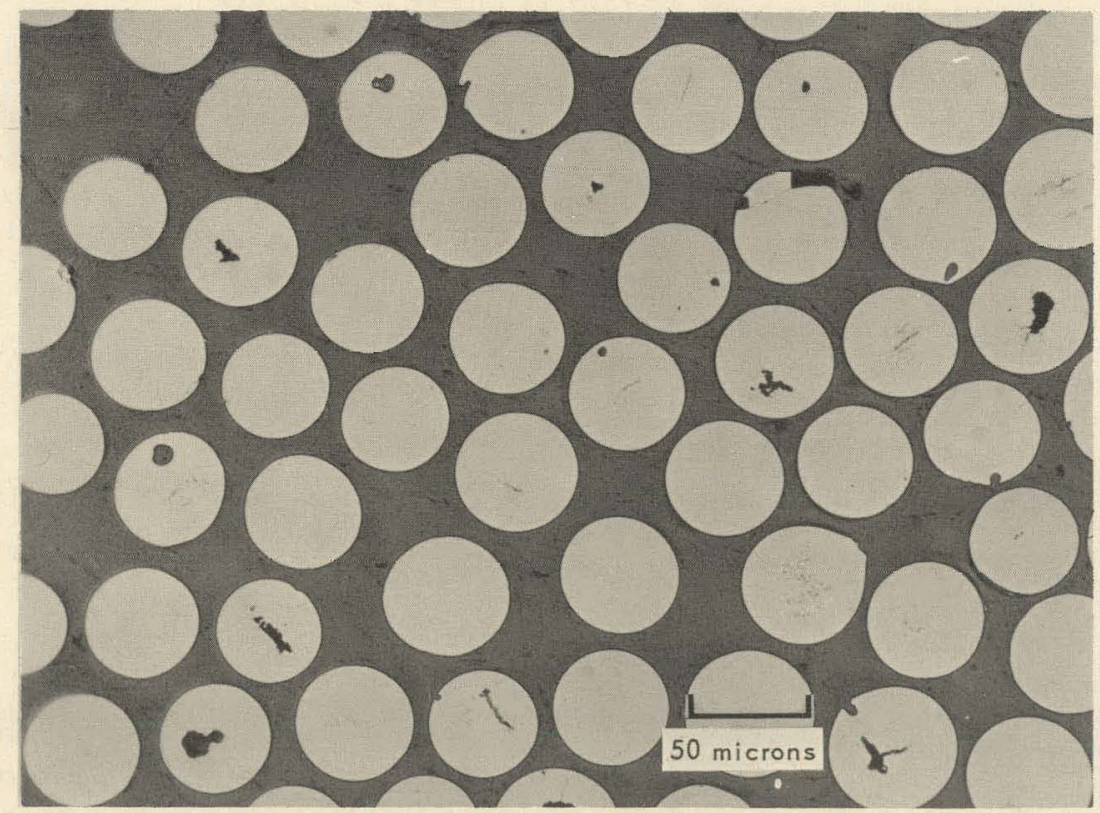

Negative 3654 Unetched

Figure 3 - Fuel Spheres Produced in Direct-Current Plasma Flame 


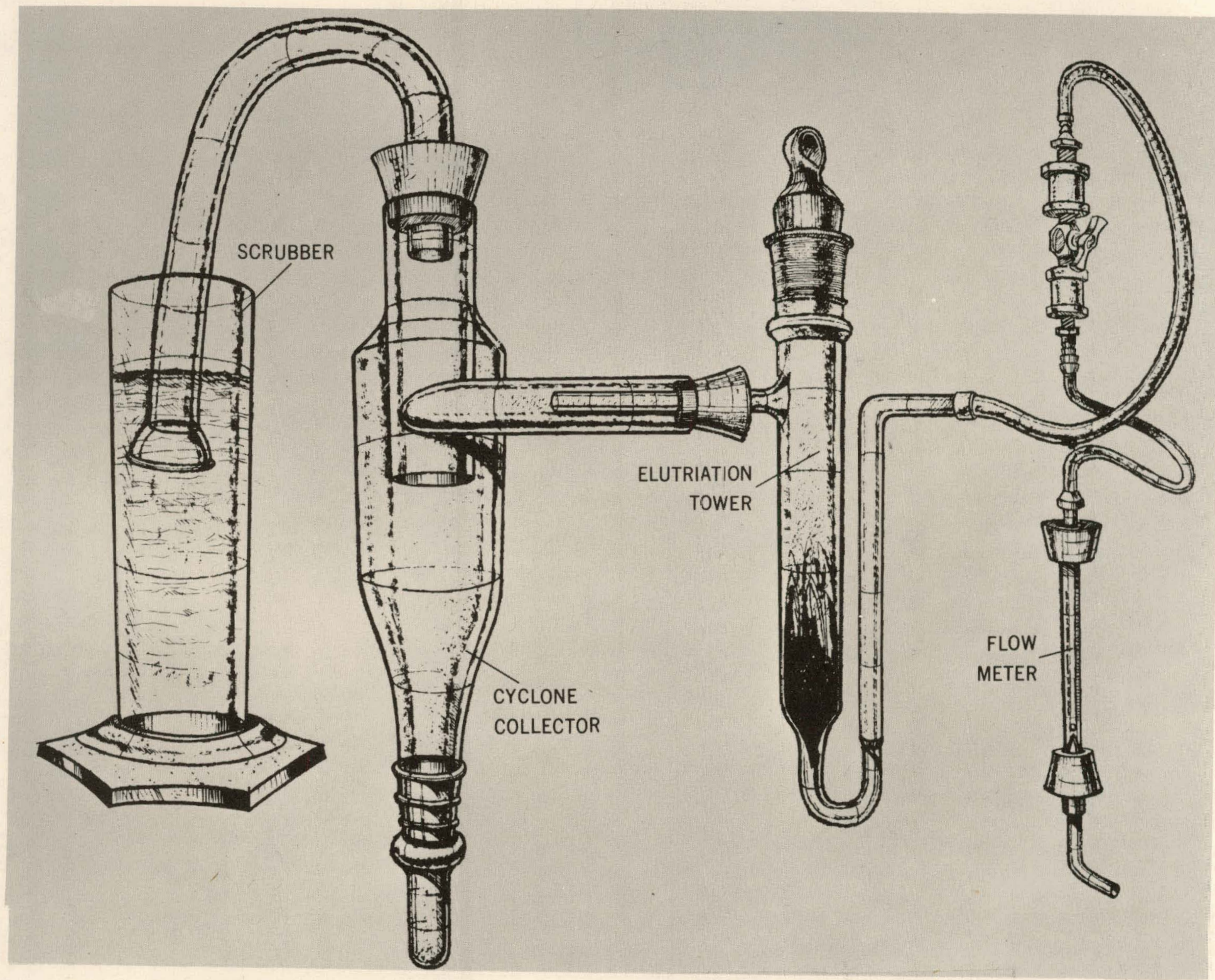

Fig. 4 - Air elutriation apparatus 


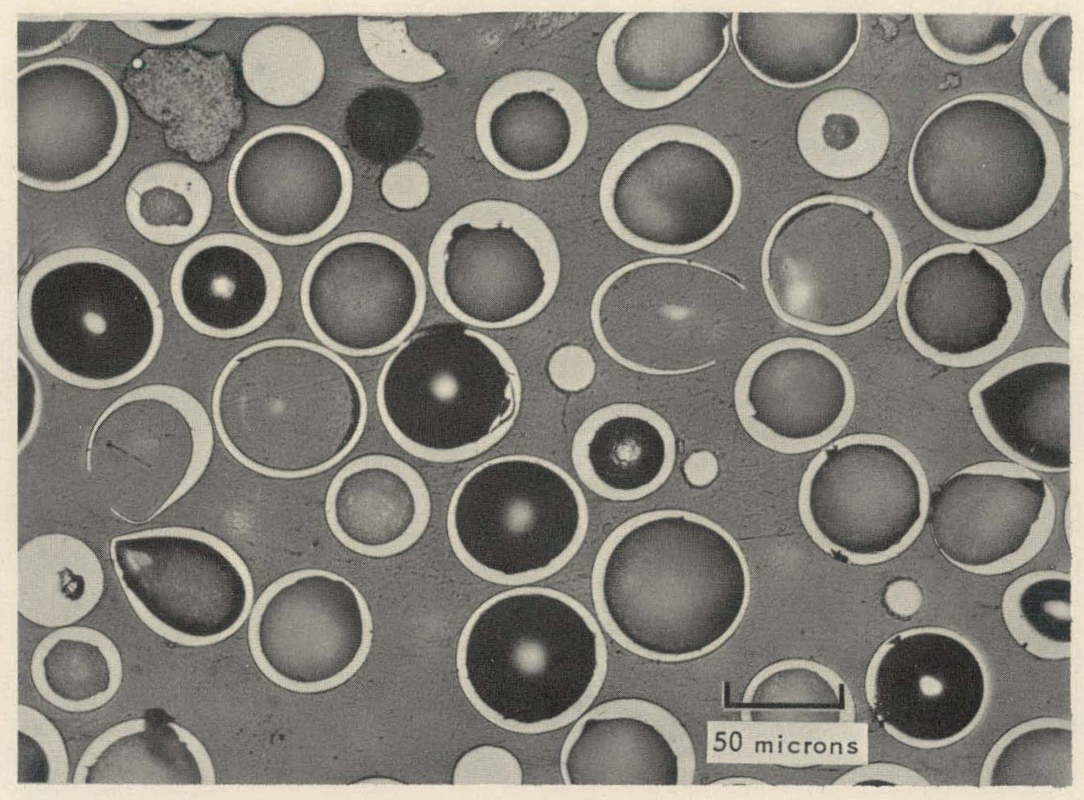

Negative 2009

Unetched

Figure 5 - Hollow fuel spheres separated by air elutriation 
THIS PAGE

\section{WAS INTENTIONALLY LEFT BLANK}


THE SOL-GEL PROCESS FOR PREPARING SPHEROIDAL PARTICLES OF THE DICARBIDES OF THORIUM AND THORIUM-URANIUM MIXTURES

\author{
By \\ James L. Kelly \\ A. Todd Kleinsteuber \\ ORNL -P- 137 \\ Sam 'D. Clinton \\ Orlen C. Dean \\ C $7-12-65$ \\ OAK RIDGE NATIONAL LABORATORY \\ Oak Ridge, Tennessee \\ ABSTRACT

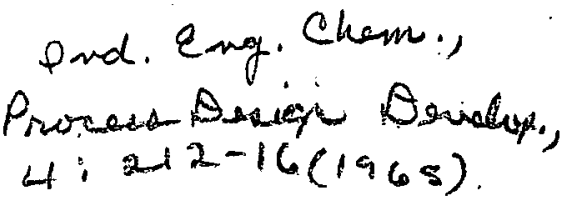

Spheres of dicarbides of thorium and thorium-uranium mixtures have been prepared from uranyl and thorium nitrate solutions by a'sol-gel process that has several advantages over more conventional processes. All steps up to conversion to carbide, including sizing and shaping, are conducted in air. The temperatures of conversion to carbide are relatively low $\left(1500-1750^{\circ} \mathrm{C}\right)$. The $\mathrm{U} / \mathrm{Th}$ atomic ratio is uniform in each particle and from particle to particle. The process cionsists of a small number of simple operations and appears suitable for remote operation with highly radioactive materials. Coated spheres of these dicarbides are of interest as fuel particles for graphite-matrix fuel elements. Such elements are favored for high-temperature nuclear reactor fuel.

Thorium dioxide, prepared by steam denitration of thorium nitrate, is dispersed to a sol in an aqueous nitrate solution. High-surface-area carbon is mixed into this sol. The resultant $\mathrm{ThO}_{2}-\mathrm{C}$ sol is formed into spheres by dispersing the sol in an immiscible organic liquid such as a $15 \%$ isopropyl alcohol-carbon tetrachloride solution. 'The spheres are set to.gel by the extraction of water from the aqueous sol phase by the alcohol. The resultant 150-450 $\mu$ spheres are recovered, dried, and fired to produce the dicarbide. In a typical firing of $\mathrm{ThO}_{2}-\mathrm{C}$ gels, greater than $98 \%$ conversion to $\mathrm{ThC}_{2}$ is obtained in $1-1 / 2 \mathrm{hr}$ at $1600^{\circ} \mathrm{C}$ in vacuum. Kinetic studies indicate that the carburization reaction is pseudo first order, with an acti-. vation energy of about $112 \mathrm{kcal} / \mathrm{mole} \mathrm{ThO}_{2}$. Thorium-uranium dicarbide spheres are produced similarly by adding uranyl nitrate solution of an appropriate concentration at the sol preparation step. 


\section{INTRODUCTION}

Spheroidal particles of thorium dicarbide and thorium-uranium dicarbide having diameters of $100-300 \mu$ have been prepared on a laboratory scale by a sol-gel process. Such particles, when coated with pyrolytic carbon, silicon carbide, or other coatings, are of interest as fuel materials for advanced gascooled reactors. The process is an adaptation of the sol-gel process for the preparation of high-density thorium oxide and thorium-uranium oxide $(1,2,6)$. The steps are few and relatively simple. High-temperature $\left(2450^{\circ} \mathrm{C}\right)$ techniques are circumvented, as well as the need for extensive inert gas-blanketed operations often associated with other decarbide processes. Grinding and mechanical shaping of the extremely hard dicarbides are also unnecessary. Dusting problems are minimized.

\section{Acknowledgements}

The authors wish to express their appreciation to T. E. Willmarth of the Analytical Chemistry Division for photomicrographic work; W. R. Laing of the 
Analytical Chemistry Division for analytical work; and D. E. Ferguson of the Chemical Technology Division for his comments and guidance.

\section{DESCRIPTION OF PROCESS}

A chemical flowsheet for the preparation of the $\operatorname{ThC}_{2}$ and $\left(\mathrm{Th}_{x} \mathrm{U}_{1-x}\right) \mathrm{C}_{2}$ spheres is presented in Fig. 1. The process consists of four relatively simple steps: preparation of the oxide sol; incorporation of carbon in the sol; formation of gel spheres; and firing of the oxide. The first three steps are performed in air, the last in vacuum or an inert atmosphere. Formation of the spheres is performed before firing the gel, thus minimizing the reoxidation problems associated with handling the reactive dicarbides. The carbide formation reaction occurs at a practical rate at relatively low temperatures, $1500-1750^{\circ} \mathrm{C}$, which makes possible the use of standard furnaces. The recycle of off-specifications products is readily accomplished.

Thorium oxide, prepared by the steam denitration of thorium nitrate $(1,2)$, is dispersed to a $2 \mathrm{M}$ sol in an aqueous nitrate solution $(1,2)$. Upon complete dispersion, which is attained by agitation at about $80^{\circ} \mathrm{C}$ and proper adjustment of the nitrate and acid concentrations $(1,2)$, the thorium oxide is present as individual crystallites of 50-100 A size. Carbon black having a high specific surface area is mixed into the sol in a quantity sufficient to give an oxide-carbon 
sol having a carbon-to-metal atomic ratio of at least 4 to 1. Carbon present in excess of this ratio will appear as free carbon in the dicarbide product. A proprietary channel black, Columbian Carbon Neo Spectra Mark II, was used in most of the carbide preparations discussed in this paper. This particular carbon black has a mean particle size of approximately 130 A and a specific surface area of approximately $1000 \mathrm{~m}^{2} / \mathrm{g}$ (3). The oxide-carbon suspension is stirred vigorously for about one hour at $50^{\circ} \mathrm{C}$ to disperse and blend the oxide and carbon thoroughly and produce, for practical purposes, an oxide-carbon sol. Actually, the product is not a true sol because appreciable aggregation and settling will occur if the system is allowed to stand without agitation. Thorium-uranium oxide-carbon sols containing up to 10 metal-atom \% uranium are similarly prepared by dispersing $\mathrm{ThO}_{2}$ from the denitration step in uranyl nitrate solutions of appropriate concentrations.

A striking feature of this preparation is the intimate contact that is obtained between the two high-surface-area reactants. This point is illustrated in Fig. 2 , an electron photomicrograph $(68,000 \mathrm{X})$ of a dried $\mathrm{ThO}_{2}-\mathrm{C}$ sol. The reported mean particle size of the carbon black was $130 \mathrm{~A}$. However, no particle seen in Fig. 2 is larger than 100 A. A possible explanation for the apparent discrepancy is that the carbon black particles are actually aggregates - which disintegrate into their component crystallites (10-20 A in size) in the dispersion process $(4,5)$. These crystallites possess acidic surface groups $(4,5)$ 
which are postulated to neutralize and chemisorb onto the basic surface groups of the hydrolyzed thoria crystallites. The dark nuclei in the photomicrograph are interpreted to be crystallites, or aggregated crystallites, of $\mathrm{ThO}_{2}$. The surrounding haloes, or lighter areas, are thought to be the less dense carbon crystallites. The net effect appears to be the production of an intimate mixture of $\mathrm{ThO}_{2}$ and $\mathrm{C}$ wherein the largest particles are approximately $100 \mathrm{~A}$. The favorable kinetics of the oxide-carbon reaction, to be discussed later, is thought to be due to this intimate contact between carbon and thoria.

\section{Preparation of Spheres}

The oxide-carbon sol is dispersed as almost uniformly sized droplets in a suitable medium, i.e., a medium which (1) is immiscible with the sol phase; (2) causes the sol droplets to assume spheroidal shapes due to surface tension effects; (3) has the ability to set or partially gel the spheroidal sol droplets; and (4) has fluid properties which yield a satisfactory settling rate of the droplets through the medium. The initial work was performed with solutions of $\mathrm{CCl}_{4}$ and isopropyl alcohol containing about $15 \%$ alcohol by volume. The immiscibility of the $\mathrm{CCl}_{4}$-sol phases and the difference in their surface tensions cause the sol droplets to assume spheroidal shapes. An important function of the alcohol is to partially gel the spheroidal droplets by extracting some of the water from the aqueous sol phase into the organic phase. 
The dispersion operation has been carried out on a laboratory scale by pouring $100 \mathrm{cc}$ of a $2 \underline{M}$ oxide-carbon sol into $300 \mathrm{cc}$ of stirred $\mathrm{CCl}_{4}$. The stirring rate was adjusted so that the resultant dispersed droplets fell predominantly in the $100-$ to $500-\mu$ range. Isopropyl alcohol was slowly mixed into the sol- $\mathrm{CCl}_{4}$ system until the organic phase was at least $15 \%$ by volume, and stirring was continued for approximately 1 hour. By this time the partially gelled spheroids were firm enough to be filtered out of the organic phase. After being washed with alcohol, the spheroids were dried in a $100^{\circ} \mathrm{C}$ oven for 12 hours. Figure 3 is a photomicrograph of $\left(T_{0.97} U_{0.03}\right)$ oxide-carbon gel-spheroids prepared in this manner. Figure 4 is a photomicrograph of product $\left(T_{0} h_{0.97} U_{0.03}\right) C_{2}$ particles obtained by reacting spheroids from the population represented in Fig. 3. The carbide spheroids shown in Fig. 4 will be discussed in greater detail later.

For larger-scale operations a spray column technique for spheroidizing gel is being studied. A schematic drawing of the spray column equipment is shown in Fig. 5. In initial studies with this system a $\mathrm{ThO}_{2}$ sol was successfully converted to the gel spheres seen in Fig. 6. The sol was sprayed downward through an immersed 0.006 in. diameter orifice into a 15 volume \% isopropyl alcohol- $\mathrm{CCl}_{4}$ solution. The organic solution was circulated upward at a controlled rate to regulate the settling velocity of the droplets and, hence, the contact time between the water-extracting organic solution and the sol. The 
partially gelled spheres were withdrawn from the bottom of the column and dried to solid $\mathrm{ThO}_{2}$ gel particles. Problems related to control of sizes áre presently being investigated.

In a modification of the above technique, 2-ethylhexanol was used as the forming and setting organic medium. Figure 7 shows the $\left(T_{0.97} U_{0.03}\right)$ oxide-carbon gel spheres formed with this system. The spheres in Fig. 8 are the corresponding carbide particles. Further work with organic solvents süch as 2-ethylhexanol is being continued.

Oxide-carbon spheroids which do not meet specifications may be recycled by two possible procedures: (1) addition of nitric acid and water to the dried oxide-carbon gel, which redisperses the solids, but sometimes results in an unstable sol; (2) air-oxidation to remove carbon at a temperature of 200 to $350^{\circ} \mathrm{C}$. If care is taken during the oxidation to avoid heating above $500^{\circ} \mathrm{C}$, the oxide can again be dispersed to sol by heating with dilute $\mathrm{HNO}_{3}$.

\section{Formation of Dicarbides}

The dried oxide-carbon spheroids are converted to the corresponding dicarbides by heating in either vacuum or a current of inert gas, such as argon. Essentially complete (>99\%) conversion of the oxide to the carbide may be attained in one to six hours in the temperature range $1500-1750^{\circ} \mathrm{C}$.

Thermodynamic data (Fig. 9) reported for the reaction. 


$$
\mathrm{ThO}_{2(\mathrm{c})}+4 \mathrm{C}_{(\mathrm{c})} \rightarrow \mathrm{ThC}_{2}+2 \mathrm{CO}(\mathrm{g})
$$

indicate that very low conversions should be expected for temperatures less than $2000^{\circ} \mathrm{C}$. However, if the reaction occurs in vacuum or in a stream of inert gas, the gaseous product, $\mathrm{CO}$, is continually removed, thereby maintaining the activity of that product below its equilibrium value. Therefore, the reaction proceeds until one of the reactants is consumed.

The kinetics of the reaction to form thorium dicarbide and thoriumuranium dicarbide was investigated. A schematic drawing of the equipment used in the kinetics study is shown in Fig. 10. The reaction took place in an inductively heated graphite cylinder suspended in an evacuated quartz envelope. The vacuum varied from about $1000 \mu$ at the start of the reaction to about $10 \mu$ at the finish. Nominal reaction temperatures were determined by sighting an optical pyrometer on the top of the bed of reactants through two aligned reflection shields. Information on the reaction rates was obtained by measuring the evolution rate of $\mathrm{CO}$ by. means of a volumetric gas meter.

The rate data thus obtained indicate that the reaction rate is proportional to the amount of unreacted $\mathrm{ThO}_{2}$ and can be represented as a pseudo first order reaction:

$$
\frac{-d\left(\mathrm{ThO}_{2}\right)}{d t}=k\left(\mathrm{ThO}_{2}\right)
$$

and therefore 


$$
-\ln (1-x)=k t+\text { constant, }
$$

where

$$
\begin{aligned}
\left(\mathrm{ThO}_{2}\right) & =\text { amount of } \mathrm{ThO}_{2} \text { at time } \mathrm{t}, \\
t & =\text { time, } \\
\mathrm{k} & =\text { rate constant, time } \\
\mathrm{x} & =\text { fraction of } \mathrm{ThO}_{2} \text { reacted at time } t .
\end{aligned}
$$

From the integrated equation it is seen that the slope of a plot of $-\ln (1-x)$ versus time equals the pseudo first-order rate constant.

Various thoria-carbon and thoria-urania-carbon gels were reacted. The resultant dicarbides contained 2-22 weight percent free carbón and 0.5 metal atom percent uranium. In these ranges reaction rates were independent of either carbonto-metal or uranium-to-thorium ratios. The data in Fig. 11 àre representative of results obtained for all the runs that were made. In Fig. $11-\ln (1-x)$ is linear when plotted versus time for the reaction at $1445^{\circ} \mathrm{C}$ (nominal temperature) of a $\mathrm{ThO}_{2}-\mathrm{C}$ gel containing a $\mathrm{C} / \mathrm{ThO}_{2}$ mole ratio of 6.8 . The reaction appears to be first order up to a conversion of thoria to thorium dicarbide of greater than $86 \%$. The pseudo first-order reaction, rate constant evaluated from the slope of this line is $0.586 \mathrm{hr}^{-1}$.

Rate constants were evaluated from the slopes of $-\ln (1-x)$-vs-time plots for oxide-carbon gels of various initial compositions reacted at various temperatures. The variation of rate constants with temperature is shown by an Arrhenius 
plot in Fig. 12. The activation energy for the reaction may be evaluated from the slope of the least-squares line. For the three oxide-carbon gels represented in Fig. 12, the activation energy is $112 \mathrm{kcal} / \mathrm{g}$-mole of metal oxide. On the basis of this relatively high activation energy, the reaction appears to be controlled by a nucleation mechanism rather than a diffusion mechanism. This conclusion is corroborated by the excellent fit of the kinetic data to first-order plots. The relative insignificance of a diffusion mechanism may be attributed to the small size and intimate mixing of the reactants.

\section{Properties of Dicarbide Products}

During the reaction the spheroids retain their shapes but undergo roughly a $30 \%$ shrinkage in diameter as seen by comparing Fig. 4 with Fig. 3 (or Fig. 7 with Fig. 8). As previously mentioned, the spheroids in Fig. 3 were prepared by dispersing a $\left(\mathrm{Th}_{0.97} \mathrm{U}_{0.03}\right)$ oxide-carbon sol in a solution of $\mathrm{CCl}_{4}$ and isopropyl alcohol. The resultant partially gelled droplets were separated from the organic solution and dried at $100^{\circ} \mathrm{C}$. A portion of the dried gel spheroids was gradually heated to $1000^{\circ} \mathrm{C}$ in vacuum $(<1 \mathrm{~mm} \mathrm{Hg})$ to permit degassing to occur. Then the temperature was increased to $1750^{\circ} \mathrm{C}$ and held at that level for $4 \mathrm{hr}$. The product spheroids of $\left(\mathrm{Th}_{0.97} \mathrm{U}_{0.03}\right)_{2}$ are shown in Fig. 4. The carbide spheroids in Fig. 8 were fired at $1750^{\circ} \mathrm{C}$ for $4 \mathrm{hr}$ in an argon stream.

In other tests, particles of fractured gel from various thoria-carbon and thoria-urania-carbon sols were reacted. The densities of the resultant irregularly shaped carbide products as measured by mercury porosimetry varied from 2.74 to 
$8.58 \mathrm{~g} / \mathrm{cc}$, depending on the porosity and the free carbon content. The range of porosities of these particles was 0.065 to 0.326 . Figure 13 is a typical plot of pore volume versus pore diameter (calculated assuming cylindrical pores) obtained by mercury porosimetry of a product of cracked, irregular, highly fragmented dicarbide particles. Two populations of pore diameters are present, one having pore diameters greater than about $0.5 \mu$, the other, less than $0.5 \mu$. The pore volume of the large-pore group was at least $50 \%$ of the total pore volume for essentially. all of the dicarbide products from the various oxide-carbon sols regardless of their free carbon contents. From visual observation it appears that the large pores arise as cracks generated in the gel fragments as a result of the drying. It is possible that these large pores would have been eliminated or minimized if the gel had been dispersed into spheroids before drying.

From these preliminary analyses of the reaction products, a wide variation in the product densities, porosities, and carbon contents is evident. It is believed that control over these factors may be effected at the sol-formation step. Also, modifications in the spheroidization step may give improved results. These aspects are being further investigated. 


\section{REFERENCES}

1. O.C. Dean et al., A New Process for the Remote Preparation and Fabrication of Fuel Elements Containing Uranium-233 Oxide-Thorium Oxide, ORNL-TM-588 (June. 10, 1963).

2. D. E. Ferguson et al., Status and Progress Report for Thorium Fuel Cycle Development for Period Ending December 1962, ORNL-3385 (June 1963).

3. Columbian Carbon Company, New York, N. Y., Technical Service Department Chart No. 201 A.

4. J. V. Hallum and H. V. Drushel, "The Organic Nature of Carbon Black Surfaces," Journal of Physical Chemistry 62, 110 (1958).

5. C. W. Sweitzer et al., "Colloidal Carbon - Its Properties and Uses," Paint, 'Oil and Chemical Review, 115 (8), 22 (April 10, 1952).

6. O.,C. Dean et al., "The Sol Gel Process for Preparation of Thoria Base Fuels, " Paper 22, p 519, Proceedings of the Thorium Fuel Cycle Symposium, Gatlinburg, Tennessee, December 5-7, 1962, TID-7650, Book II. 
UNCLASSIFIED

ORNL-DWG 63-1101 RI

$\mathrm{ThO}_{2}$ PREPARED BY STEAM -

DENITRATION OF Th $\left(\mathrm{NO}_{3}\right)_{4}$ UO
SOLUTION $\left(\mathrm{NO}_{3}\right)_{2}$$\rightarrow \begin{gathered}\begin{array}{c}\text { OXIDE SOL } \\ \text { PREPARATION }\end{array} \\ \text { AGITATION } \\ 80^{\circ} \mathrm{C} \\ \mathrm{NO}_{3}^{-} \text {ADJUSTMENT } \\ \mathrm{NH}_{3} \text { ADDITION }\end{gathered}$

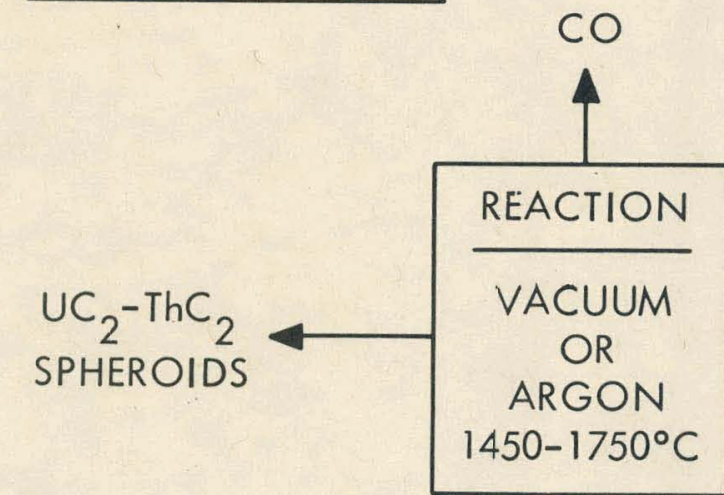

HIGH-SURFACE AREA

CARBON

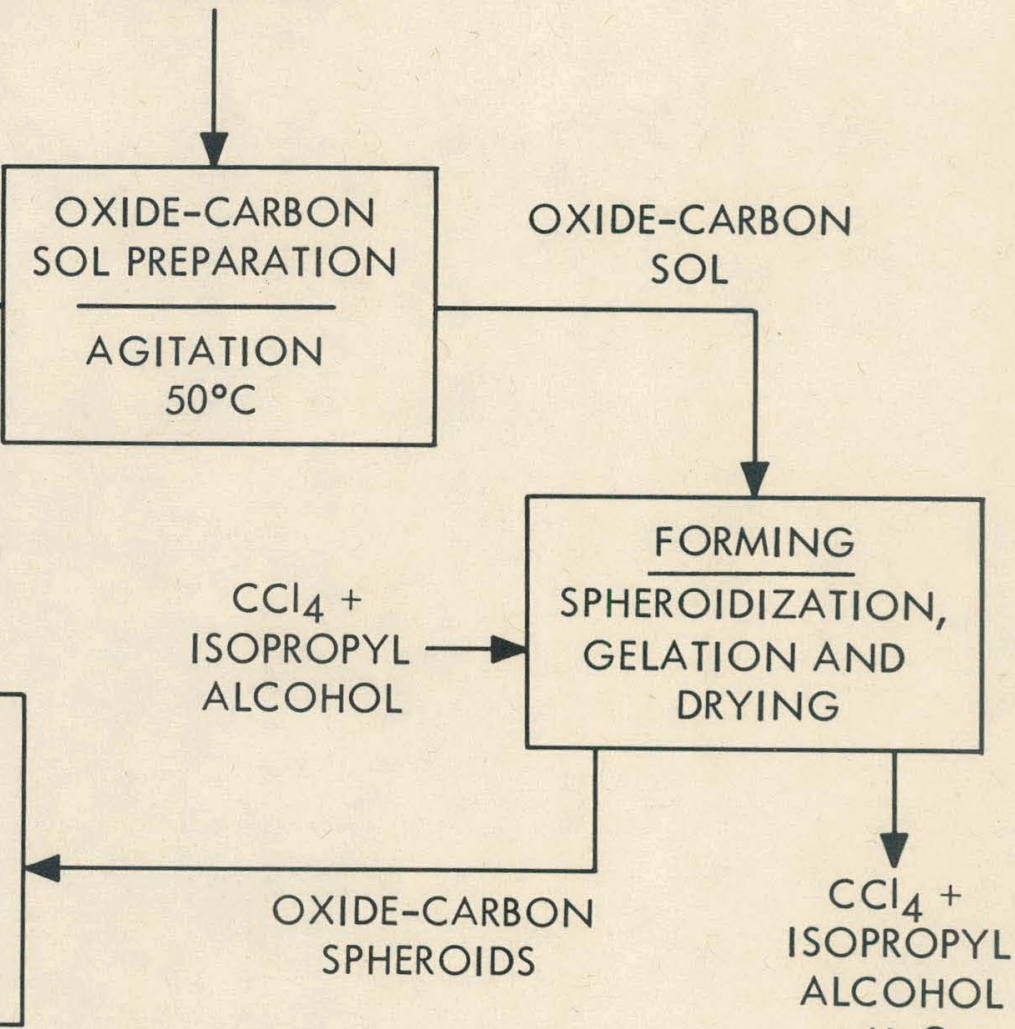

$+\mathrm{H}_{2} \mathrm{O}$

Fig. 1. Flowsheet for the Preparation of Thorium-Uranium Dicarbide Spheroids. 


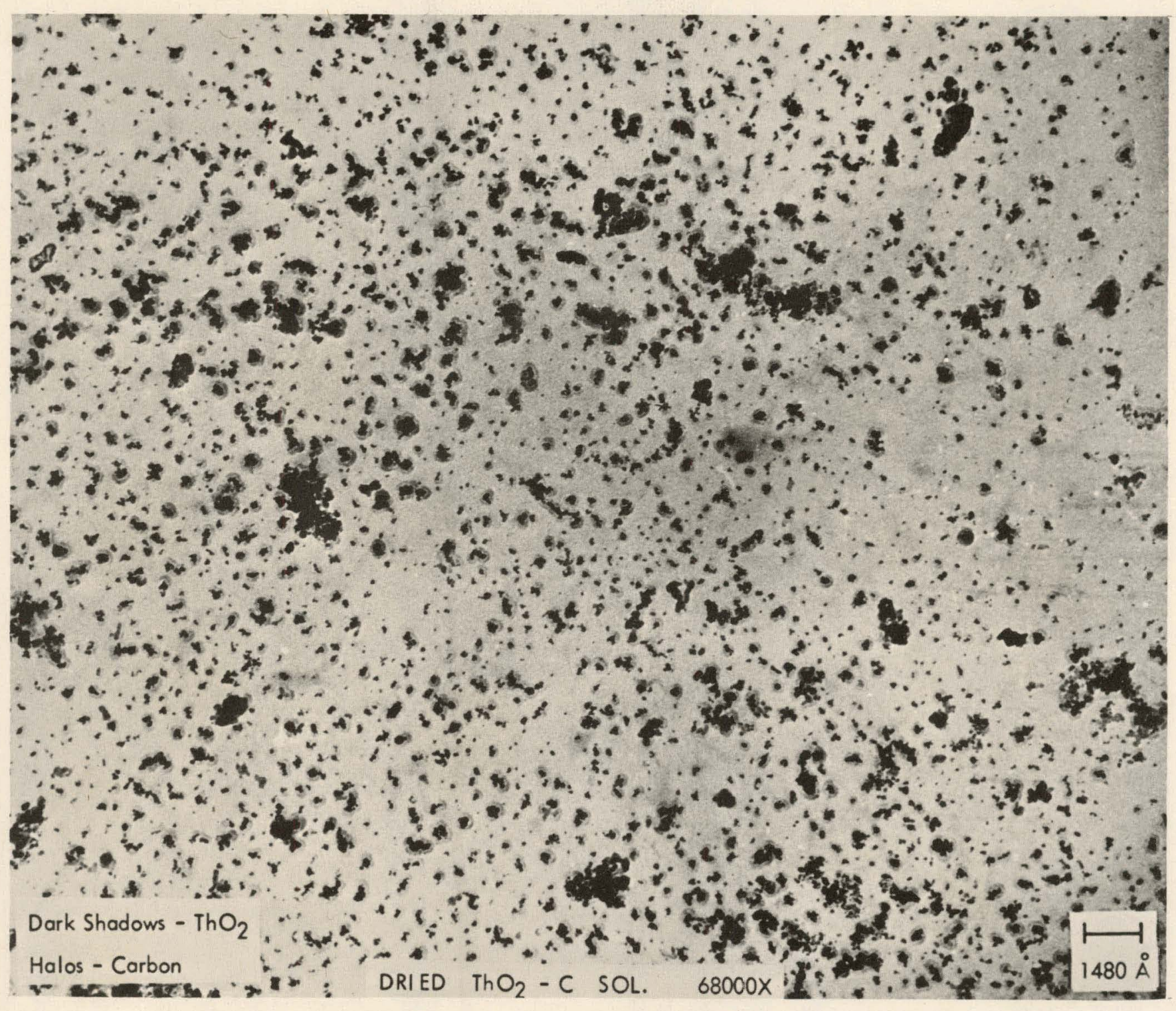

Fig. 2. Electron Photomicrograph $(68,000 \mathrm{X})$ of a Dried $\mathrm{ThO}_{2}-\mathrm{C}$ Sol. 


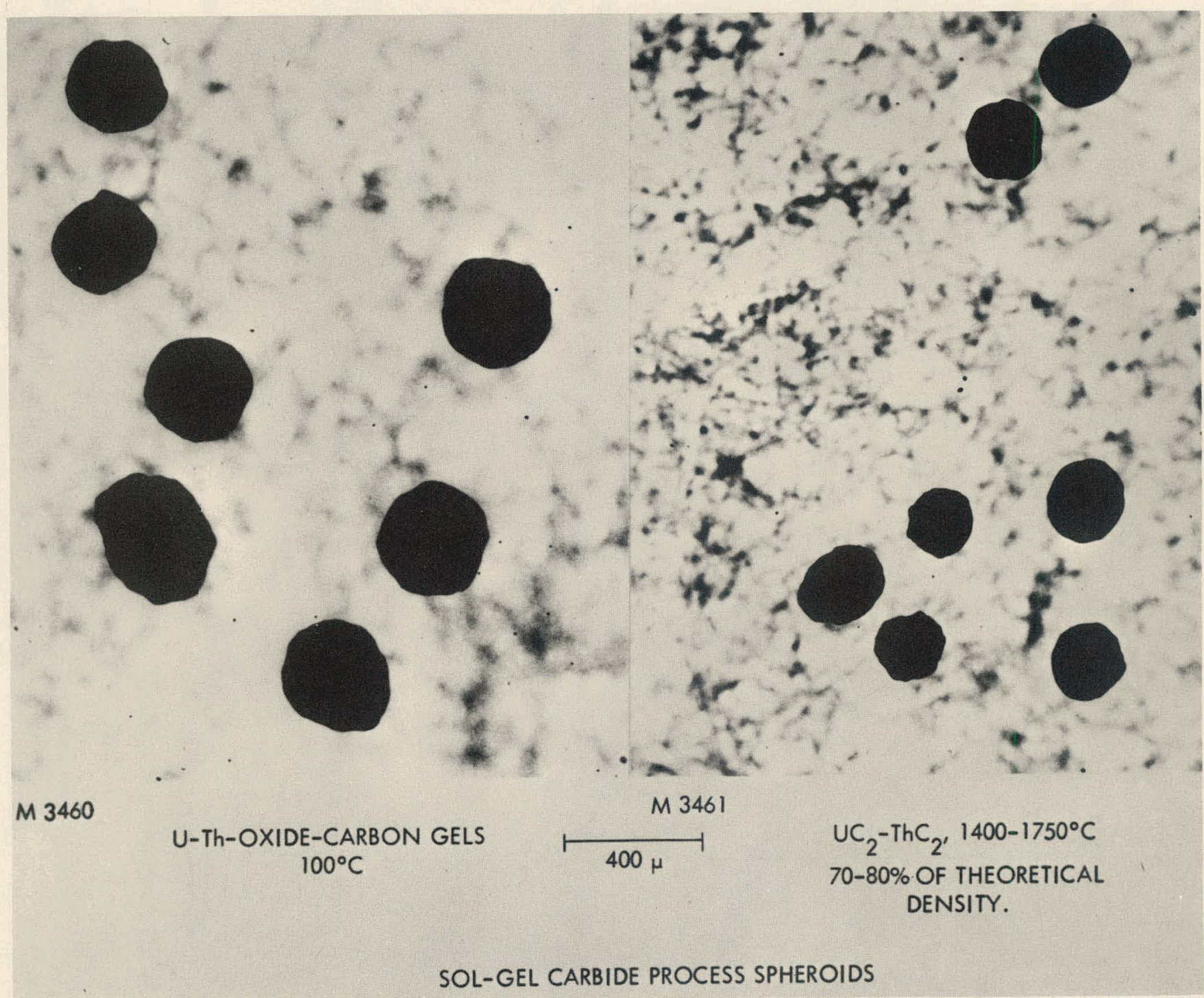

Fig. 3. (Th $0.97 \mathrm{U}_{0.03}$ ) Oxide-Carbon Spheroids Formed in Stirred Solutions of

Fig. 4. $\left(\mathrm{Th}_{0.97} \mathrm{U}_{0.03}\right) \mathrm{C}_{2}$ Spheroids Fired at $1750^{\circ} \mathrm{C}$ in Vacuum. Isopropyl Alcohol-Carbon Tetrachloride. Spheroids Dried at $100^{\circ} \mathrm{C}$. 


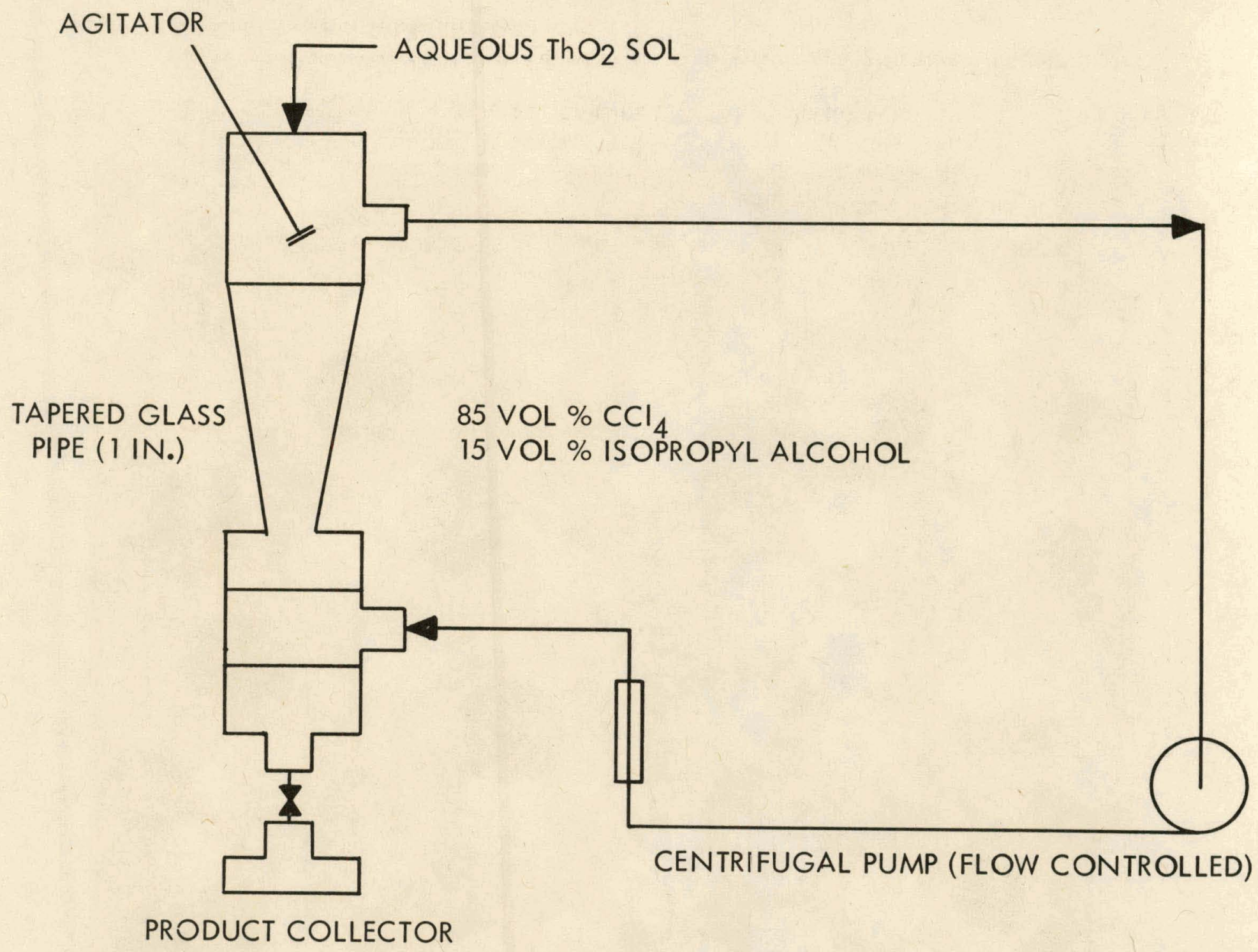

Fig. 5. Spray Column for Forming Spheroids. 


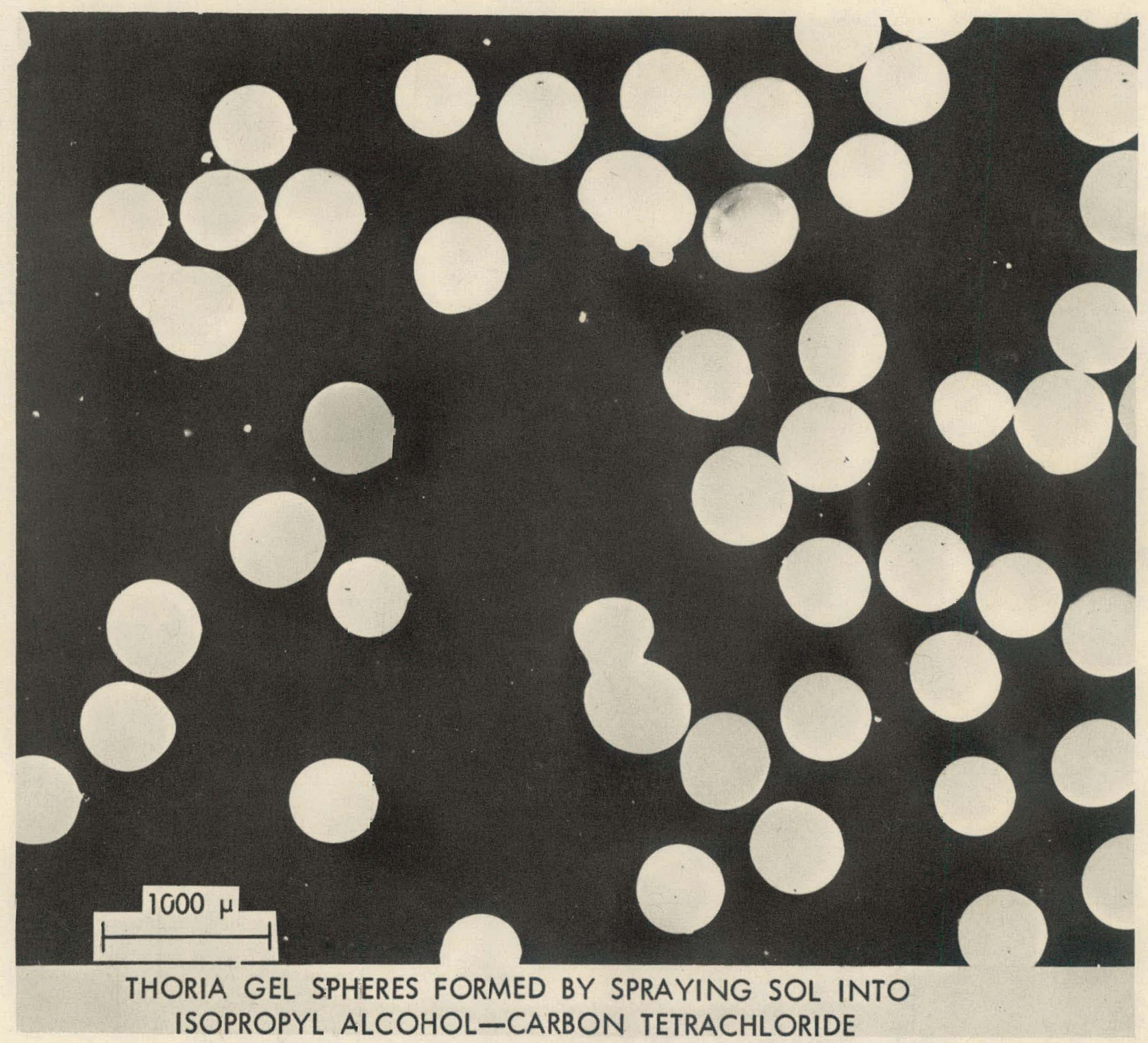

Fig. 6. Thoria Gel Spheroids Formed by Spraying Sol into Isopropyl AlcoholCarbon Tetrachloride. 


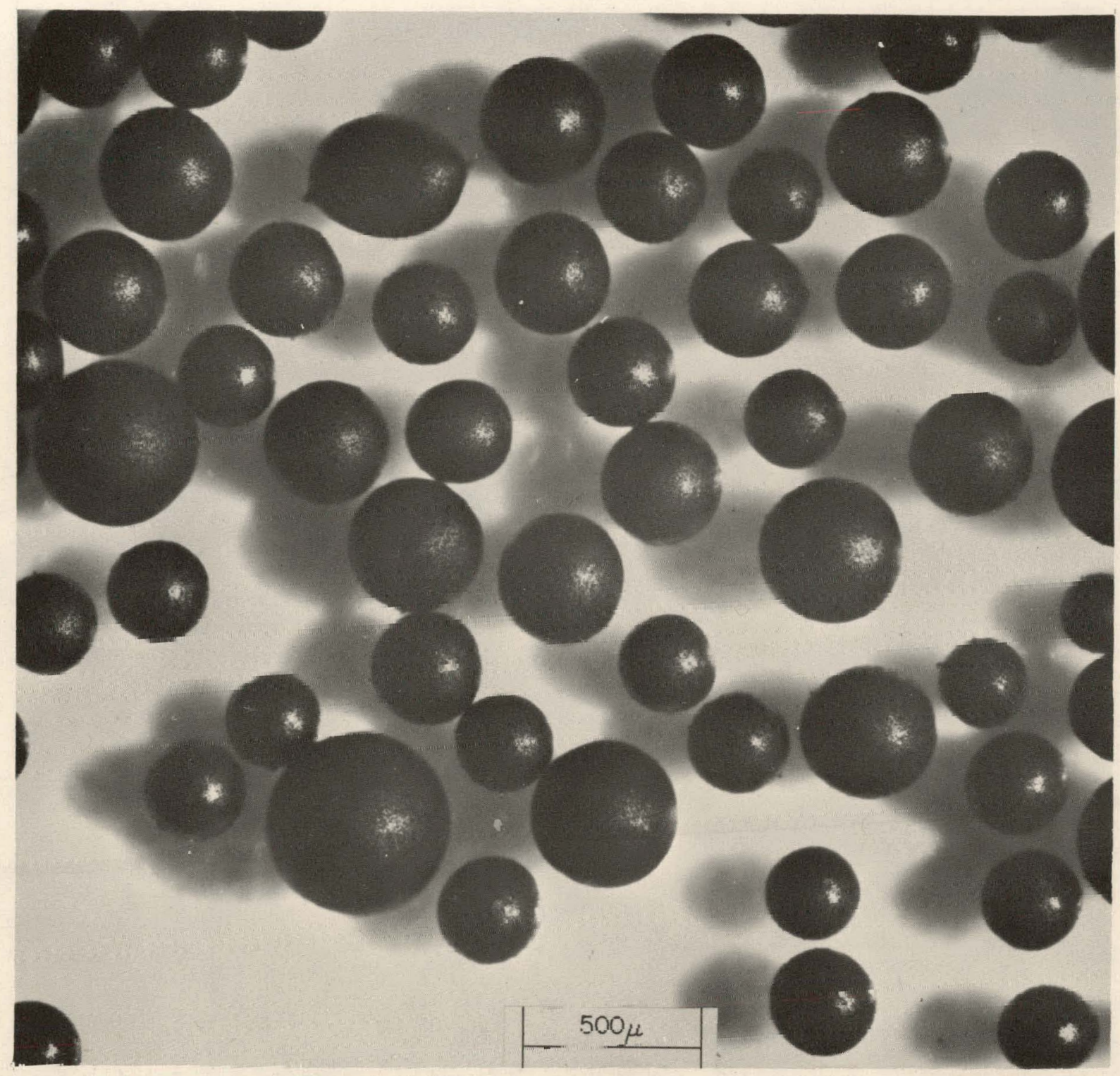

Fig. 7. (Th $\left.\mathrm{Th}_{0.97} \mathrm{U}_{0.03}\right)$ Oxide-Carbon Spheroids Formed in 2-Ethylhexanol. 


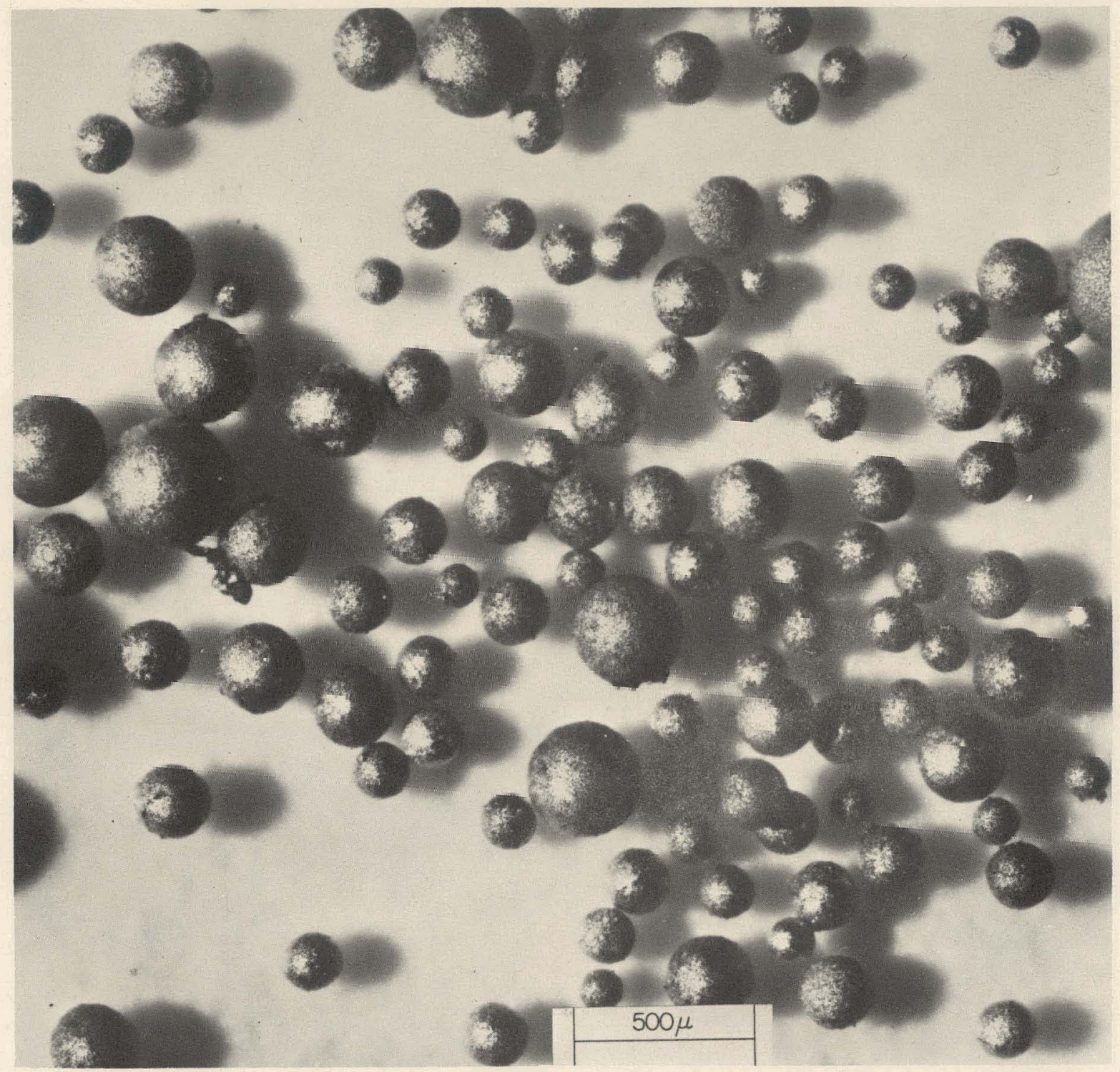

Fig. 8. $\left(\mathrm{Th}_{0.97} \mathrm{U}_{0.03}\right) \mathrm{C}_{2}$ Spheroids Fired at $1750^{\circ} \mathrm{C}$ in Argon for 4 Hours. 


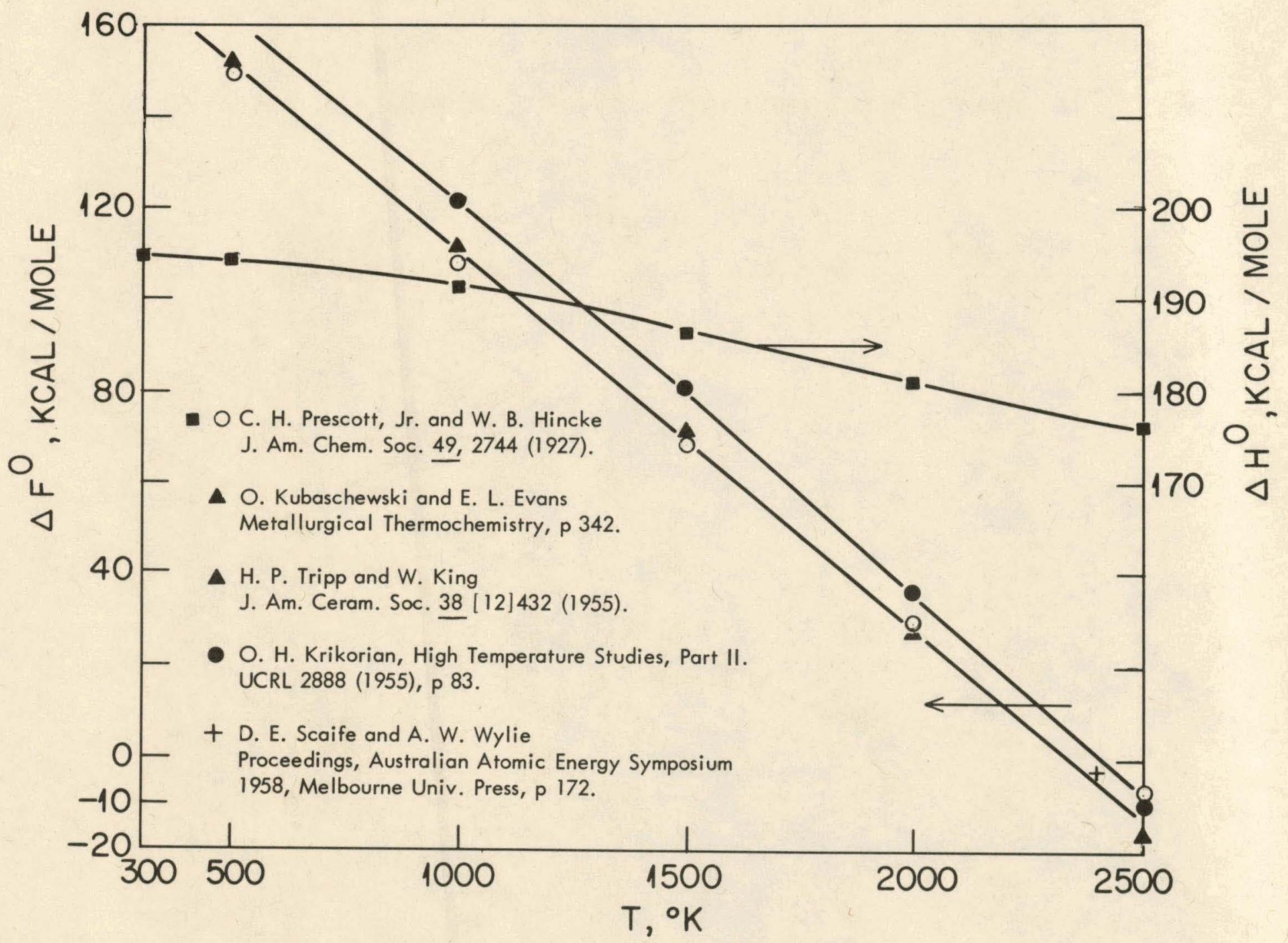

Fig. 9. Thermodynamic Data for the Oxide-Carbon Reaction,

$$
\mathrm{ThO}_{2}+4 \mathrm{C} \quad \mathrm{ThC}_{2}+2 \mathrm{CO} \text {. }
$$




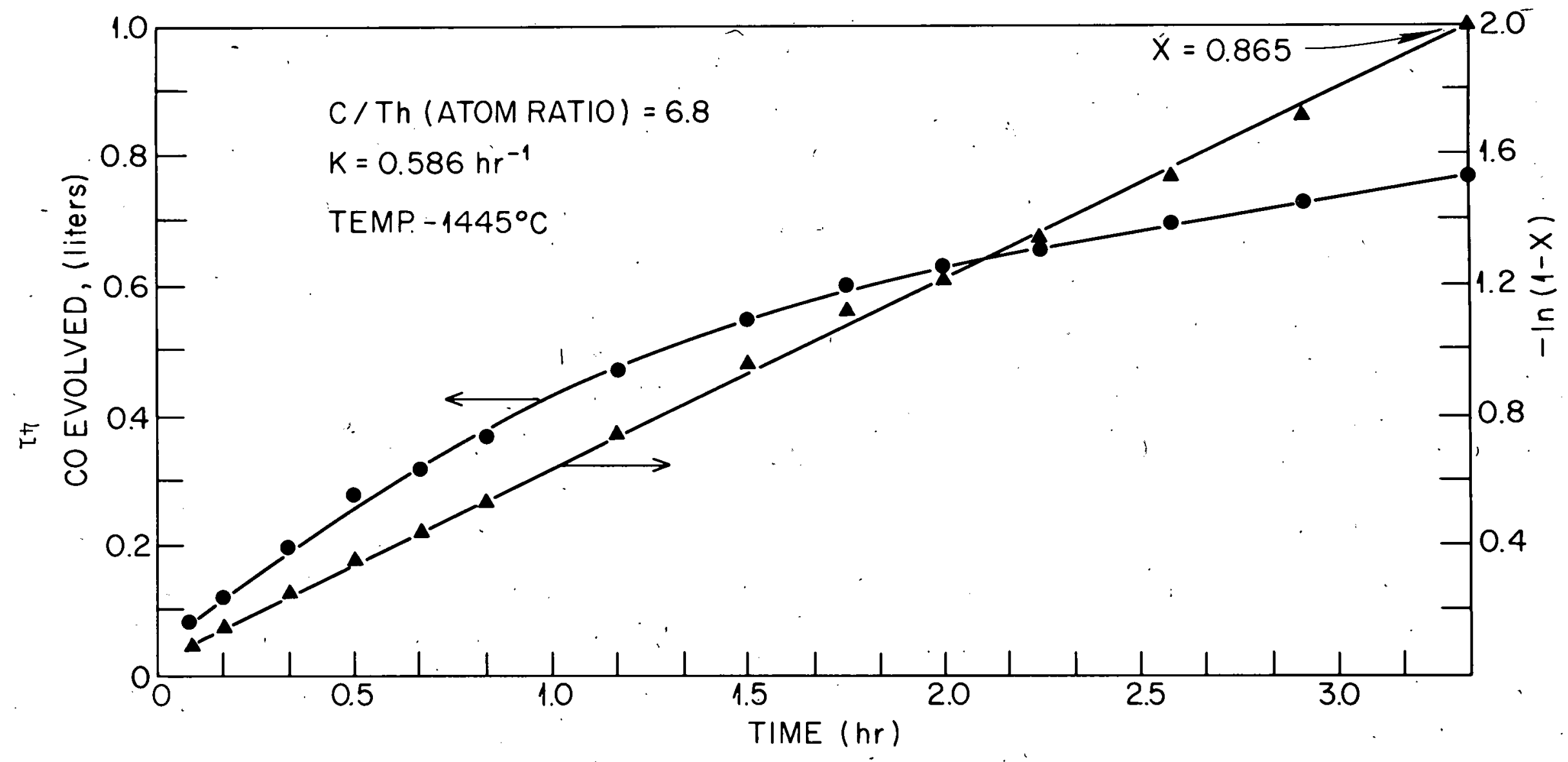

Fig. 10. Schematic Diagram of Apparatus Used in Kinetic Studies. 


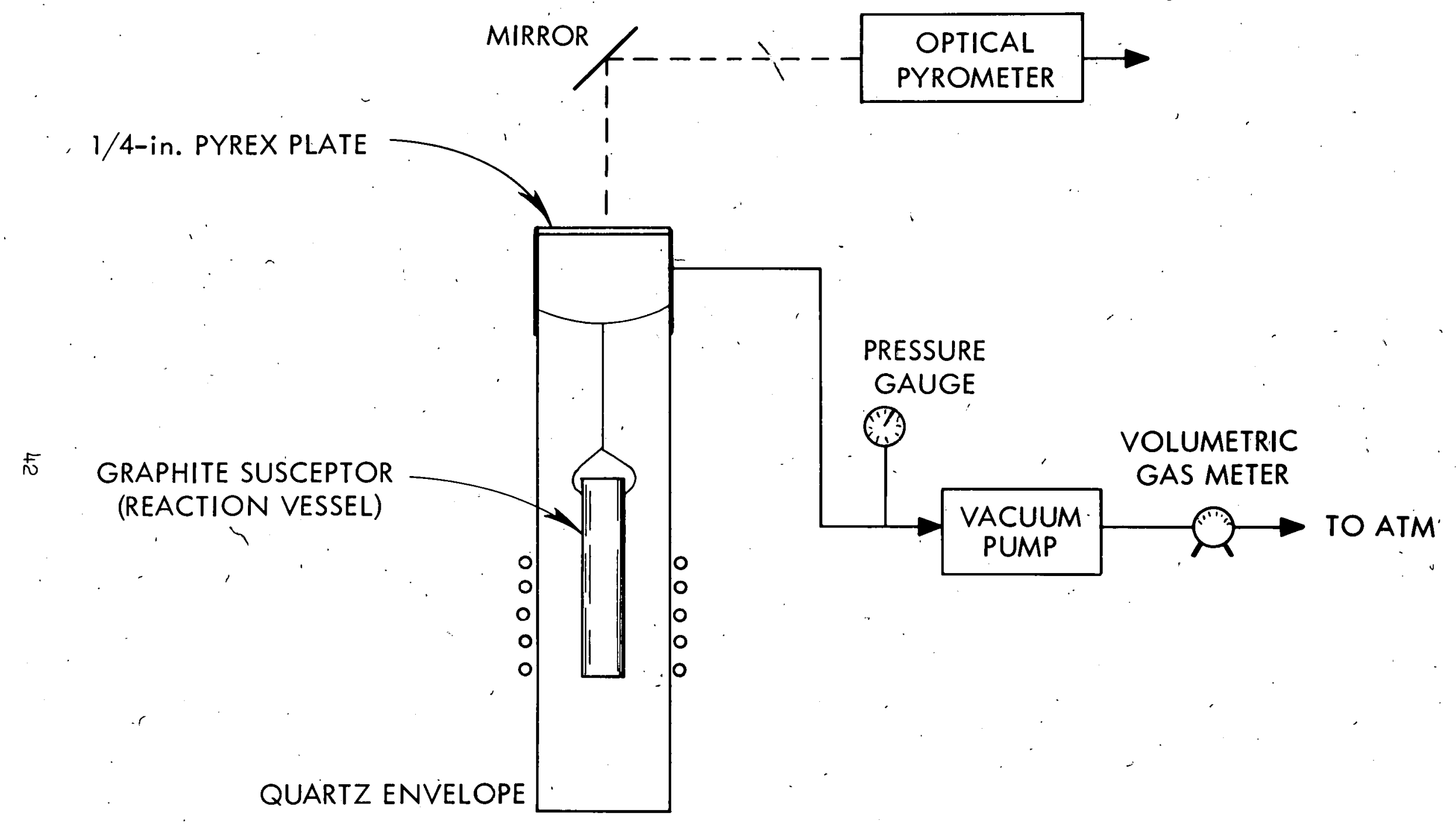

Fig. 11. Kinetic Data Obtained in the Firing of a ThO $\mathrm{O}_{2}-\mathrm{C}$ Gel at $1445^{\circ} \mathrm{C}$. 


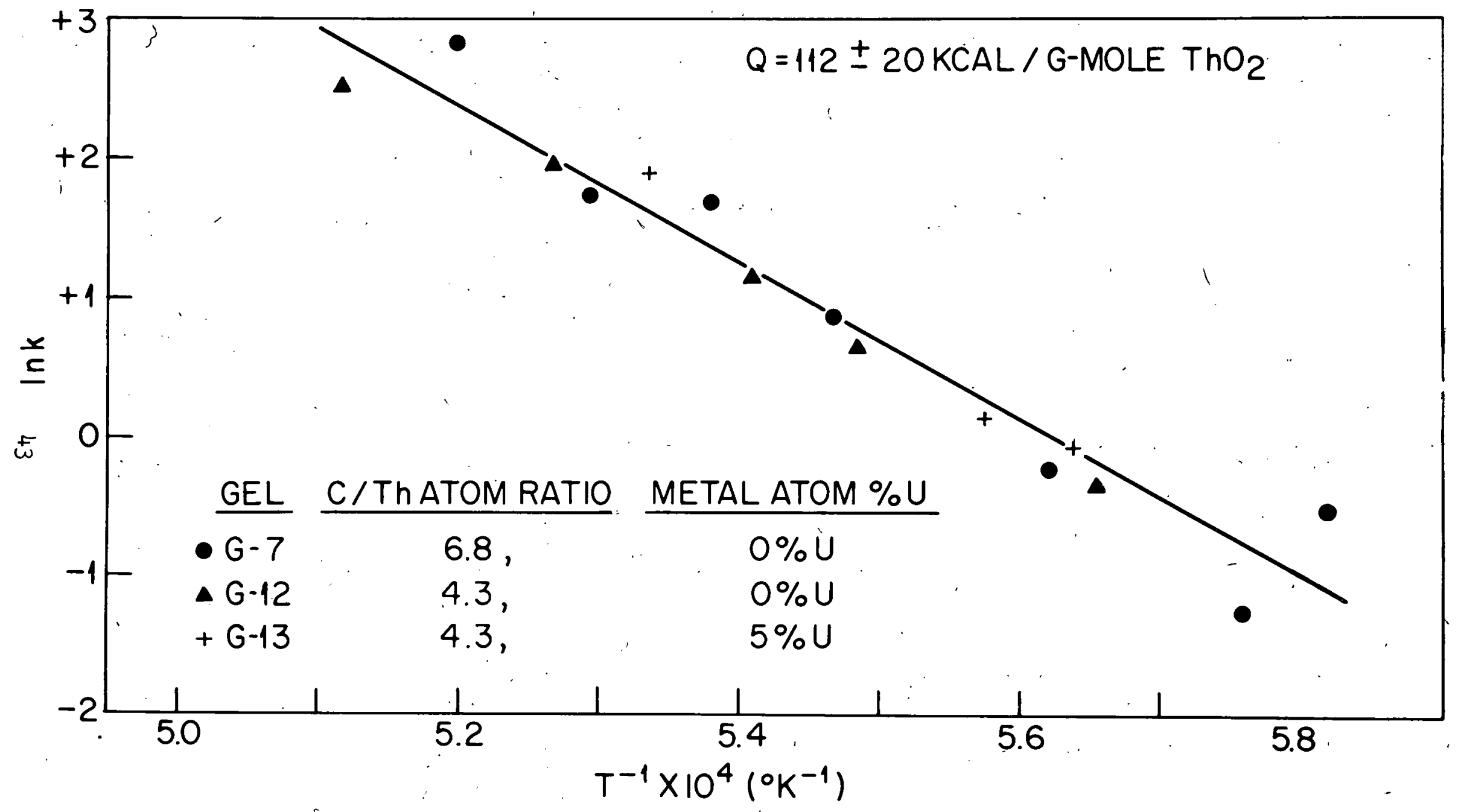

Fig. 12. Arrhenius Plot Showing Variation of Rate Constants with Temperature. 


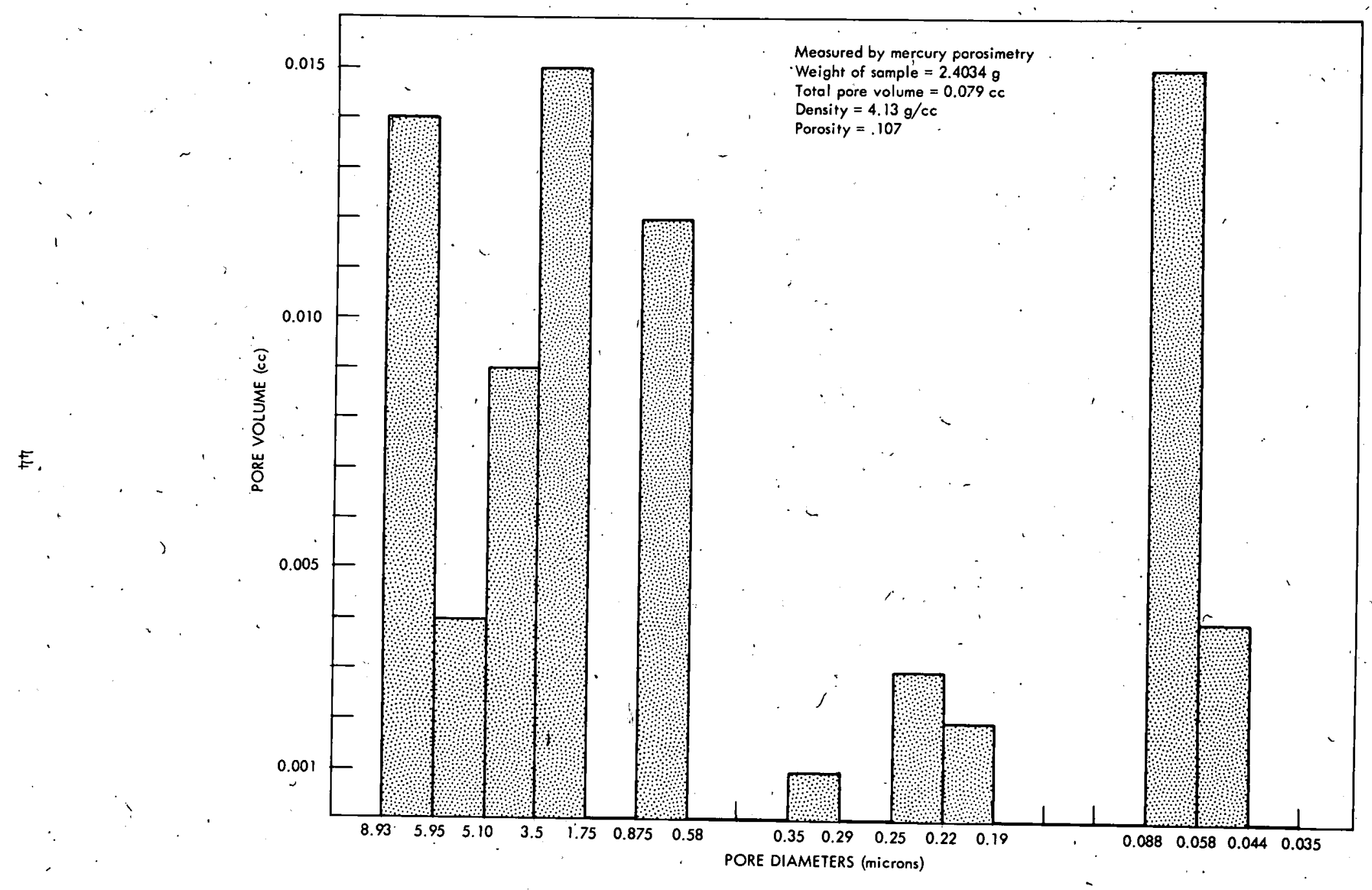

6

Fig. 13. Distribution of Pore Volumes with.Pore Diameters for Non-spheroidal Dicarbide Particles. 


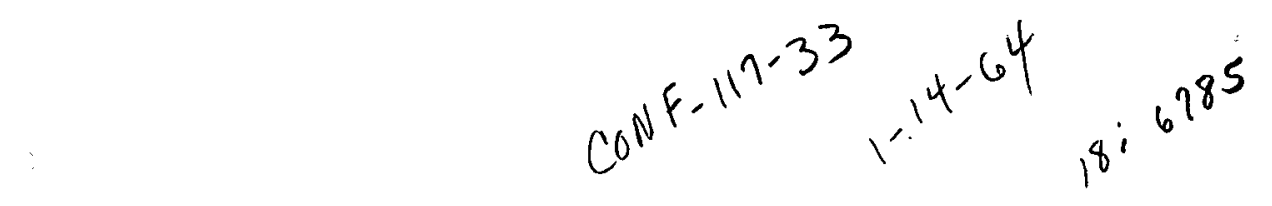

PREPARATION OF DENSE URANIIUM DIOXIDE PARTICLES

FROM URANIUM HEXAFLUORIDE IN A FLUIDIZED BED

\begin{abstract}
by
Irving E. Knudsen, Norman Levitz, and Albert A. Jonke

Argonne National Lab., Argonne, Illinois
\end{abstract}

\title{
ABSTRACT
}

A fluid-bed method has been developed for the direct preparation from uranium hexafluoride of dense, spheroidal uranium dioxide particles for dispersion and packed fuel element applications. The uranium hexafluoride. is reacted with mixtures of steam and hydrogen in a bed of uranium dioxide maintained at 650 to $700^{\circ} \mathrm{C}$, the solid reaction products depositing as a dense layer on the surface of the bed particles. The operating proccdure, involves alternating periods of uranium hexafluoride feed with periods of fluoride cleanup when only steam and hydrogen are fed.

Uranium dioxide particles in the size range $-16+140$ mesh and having densities of $9.5 \mathrm{~g} / \mathrm{cc}$ and $9.75 \mathrm{~g} / \mathrm{cc}$ (up to 89 percent of theoretical density) were produced at $650^{\circ} \mathrm{C}$ and $700^{\circ} \mathrm{C}$, respectively, using a uranium hexafluoride feed rate of $25 \mathrm{~g} / \mathrm{min}$ [44 $\mathrm{lb}$ uranium/(hr)(sq ft reactor cross section)]. The average residual fluoride content of the uranium dioxide was about $300 \mathrm{ppm}$. The densest material was obtained when 0.75 to 1.4 times the stoichiometric steam requirement (based on the reaction $\mathrm{UF}_{6}+2 \mathrm{H}_{2} \mathrm{O}+\mathrm{H}_{2} \longrightarrow \mathrm{UO}_{2}+6 \mathrm{HF}$ ) was used. The éffect on product density of other process variables such as uranium hexafluoride feed rate, hydrogen concentration, bed height and duration of hexafluoride feed period was also determined. Further densification of the 
material to 10.4 to $10.6 \mathrm{~g} / \mathrm{cc}$, up to 96.5 percent of theoretical density, and reduction of the fluoride content to about 5 ppm was achieved by sintering in hydrogen at about $1700^{\circ} \mathrm{C}$ for 2.5 hours.

\section{Introduction}

The preparation of dense particles of uranium dioxide for use in nuclear fuel elements is currently accomplished by physical treatments of the powdered oxide. Steps such as pressing, granulating, sizing, sintering, and spherodizing are required to produce particles of suitable size, density, and shape. Dense, spheroidal particles of uranium dioxide now have-been produced directly from uranium hexafluoride in a semicontinuous fluid-bed process developed at. the Argonne National Laboratory. Uranium dioxide particles with densities up to $89 \%$ of theoretical density (as measured by mercury displacement), were produced in sizes ranging from 100 to 1000 microns.

The process is described by reaction (I):

$$
\mathrm{UF}_{6(\mathrm{~g})}+2 \mathrm{H}_{2} \mathrm{O}(\mathrm{g})+\mathrm{H}_{2(\mathrm{~g})} \longrightarrow \mathrm{UO}_{2(\mathrm{~s})}+6 \mathrm{HF}_{(\mathrm{g})}
$$

Uranium hexafluoride is reacted with mixtures of steam and hydrogen in a fluidized bed of uranium dioxide particles. The reaction occurs preferentially on the surface of the bed particles, the solid reaction products being deposited as a dense, adherent layer. The operating procedure involves alternating periods of uranium hexafluoride feed with periods of fluoride clean-up when only steam and hydrogen are fed.

\section{Chemistry}

Uranium hexafluoride is converted to the dioxide by reaction with steam and hydrogen through a series of concurrent and consecutive reactions. 
Initially, gas-gas reactions occur between the uranium hexafluoride and the hydrogen or steam producing uranium tetrafluoride and $\mathrm{U}_{3} \mathrm{O}_{8}$.

$$
\begin{gathered}
\mathrm{UF}_{6(\mathrm{~g})}+\mathrm{H}_{2(\mathrm{~g})} \longrightarrow \mathrm{UF}_{4(\mathrm{~s})}+2 \mathrm{HF}_{(\mathrm{g})} ; \Delta_{298 \mathrm{~K}}=-60.4 \mathrm{kcal} / \mathrm{mole} \\
\mathrm{UF}_{6(\mathrm{~g})}+3 \mathrm{H}_{2} \mathrm{O}(\mathrm{g}) \\
\longrightarrow 1 / 3 \mathrm{U}_{3} \mathrm{O}_{8(\mathrm{~s})}+6 \mathrm{HF}_{(\mathrm{g})}+1 / 6 \mathrm{O}_{2(\mathrm{~g}) ;} \\
\Delta \mathrm{H}_{298 \mathrm{~K}}=+16.8 \mathrm{kcal} / \mathrm{mole} .
\end{gathered}
$$

These products are converted to uranium dioxide by reaction with additional quantities of steam and hydrogen.

$$
\begin{aligned}
& \mathrm{UF}_{4(\mathrm{~s})}+2 \mathrm{H}_{2} \mathrm{O}(\mathrm{g}) \longrightarrow \mathrm{UO}_{2(\mathrm{~s})}+4 \mathrm{HF}(\mathrm{g}) ; \Delta \mathrm{H}_{298 \mathrm{~K}_{\mathrm{K}}}=+44 \mathrm{kcal} / \mathrm{mole} \\
& 1 / 3 . \mathrm{U}_{3} \mathrm{O}_{8}(\mathrm{~s})+2 / 3 \mathrm{H}_{2}(\mathrm{~g}) \longrightarrow \mathrm{UO}_{2}(\mathrm{~s})+2 / 3 \mathrm{H}_{2} \mathrm{O}(\mathrm{g}) \text {; } \\
& \Delta \mathrm{H}_{298^{\circ} \mathrm{K}}=-13.7 \mathrm{kcal} / \mathrm{mole}
\end{aligned}
$$

Reactions (4) and (5) are important, also, during the fluoride cleanup period. The kinetics of these latter reactions establishes the residence time required for cleanup.

Apparatus and Procedure

The development work on the process has been carried out in a 3 inch. diameter Monel column shown schematically in Fig. 1. The reactor was 30 inches high. and had a 60-degree cone bottom. "A I/4-inch OD tube which passed through the apex of the cone bottom and extended about $31 / 2$ inches into the bed served as the uranium hexafluoride feed nozzle. The annulus around this nozzle provided for entrance of the fluidizing and/or reactant gases. A solids feed line for the addition of seed particles was provided at a point 20 inches up the column. Product was withdrawn from an outlet located near the bottom of the cone. 
SCHEMATIC DRAWING OF FLUID-BED COLUMN FOR THE PREPARATION OF DENSE URANIUM DIOXIDE FROM URANIUM HEXAFLUORIDE

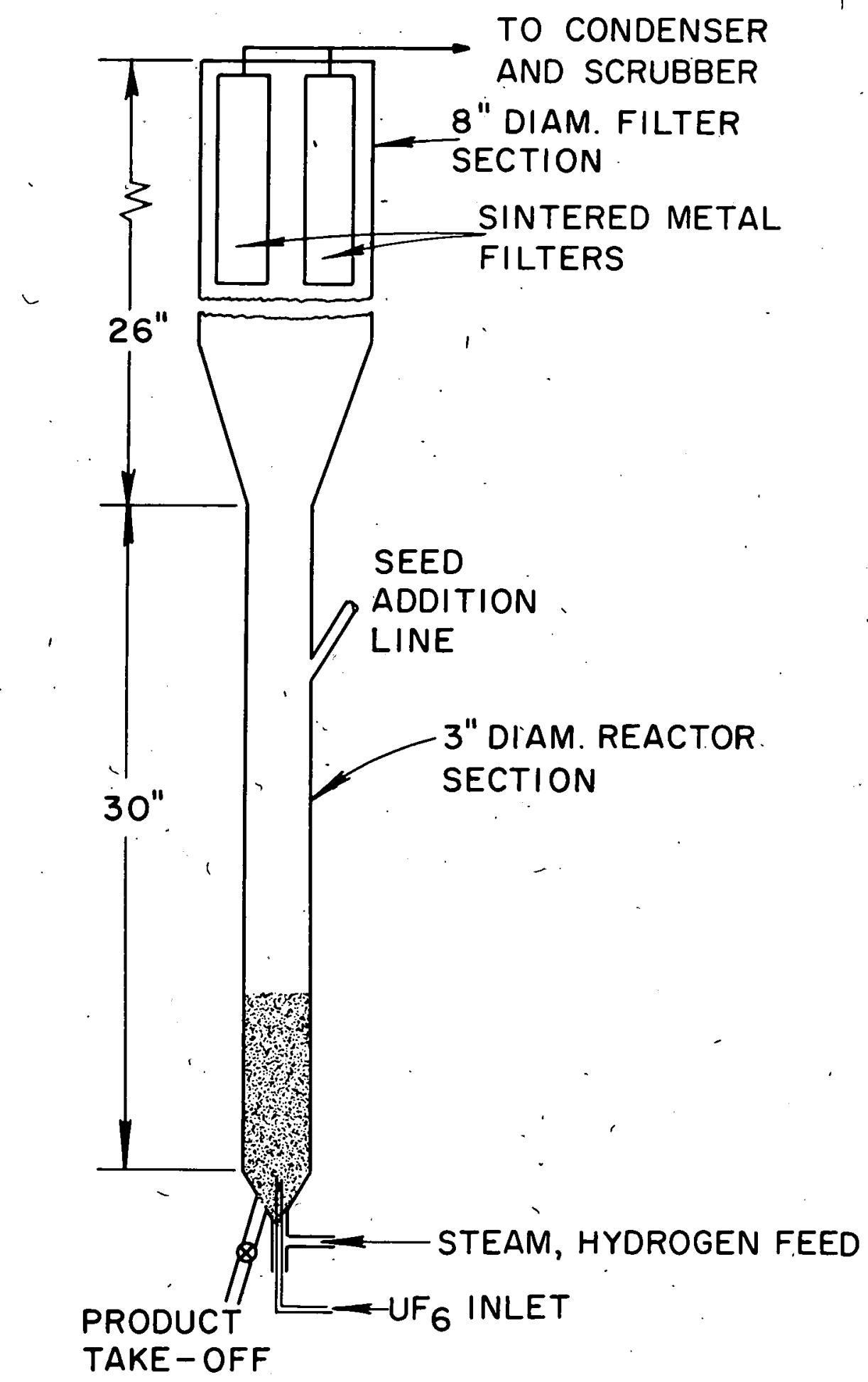


An eight-inch diameterisection containing sintered metal filters surmounted the reactor. Three Monel bayonet filters, 3 inches wide and nine inches long, were employed. An automatic jet-pulse blowback system, which utilized an 80 psig nitrogen supply, discharged accumulated solids from the filters. The off-gas passed to a Monel condenser. The hydrofluoric acid condensate was collected in plastic receivers. The noncondensable gases were scrubbed further downstream in a circulating caustic scrubber. Condensate and caustic samples were analyzed to estimate uranium Iosses.

The operating procedure involved, first, starting of the nitrogen purge and fluidizing gas streams and charging of the uranium dioxide bed. The flow of steam and hydrogen was started shortly before the desired operating temperature was reached; the flow of fluidizing nitrogen was then stopped. When operating conditions were stabilized, the uranium hexafluoride feed was introduced. The process was cyclic in operation; periods of hexafluoride feed were alternated with periods of fluoride cleanup when only steam and hydrogen were fed. These periods were generally of 30 -minute duration, each. By adding seed particles obtained by grinding and recycling . a portion of the products, particle growth (as a result of solids deposition) was offset and a uniform average particle diameter was maintained in the fluid bed. Product was withdrawn from the reactor at the end of each cleanup period. 
Typical operating conditions were as follows:

$\begin{array}{ll}\text { Reactor temperature } & 650^{\circ} \mathrm{C} \\ \text { Steam rate } & 3.3 \mathrm{~g} / \mathrm{min} \\ \text { Hydrogen rate } & 2.5 \mathrm{~g} / \mathrm{min} \\ \text { Uranium hexafluoride rate. } & 25 \mathrm{~g} / \mathrm{min} \\ \text { Uranium hexafluoride feed period } & 30 \mathrm{~min} / \mathrm{hr} \\ \text { Bed weight and depth } & 6.0 \mathrm{~kg}, 9 \text { inches (static) } \\ \text { Seed addition rate } & \sim 15 \% \text { (by weight of the } \\ & \text { UF rate) }\end{array}$

Results and Discussion

The process variables which were found to affect the density of the uranium dioxide product were the steam and uranium hexafluoride rates, the operating temperature, the duration of the hexafluoride feed period, the depth of the fluidized bed, and the location of the uranium hexafluoride inlet in the fluidized bed.

In the experimental work, essentially complete conversion of the uranium hexafluoride to solids was achieved. Losses of uranium to the off-gas were less than $0.01 \%$ of the hexafluoride feed. The average coating rate was about 10 microns/hr of uranium hexafluoride feed.

Effect of Reactant Rates on Oxide Density

Uranium dioxide particles with densities up to $9.5 \mathrm{~g} / \mathrm{cc}$ (about $86.5 \%$ of theoretical density) were produced at $650^{\circ} \mathrm{C}$ when optimum amounts of steam were used. A steam-to-uranium hexafluoride mole ratio of about $2 / 1$, (the stoichiometric ratio based on the overall reaction) was found to give the highest oxide density (see Fig. 2). Smaller amounts as well as larger amounts of steam resulted in lower density of the uranium dioxide product. 
THE EFFECT OF STEAM RATE ON THE PARTICLE DENSITY OF URANIUM DIOXIDE PRODUCED BY REACTION OF HYDROGEN AND STEAM WITH URANIUM HEXAFLUORIDE

\section{Run Conditions}

Temperature:

$U_{6}$ Rate:

$650^{\circ} \mathrm{C}$

Duration of Feed Period: $30 \mathrm{~min} / \mathrm{hr}$

Bed Depth (static): $\quad 9$ in.

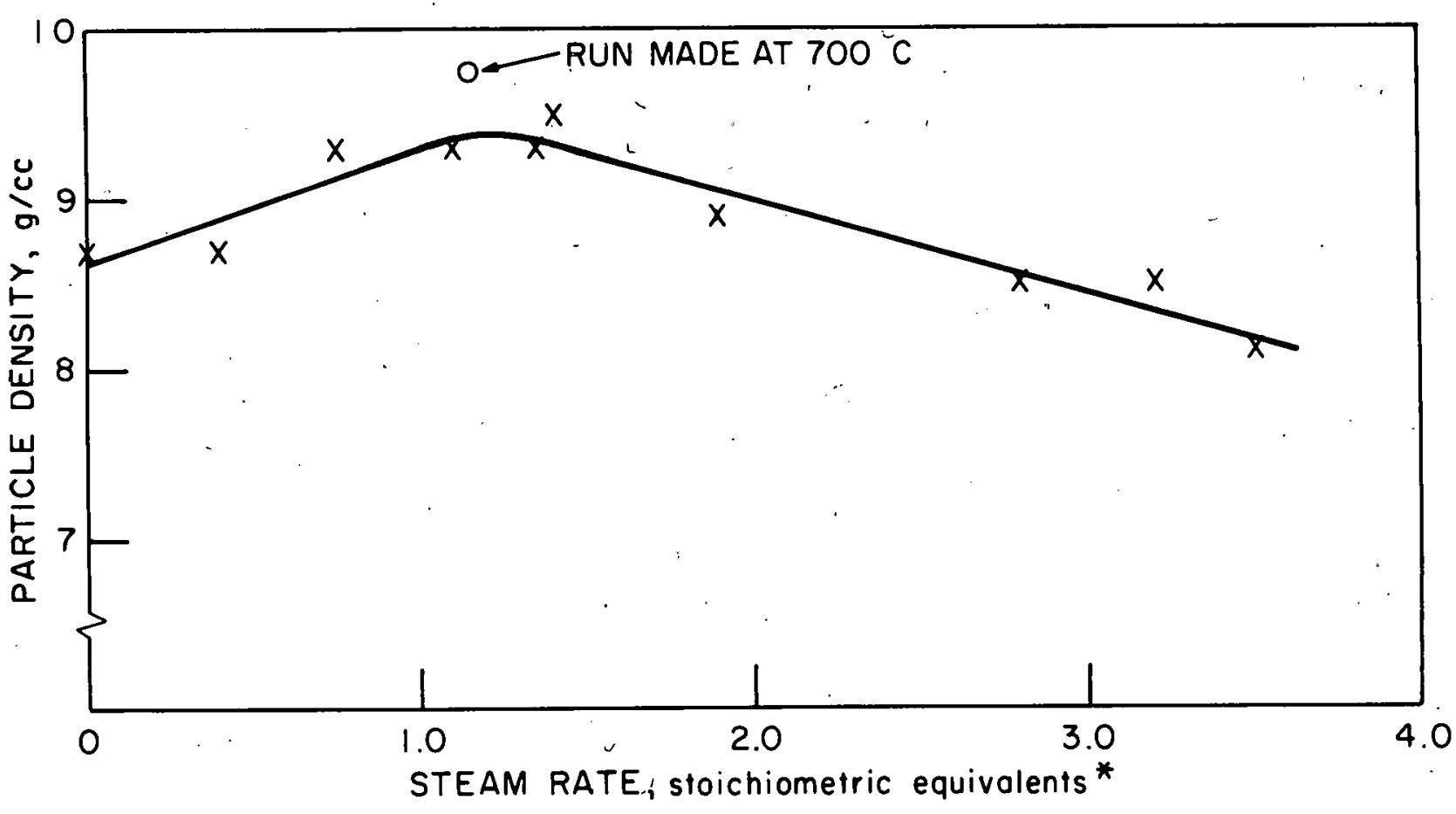

( ${ }^{*}$ BASED ON THE REACTION UF $6+2 \mathrm{H}_{2} \mathrm{O}+\mathrm{H}_{2} \rightarrow \mathrm{UO}_{2}+6 \mathrm{HF}$ ) 
The observed density variations with steam rate are believed to be associated with the sintering, on the particle surfaces of relatively low melting mixtures of uranium tetrafluoride, uranium dioxide, and $\mathrm{U}_{3} \mathrm{O}_{8}$. Sintering of mixtures of uranium tetrafluoride and uranium dioxide at these temperatures has been reported in the literature ${ }^{1,2}$. Actual evidence of particle sintering was obtained in a study with a starting bed of relatively low-density uranium dioxide particles. In an eight hour test, increases in density of about $24 \%$ were observed, the density increasing from $6.9 \mathrm{~g} / \mathrm{cc}$ to $8.6 \mathrm{~g} / \mathrm{cc}$ for the full-size range bed (see Fig. 3). Only - about half of this increase can be attributed to the displacement of the lơw-density starting material by the denser oxide, the remainder resulting from sintering of the original particles. The density increases were similar for the different size fractions. Microscopic examination of the particles of the starting and final beds showed that voids had been eliminated from the interior of the starting particles during the run. Another indication of the apparent densification of the starting material was the absence of any overall particle growth (a 19\% increase in average particle diameter had been anticipated). These results suggest that this process scheme would be suitable for upgrading low-density oxide.

In contrast to the effect of the steam rate, the amount of hydrogen in the reactant stream in the range of 5 to 20 times the stoichiometric requirement (based on the overall reaction) had no effect on the density of the uranium dioxide product. Also, since the steam rate during the fluoride cleanup period was found to have no effect on the product density, larger amounts of steam, up to $12 \mathrm{~g} / \mathrm{min}$, were used during the cleanup period to increase the rate of fluoride removal. 
INCREASE IN DENSITY OF URANIUM DIOXIDE BED PARTICLES OCCURRING DURING DEPOSITION OF DENSE OXIDE FROM REACTION OF HYDROGEN AND

STEAM WITH URANIUM HEXAFLLUORIDE
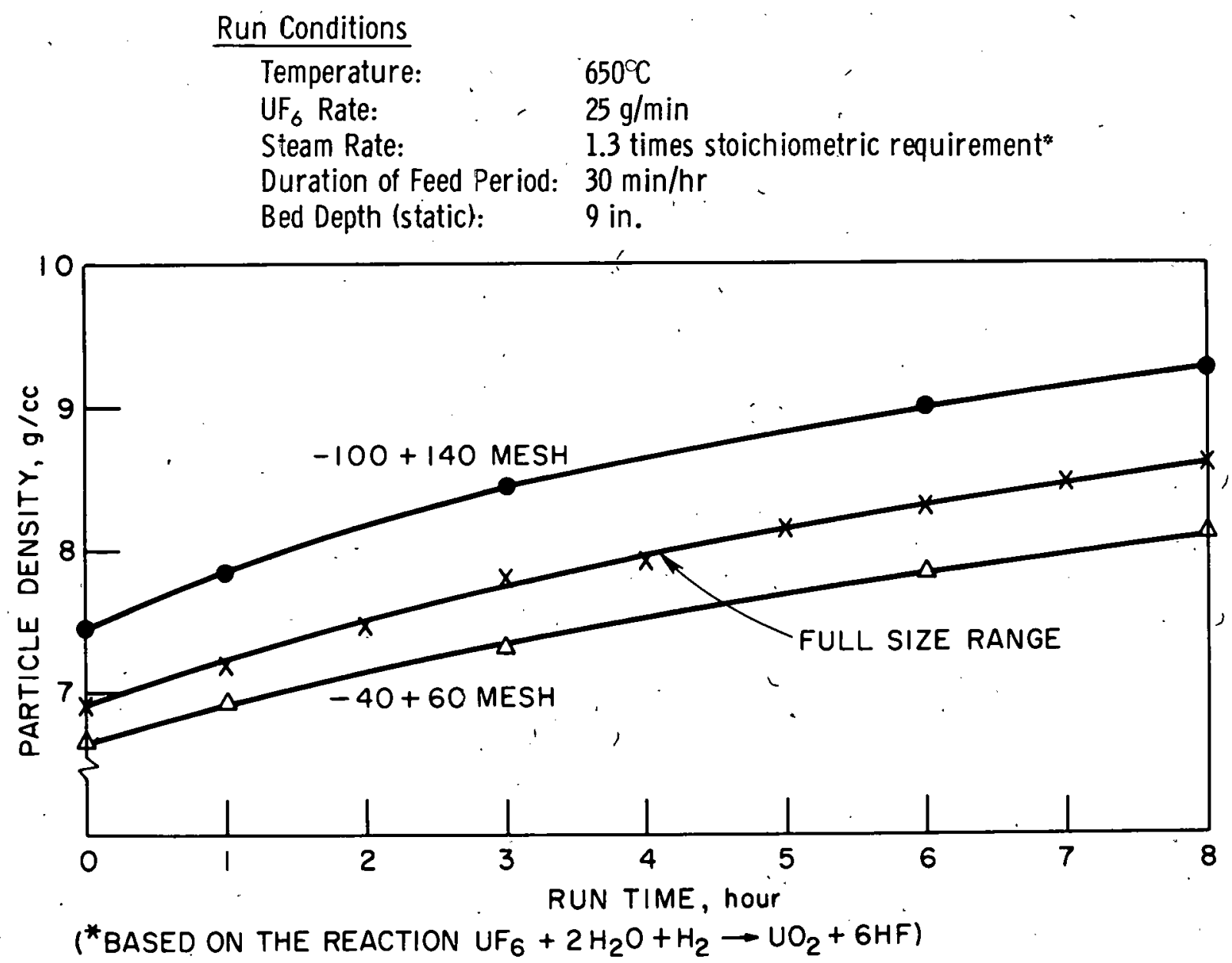
The effect of the uranium hexafluoride feed rate at a constant steam/hexafluoride ratio on the density of the dioxide product was investigated in the interest of increasing the capacity of the unit. Doubling the uranium hexafluoride rate from 25 to $50 \mathrm{~g} / \mathrm{min}[$ from 44 to $88 \mathrm{lb}$. uranium/(hr) (sq ft reactor cross section)] resulted in about a $6 \%$ reduction in density of the dioxide product from $9.3 \mathrm{~g} / \mathrm{cc}$ to $8.7 \mathrm{~g} / \mathrm{cc}$ (see Fig. 4).

\section{Effect of Other Variables on Oxide Density}

Operation at a reactor temperature higher than $650^{\circ} \mathrm{C}$ resulted in a denser product. Uranium dioxide with a density of $9.75 \mathrm{~g} / \mathrm{cc}$ (about $89 \%$ of theoretical density) was obtained in a test at $700^{\circ} \mathrm{C}$ when the $2 / 1$. ratio of steam and uranium hexafluoride was used with a uranium hexafluoride feed rate of $25 \mathrm{~g} / \mathrm{min}$. In comparison, a density of $9.3 \mathrm{~g} / \mathrm{cc}$ 'was obtained for similar conditions at $650^{\circ} \mathrm{C}$. Temperatures below $650^{\circ} \mathrm{C}$ were not investigated.

The duration of the uranium hexafluoride feed period up to periods of 30 minutes had no effect on the density of the uranium dioxide. However, extending the duration of the hexafluoride feed period to one hour between cleanup periods resulted in a slight reduction in product density.

An effect of bed depth on product density was also noted. In tests at $650^{\circ} \mathrm{C}$, with the optimu $2 / 1$ steam-uranium hexafluoride ratio and a uranium hexafluoride rate of $25 \mathrm{~g} / \mathrm{min}$, an increase in the density of the uranium dioxide product from $9.3 \mathrm{~g} / \mathrm{cc}$ to $9.6 \mathrm{~g} / \mathrm{cc}$ was obtained when the bed depth (static) was doubled from 9 to 18 inches. Doubling the bed inventory, in effect, results in halving the thickness of the deposited layer, and apparently, thinner layers densify or. "sinter" more readily. 
THE EFFECT OF URANIUM HEXAFLUORIDE RATE ON THE PARTICLE DENSITY OF URANIUM DIOXIDE PRODUCED BY REACTION OF HYDROGEN AND STEAM WITH URANIUM HEXAFLUORIDE

Run Conditions
Temperature:
'Steam Rate:
Duration of Feed Period: $30 \mathrm{~min} / \mathrm{hr}$
$650^{\circ} \mathrm{C}$
1.15 to 1.35 times stoichiometric requirement*
Bed Depth (static):

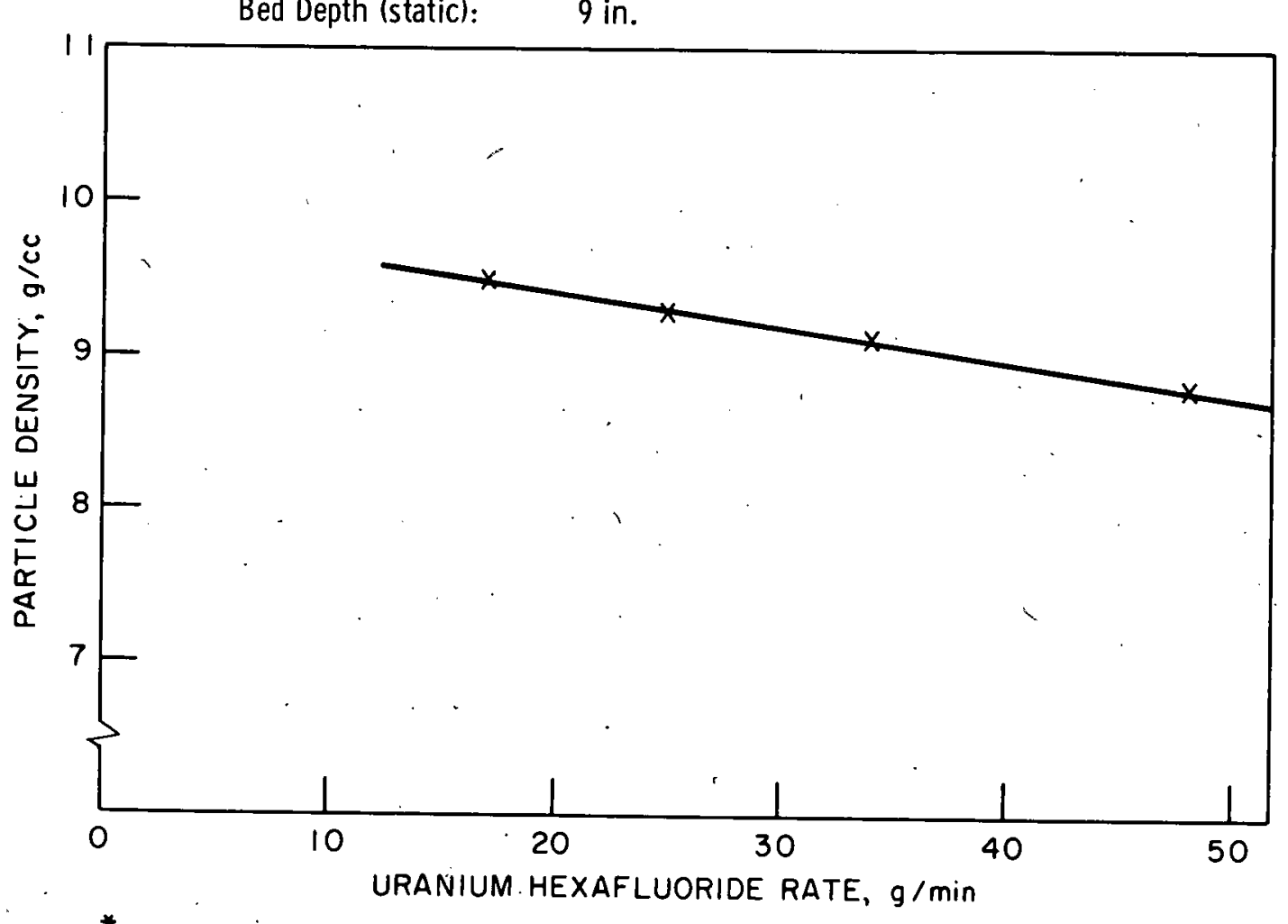

( ${ }^{*}$ BASED ON THE REACTION UF $6+2 \mathrm{H}_{2} \mathrm{O}+\mathrm{H}_{2} \longrightarrow \mathrm{UO}_{2}+6 \mathrm{HF}$ ) 
During the course of the experimental work, the uranium hexafluoride inlet was re-positioned so that it extended only $3 / 4$ inch, rather than $31 / 2$ inches, into the bed of particles. With this shorter inlet, a lowerdensity product was obtained, $9.0 \mathrm{~g} / \mathrm{cc}$ at conditions at which product densities of $9.3 \mathrm{~g} / \mathrm{cc}$ had been previously obtained. The reduction in product density with the short hexafluoride inlet was reproduced in several tests with different steam-to-uranium hexafluoride ratios and is attributed to different solids-mixing patterms in the cone section of the reactor.

\section{Properties of the Uranium Dioxide Product}

The uranium dioxide products contained about 200 to $300 \mathrm{ppm}$ residual fluoride and about $1 \%$ to $2 \%$ hexavalent uranium. The oxygen-to-uranium ratio was 2.03 . Contamination of the oxide from corrosion of the Monel. reactor was low; only 10 to $20 \mathrm{ppm}$ copper and nickel were found in typical products.

Pore size distribution measurements ${ }^{*}$ indicated that much of the porosity in the particles consisted of pores less than $0.4 \mu$ in diameter and a significant number were smaller than $0.06 \mu$. The fine-grained structure of the particles may be seen in Fig. 5, a high-magnification (533X) photomicrograph of a sectioned particle. Figure 6 shows the smooth, sphcroidal appearance of the particle as produced in the fluid-bed and FIg. 7, which shows cross sections of a number of particles, illustrates the uniform manner in which the layers are deposited. Results of Sintering Tests

Sintering of representative samples of uranium dioxide particles in hydrogen resulted in significant further densification of the particles

* Pore size distribution measured on a porosimeter by Armour Research Foundation, Chicago, Illinois. 
Figure 5

\section{CROSS SECTION OF DENSE URANIUM DIOXIDE PARTICLE SHOWING FINE-GRAIN STRUCTURE}

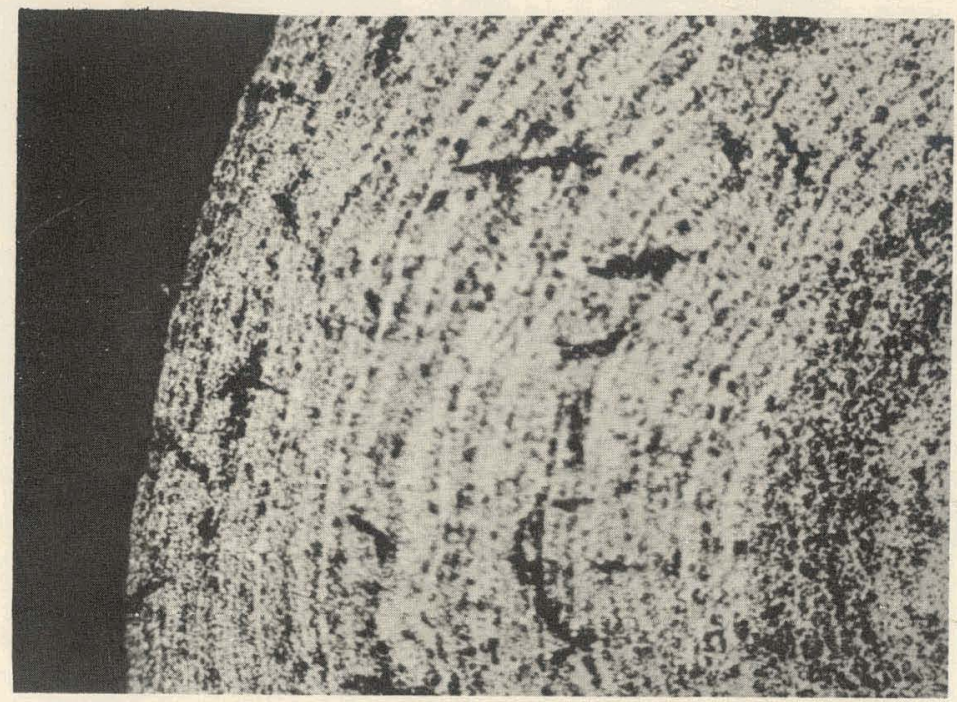

Particle Density, $9.7 \mathrm{~g} / \mathrm{cc}$

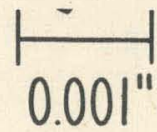


Figure 6

DENSE URANIUM DIOXIDE PARTICLES AS PRODUCED

IN THE FLUID-BED REACTOR
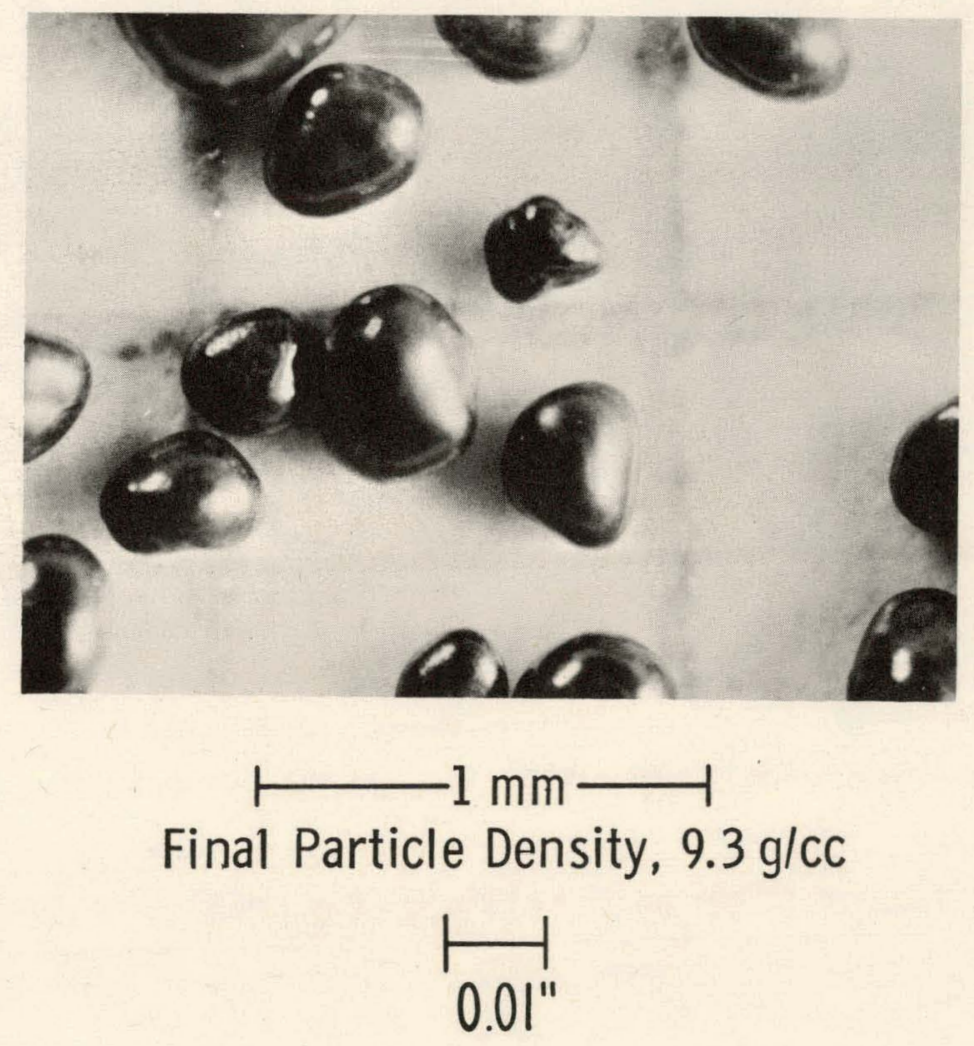
CROSS SECTION OF DENSE URANIUM DIOXIDE PARTICLES SHOWING LAYER DEPOSITION

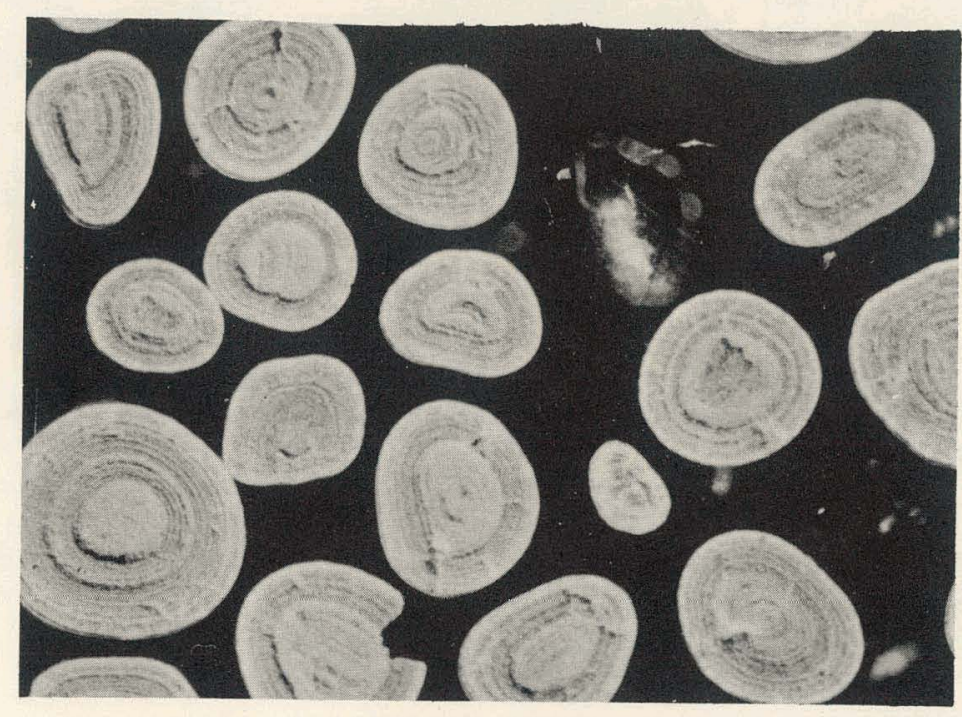

Particle Density, $9.3 \mathrm{~g} / \mathrm{cc}$

Etched $60 \mathrm{sec}$ with One Part Conc, $\mathrm{H}_{2} \mathrm{SO}_{4}$, Nine Parts $30 \% \mathrm{H}_{2} \mathrm{O}_{2}$

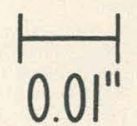


and further removal of fluoride. Final densities of $95 \%$ to $96.5 \%$ of theoretical density were obtained by heating material with densities ranging from 72 to $89 \%$ of theoretical in hydrogen for 2.5 hours at $1700^{\circ} \mathrm{C}$ (see Table 1). The highest density, $96.5 \%$ of theoretical, was obtained on the particles having the highest initial density. The residual fluoride content of all the samples was reduced to about $5 \mathrm{ppm}$.

The final sintered particles were smooth-surfaced and spheroidal in appearance like the original particles (see Figures 8 and 9). A crosssection of the sintered particle (Fig. 10) shows the elimination of the fine-grained structure previously noted.

\section{Conclusions}

The preparation of dense uranium dioxide particles from uranium hexafluoride by reaction with steam and hydrogen in a fluidized bed has been demonstrated. The process also appears to be directly applicable for the conversion of mixtures of uranium and plutonium hexafluorides to the oxides as well as to the conversion of pure plutonium hexafluoride. Currently, work is in progress at ANL on the construction of a 2-inch diameter fluid-bed unit for the preparation of mixed-oxide particles containing up to $20 \%$ plutonium. Operation of this unit is expected to begin early in 1964 .

This work was supported by the U. S. Atomic Energy Commission Contract W-31-109 eng-38 . 
Table 1

SINTERING TEEST RESULTS ON DENSE URANIUM DIOXIDE

PARTICLES PRODUCED BY STMULTANEOUS

RFACTION PROCEDURE

$\begin{array}{cc}\begin{array}{ll}\text { Particle Size: } & -20+200 \text { mesh } \\ \text { Sintering Atmosphere: } & \begin{array}{l}\text { Hydrogen (300 ppm } \\ \text { oxygen impurity) }\end{array} \\ \text { Sintering Temperature: } & \begin{array}{l}1600-1725^{\circ} \mathrm{C} \text { for } \\ 2-1 / 2 \text { hours }\end{array} \\ \hline \text { Particle Density }(\mathrm{g} / \mathrm{cc})\end{array} \\ \begin{array}{cc}\text { Before Sintering } & \text { After Sintering }\end{array} \\ 9.75 & 10.6 \\ 8.0 & 10.4 \\ 10.4\end{array}$




\section{Figure 8}

DENSE URANIUM DIOXIDE PARTICLES PRODUCED BY THE CONVERSION OF URANIUM HEXAFLUORIDE - AFTER SINTERING
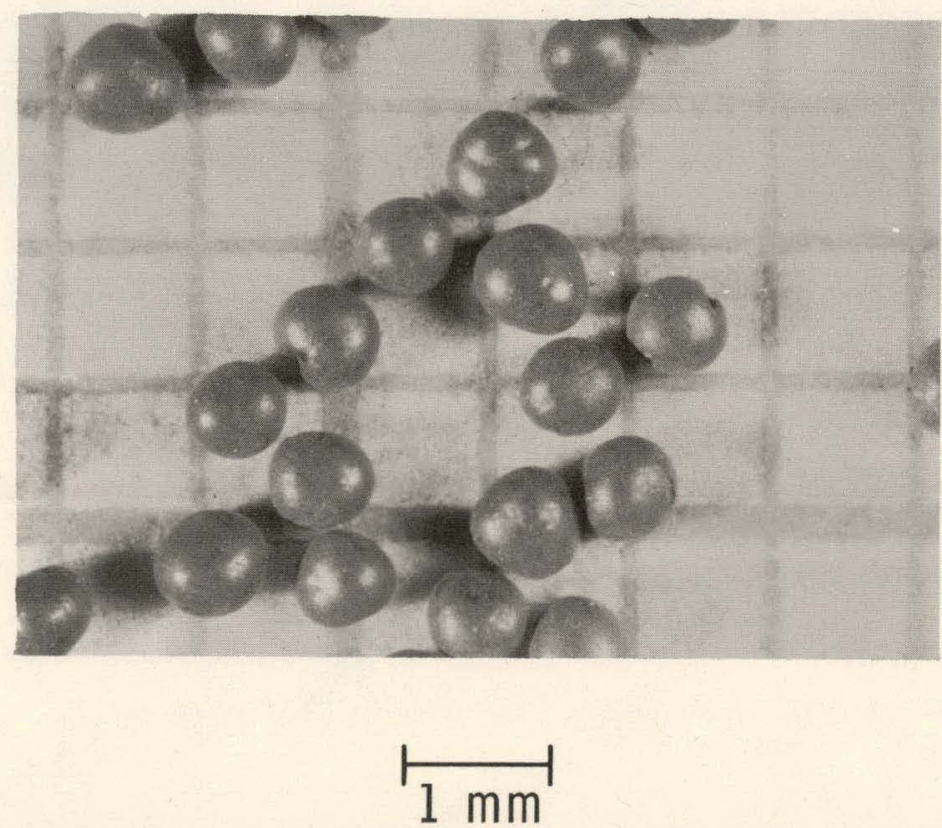

Particle Density $\quad 10.6 \mathrm{~g} / \mathrm{cc}$

Particle Diameter $\sim 650 \mu$ 


\section{DENSE URANIUM DIOXIDE PARTICLES PRODUCED BY THE CONVERSION OF URANIUM HEXAFLUORIDE - AFTER SINTERING}
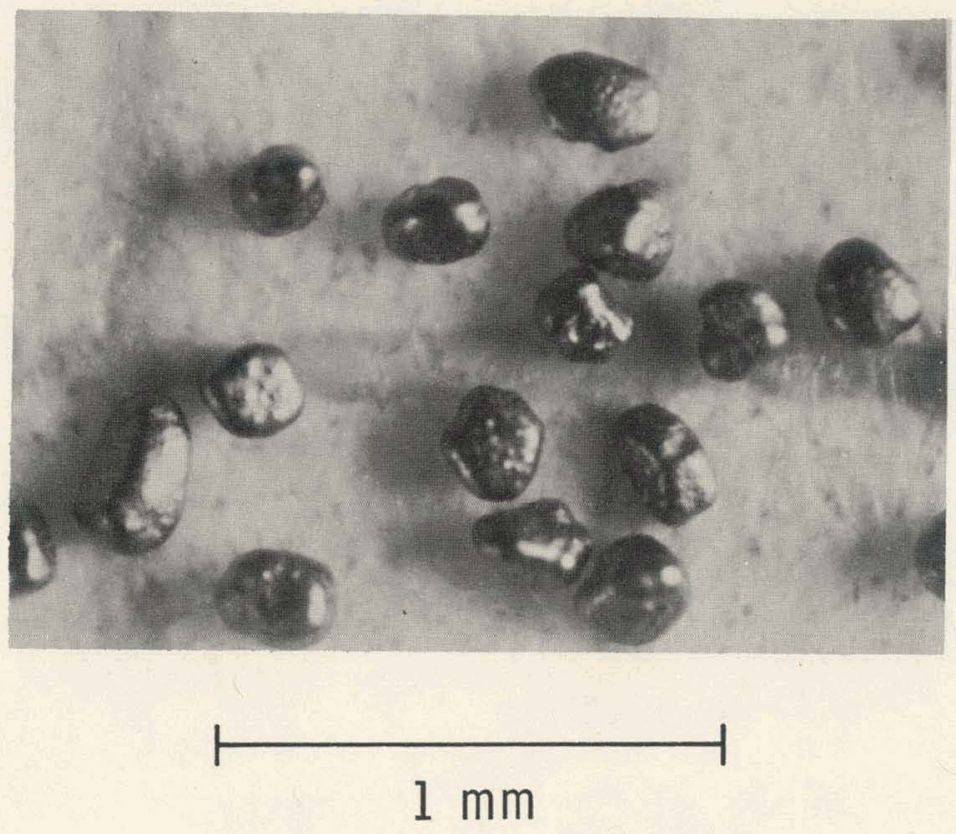

Particle Density $\quad 10.6 \mathrm{~g} / \mathrm{cc}$ Particle Diameter $160 \mu$ 
CROSS SECTION OF DENSE URANIUM DIOXIDE PARTICLE SHOWING STRUCTURE AFTER SINTERING IN HYDROGEN AT $1700 \mathrm{C}$

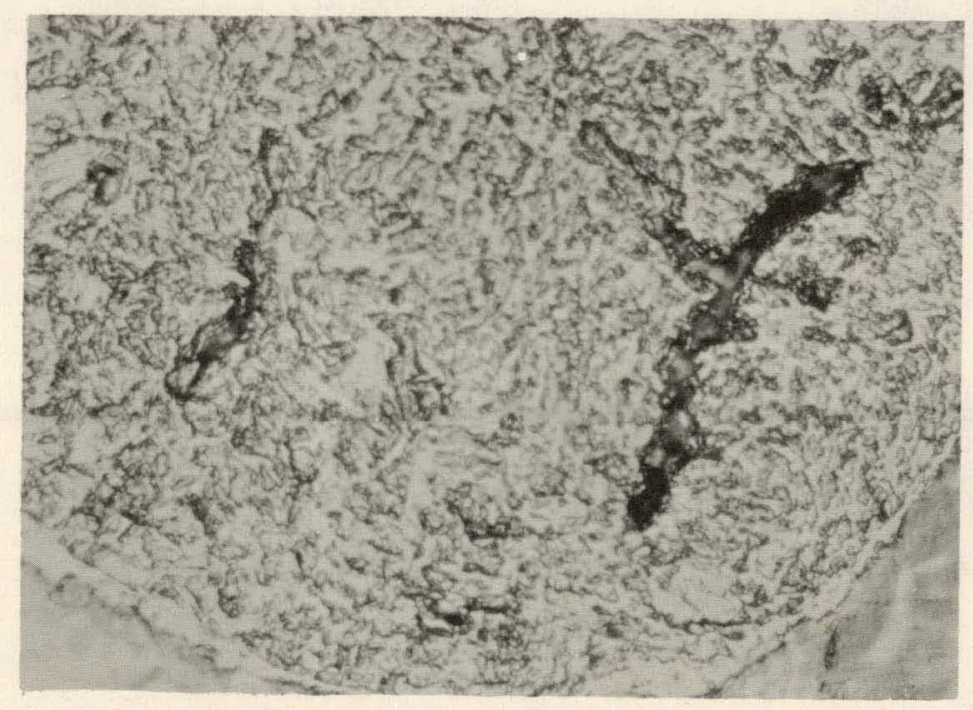

Particle Density, $10.6 \mathrm{~g} / \mathrm{cc}$<smiles>C1C[Te][Te]1</smiles> 


\section{REFERENCES}

(1) Ewing, R. A., and Bearse, A. E., "Differential Thermal Analysis of Uranium Tetrafluoride-Uranium Dioxide Mixtures", USAEC Report BMI-1103 (June 1956).

(2) Barber, E. J., "Solid-Liquid Equilibrium and Sintering Temperatures of Uranium Tetrafluoride-Uranium Dioxide Mixtures", USAEC Report KLI-3588 (1955). 
THIS PAGE

WAS INTENTIONALLY

LEFT BLANK 


\title{
FUEL REQUIREMENTS FOR FISS IOCHEMICAL PRODUCTION* \\ by
}

\author{
R.L. Pearson, J. H. Cusack, D. E. Deutsch \\ Aerojet-Genera1 Nucleonics \\ San Ramon, California
}

A B S T R A C T

Fuel systems for a fissio-chemical reactor were evaluated. The efficiency at which fission fragments deposit their energy depends largely upon fuel geometry and composition. Three types of fuel can be úsed to generate fission fragments: homogeneous solutions or mixtures, fixed fuels, and heterogeneous mixtures. It was concluded that a slurry of spherical particles of fully enriched $\mathrm{UO}_{2}^{-}$, less than 3 microns in diameter, suspended in liquid ammonia is best suited for fissiochmical production of hydrazine. The slurry should be stable, insoluble, nonabrasive and noncorrosive, should form uniform dispersions and loosely packed sediment, should not promote catalytic decomposition of the product, and should have minimum susceptibility to irradiation damage.

*AN $-\mathrm{TP}-74$ 
With the onset of nuclear technology late in 1942, a potent new source of energy became available for the production of chemicals. Until recently, bulk heating and gamma-ray absorption were the only seriously considered methods of applying nuclear energy. A third method now being -evaluated at several laboratories, utilizes kinetic energy released by fission fragments during irradiation. The atomic fragments born during fissioning are allowed to deposit their kinetic energy of mass motion directly into the process fluid. The two new atoms created by the fission event recoil in opposite directions. Because of their substantial mass--averaging 117 atomic mass units--and their substantial charge--averaging plus 20 electron equivalents--they interact strongly with surrounding matter, disrupting molecular structures and producing a very dense ionization track. This formation of ions, free radicals, and activated species, followed by their molecular recombination, is called the "fissiochemical" process.

The efficiency with which this fission fragment recoil energy can be used is the most important consideration in selecting the fuel system for a fissiochemica1 reactor. About $84 \%$ of the 200 million electron volts resulting from the fissioning of a uranium atom appears as fragment recoil energy. Because these fragments lose their energy when they contact matter, the farther the fragments must travel through fuel or fuel diluent, the less energy they can deposit in the process stream. Therefore, fuel composition and geometry are crucial to energy deposition efficiency. 
Uranium dioxide particles in the form of spheres, fibers, and slabs--both pure and glass-bonded--are fuel forms which have been investigated. Some effects of fuel shape, size, and composition on energy deposition efficiency are shown in Figure 1. The curves show that energy deposition efficiency is influenced more by the shape and size of the $\mathrm{UO}_{2}$ than by the amount of diluent added. Pure $\mathrm{UO}_{2}$ spheres are more efficient than pure

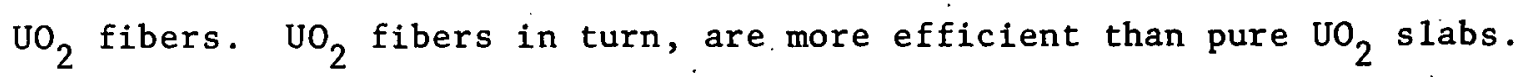
And diluting the $\mathrm{UO}_{2}$ with glass curtails energy deposition efficiency in all of these fuel forms.

AGN recently began an experimental program to compare the energy deposition, or escape efficiency, of various fuel compounds and geometries. A solid-state detector and a multichannel pulse height analyzer were used to determine the energy spectra of the fission fragments escaping from ${ }^{c} \mathrm{U}-235$ sources. The average energy of the escaped fragments was calculated from the integrated area under the spectral curve. The average number of fragments escaping per fission was calculated from the ratio of measured-to-total fissions. And the product of these two values gave the energy deposition efficiency.

Figure 2 shows the results of experiments with three fuel forms in a slab of geometry. The solid lines represent predictions based on various mechanistic assumptions. ${ }^{1}$ The points represent experimental results. Although the discrepancies between calculated and measured values are sma11, more theoretical and experimental work must be done to obtain closer agreement.

Three types of fuel systems will be considered--homogeneous solutions or mixtures, fixed fuels, and heterogeneous mixtures. A detailed consideration of all three is not pertinent at a particulate fuel symposium. 
Therefore, this report will touch only briefly on homogeneous mixtures and fixed fuels, and will concentrate on the advantages and disadvantages of heterogeneous mixtures. Homogeneous solutions or gaseous mixtures of uranium in a reactant stream theoretically allow complete utilization of the recoil energy. In practice, complete utilization is not possible, usually because of thermal decomposition, chemical reactivity, instability under irradiation, or product decomposition.

The halide $\mathrm{UF}_{6}$ is one uranium/gas compound which has sufficient vapor pressure to circulate as a gas during reactor operation, but is too chemically, reactive and too unstable under irradiation to be usable as a reactor fuel. Ako, the fluoride ion (and other products) resulting from the decomposition of $\mathrm{UF}_{6}$ may recombine with materials in the product stream to contaminate the end product.

Clearly, exhaustive research will be required to discover a soluble uranium compound and to demonstrate its suitability for the fissiochemical production of a specified product. The Homogeneous Reactor Project ${ }^{2}$ at Oak Ridge expended a great deal of time, and effort investigating the properties of aqueous fuel solutions. These solutions are very corrosive. One of the most promising fuels, uranyl sulfate, was unstable at high temperatures where it formed a second phase. Financed in part by an Air Force contract to explore the fissiochemical production of hydrazine, a powerful liquid rocket propellant, AGN investigators have tried to isolatea uranium compound which is both soluble and stable in liquid ammonia. Uranyl di-8-hydroxyquinalate is the only compound AGN has found so far which is soluble enough in liquid ammonia to meet fuel requirements; however, this compound is subject to severe thermal decomposition. 
Efficient fission fragment energy deposition is almost impossible to realize in a fixed fuel system. The upper limit of energy deposition efficiency for any practical fixed fuel form is estimated to be between $40 \%-50 \%$. And it may prove very difficult to design a fixed fuel element which is thin enough for centerline fissions to deposit their recoil energy in the chemical medium, and at the same time'strong enough to withstand the stresses induced by the velocity of the process stream. On the other hand, fixed fuels are adaptable to either gaseous or liquid media. They demand a minimum fuel inventory. And they pose negligible problems of stability. contro1. Furthermore, less fuel must be removed from a fixed fuel system during processing and product withdrawal than from a homogeneous or heterogeneous systemi.

Experimenters at AGN, Rensselaer, and Brookhaven ${ }^{3,4,5}$ are currently investigating such fixed fuel forms as flat or distorted plates, wires, fibers, cylinders, honeycombs and other porous materials, in geometrically fixed or random-packed configurations. Rensselaer and Brookhaven have developed and tested random-packed, uranium-loaded glass fibers for the gas phase fixation of nitrogen. All three organizations are using uranium alloys or uranium-coated structural materials. Alloy fuels are physically stable, easy to fabricate, and have good.burnup properties. Fuel coatings on strong structural materials increase fuel strength without increasing fuel thickness. If a 1-micron-thick coating of uranium is applied to a base structural material, $50 \%$ of the fission fragment energy is deposited in the structural material, and about $10 \%$ is lost in the coating. Thus, fuel coatings with energy depositions of $40 \%$ compare favorably with any practical alloy fuels whose maximum deposition efficiency will be 40-50\%. 
However, plated fuels are difficult and expensive to fabricate. They must be stable in the chemical system. Their integrity after reasonable burnup is doubtful. And they promote spallation, erosion and uranium depletion at fission sites. If application of a very thin cladding on top of the plated fuel can diminish these surface effects at a small sacrifice of energy deposition efficiency, fixed fuel forms may be usable in fissiochemical reactors.

Heterogeneous mixtures combine many of the advantages and few of the disadvantages of homogeneous and fixed fuel forms. A heterogeneous system, in this, instance, is defined as a particulate fuel suspended in a process stream. Most of the experience at AGN has been with micron-size particles suspended in liquid. But sols suspended in liquid, and dusts suspended in gas are also heterogeneous mixtures.

W. R. Grace and Company* has developed aqueous sols of uranium dioxide and thorium oxide which remain stable in a non-radiation environment for three or four years. Limited in-pile experiments with these sols have not disclosed radiation instabilities. During the past year, Grace has attempted to develop an ammonious $\mathrm{UO}_{2}$ sol. While not yet totally successful, Grace expects to advance preparation and handling techniques to the point where the $\mathrm{UO}_{2}$ can be maintained as a colloid, which, when suspended, will form a stable ammonia dispersion.

* Personal Communications: F. T. Fitch, W. R. Grace and Co., to R. L. Pearson, AGN. (1958-1963) 
Little information is available on fissioning dust suspended in a process stream. To circulate an aerosol suspension in a closed loop demands close attention to numerous parameters, including selection of particle size for a given gas velocity. Excessive wall deposit results if the particles are too small, and overlarge particles cause serious erosion. Armour Research Foundation spent a year designing and evaluating a DustFueled Reactor concept. ${ }^{6}$ After successfully suspending 10-micron particles of alumina in a circulating gas mixture, Armour evaluated the characteristics of $\mathrm{UO}_{2}$ dusts, and found that 8 -micron $\mathrm{UO}_{2}$ circulated freely, but that 1-micron $\mathrm{UO}_{2}$ particles plated out severely on the walls of the loop.

During a program to determine the practicality of nitrogen fixation through fissiochemistry, $\mathrm{AGN}^{7}$ ran a series of capsule tests using a fissionable aerosol as fuel. The fuel was a mixture of $75 \mathrm{wt} / \% \mathrm{U}_{3} \mathrm{O}_{8}$ particles 1.3 microns in diameter, and $25 \mathrm{wt} / \% \mathrm{U}_{3} \mathrm{O}_{8}$ particles 174 microns in diameter. The larger particles were added as an abrasive in an attempt to scour the wall deposit of submicron particles. Examination of the capsules after irradiation showed that most of the 1.3 micron particles had plated out on the walls. These results and the experience with the dust-fueled reactor experiments indicate that fissionable particles somewhere between 1.3 and 8 microns probably can be circulated as an aerosol. Therefore, since the energy deposition efficiency of particles in this size range is between 92 and 65 percent, this fuel form would probably work successfully in a gaseous fissiochemical system.

The most extens ive work done at AGN has been done with slurries. The very' nature of slurries limits their application to the production of chemicals in a liquid suspending medium. Although the specific requirements will vary with the chemical production system, certain slurry properties 
are generally desirable.

At its maximum operating temperature, the slurry s hould be chemically stable in the process stream.

- It should be nearly insoluble in its reacting medium.

- It should form stable suspensions at the pertinent fuel and product concentrations.

- It should maintain $f$ ixed physical properties.

- To provide uniform dispersions and to avoid plugging the circulating system, it should have good hydrodynamic characteristics and little affinity for pipe walls, pump housing, and impellers.

- It should not be so abrasive or corrosive as to cause excessive wear in the flow system.

- When settling in a quiescent container, the slurry should pack loosely and the sediment should flow freely.

- It should not decompose the desired chemical products.

- It should evidence minimum susceptibility to irradiation damage.

- The fuel particles should contain as little non-fissionable diluent as possible.

A slurry can be composed of uranium-235, plutonium-239, or compounds or mixtures of these, elements. The properties of uranium and plutonium, and techniques for fabricating their oxides, are well understood. Uranium carbide, uranium nitride, or possibly uranium sulfide might also serve as the fissionable compound. AGN has concentrated largely on uranium dioxide, 
because $\mathrm{UO}_{2}$ is the most chemically stable, is quite insoluble in ammonia and its technology is highly developed. $\mathrm{UO}_{2}$ powders are commercially available in a number of sizes. The size and shape of the powders selected should be based on energy deposition, efficiency and erosiveness. In Figure 1 it was evident that fission fragment energy deposition efficiency is a function of particle diameter. The larger the particle diameter, the less efficient the energy deposition. A 2-micron diameter particle is approximately $90 \%$ efficient, while a 4 -micron particle is only $80 \%$ efficient, and so on. When a particle-laden fluid impinges on a solid body, the fluid will be deflected around the solid, but the particles, because of their inertia, will collide with the body. The rate of impingement controls erosion which is proportional to the square of the particle diameter. The Homogeneous Reactor Project at Oak Ridge demonstrated that erosion is insignificant in a slurry unless the particles are larger than 3 microns in diameter. ${ }^{2}$

The AGN Hydrazine Program uses 1-micron particles of $\mathrm{UO}_{2}$ suspended in liquid ammonia. No erosion has been detected when slurries of up to 50 grams of this fuel per liter of ammonia are circulated at up to 30 feet per second. These tests were conducted under out=of-pile conditions. While stirred capsules of similar slurries have behaved comparably under irradiation, it cannot yet be unequivocally predicted that pumped, fissioning slurries will not erode their containers.

In the spring of 1964 AGN will begin operation of an in-reactor loop test which should resolve many of the remaining questions about the engineering 
feasibility of the fissiochemical production of hydrazine. Five gallons per minute of $\mathrm{UO}_{2}$-ammonia slurry will be circulated through a half-inch tube next to the Materials Test Reactor core in Idaho Falls.' During the scheduled two-to-four months of operation, the slurry concentration will gradually be increased to 60 grams per liter. At this point the total loop fission power will be 15 kilowatts with a peak power density of 130 kilowatts per liter in, the loop tip.

The preparation and testing of the particulate fuel to be used in this experiment will be the subject of another report.

This work was supported in part by U. S. Air Force Contract $\operatorname{AF3} 3(600) 42996$. 


\section{REFERENCES:}

1. Steinberg, M., "Deposition Efficiency of Fission-Fragment Energy," Nucleonics Vo1. 21, No. 8, p 151-153, August 1963.

2. Lane, J., et a1., Fluid Fuel Reactors, Addison-Wesley Publishing Company, Reading, Mass. (1958)Ch. 3, "Properties of Aqueous Fuel Solutions," Ch. 4, "Technology of Aqueous Suspensions."

3. Steinberg, M., and Farber, G., "Chemonuclear Fission Fragment

Source and Fuel Element Development Progress Report," BNL-827, Oct. 1963.

4. Harteck P., and Dondes, S., "Glass Fibers - A new Form of Reactor Fuels," Nucleonics, August 1957, p 94-8.

5. Lockwood, P. A., "Investigations of Radioactive Fuel-Bearing Glasses," NY0-9736, June 1962 .

6. Krucoff, D., "The Armour Dust-Fueled Reactor," AECU-3909

7. Ulbrich, F., "Final Report: Design, Fabrication, and Operation of A Miniturized Loop Capsule for the Nuclear Nitrogen Fixation Reactor," AGN-3048, Nov. 1959 .

8. Richards, P. and'Rubin, B., "Irradiation of Sma11 Volumes of Contained Radioisotopes," Nucleonics 6, No. 6, 42(1950).

9. Long, G., "The Production of Chenicals from Reactors. Part II. Deposition of Energy by Fission Fragments in Two-Phase Systems," AERE-C/M-345, Nov. (1958).

10. Sears, J. and Steinberg, M., "Fission Fragment Energy Deposition for Formation of Chemical Products in Two Phased Systems," BNL-695 Sept. 1961:- 


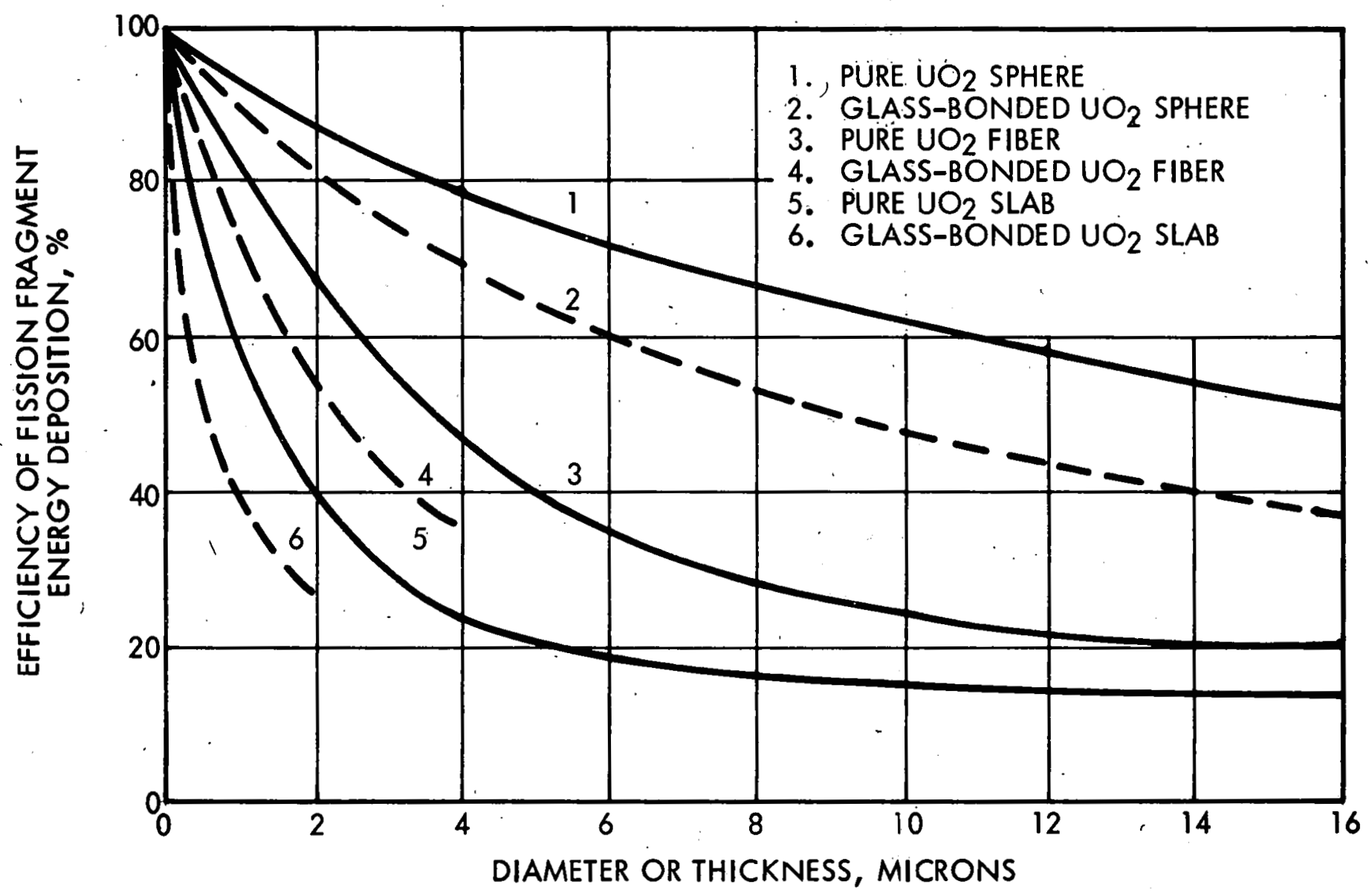

FIGURE 1. SİEE EFFECT ON FISSION FRAGEMENT ENERGY DEPOSITION EFFICIENCY 


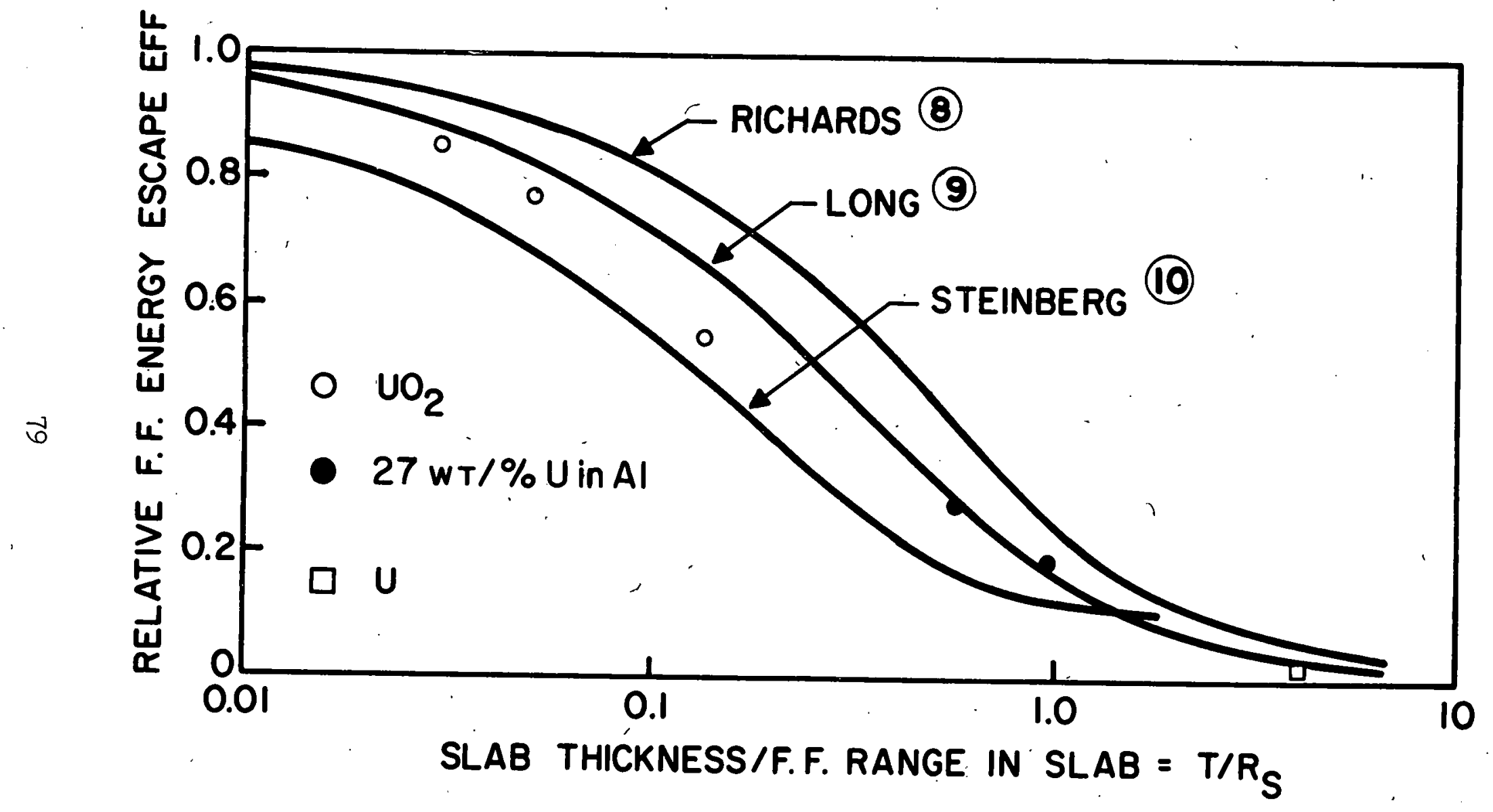

FIGURE 2. RELATIVE FISSION FRAGMENT ENERGY ESCAPE EFFICIENCY, SLAB GEOMETRY 


\section{THIS PAGE}

\section{WAS INTENTIIONALLY LEFT BLANK}


THE PREPARATION AND PROCESS ING OF FUEL FOR

FISS IOCHEMICAL REACTORS*

by

Dr. R. L. Pearson - Aerojet-General Nucleonics

\section{ABSTRACT}

Preparation of a $\mathrm{UO}_{2}-1 \mathrm{iquid}$ ammonia slurry for fissiochemical production of hydrazine is described. Because spherical or spheroid $\mathrm{UO}_{2}$ particles of less than 3 micronś are not commercially available, a ceramic grade $\mathrm{UO}_{2}$ power of 1 micron or less particle size was used. The power was fired at $1300^{\circ} \mathrm{C}$ in hydrogen to strengthen the particles and slurried in liquid ammonia. This slurry caused no unacceptable erosion in out-of-pile tests.

Irradiation of the slurry increased the range of particle size. Little change was observed in the shape of most solids although some crystals were observed.

The slurry described will be tested in the MTR core; fission production distribution and rate of, crystal growth will be determined.

*ANT-TP-75

$81-9$ 
INTRODUCTION

In a preceding report, fissiochemistry was defined as a complex series of reactions whereby the two new atoms created in a fission event recoil in opposite directions and deposit their kinetic energy into the process fluid to form ions, free radicals and activated species which can recombine into molecules of known, or entirely new, chemicals. The efficiency at which fission fragments deposit their energy depends largely upon fuel composition and geometry. Three general fuel forms were described which can be used in fissiochemical reactors, emphasizing part1culate fuels. Most of AGN's experience, accumulated under the Air Force-funded Hydrazine Program, has been with 0.4 to 1 micron size particles of enriched uranium dioxide suspended in liquid ammonia. This, or any slurry, should be chemically stable and nearly insoluble. It should retain fixed physical properties, have good hydrodynamic characteristics, and be comparatively radiation-resistant. During settling, the slurry should pack loosely and the sediment flow freely. It must not be abrasive or corrosive, and must not decompose the end product. It was concluded that spherical particles of $93 \%$-enriched $\mathrm{UO}_{2}$, less than 3 microns in diameter, suspended in liquid ammonia, provide the best fuel system to use in the fissiochemical production of the liquid rocket engine propellant, hydrazine.

\section{FUEL PREPARATION}

Current techniques for controlling $\mathrm{UO}_{2}$ particle shape have been thoroughly investigated. There are three ways of forming spherical or spheroidal $\mathrm{UO}_{2}$--by the plasma flame process; by emulsifying a sol into a gel, and by precipitation. 
. Angular $\mathrm{UO}_{2}$ particles can be fed through a plasma flame to form particles like those shown in Figure 1 . This treatment is most effective with particles in the 50 to 100 micron size range, but is not applicable to powdered $\mathrm{UO}_{2}$ partićles less than 10 microns in diameter. When these tiny particles are passed through a plasma torch, they vaporize to such an extent and are so hard to collect that over half of the fuel is lost. It- is doubtful, then, that 1 to 3 micron particles of enriched $\mathrm{UO}_{2} \mathrm{can}$ be spheroidized by this method.

A second approach involves applying techniques developed by the petroleum industry for the production of catalysts. An aqueous sol of the oxide is sprayed or emulsified into globules which then solidify as a gel. These gel spheres are the same size as the sol drops and can be converted into the corresponding spherical oxides by drying and firing. The size distribution of the spheres is determined during the spraying or emulsifying process. Experimenters at KEMA in the Netherlands ${ }^{2}$ and at Houdry Process Corporation ${ }^{*}$ in the United States have devised an emulsifying, drying, and firing technique for forming thorium oxide spheres in 1 to 3 micron sizes. This technique is not yet applicable to uranium oxide because of the difficulty of preparing aqueous $\mathrm{UO}_{2}$ sols which behave properly during gelation.

Spheroidal, as distinct from spherical, $\mathrm{UO}_{2}$ particles can in a few cases be produced by precipitation. If precipitation occurs under flocculating conditions, the primary particles of the precipitating compound form agglomerates which are transformed into integral particles through the deposition of new materials. The size of these integral particles is governed

* Personal communications J. Donovan, Houdry Process Corporation, to R. L. Pearson, AGN (1956-1958). 
by the collodial chemical conditions in the liquid, and by the shear stresses created by the stirring mechanism. The KEMA people have made 1 to 3 micron size spheroidal $\mathrm{UO}_{2}$ particles by adding solid ammonium sulfate, ${ }^{2}$ under vigorous agitation, to uranyl nitrate solutions. And Dr. Levey at Oak Ridge National Laboratory has formed.spheroidal $\mathrm{UO}_{2}$ using a uranyl peroxide starting solution. 3

Since spherical or spheroidal $\mathrm{UO}_{2}$ particles less than 3 microns required by the Hydrazine Program are not commercially available, ceramfc grade $\mathrm{UO}_{2}$ poinder, 1 micron in diameter or less was procured and evaluated. Uranium dioxide in 0.4 to 0.7 micron size produced from ammonium diuranate was procured. from Davison Chemical Company, a division of W. R. Grace and Company. United Nuclear Corporation supplied 0.7 to 1 micron $\mathrm{UO}_{2}$ particles formed in a process using uranium tetrafluoride as the starting material. AGN PROCESSING TREATMENT

The $\mathrm{UO}_{2}$ powders, as received, are relatively soft. Their resistance to degradation during circulation can be increased by firing them at a temperature just below that at which the particles begin to form clinkers. This maximum temperature was determined by measuring the clinker content of samples fired in dry hydrogen at temperatures between 1000 and $1600^{\circ} \mathrm{C}$.

The samples were fired in a heavy-duty, molybdenum-wound, single-end tube furnace. The clinker content was measured with a setiting apparatus consisting of a Pyrex tube 7 feet long and 14 millimeters in diameter, fitted with a stopcock and clinker receptacle at one end, and a funnel at the other end. One-half-gram samples of fired and unfired $\mathrm{UO}_{2}$ powder 
were agitated for 16 hours in a 0.005 molar solution of trisodium phosphate in an Eberbach clinical shaker. A sample of unfired $\mathrm{UO}_{2}$ was rinsed into the funnel at the top of the settling apparatus filled with the same trisodium phosphate solution. It took 9 minutes for the first particles to fall to the stopcock. In succeeding measurements of fired $\mathrm{UO}_{2}$ samples; the stopcock was closed after 9 minutes. Clinkers formed by sintering fell through the stopcock into the receptacle during the first 9 minutes of settling, and then were dried and weighed.

Results of these tests are illustrated, in Figure 2. It is evident from this figure that the fired $\mathrm{UO}_{2}$ powder was not we11 dispersed in the 0.005 mol trisodium phosphate solution. Curve B shows the results of tests repeated with a 0.002 mol trisodium phosphate solution as the dispersant. The curves indicate that sintering begins at some temperature above $1300^{\circ} \mathrm{C}$. The final procedure selected is to fire, the as-received powder 4 hours in a hydrogen atmosphere at $1300^{\circ} \mathrm{C}, \operatorname{cool} \mathrm{it}$, and then shake it through a 100-mesh screen. When this powder is added to the in-pile loop, it is quickly broken down into individual particles by several passages through the pump.

PROPERTIES OF THE PROCESSED FUEL.

The particles in the $\mathrm{UO}_{2}$ powder purchased from Davison and United Nuclear are aggregates, not single crystallites. This is obvious from Figure 3 . The measured specific surface area of the fired powder was $0.6 \mathrm{~m}^{2} / \mathrm{gram}$. Because circulating slurry, and particularly slurry composed of angular particles is erosive, a toroid apparatus was constructed at AGN to measure 
the slurry erosion rates in a simulated in-reactor loop environment. Loadings of 50 grams of $\mathrm{UO}_{2}$ per liter of liquid ammonia were circulated at 20 feet per second, at $160^{\circ} \mathrm{F}$, for 100 hours. At the end of this time, sample pins made of 347 stainless steel which had been placed in the flow. stream had not lost enough weight to be detectable on an analytical balance. When conditions were altered to 500 grams of $\mathrm{UO}_{2}$ per liter of liquid ammonia, circulating at 30 feet per second, and $160^{\circ} \mathrm{F}$ for 100 hours, conditions which are much more severe than any anticipated in the AGN application, the measured erosion rate was $2.4 \mathrm{mils}$ per year, an entirely accpetable figure.

AGN built and operated a materials and component test loop similar to the loop which will be inserted this spring in the Materials Test Reactor. One purpose of these out-of-pile tests was to discover as much as possible about the behavior of $\mathrm{UO}_{2}-1$ iquid ammonia slurry before beginning the AGN in-pile experiment. It was found that fired $\mathrm{UO}_{2}$ suspended in liquid ammonia settles rapidly because it flocculates easily. After this slurry is circulated for a short time, the fuel flows as individual particles which do not reflocculate until several hours after the flow is stopped. This is highly desirable, since the particles acting as separate entities during flow and irradiation increase the efficiency with which fission fragments deposit their energy in the stream. When irradiation is concluded and the flow, stopped, the fuel particles, will then agglomerate into flocs which can readily be handled during the fuel reprocessing cycle. 
EFFECTS OF CAPSULE IRRADIATION

The distribution of fission products among the liquid, solid, and gaseous phases is crucial to determining what reprocessing is required. in. the fuel cycle. Therefore, capsules were irradiated in the Battelle Research Reactor, examined in their hot cells, and analyzed in their radiochemical laboratories to ascertain the fission product distribution. Samples of ammonia and uranium were withdrawn after each irradiation and gamma-scanned with a 128-channel pulse height analyzer. The results are summarized in Figure 4. Iodine and ruthenium were found in the liquid phase, and all other radioisotopes, except for the gases, appeared with the solids. Almost all of the iodine was present in the liquid ammonia, while ruthenium was distributed randomly between the liquid and solid phases; ruthenium is thus presumed to form a complex molecule with the ammonia, as do several noble metals. Tests performed on fuel samples having different mean particle sizes and subjected to different burnups showed essentially the same fission product distribution.

Thorough examination of $\mathrm{UO}_{2}$ particles irradiated to burnups of 0.06 atom percent revealed that the range of particle size distribution increased. Fines as sma 11 as 100 angstroms were formed. The surface area of $\mathrm{UO}_{2}$ solids. was tripled to $2.0 \mathrm{~m}^{2} /$ grams. No colloidal suspensions were detected. The bulk of the solids were very much the same shape after as before irradiation, although some particles showed distinct crystal structure, and a few quite perfect single crystals were formed. The extent of this crystal growth does not seem to depend upon $\mathrm{UO}_{2}$ burnup. Figure 5 shows a large crystal taken from the bulk solids after gravity settling of slurry from the low burnup capsule. It has developed several triangular faces. Figure 6 shows some of 
the same solids separated from the supernate by centrifugation. Clearly, these crystals grew from the surfaces of the original, irregularly shaped particles. The next two are photomicrographs of crystalline $\mathrm{UO}_{2}$ from the highest burnup capsule. The crystals in Figure 7 were accumulated by gravity settling, those in Figure 8 by centrifugation. These faceted crystals have probably grown from a supersaturated solution. If crystal growth continues to the extent that fission fragment energy deposition efficiency is impaired, or erosion becomes excessive, a side stream will have to be built into the reactor flow scheme to remned the oversize: particles.

PLANNED IN-PIL̀E LOOP TESTS AND POST-IRRADIAIIION EVALUATION

The AGN-302 experimental loop, containing a circulating enriched $\mathrm{UO}_{2}-$ liquid ammonia slurry, will be introduced into the MTR core sometime in the spring of 1964. Six loop cycles are scheduled--the first at 1 kilowatt, the next four at 5 kilowatts, and the last at 15 kilowatts total power. The loop is so constructed that whilè fuel can be added to ther loop to increase power level, it cannot be removed until the test series has been completed. At the end of the experiment, the loop will be transferred to a hot cell and sectioned to recover the fuel. Fission product distribution and the extent of crystal growth at these higher burnups will be determined from post-irradiati on tests of $\mathrm{UO}_{2}$ samples. Reșults of what we expect to be a highly significant experiment will be reported sometime in the fal1 of 1964 .

This work was supported in part by U. S. Air Force Contract $\operatorname{AF3} 3(600) 42996$. 
1. Pearson, R. L., et al., "Fuel Requirements for Fissiochemical Production," AN-TP-74

2. Hermans, M. F. A. and Slooten, H. S. G., "Preparation of $\mathrm{UO}_{2}$ and $\mathrm{ThO}_{2}$ Powders with Specific Properties," NP-9217.

3. Levey, R. P., Jr., "Preparation of Dense, Spheroidal UO 2 " Y-1299. 


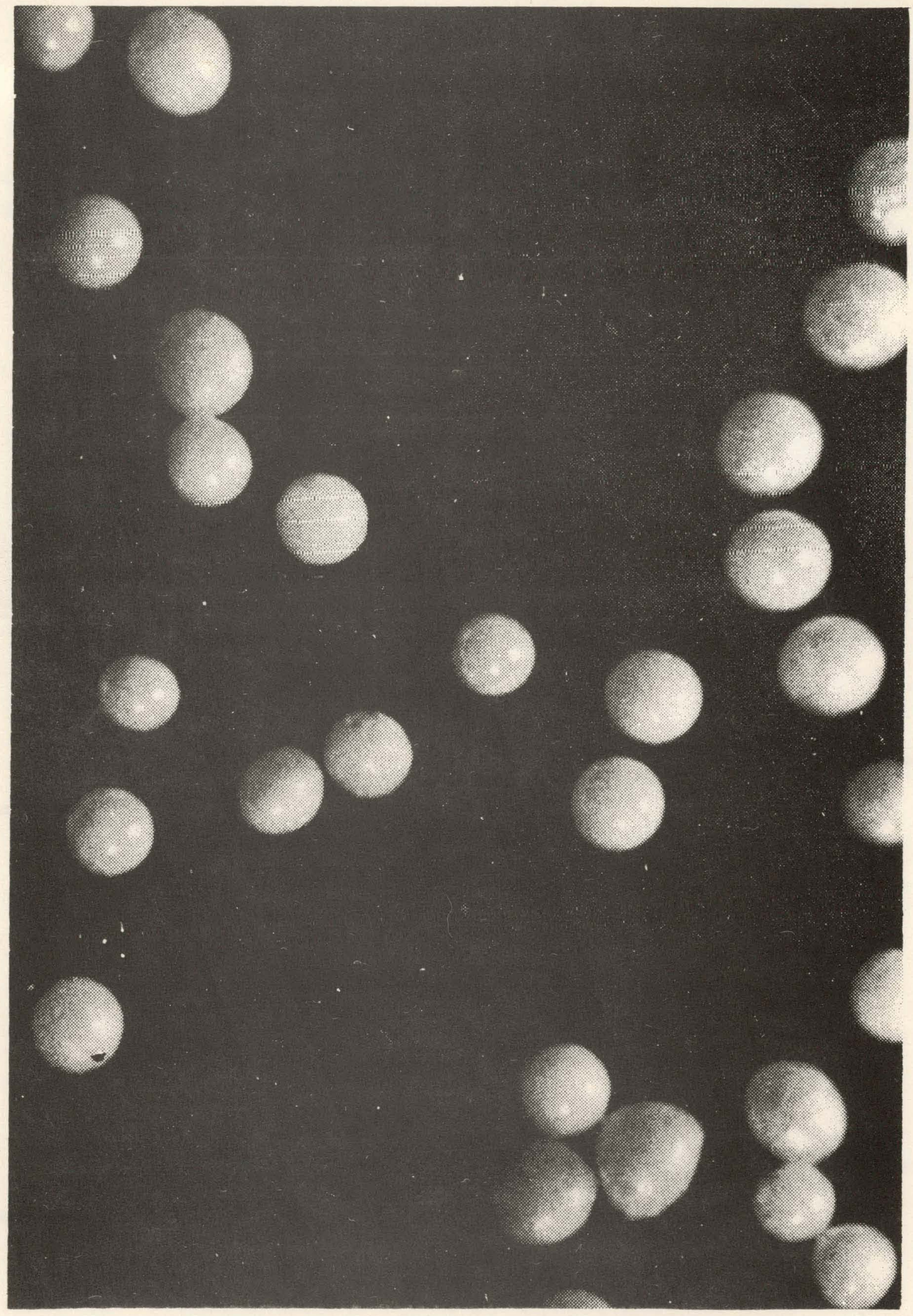

FIGURE 1. PARTICLES SPHEROIDIZED BY THE PLASMA FLAME PROCESS 


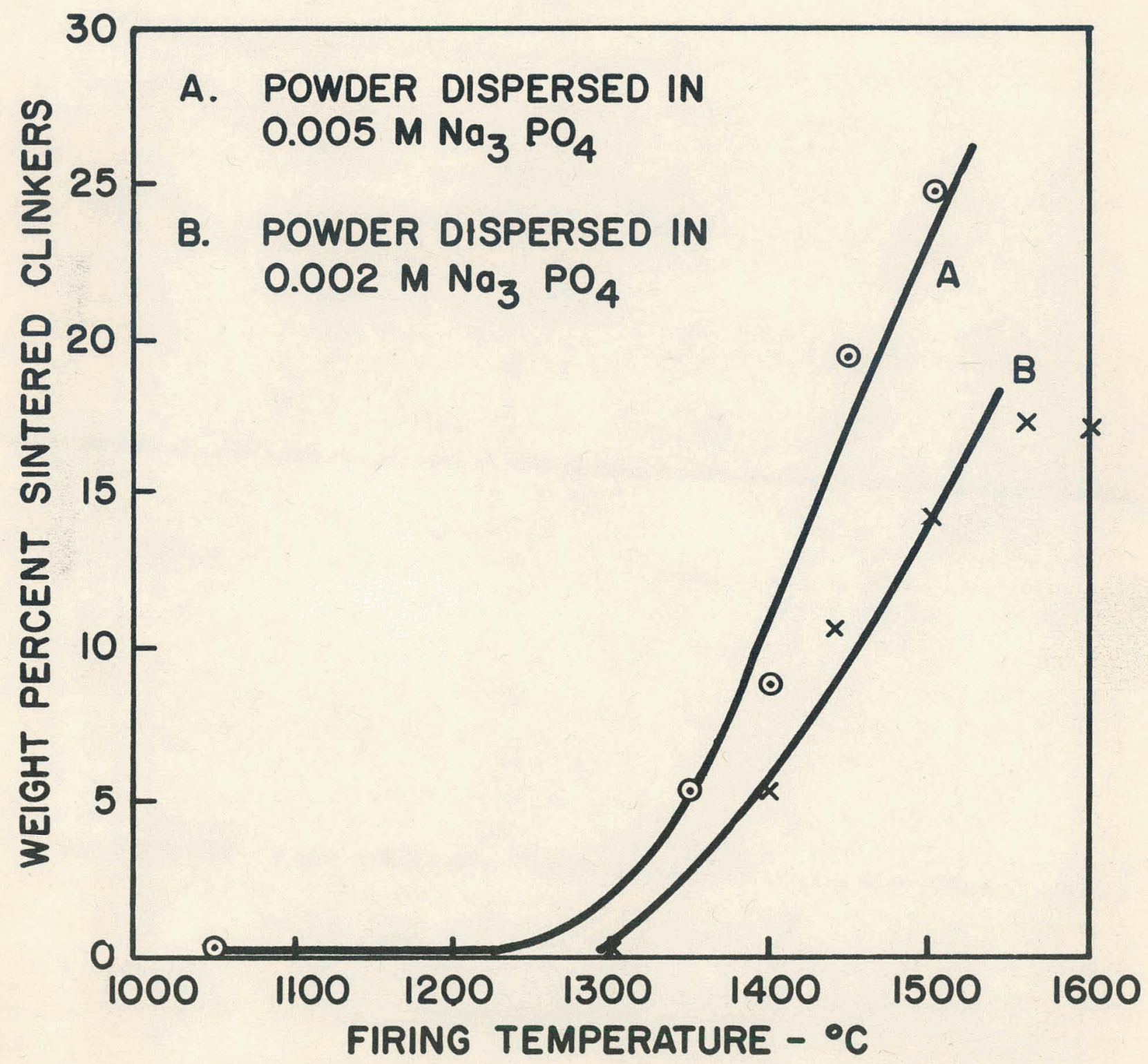

FIGURE 2. PERCENT SINTERED CLINKERS IN UO 2 POWDER AFTER FIRING 


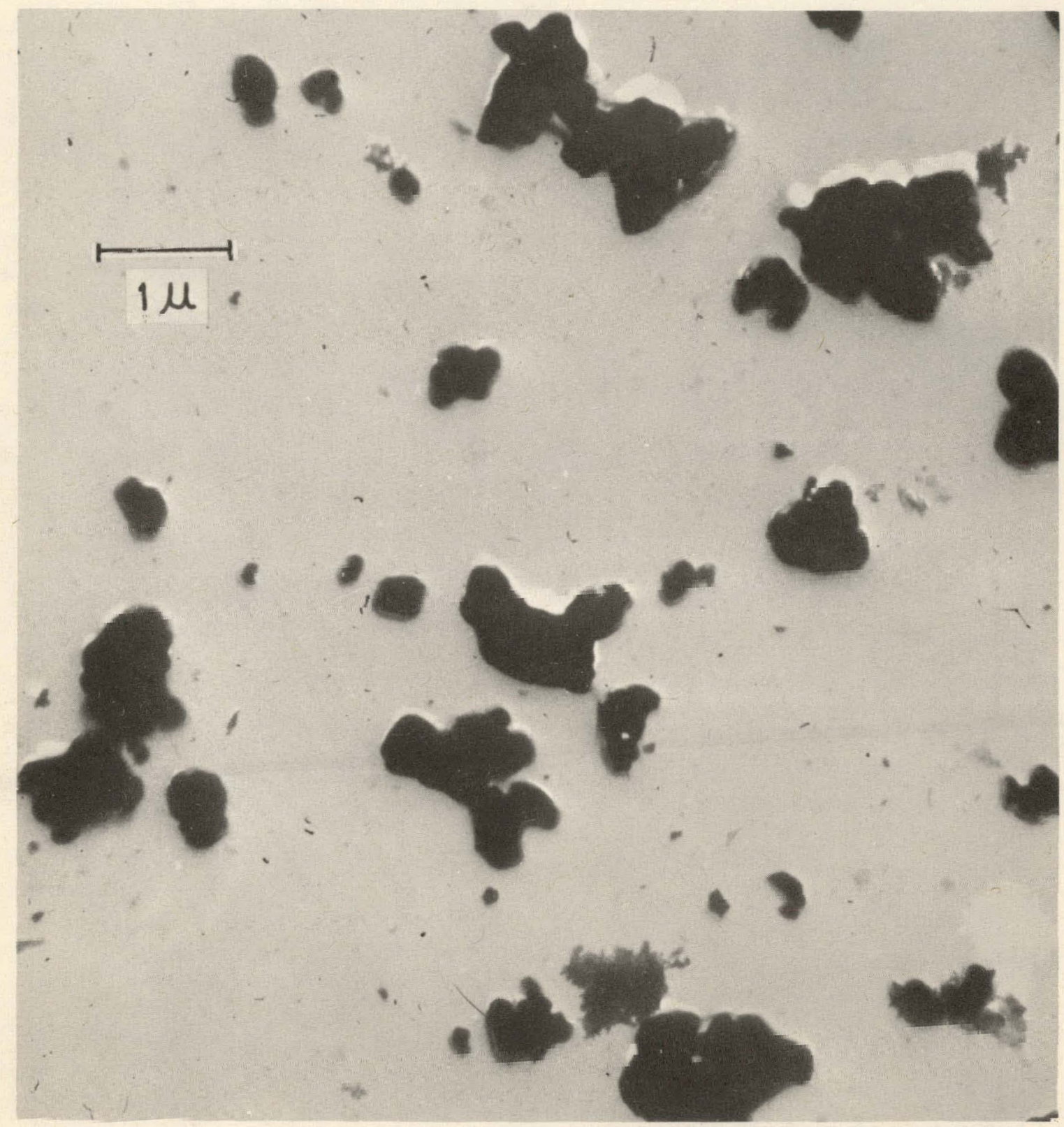

FIGURE 3. ORIGINAL ENRICHED UO 2 PARTICLES 


\begin{tabular}{l|c|c}
\multirow{2}{*}{\multicolumn{1}{c|}{}} & \multicolumn{2}{c}{ DISTRIBUTION $(\%)$} \\
\cline { 2 - 3 } RADIOISOTOPE & LIQUID & UMMON \\
AMMNIA & SOLIOS \\
\hline IODINE-I3I & 80 & 20 \\
RUTHENIUM-103 & 50 & 50 \\
ZIRCONIUM-NIOBIUM-95 & NIL & 100 \\
CERIUM-141 & NIL & 100 \\
CERIUM-144 & NIL & 100 \\
LANTHANUM-140 & NIL & 100 \\
BARIUM-140 & NIL & 100 \\
STRONTIUM-90 & NIL & 100 \\
CESIUM-137 & NIL & 100
\end{tabular}




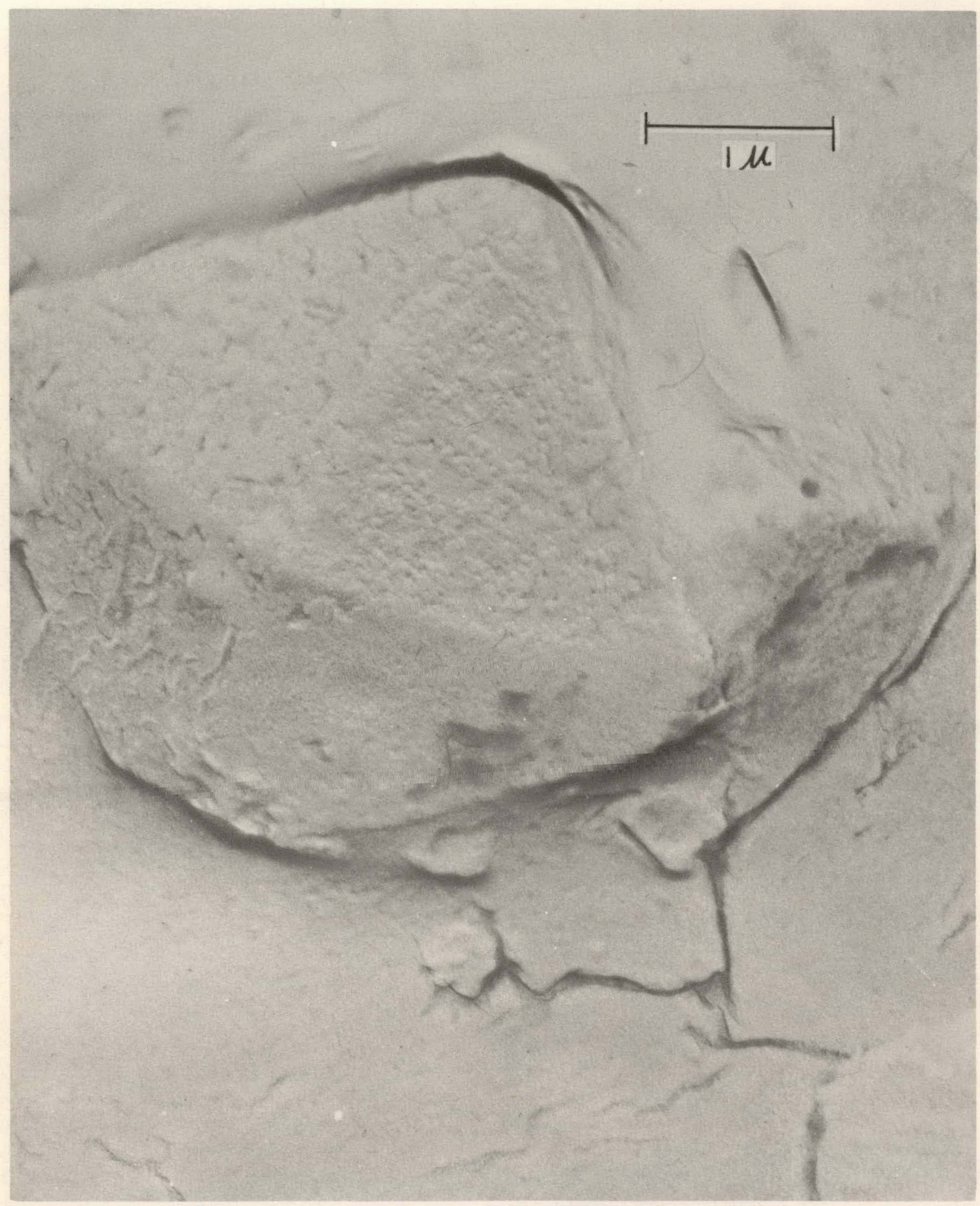

FIGURE 5. TRIANGULAR FACED UO ${ }_{2}$ CRYSTAL AFTER $0.01 \%$ BURNUP 


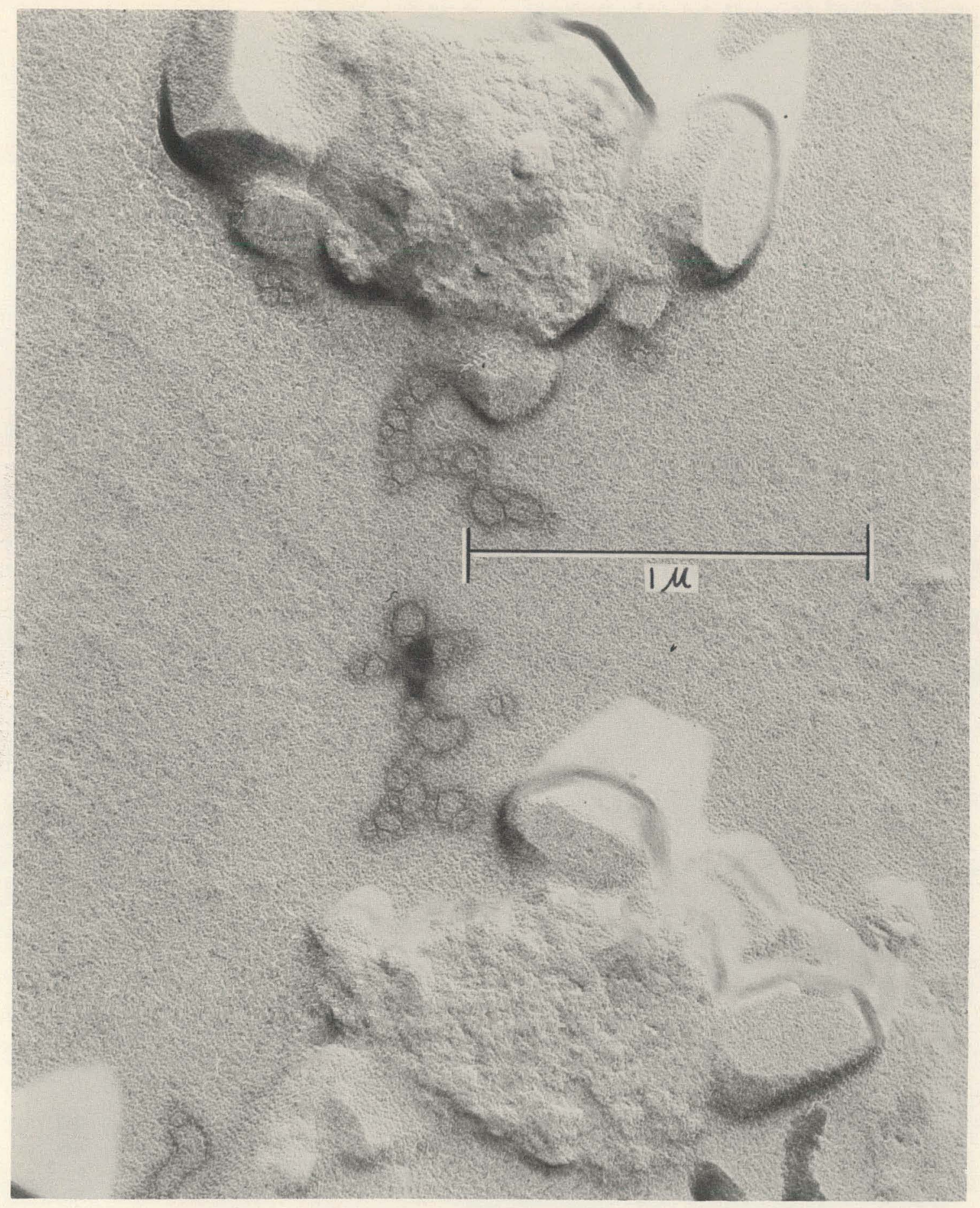

FIGURE 6. CRYSTALLINE UO 2 GROWING ON ORIGINAL PARTICLES AFTER 0.01\% BURNUP 


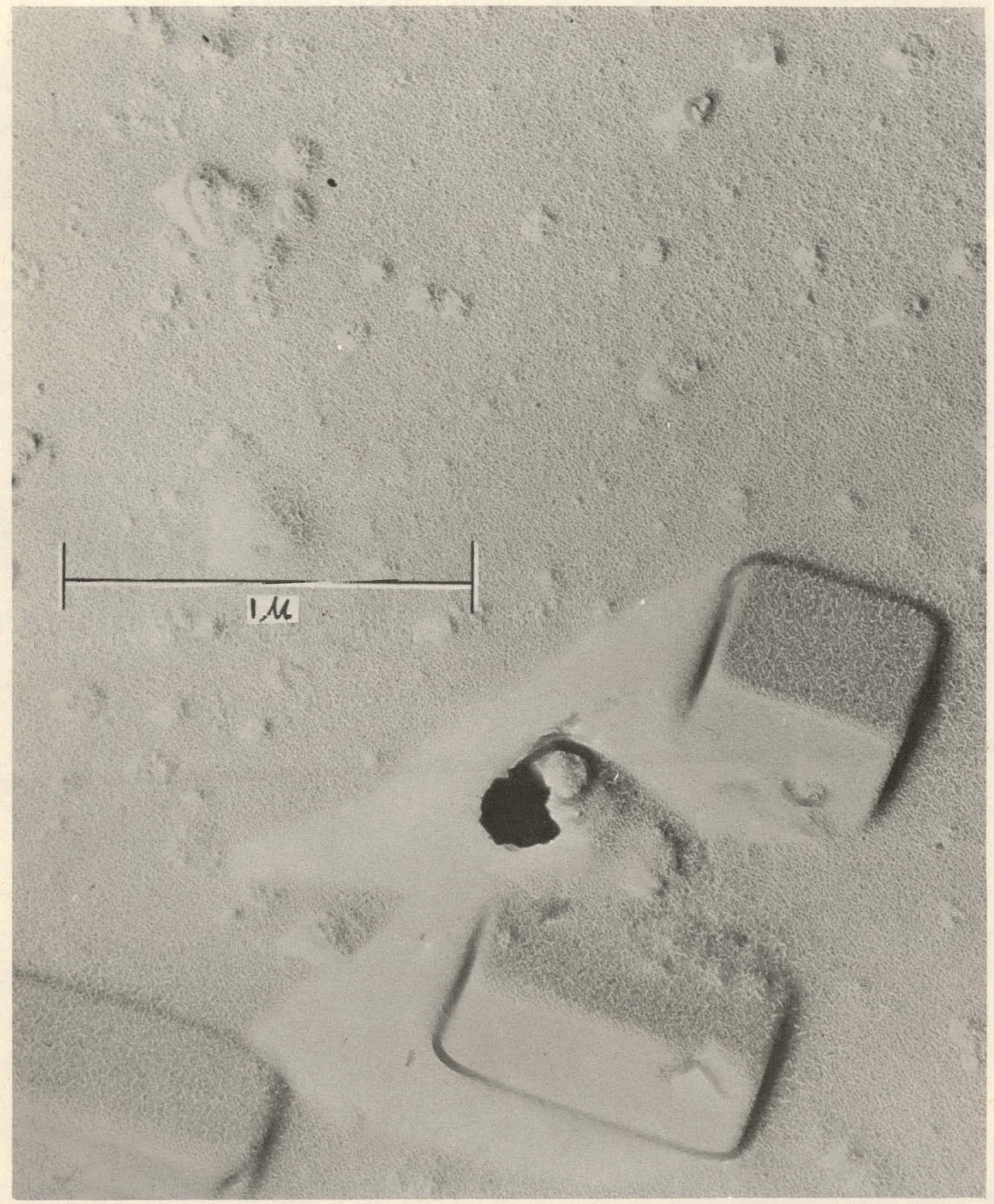

FIGURE 7. CUBIC SHAPED UO ${ }_{2}$ CRYSTALS AFTER $0.056 \%$ BURNUP 


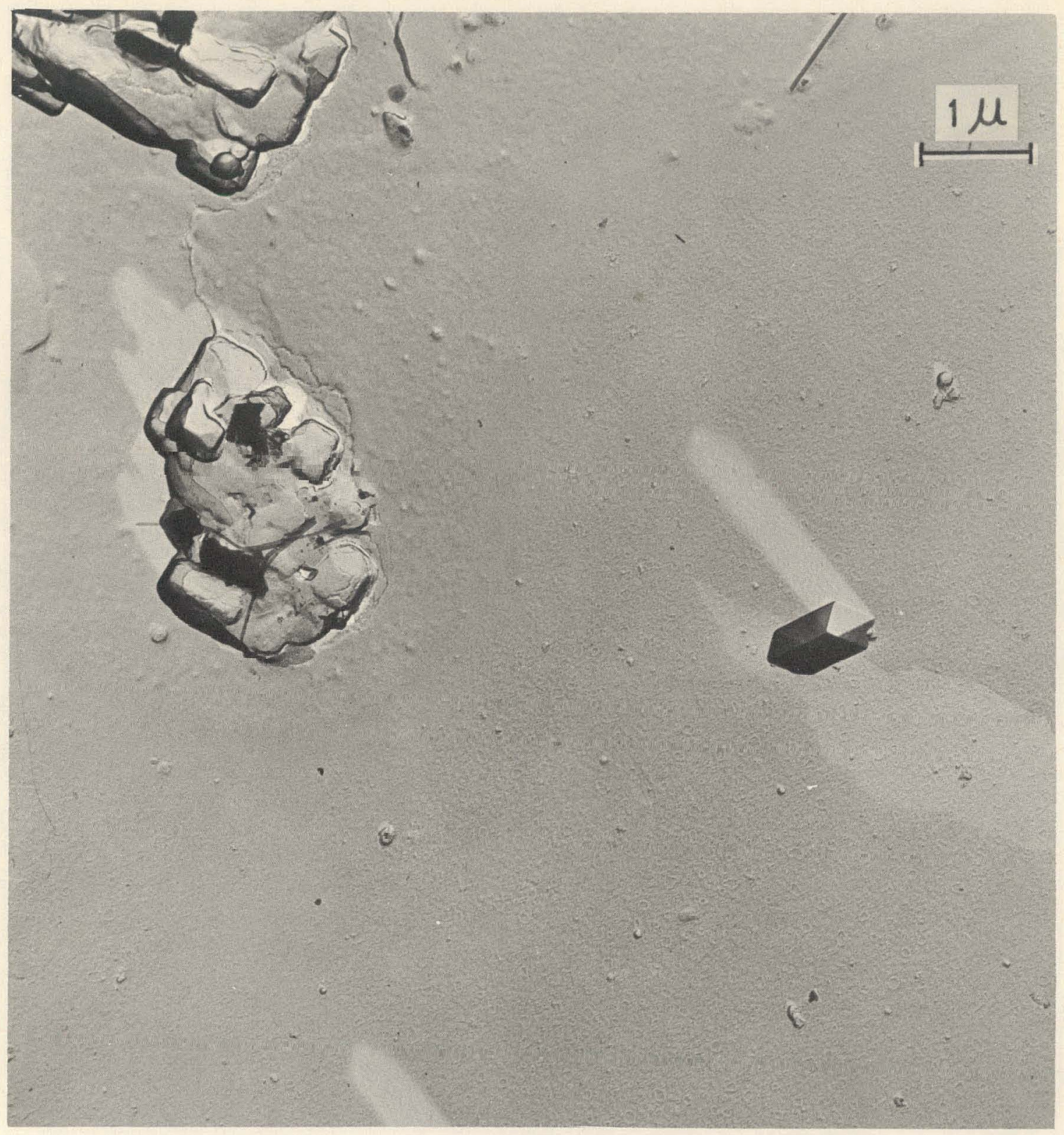

FIGURE 8. CRYSTALS OF UO ${ }_{2}$ AFTER $0.056 \%$ BURNUP 



$$
\begin{aligned}
& \text { C6-4-64 } \\
& \text { Ind. Eng. Chem., Prod. } \\
& \text { Red. Psparti, 3: } 78.82 \text { (Gunes 1964) } 18: 26008
\end{aligned}
$$

\title{
PREPARATION AND PROPERTIES OF \\ PLUTONIUM-BEARING OXIDE PARTICULATES*
}

\author{
LERROY V. JONES, DONALD OFTE, KENNETHD. PHIPPS, \\ ANDPHILIPA. TUCKER \\ Monsanto Research Corp., Mound Laboratory, Miomisbug, Ohio
}

\begin{abstract}
Microspheres of plutonium dioxide and plutonium dioxide combined with uranium dioxide, thorium dioxidc, and zirconium dioxide were prepared in an induction-coupled plasma torch. The microspheres are thermally and chemically stable, and exhibit a remarkable freedom from loose contamination. Feed material for the process was prepared by die pressing the oxide powders, sintering the pellets, and grinding the fired pellets to the desired size. An oxygen-enriched plasma was employed to inhibit the loss of oxygen from plutonium dioxide during melting. The spheroidal particles were characterized by $x$-ray diffraction analysis, by measurement of their physical properties, and by evaluation of their chemical inertness. Plutoniumbearing microspheres are applicable to dispersion, slurry, and paste-type reactor fuels.
\end{abstract}

$\mathbf{C}^{\mathrm{n}}$ ERAMIC NUCLEar FUELs, because of their in-pile dimensional stability at high temperature and high burnup, are receiving ever increasing research and development attention. Much of this attention is focused on the investigation of plutonium-bearing ceramics. Plutonium ceramic fuels will play an important role in the utilization of reactor-produced plutoniun for power production.

This paper describes the preparation of plutonium-bearing oxide microspheres in an induction-coupled plasma torch. These microspheres are thermally and chemically stable and exhibit a remarkable freedom from loose contamination.

\section{Method of Preparation}

A unique feature of the method developed at Mound Laboratory $(10)$ is the employment of an inductively coupled plasma torch $(8,14)$. This electrodeless torch permits operation in reducing, inert, and oxidizing atmospheres at temperatures as high as $20,000^{\circ} \mathrm{K}$.

At Mound Laboratory, plasmas of argon, oxygen, and mixtures of argon with oxygen and with helium were employed. The plasma was contained in a silica glass tube of approximately $40 \mathrm{~mm}$. in diameter. This envelope was kept below its softening point by the combined effects of external air cooling and the cooling effect of the fuel gas which flows tangentially down the inside wall. Power was supplied to the gas by a $10-\mathrm{kw}$., megacycle frequency electronic generator through a water-cooled copper coil surrounding the silica glass envelope (Figure 1).

In these studies, the feed materials were introduced into the plasma through a small diameter silica tube concentric to the silica envelope. During residence time in the plasma, the particulates were heated to temperatures above their melting points. Upon emerging from the plasma, they solidified as spheroids and were collected in a receiver. The spheroidization process was conducted in an alpha box enclosure built around the plasma torch (Figure 2).
The feed materials for the microspheroidization studies were prepared by compacting oxide powder into pellets, sintering for 1 hour at $1500^{\circ} \mathrm{C}$, and grinding the $3 / 16^{-i n c h}$ high by $3 / 16^{-}$ inch diameter sintered pellets to the desired mesh size. The rough-ground particulates were used as the feed material for the production of the dense uniform microspheres. This technique was used for preparing feed particles of plutonium dioxide as well as mechanically blended oxide mixtures.

Mixed oxides which did not form solid solutions at $1500^{\circ}$ C. in 1 hour were melted in the plasma flame to facilitate reaction. Sintered pellets of mechanically mixed oxides were inscrtcd in the core of the plasma torch flame on top of $a^{1 / 8}$. inch diameter zirconia or thoria rod. When the pellet was raised slowly and steadily in the plasma flame, the top half of the pellet melted in less than 1 minute, regardless of the melting point of the material. Longer time in the plasma resulted in vaporization of the molten portion of the pellet rather than in complete melting. Thorium oxide pellets (melting point, $3200^{\circ}$ C.) were melted by this method. After this humogenization, the pellets were ground to the appropriate mesh size for plasma spheroidization.

In this investigation $\mathrm{PuO}_{2}, \mathrm{UO}_{2}, \mathrm{ZrO}_{2}, \mathrm{ThO}_{2}$, and $\mathrm{PuO}_{2}-$ $\mathrm{UO}_{2}$ feed materials were prepared from sintered pellets. The $\mathrm{PuO}_{2}, \mathrm{ZrO}_{2}$, and $\mathrm{ThO}_{2}$ pellets were sintered in air at approximately $1500^{\circ} \mathrm{C}$. for 1 hour. The $\mathrm{UO}_{2}$ pellets were sintered in hydrogen at $1500^{\circ} \mathrm{C}$. for 1 hour, and $\mathrm{PuO}_{2}-\mathrm{UO}_{2}$ pellets were sintered in wet hydrogen for 1 hour at $1500^{\circ} \mathrm{C}$. Feed materials of $\mathrm{PuO}_{2}-\mathrm{ZrO}_{2}$ and $\mathrm{PuO}_{2}-\mathrm{ThO}_{2}$ were prepared from pellets melted in an argon plasma flame containing greater than $50 \%$ oxygen.

The $\mathrm{UO}_{2}$ and $\mathrm{UO}_{2}-\mathrm{PuO}_{2}$ particulates were spheroidized in an argon plasma and collected in an argon atmosphere.

-Reprinted from I \& EC Product Research and Development Quarterly, Vol. 3, No. 2, Page 8, June, 1964. Copyright 1964 by the ACS. Reproduction forbidden without permission of copyright owner. 
All of the other materials were spheroidized in an oxygen enriched plasma.

\section{Results and Discussion}

Plutonium dioxide microspheres, $150 \mu$ in diameter, are shown in Figure 3. The change in particle size during spheroidization was moderate. For example, when feed material between 105 and $125 \mu$ in diameter was spheroidized, the spherical product was equally divided between the 105 to $125 \mu$ fraction and the 90 to $105 \mu$ fraction, which is the next finer sieve fraction. Spheres produced from feed material in finer sieve fractions were similarly distributed. The maximum feed size was 35 mesh, and the minimum feed size was -400 mesh. The microspheres ranged from 10 to $250 \mu$ in diameter. Microspheres less than $50 \mu$ in diameter were amber colored and had a clear, vitreous appearance, but those above $50 \mu$ did not transmit light but appeared opaque black in reflected light.

Evaluation of the plutonium dioxide spheroids by alpha survey wipe indicated a remarkable freedom from loose contamination. No airborne contamination is released during normal handling, and surfaces which come in contact with the microspheres do not become contaminated. The alpha emissions of a number of individual microspheres were measured in an alpha scintillation counter. A typical particle 0.189 $\mathrm{mm}$. in diameter gave an alpha emission of 368,000 counts per minute. After these particulates had been rolled on a standard alpha wipe, an assay of the wipe by standard counting techniques indicated no alpha contamination.

The chemical stability of the plutonium dioxide microspheres was evaluated by a technique previously employed for evaluating the durability of plutonium-bearing glass (18). Ten spheroids were placed in $250 \mathrm{ml}$. of each of the following leach solutions: $1 N \mathrm{HCl}, 1 N \mathrm{HNO}_{3}, 1 N \mathrm{NaOH}, \mathrm{H}_{2} \mathrm{O}\left(25^{\circ} \mathrm{C}\right.$.), and $\mathrm{H}_{2} \mathrm{O}\left(100^{\circ} \mathrm{C}\right.$.). After four weeks, a $30-\mu \mathrm{l}$. $\left(30 \times 10^{-3}\right.$ $\mathrm{ml}$.) aliquot was removed from each solution, evaporated to dryness on a tantalum slide, and counted for alpha radiation in a gas flow proportional counter. The alpha count on each of these slides was zero, indicating that the plutonium oxide microspheres were not attacked by the leach solutions.

These leach tests were then duplicated using $6 N \mathrm{HCl}, 6 N$ $\mathrm{HNO}_{3}$, and $6 \mathrm{~N} \mathrm{NaOH}$. After 14 days, these leach solutions were sampled, and the aliquots were alpha counted. Again, no alpha radiation wàs detected.

The microspheres were characterized as crystalline $\mathrm{PuO}_{2}$ by $x$-ray diffraction analysis. The $x$-ray patterns revealed a face-centered cubic (FCC) structure whose unit cell dimension was calculated to be $5.395 \pm 0.002 \mathrm{~A}$. These crystallographic data agreed well with the accepted literature value (9) for stoichiometric $\mathrm{PuO}_{2}$ of $5.396 \pm 0.001$ A. (see Table I).

Table I. Physical Characteristics of $\mathrm{PuO}_{2}$

\begin{tabular}{lcccc} 
& $\begin{array}{c}\text { Crystal } \\
\text { Lattice }\end{array}$ & $\begin{array}{c}\text { Unit Cell } \\
\text { Dimension, } A .\end{array}$ & \multicolumn{1}{c}{$\begin{array}{c}\text { Density, } \\
G . / C c .\end{array}$} & $\begin{array}{c}\text { Micro- } \\
\text { hardness }\end{array}$ \\
$\begin{array}{llll}\text { Literature } \\
\text { value }\end{array}$ & FCC $(13)$ & $5.396 \pm 0.001$ & $11.46(16)$ & $105(12)$ \\
Present work & FCC & $5.395 \pm 0.002$ & 11.0 & 1163
\end{tabular}

The stoichiometric ratio of oxygen to plutonium in the compound was maintained at 2.0 throughout the thermal history of the product, first as the calcined powder, then as the sintered feed material, and, finally, through the spheroidization of the oxide in the plasma torch.

The preservation of the stoichiometry is significant in relaion to the oxygen deficient species found by all previous investigators in the material remaining after melting $\mathrm{PuO}_{2}$. Holley et al. ( $(9)$ indicated a cell size of 5.42 to $5.47 \mathrm{~A}$. in the melted oxide; Chikalla (3) reported a cell size of $5.417 \mathrm{~A}$. for his melted material; and Russell (15) et al. stated that after arc melting $\mathrm{PuO}_{2}$ in argon, the product contained $50 \%$ $\mathrm{Pu}_{2} \mathrm{O}_{3}$. In the studies at Mound Laboratory, the oxygenenriched atmosphere surrounding the molten particles as they passed through the plasma and the short residence time at high temperature are believed to be the significant factors in maintaining the oxygen to plutonium ratio at 2.0 .

The importance of using stoichiometric $\mathrm{PuO}_{2}$ for reactor fuel applications is apparent from the plutonium-oxygen phase diagram $(4,9)$. In the most recently proposed diagram, Chikalla et al. (4) indicated a $\mathrm{PuO}_{2-x}$ species for compositions from 1.62 to 1.98 atom \% oxygen which decomposes eutectoidally at $300^{\circ} \mathrm{C}$. to $\mathrm{PuO}_{1.88}$ and $\mathrm{Pu}_{2} \mathrm{O}_{3}$. A two-phase field of hexagonal $\mathrm{Pu}_{2} \mathrm{O}_{3}$ plus cubic $\mathrm{Pu}_{2} \mathrm{O}_{3}$ is indicated for compositions from 1.5 to 1.62 atom \% oxygen, and a solid state transformation at about $725^{\circ} \mathrm{C}$. is shown for the cubic $\mathrm{Pu}_{2} \mathrm{O}_{3}$. Additionally, at compositions about $\mathrm{PuO}_{1.8}$, Brett (7) has observed a discontinuity in dilatometric curves and $x$-ray data that indicated a transition between $650^{\circ}$ and $750^{\circ} \mathrm{C}$. from a two-phase region to a one-phase region. Therefore, the use of stoichiometric $\mathrm{PuO}_{2}$ as a reactor fuel is desirable for two reasons:

The dimensional stability of the single-phase oxide is superior when the material is cycled over a wide temperature range.

On the basis of crystallographic symmetry, the higher symmetry of stoichiometric $\mathrm{PuO}_{2}$ is more likely to result in better radiation stability than the expanded lattice of the oxygen deficient material.

The density of the product was slightly less than theoretical crystalline density of 11.46 grams per cc. (16) based on experimental determinations by two independent techniques. Ten randomly selected microspheres were weighed on a microbalance after their diameters were measured microscopically. This determination indicated an average density of 11.0 grams per cc. The density was also measured using a liquid displacement technique employing General Electric silicone oil (SF-96), diethylene glycol monoethyl ether (Carbitol), and triply distilled mercury as the displaced liquids. The average density observed with each liquid was 11.0 grams per cc.

Metallographic examination of cross-sectioned microspheres revealed small voids in a majority of the microspheres. Close examination of broken spheres, however, indicated that most of the spheres did not contain actual voids but rather contained unmelted regions of varying porosity. Metallographic polishing had resulted in the removal of the unmelted material, thus exposing the voids. Many of the spheres were completely melted and exhibited no voids and no microporosity. A few spheres contained spherical-shaped central voids of various sizes. These voids, which were also observed in the broken microspheres, did not result from the removal of unmelted material on polishing, but are vapor pockets which are formed when individual microspheres become overheated in the plasma flame. Some spherical voids became so large that a microbubble resulted rather than a microsphere. As a result of this small amount of internal porosity, owing to unmelted powder and spherical voids, the microspheres had an average density equivalent to $96 \%$ of the theoretical crystalline value.

The microhardness of the plutonium dioxide spheres was measured by indentations with a Vickers diamond on the flat polished surfaces of spheres which were imbedded in plastic and cross-sectioned metallographically. The maximum load employed for the indentation which did not result in brittle fracture of the surface was 50 grams. At this load, an average Vickers hardness of $1163 \mathrm{~kg}$. per square mm. was obtained, which places plutonium oxide on Mohs' Hardness Scale at a number between 7 and 8 . This is in wide disagreement with an earlier reported value (12) of $105 \mathrm{~kg}$. per square $\mathrm{mm}$. Some variation in hardness from center to edge might be anticipated from internal stresses caused by the severe quench in the preparation of the microspheres. However, no such variation was observed. 
X-ray examination of microspheres by single-crystal techniques revealed only several crystals per particulate. Under ideal conditions, single crystal microspheres could be prepared from the plasma spheroidization process.

The investigation of the spheroidization of pure $\mathrm{PuO}_{2}$ was extended to include $\mathrm{PuO}_{2}$ in combination with other oxide materials. Uranium dioxide was a logical choice to initiate the mixed oxide work because of its possibilities as both a fertile and fissile diluent, and its reported solid solubility in all proportions with plutonium dioxide (11). Before passing the mixed oxides through the plasma torch, a study of the spheroidization characteristics of pure uranium oxide under these conditions was undertaken.

Near-stoichiometric $\mathrm{UO}_{2}$ microspheres were prepared when the particulates were spheroidized and collected in argon. The $\mathrm{UO}_{2}$ spheres, less than $50 \mu$ in diameter, were transparent red. Those greater than $50 \mu$ were opaque black. The deep red color and transparency were used as visual criteria for ascertaining that the material was approximately stoichiometric. When the $\mathrm{UO}_{2}$ feed was propelled through the plasma torch flame without adequate precautions against the presence of oxygen in the torch or collector, the resulting microspheres were opaque black. When fractured, these microspheres exhibited red interiors surrounded by a thick black shell of what was assumed to be hyperstoichiometric $\mathrm{UO}_{2}$. When these black microspheres were heated at $1000^{\circ} \mathrm{C}$. in hydrogen for 1 hour, the transparent red color of $\mathrm{UO}_{2}$ was restored.

Microspheres were produced in all size ranges from solid solutions of $\mathrm{PuO}_{2}-\mathrm{UO}_{2}$ containing 10, 20, and 60 weight $\%$ $\mathrm{UO}_{2}$ in the feed material. Cross-sections of these microspheres, which had been formed in an inert argon plasma flame, revealed that they were opaque black from the outer shell to the core.

Thorium dioxide also has the possibility of service as a fertile diluent in ceramic fuels. The $\mathrm{PuO}_{2}-\mathrm{ThO}_{2}$ system also exhibits complete solid solubility (6).

Microspheres of $\mathrm{ThO}_{2}$ produced in an oxygen enriched argon plasma were transparent below $80 \mu$ in diameter. Those above $80 \mu$ were translucent white. Spheroidization of $\mathrm{PuO}_{2}-\mathrm{ThO}_{2}$ in an oxygen enriched plasma formed transparent to translucent yellow spheres. Microspheres of 50 weight $\% \mathrm{PuO}_{2}-$ $\mathrm{ThO}_{2}$ were shown by x-ray diffraction to be a single phase solid solution having a fluorite-type structure of the face-centered cubic lattice with $a_{0}=5.53 \pm 0.01 \mathrm{~A}$.

The spheroidization characteristics of $\mathrm{ZrO}_{2}$ were studied before undertaking a study of the $\mathrm{PuO}_{2}-\mathrm{ZrO}_{2}$ system. When $\mathrm{ZrO}_{2}$ feed material was passed through a pure argon plasma, approximately one third of the microspheres were opaque black. The remainder of the spheres were translucent to transparent white. The black spheres were apparently oxygen deficient (7) with an undetermined formula. Microspheroidization in oxygen-enriched plasmas produced white $\mathrm{ZrO}_{2}$ spheres with a room temperature monoclinic structure. However, one sphere was isolated which appeared to be a single crystal of the tetragonal high temperature form.

The oxygen enrichment of the plasma gas necessary to produce white $\mathrm{ZrO}_{2}$ was applied to the production of $\mathrm{PuO}_{2}-\mathrm{ZrO}_{2}$ microspheres (17). Microspheres of $\mathrm{PuO}_{2}-\mathrm{ZrO}_{2}$ were prepared containing $2.4,27$, and 50 mole $\% \mathrm{PuO}_{2}$. Those containing 2.4 mole $\% \mathrm{PuO}_{2}$ were translucent to transparent light green. X-ray examination revealed a two-phase structure: one phase was monoclinic $\mathrm{ZrO}_{2}$ and the other phase was a solid solution of $\mathrm{PuO}_{2}-\mathrm{ZrO}_{2}$ of undetermined composition or structure.

Microspheres containing 27 mole $\% \mathrm{PuO}_{2}$ were emerald green. These spheres were single phase having a tetragonal structure with $a=3.622 \mathrm{~A} ., c=5.192 \mathrm{~A}$. The tetragonal structure was assigned on the basis of the splitting of the 113 and 311 lines on a powder pattern. Our indexing of this structure is strongly reminiscent of the findings for the
$\mathrm{UO}_{2}-\mathrm{ZrO}_{2}$ system by Cohen and Schaner, (5) who assigned a tetragonal structure to $7 \mathrm{rO}_{2}-\mathrm{UO}_{2}$ in the range of $0-25 \mathrm{~mole} \%$ $\mathrm{UO}_{2}$ on the basis of the splitting of the 311 and 113 diffraction peaks. This finding is in disagreement with the work of Carroll (2), who assigned a cubic structure to $\mathrm{PuO}_{2}-\mathrm{ZrO}_{2}$ solid solution in the range of $27 \mathrm{~mole} \% \mathrm{PuO}_{2}$. The disagreement probably arises because two different systems were being investigated. Since Carroll's pellets were sintered under an atmosphere of gettered helium, he was probably working with the $\mathrm{PuO}_{2-x}-\mathrm{ZrO}_{2}$ system.

Microspheres containing $\mathrm{PuO}_{2}-50$ mole $\% \mathrm{ZrO}_{2}$ were olive green and exhibited cubic structure. This observation is in agreement with the findings of Carroll (2) for this composition.

All of the plutonium-bearing microspheres produced in the induction-coupled plasma torch exhibited the same remarkable freedom from loose contamination as the $\mathrm{PuO}_{2}$ microspheres.

\section{Conclusions}

The induction-coupled plasma torch has provided a unique method for producing nuclear fuel particles of $\mathrm{PuO}_{2}$ and solid solutions of $\mathrm{PuO}_{2}$ with other high melting oxides. It has further provided a means for maintaining the stoichiometry. of of $\mathrm{PuO}_{2}$ during melting.

The high density plutonium-bearing microspheres have shown such a surprising freedom from loose contamination that they can be safely handled in an open room. Protective devices such as respirators, which normally must be worn when handling plutonium dioxide, are unnecessary. Plutoniumbearing microspheres are potentially applicable to dispersion, slurry, and paste-type fuels. Microspheres may also find application in chemonuclear reactors which utilize fission fragments as sources of ionizing radiation.

Zirconium dioxide has proved to be a good inert diluent for $\mathrm{PuO}_{2}$ forming single-phase solid solutions over a wide range of compositions. Two crystalline forms of $\mathrm{ZrO}_{2}$, tetragonal and cubic, are stabilized by $\mathrm{PuO}_{2}$. The initial work on $\mathrm{PuO}_{2}$ $\mathrm{UO}_{2}$ and $\mathrm{PuO}_{2}-\mathrm{ThO}_{2}$ is encouraging, although further characterization of all the mixed oxide microspheres is required before their potential as reactor fuels can be accurately appraised.

\section{Acknowledgment}

The authors gratefully acknowledge the assistance of C. R. Hudgens and R. J. DeSando for the x-ray analyses they performed during the investigation.

\section{Liferafure Cited}

(1) Brett, N. H., Russell, L. E., Plutonium 1960, Proc. Intern. Conf. Plutonium Met., Grenoble, France, 1960, p. 426, Cleaver Hume Press, London, 1961.

(2) Carroll, D. F., J. Am. Ceram. Soc. 46, 194-5 (1963).

(3) Chikalla, T. D., Plutonium 1960, Proc. Intern. Conf. Plutonium Met., Grenoble, France 1960, p. 455-88, Cleaver Hume Press, London, 1961.

(4) Chikalla, T. D., McNeilly, C. E., Skavdahl, R. E., "The Plutonium-Oxygen System," Hanford Atomic Products Operation, HW-74802, September 1962.

(5) Cohen, I., Schaner, B. E., "A Metallographic and X-Ray Study of the $\mathrm{UO}_{2}-\mathrm{ZrO}_{2}$ System," Bettis Atomic Power Laboratory, WAPD-253, June 1962.

(6) Freshley, M. D., Mattys, H. M., "Properties of Sintered $\mathrm{PuO}_{2}-\mathrm{ThO}_{2}$," Hanford Atomic Products Operation, HW-76300, 2.6-2.8, October-December 1962.

(7) Gebhart, E., Seghazzi, H., Durrschnabel, W., "Investigations of the Zirconium-Oxygen System," Part 2, AEC-TR-5060, January 18, 1962.

(8) Hedger, A. J., Hall, A. R., Powder Met. No. 8, 65-72 (1961).

(9) Holley, C. E., Jr., Mulford, R. N. R., Huber, E. J., Jr., Hend, E. L., Ellinger, F. H., Bjorklund, C. W., Second Geneva International Conf. 6, 215-220 (1958).

(10) Jones, L. V., Ofte, D., Tucker, P. A., Wittenberg, L. J., "High Density Plutonium Dioxide Microspheres for a Reactor Fuel," Nuclear Reactor Chemistry, Third Conference, Gatlinburg, Tenn., TID-7641, October 1962.

(11) Mulford, R. N. R., Ellinger, F. H., J. Am. Chem. Soc. 80, No. 8, 2023 (1958). 
(12) Rare Metals Handbook, C. A. Hampel, Ed., 2nd ed., p. 369, Keinhold, New York, 1961

(13) Reactor Handbook, G. R. Tipton, Jr., Ed., 2nd. ed., Vol. 1, Materials, p. 278, Interscience, New York, 1960.

(14) Reed, T. B., J. Appl. Phys. 32, No. 5, 821 (1961).

(15) Russell, L. E., Brett, N. H., Harrison, J. D. L., Williams, J., J. Nucl. Mater. 5, No. 2, 216-27 (1962).

(16) Seaborg, G. T., Katz, J. J., Manning, W. M., "The Trans- uranium Ëlements," National Nuclear Energy Series, IV, 14B, Parts I and II, McGraw-Hill, New York, 1949.

(17) Sullenger, D. B., Phipps, K. D., J. Am. Ceram. Soc., to be published.

(18) Tucker, P. A., Jones, L. V., Wittenberg, L. J., "Development of Plutonium-Bearing Glass for a Reactor Fuel," Nuclear Reactor Chemistry, Second Conference, Gatlinburg, Tenn., TID-7622, October 1961.

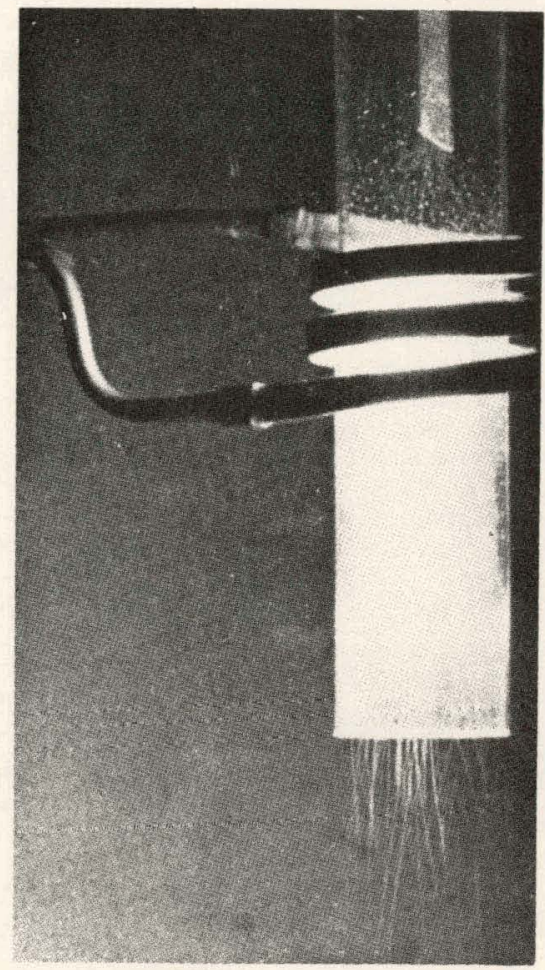

Figure 1. Plutonium dioxide particles passing through an induction-coupled plasma torch

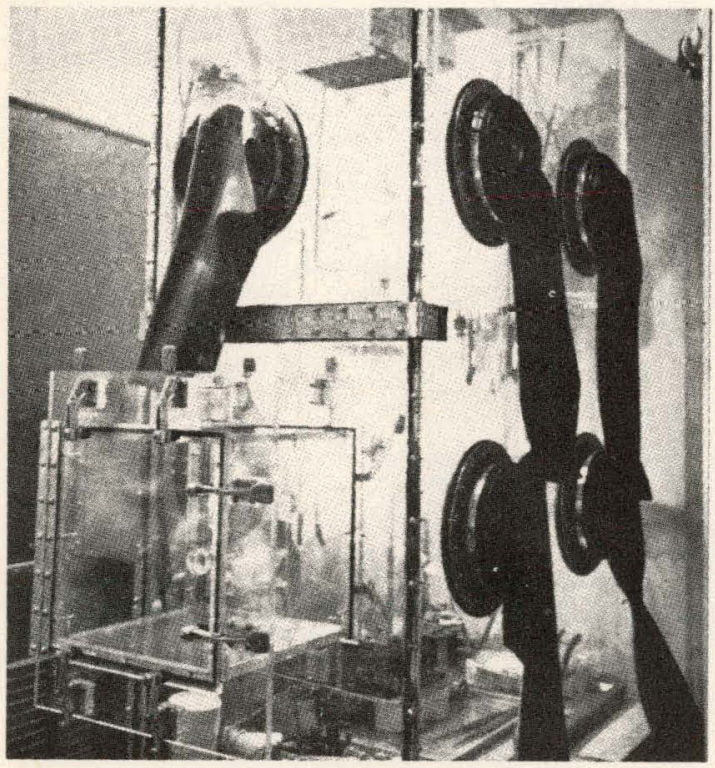

Figure 2. Alpha box enclosure and plasma flame equipment for producing radioactive microspheres

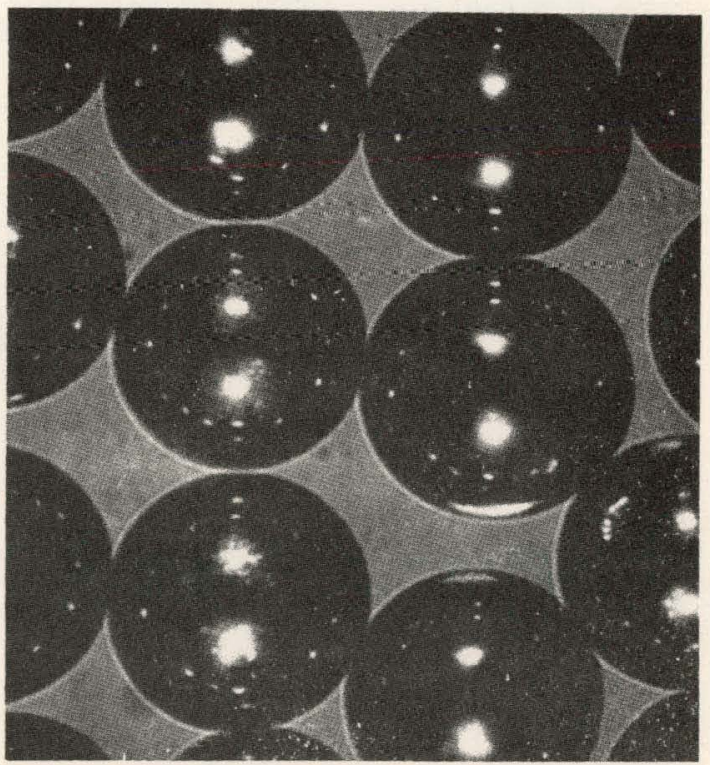

Figure 3. Microspheres of $\mathrm{PuO}_{2}$ (150 microns in diameter) produced with induction-coupled plasma torch 


\title{
PREPARATION AND PROPERTIES \\ OF SPHERICAL PARTICULATE NUCLEAR FUELS \\ FOR PLUTONIUM-FUELED REACTORS
}

R. J. Atkins, E. M. Benson, C. S. Caldwell, R. S. Swain, M. J. Zambernard Nuclear Materials and Equipment Corporation Apollo, , Pennsylvania

\begin{abstract}
Plutonium-based nuclear fuels in spherical,particle form offer unique features in terms of fabrication, utilization, and spent fuel recovery. These features are discussed.
\end{abstract}

The applications cover a broad range of reactor types such as thermal and epithermal converters, fast breeders and thermal burner reactors, therefore a wide, spectrum of plutonium-based materials in varying compositions is of interest.

Methods of preparation and spheroidization of plutonium and plutoniumuranium oxides are reported. Methods for the application of metallic coatings to the particles and the fabrication of suitable fuel by various consolidation techniques are also compared. Factors controlling compatibility of coatings and matrix materials with the substrate particles are discussed. , 
This symposium has shown that the availability of reliable particulate fuel materials will be the key factor in development of a broad range of reactor types utilizing fixed dispersion elements, pebble beds, slurries, fluid beds, dust or paste fuels. The particulate material may be used bare, but in most cases will be surrounded by some type of matrix or coating. Coated particulate fuel materials generally are more suitable than bare particulates because they can provide one or more of the advantages shown in Figure 1. By exploiting these features, the performance of uranium-based reactor cores has been improved during the past six years as a result of major advances, both in the area of spherical particle production and in particle coating $(1,2)$.

With this background of experience on particulate uranium-based fuel development, attention was directed to development of corresponding types of fuels bàsed on plutonium. This paper presents thoughts on the utilization of plutonium bearing particulate fuels and is based on the results of development work recently performed at the NUMEC Advanced Materials Center. The preparation, coating and fabrication of plutonium oxide-based particulate materials has been studied concurrently with the development of conventional pellet-in-tube plutonium fuels. The attractive features of plutonium-based coated 


\section{PARTICLE COATING PROVIDES}

- DIFFUSION BARRIER

- CORROSION PROTECTION

- heAT TRANSFER BOND

- DISPERSION UNIFORMITY

- FISSION PRODUCT RETENTION

Figure 1

Advantages of Coated Particles

UNIQUE FEATURES OF COATED SPHERE PU FUELS

- LONG CORE LIFE-Pu-240 EFFECT

- REDUCE ACCIDENTAL RELEASE hazARD

- PREVENT LOCALIZEO PU-U SEgREgation,

- PU ALLOY REINFORCEMENT

- FAST REACTOR SAFETY

Figure 2

Featurés of Coated Plutonium Spheres 
particulate fuels are summarized in Figure 2. Plutonium fuels offer a potentially long core life from a physicists viewpoint as a result of the formation of high-cross section, fertile Pu-240 by neutron capture from Pu-239. Full advantage of this potential cannot be realized without a correspondingly long metallurgical or structural life. Coated particles offer just such an increase in structurai life by minimizing the effects of radiation induced damage and confining degradation to localized areas that are surrounded by a continuous network which remains structurally sound.

Irradiation tests of binary oxides, such as $\mathrm{UO}_{2}-\mathrm{PuO}_{2}, \mathrm{PuO}_{2}-\mathrm{ZrO}_{2}$, at high central temperatures may show..considerable local segregation due to differences in volatility and stability. By use of a coated particle, which is a small unit-cell of fuel surrounded by a thin metallic or ceramic barrier, gross radial and axial segregation within the fuel element can be prevented.

Metallic plutonium has a low melting temperature $\left(640^{\circ} \mathrm{C}\right)$ and exhibits considerable growth both as a result of temperature increases and irradiation effects, therefore its alloys are handicapped for reactor fuel. These alloys might be used if reinforced, by coating techniques with compatible, structurally strong coatings.

In fast reactor cores, rapid power excursions may result in deformation or failure of cladding by thermal stresses or internal pressure generation due to thermal expansion or vapor pressure of fuel. In addition, 
densification or redistribution of fuel following transient melting might occur. The high integrity unit-cell coated particle can be tailored to meet these extreme requirements of containment.

The allowable body burden of plutonium is approximately 0.5 microgram, but plutonium is largely an inhalation hazard and use of the relatively large particles characteristic of this class of fuels minimizes the magnitude and the consequences of release during fabrication or service.,

\section{Feed Powder Preparation}

The materials of interest for testing cover the full range of compositions for thermal and epithermal converters, fast breeder and thermal burner reactors, therefore both mixed oxides and pure $\mathrm{PuO}_{2}$ were used as starting materials. The current methods used for preparation of the high quality ceramic grade powder needed for fabrication of the spherical particles is shown schematically in Figure 3.

$\mathrm{PuO}_{2}$ is prepared by adding oxalic acid to plutonium nitrate to precipitate plutonium IV oxalate which is filtered, calcined and deagglomerated to yield a finely divided $\mathrm{PuO}_{2}$. The mixed uraniumplutonium oxide is prepared by coprecipitation of a mixture of uranium and plutonium nitrates using ammonia to yield a co-precipitate of plutonium hydroxide-ADU which is filtered, calcined, reduced in a $\mathrm{N}_{2}-6 \% \mathrm{H}_{2}$ atmosphere and deagglomerated to a fine powder. Both processes rely upon close control of all steps, including final furnace temperature, to produce powder with the proper surface area and particle size. 


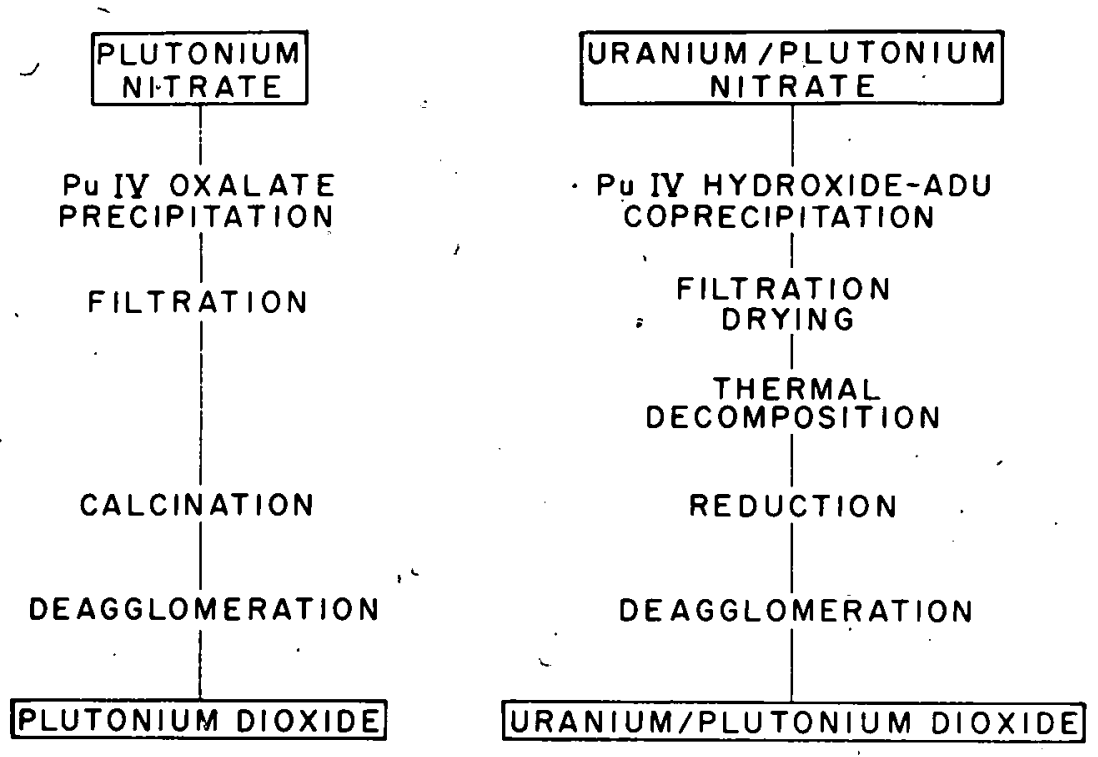

Figure 3

Preparation Routes for Ceramic Grade Powder

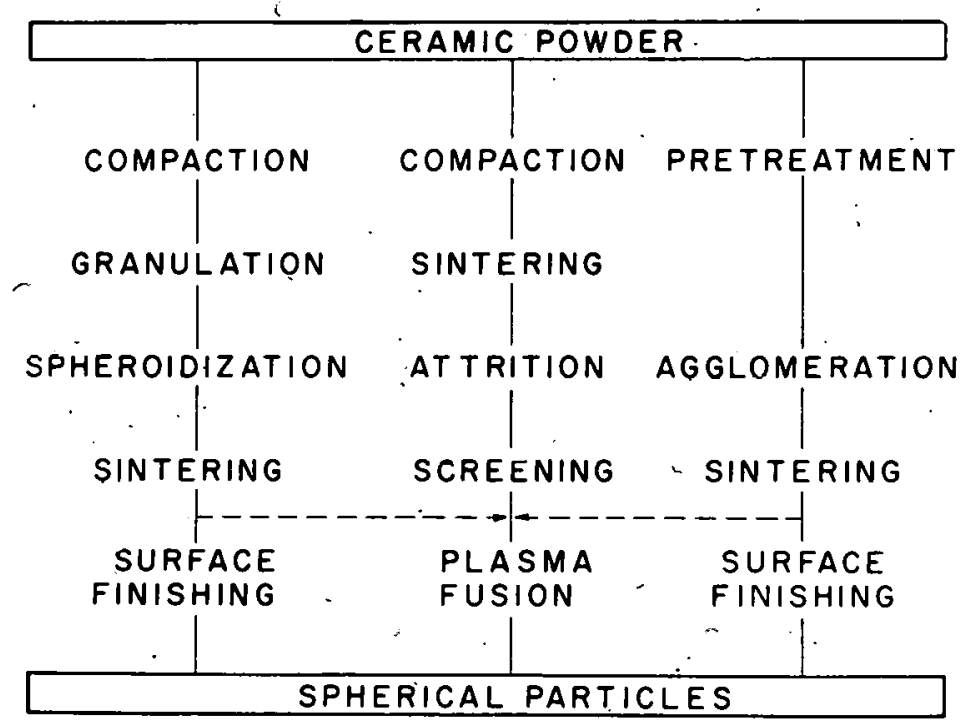

Figure 4

Spheroidization Routes for Ceramic Powders 


\section{Spheroidization}

Spheroidization of the ceramic grade powder is accomplished by one or more of the methods shown schematically in Figure 4. The green powder may be compacted by slugging into pellets, which are then granulated to the proper size and spheroidized by abrasion grinding followed by multi-step sintering with intermediate deagglomeration. An alternate method is to sinter the compacted powder, granulate by attrition and use these granules as feed for fusion by plasma torch. A third method which has been used is direct spheroidization of properly ground green powder using a "snow balling" technique with and without binders, for the agglomeration, followed by multiplestep sintering with intermediate deagglomeration. Spheroids agglomerated by the snow balling technique can be made over a wide, controllable range of densities and sizes from approximately 30 percent to more than 90 percent of theoretical density in sieve sizes ranging from 325 up to approximately 40 U. S. Standard mesh. Agglomeration by snow balling requires close control of feed powder particle size to insure a constant supply of the fines necessary to sustain the process. Figure 5 shows typical powder particle size distribution before and after batch spheroidization. Figure 6 shows agglomerated $\mathrm{PuO}_{2}$ spheres made from oxalate derived powder. The 150 micron diameter spheres were air sintered at $1600^{\circ} \mathrm{C}$ to 92 percent density. Spheroids produced by the abrasion grinding technique are 


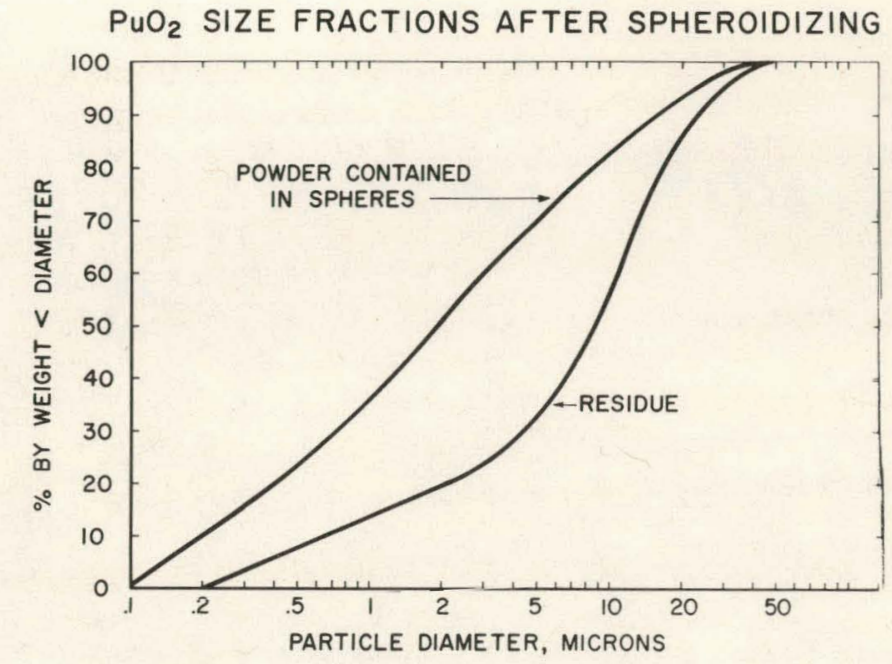

\section{Figure 5}

Powder Particle Size Distribution

After Batch Spheriodization by Snow Balling

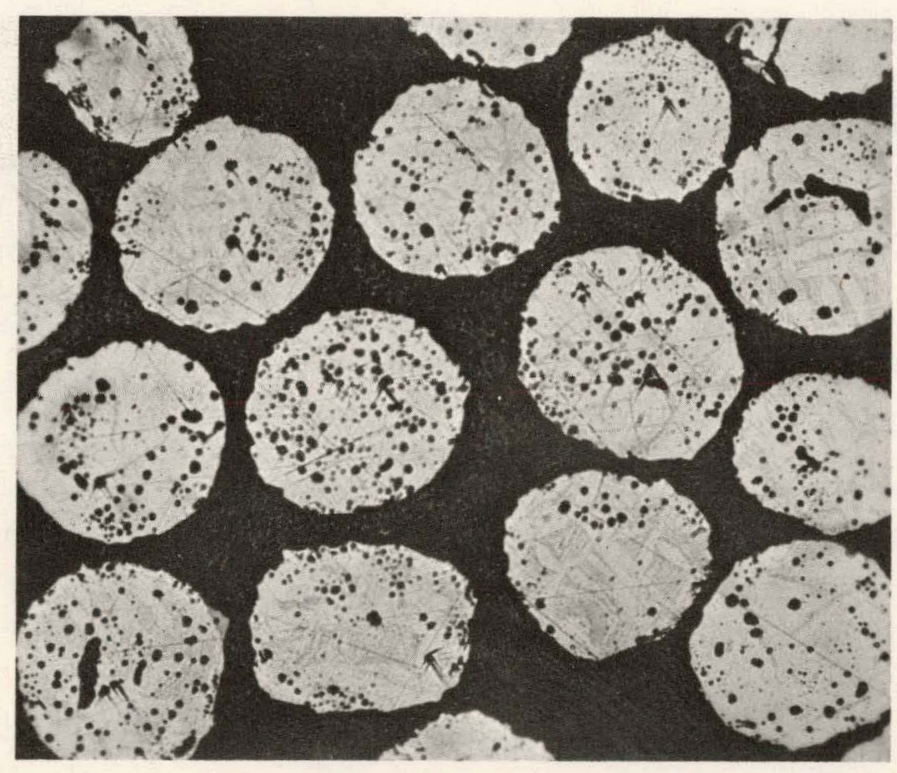

Figure 6

$\mathrm{PuO}_{2}$ Spheres Formed by Snow Balling Technique 2150 Micron Diameter, Air Sintered $1600^{\circ} \mathrm{C}$ 
generally in the higher density and size ranges from approximately 60 to 95 percent of theoretical density in sizes from 200 to greater than 20 U. S. Standard mesh. Plasma-fused spheroids generally are produced much faster and exhibit better surface texture as shown in Figure 7. Both modified high enthalphy D.C. arc torches and RF coupled plasmas have been used although most work has been done on the 40 kilowatt arc torch using $\mathrm{A} / \mathrm{H}_{2}, \mathrm{He} / \mathrm{H}_{2}$ or $\mathrm{N}_{2}$ plasmas. By increasing power level and gas velocity, the character of the particles is changed from high density (nearly 100 percent theoretical) to distributed voids to central cavity as shown in Figure 8. Although plasma torch equipment is becoming commonplace in the metals finishing industry, use of a high power system in a plutonium glove box requires careful engineering and operation. The 40 kilowatt vertical plasma torch unit used in these studies is mounted totally within a two-module-high glove box as shown in Figure 9. A higher power, more elaborately controlled five-high-module system is currently being constructed.

Particle Coating

Considerable work has been done at NUMEC on coating of particulate materials with great emphasis on microspheroids. The methods used or developed have included almost every type of chemical or physical deposition process known for elemental or compound coatings. Metallic, alloy and ceramic spheroids have had coatings, tailored for a variety of applications, deposited by electro- and electroless plating from solutions, gas phase surface reactions, and chemical and physical 


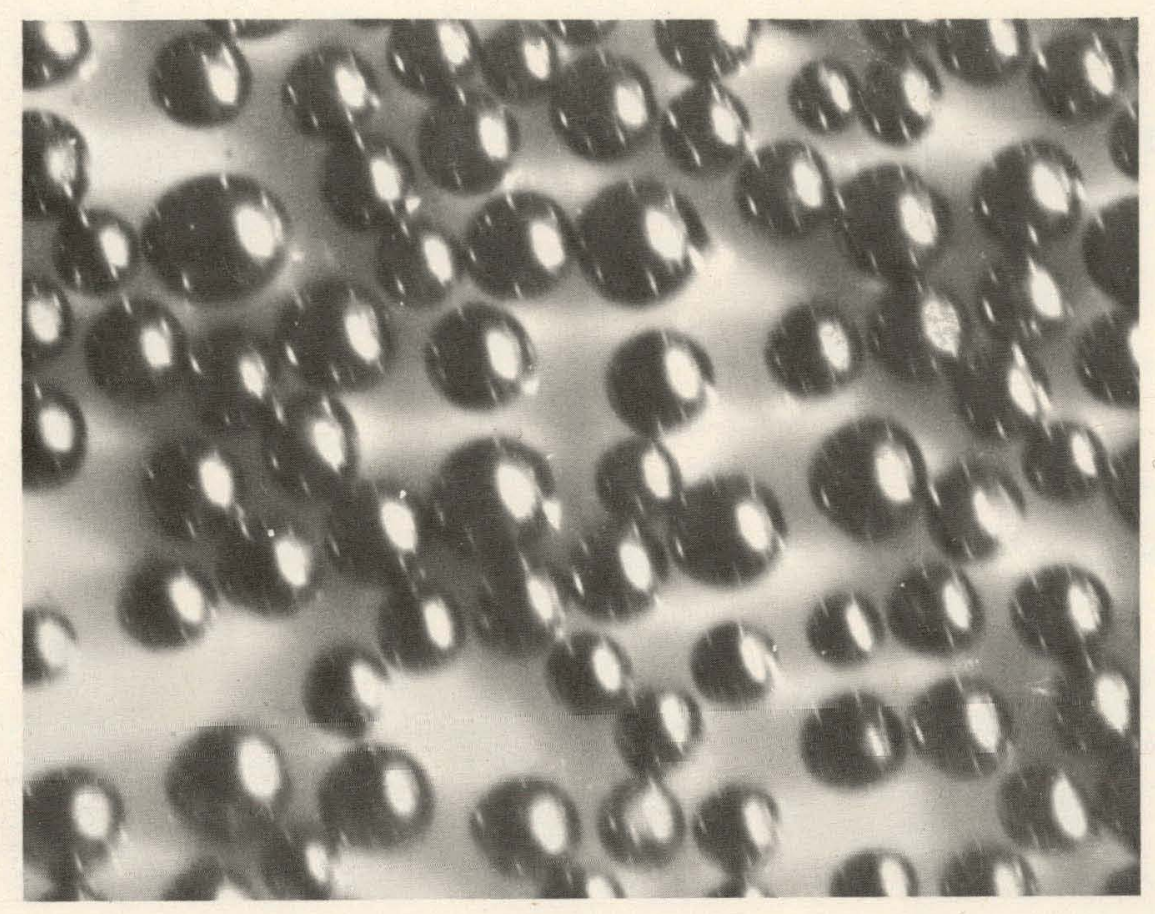

Figure ?

Plasma-Fused $\mathrm{PuO}_{2}$ Spheres

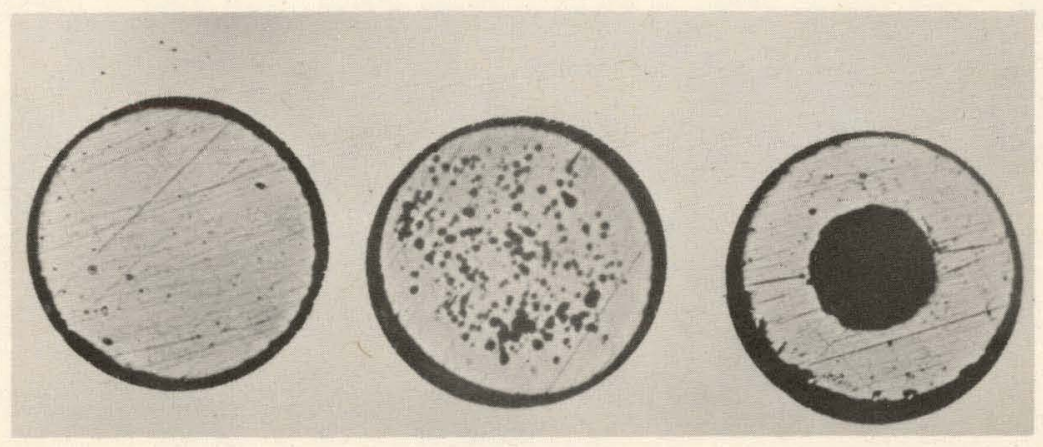

Figure 8

Variations in Plasma-Fused $\mathrm{PuO}_{2}$ Spheres 


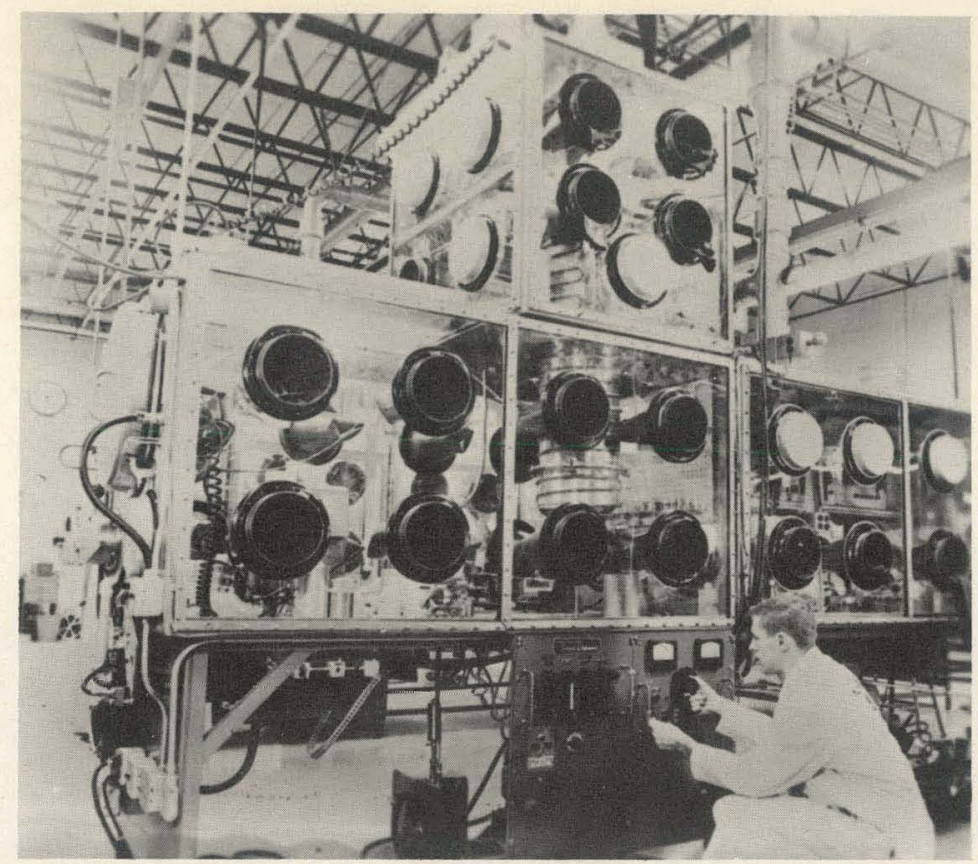

Figure 9

40 kw D.C. Arc Plasma Torch Enclosed in Plutonium Glove Box

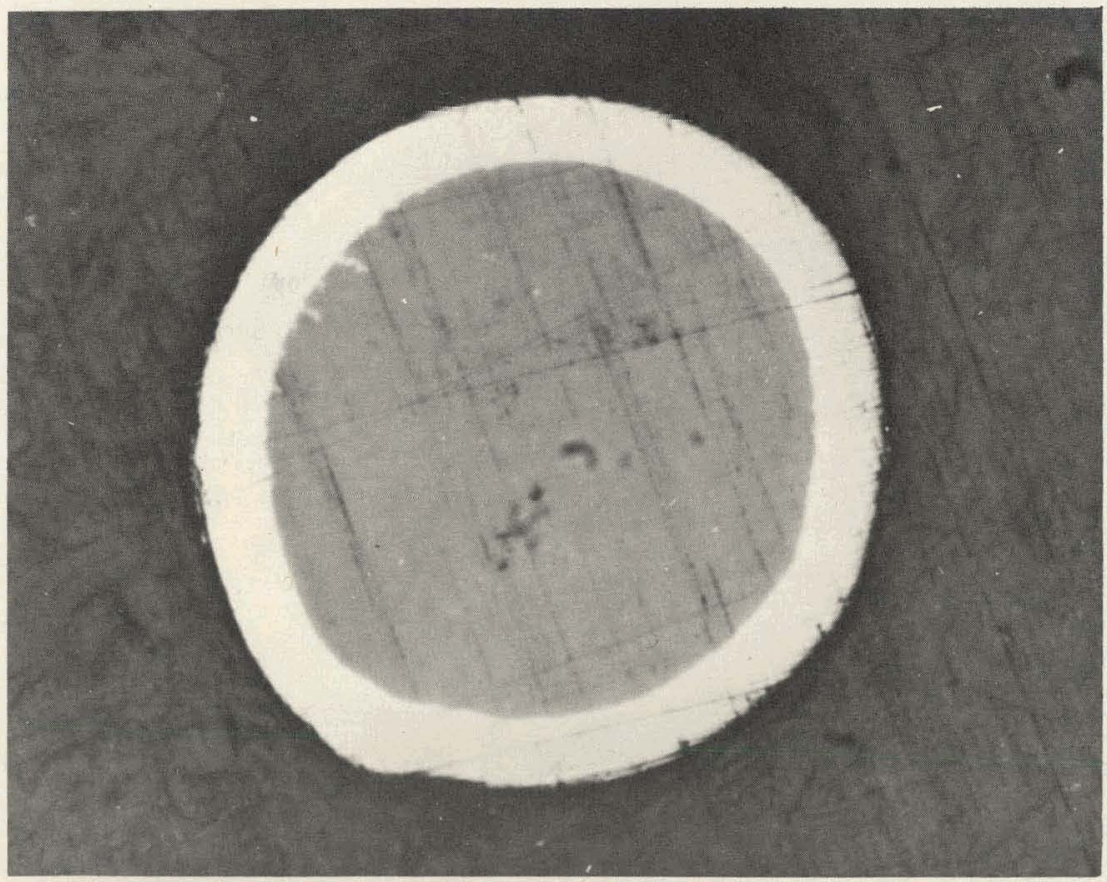

Figure 10

High Purity Tungsten Coating on $\mathrm{PuO}_{2}$ Sphere 
vapor deposition, including halide reduction, thermal decomposition, vacuum sputtering and high energy vacuum evaporation. Chemical vapor deposition is particularly adaptable to coating microspheroids and most of the work done on plutonium bearing particles has been by this method. Figure 10 shows an example of high purity tungsten coating on $\mathrm{PuO}_{2}$, illustrating the uniformity, density and bonding typical of these coatings. The degree of vapor penetration and the uniformity of coating in all accessible regions is illustrated in Figures 11 and 12, which show hollow spheres with and without surface-connected voids. Refractory metal and compound coatings are applied by hydrogen reduction of the volatile halides or by thermal decomposition of the volatile carbonyls. Coating rates range up to one micron per minute.

Tabulation of some chemically vapor deposited refractory metal coatings which have been deposited on microspheres is made in Figure 13. Duplex and multiplex coatings are practically limitless. The multiplex coatings are applied when barrier layers are needed to prevent interaction. Figure 14 tabulates some chemical interaction considerations which may determine the need for single or multiplex coating layers. Chemical vapor coating of microspheres is usually done in externally heated reactors containing the particles in a state of fluidization maintained by a mixture of plating gases and carrier gases which may or may not contribute to the chemical reaction. Figure 15 illustrates schematically, the spouted bed type of system commonly used for the large, dense particles of interest. 


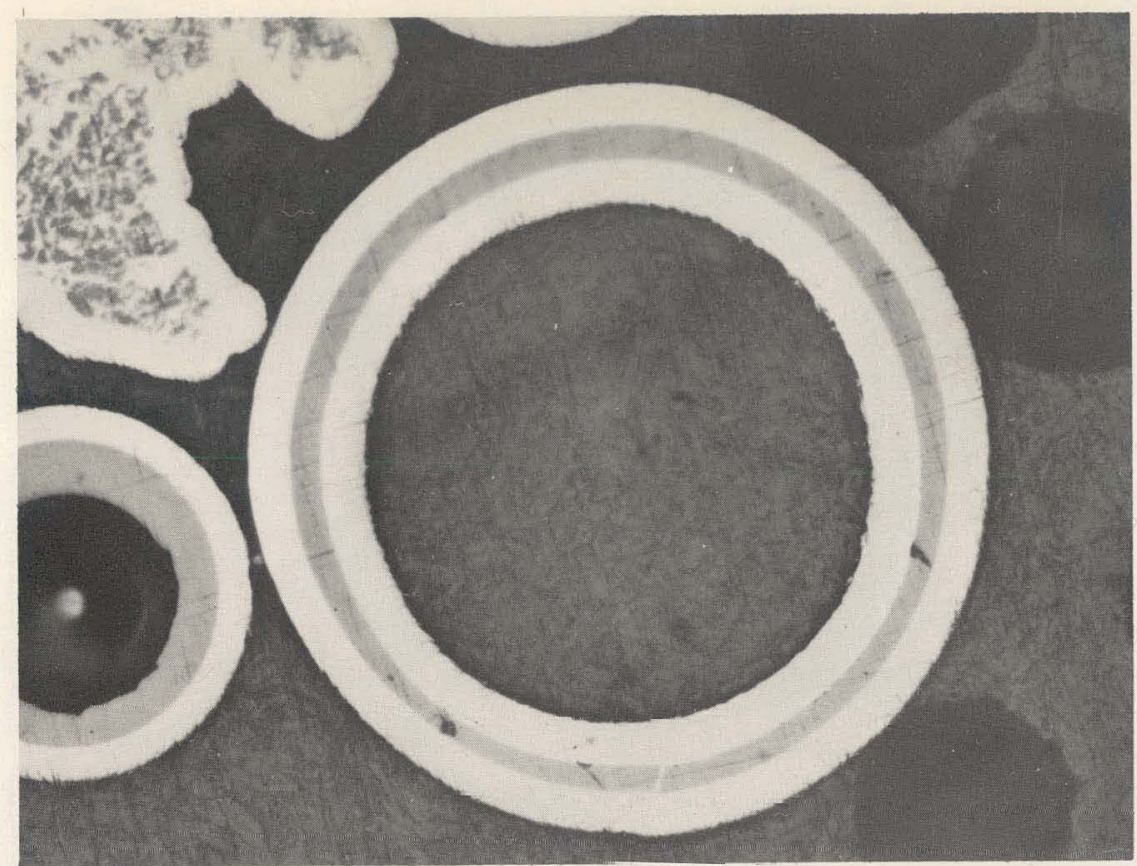

Figure 11

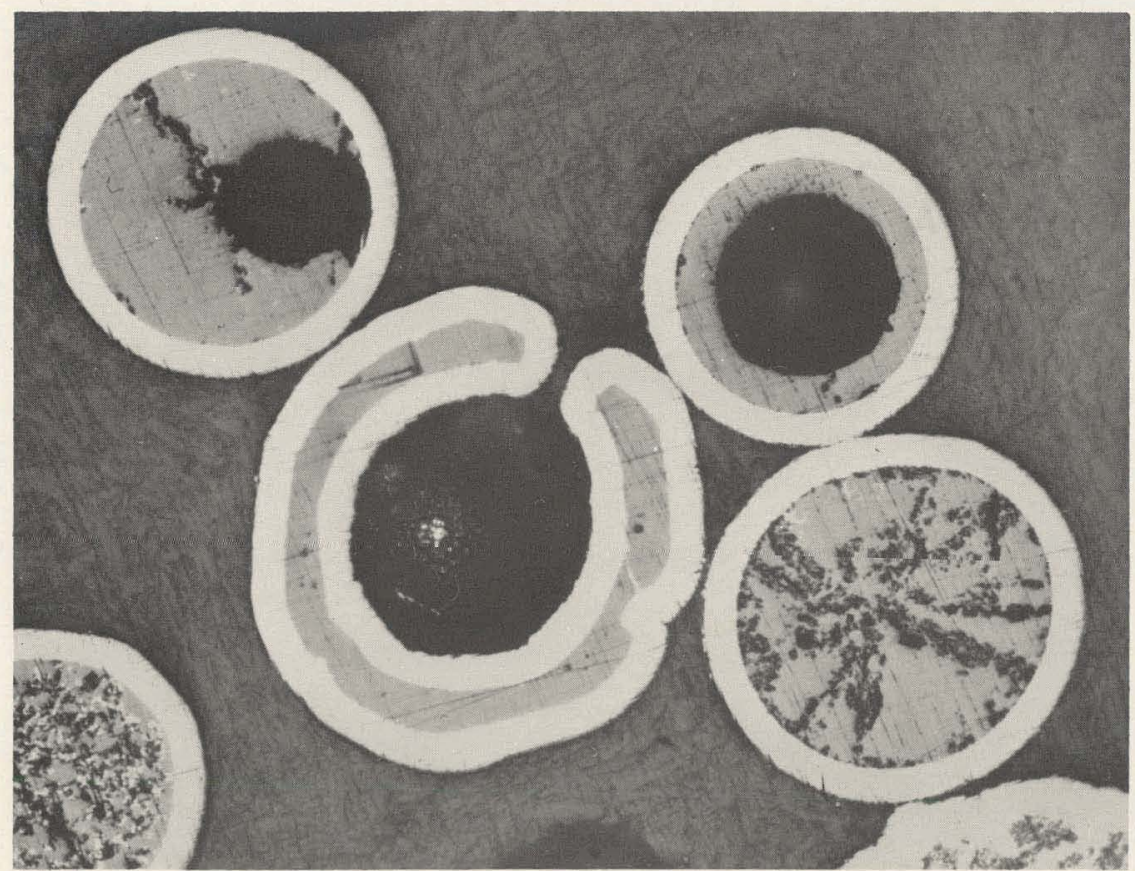

Figure 12

Penetration of Chemical Vapor Deposits in Porous Spherical Particles 


\title{
VAPOR-DEPOSITED COATINGS
}

\author{
ELEMENTAL Mo $W$ Ta $\vee$ Nb Ni $\mathrm{Cr}$ \\ DUPLEX $\frac{\mathrm{Nb}}{\mathrm{Mo}} \frac{\mathrm{Cr}}{\mathrm{Mo}} \frac{\mathrm{Mo}}{\mathrm{Nb}} \frac{\mathrm{W}}{\mathrm{Ni}} \frac{\mathrm{Ta}}{\mathrm{Ni}} \frac{\mathrm{Cr}}{\mathrm{Ni}} \frac{\mathrm{Cr}}{\mathrm{Nb}}$ \\ OXIDE $\quad \mathrm{Al}_{2} \mathrm{O}_{3} \quad \mathrm{BeO}$ \\ ALLOY $\mathrm{Nb}-5 \% \mathrm{~V}$
}

Figure 13

Refractory Metal Coatings of Interest

For Plutonium-Based Microspheres

\section{CHEMICAL INTERACTION CONSIDERATIONS}

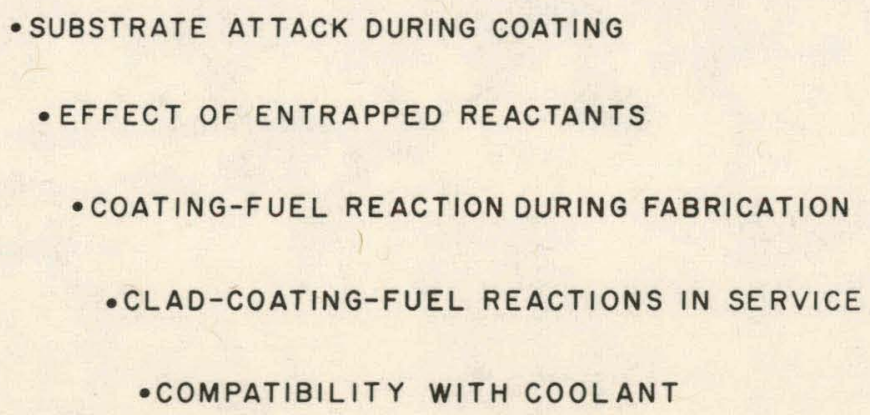

Figure 14

Chemical Interaction Considerations for Coated Microspheres 


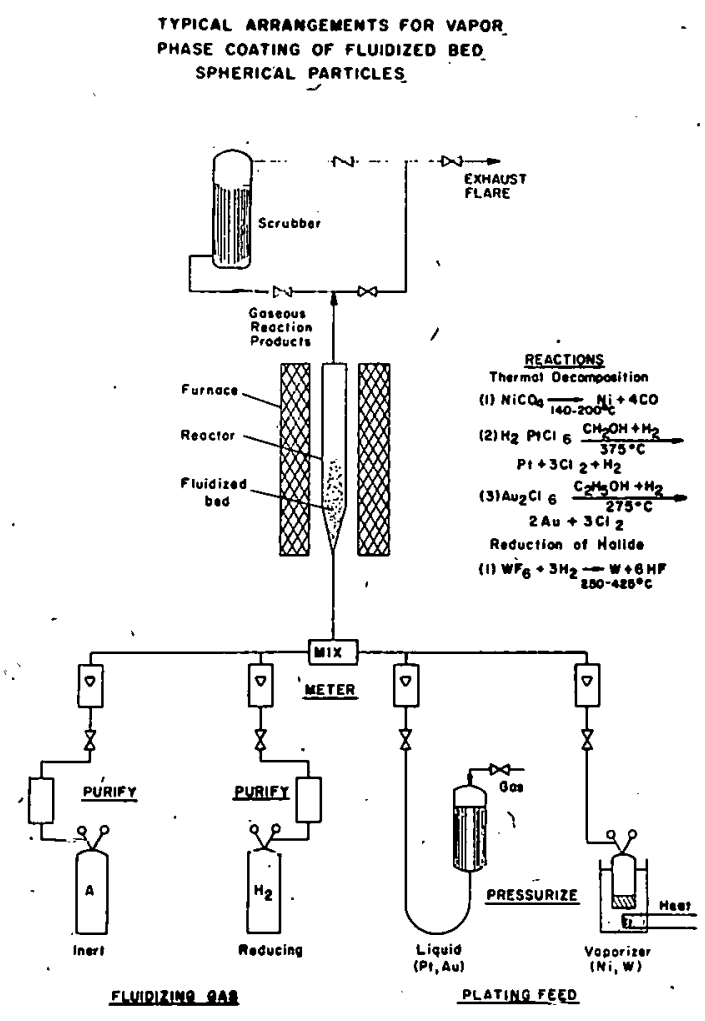

Figure 15

Typical Arrangements for Chemical

Vapor Phase Coating of Spherical Particles 


\section{Consolidation}

Final consolidation to form dispersion elements is performed by one or more of 'several methods as illustrated in Figure 16. The conventional blending and rolling method has been used successfully for production, but requires rather high crush strength particles to prevent particle fracturing and/or stingering: Precoating with metal powder, followed by pelletizing, densification by sintering and coining with intermediate annealing has been reported to yield uniform dispersions containing up to $50 \mathrm{v} / \mathrm{o}$ spheroids in stainless steel with no fracturing. of the ceramic. Hot extrusion $(1,2)$ and hot pressing (2) have also been used at NUNEC with some success. Chemical coating by vapor deposition, or other methods, followed by vibratory compaction and vapor cementation is one of the new routes we are actively exploring at present. Vapor cementation uses the same process and equipment as chemical vapor coating, except that the prepacked spheres are in a fixed bed which is confined within rigid molds and supported by porous, low thermal condustivity end retainers.. The plating gas mixture is passed through the heated bed and cementation occurs at the hot solid surfaces. Heat transfër and gas flow rates change constantly during the cementation and careful attention to proper balances must be made. Some of the features of this technique are shown in Figure 17. Cemented compacts up to five inches in length and one inch in diameter have been made. Rods as small as 1/16 of an inch 


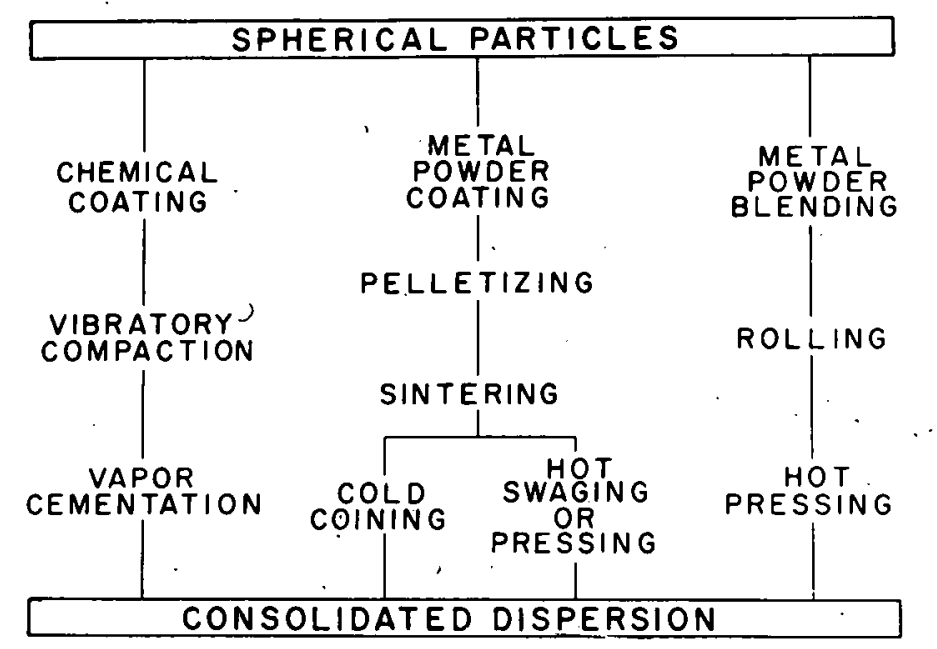

Figure 16

Consolidation Routes for Spherical Particles

\section{VAPOR-DEPOSITED MATRIX ADVANTAGES}

- controllable spatial distribution

- nominal particle strength adequate

- COMPLEX GeOMETRY fabRicABle

- Lower matrix contamination

- REDUCE FABRICATION SCRAP

Figure 17

Advantages of Consolidation by Vapor Cementation 
and rods with $\mathrm{L} / \mathrm{D}$ ratios up to 150 have been made. Plates and complex shapes are readily adaptable to this process and at present there appears to be little limitation to the shape or, size which can be made, provided care is taken to control heat transfer and fluid flow. By prepacking the bed with multi-sized spheres in the proper ratio of diameters, or by, precoating to get the required center-to-centel distance between spheres, a close control over spatial distribution of the fuel particles is possible. The particles need have no more strength than that required to support the bed since no additional stresses are imposed during consolidation. By control of the purity of the gas atmosphere during the cementation, little or no matrix contamination is introduced. With proper mold design, many shapes can be fabricated with no subsequent machining required for the finished shape, others require only minor machining. Some elements such as rods may be cemented directly in the tube container, and with nothing more than end-facing, be ready for closure. This in-situ cementation gives matrix-to clad-to fuel particle bonding on a molecular scale thus maximizing heat transfer. Final cemented solids densities (matrix plus fuel) as high as 96 percent have been achieved without further treatment and if vapor cementation is followed by pressing, extrusion or coining, even higher densities should be possible. Depending upon the nature of the composite structure and the method of post-cementation consolidațion, the particles may or may not be damaged, but in any event appear to be retained within the 
original sphere volume. Figure 18 shows a $\mathrm{UO}_{2}-\mathrm{Nb}$ cermet, $\left(\mathrm{UO}_{2}\right.$ spheres in a $\mathrm{Nb}$ matrix) which has been cold pressed after cementation. The compact was ductile enough to densify, and even though the $\mathrm{UO}_{2}$ spheres fractured, the surrounding matrix retained the fragments in nearly the original spherical shape. Figure 19 shows $\mathrm{UO}_{2}$ spheres coated with tungsten, and vapor cemented with nickel, to form the composite structure. The oxide spheres were prepared by powder agglomeration and sintering. No additional consolidation or machining was performed on this sample.

Aside from the chemistry of the deposition processes and the problems of obtaining the proper structural strength, the problems of chemical interaction during coating, fabrication and service are by far the most challenging. Substrate attack by halides is not a problem for oxides, but with alloys or interstitial plutonium compounds, barrier protection is needed. Entrapped hydrogen, carbon monoxide or inorganic impurities must be removed or post coating attack may result. Temperature conditions during fabrication may be tolerable, but during service, enhanced diffusion or reaction with oxygen released from the $\mathrm{PuO}_{2}$ may degrade materials. Based on short-term tests it is believed that $\mathrm{PuO}_{2}$ is compatible with most of the stainless steels. to temperatures within $100-200^{\circ} \mathrm{C}$ of the metal melting point, however $\mathrm{Si}$ reacts, even in alloy concentrations as low as that of $302 \mathrm{~B}$ stainless. A summary of data on compatibility of metals with $\mathrm{PuO}_{2}$ reported by LASL, HANFORD, BMI, and NUMEC is tabulated in Figures 20 and 21. NUMEC is currently performing compatibility tests with 


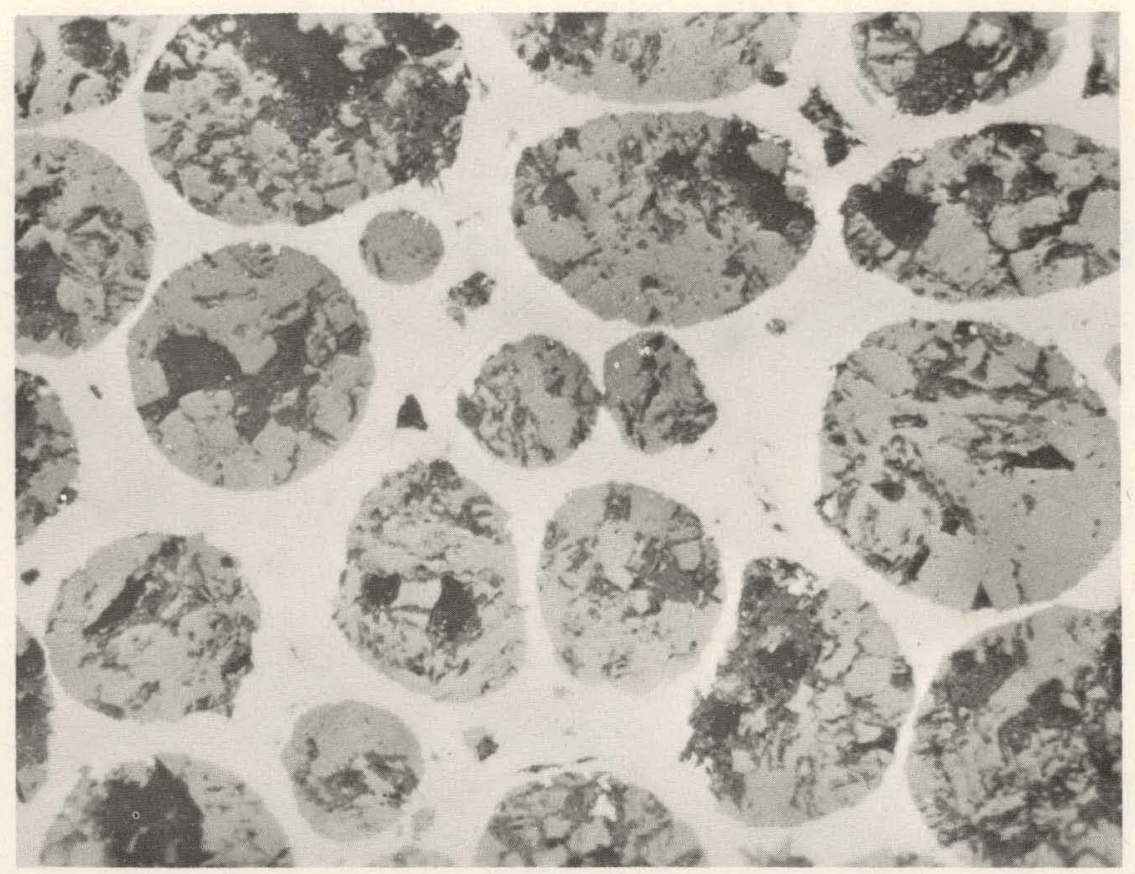

Figure 18

Vapor Cemented Cermet of UO Spheres

in a Niobium Matrix After Cold Pressing

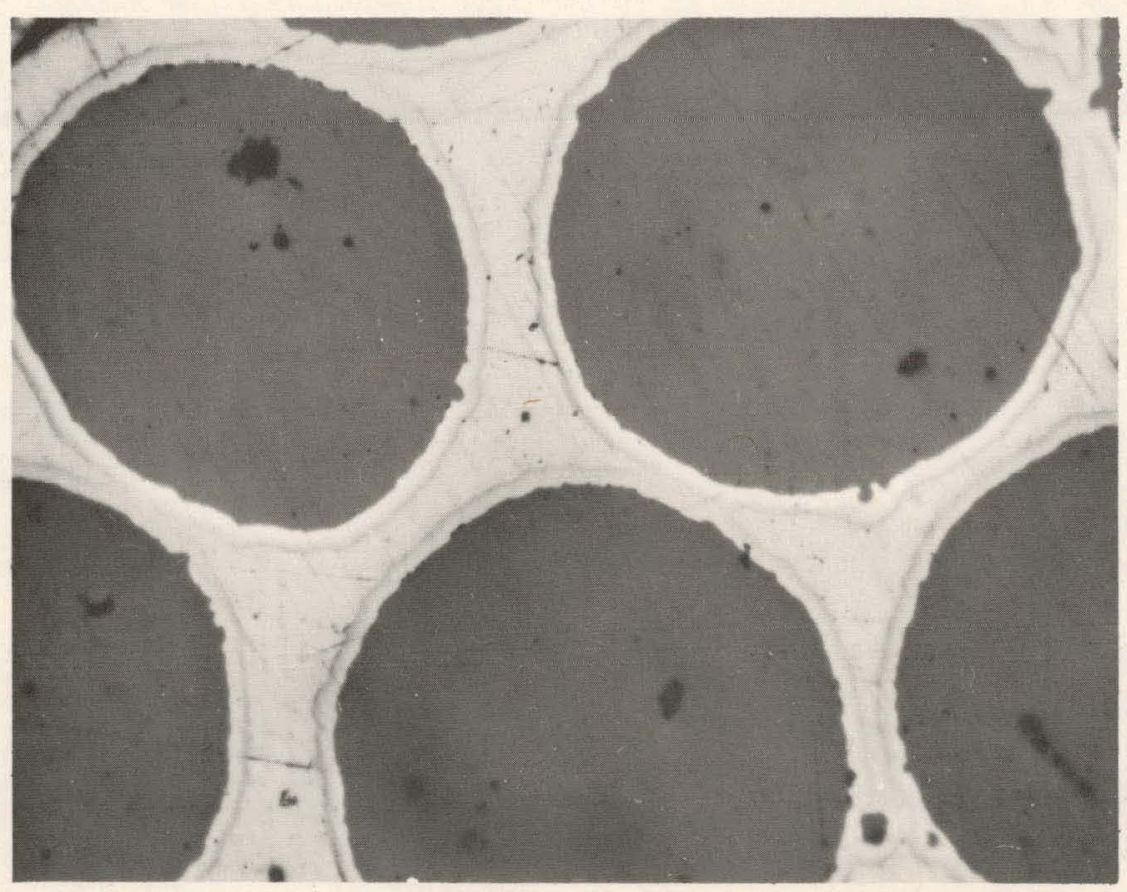

Figure 19

Vapor Cemented Cermet of $\mathrm{UO}_{2}$ Spheres Coated

With Tungsten and Cemented With Nickêl - As Cemented Structure 
METAL-PUO 2 COMPATIBILITY

MP ${ }^{\circ} \mathrm{C}$ ATM TEMP ${ }^{\circ} \mathrm{C}$ DURATION,H OBS. REF.

$\begin{array}{cccccccc}\mathrm{Cr} & 1615 & \mathrm{Ar} & 1425 & & 7 & \mathrm{R} & \mathrm{L} \\ \mathrm{Fe} & 1535 & \mathrm{Ar} & 1325 & & 2 & \mathrm{NR} & \mathrm{B} \\ \mathrm{Ni} & 1452 & \mathrm{Ar} & 1425 & & 2 & \mathrm{~N} \\ \mathrm{Si} & 1420 & \mathrm{Ar} & 1325 & & 2 & \mathrm{NR} & \mathrm{L} \\ 302 & 1420 & \mathrm{Ar} & 1325 & & 8 & \mathrm{R} & \mathrm{L} \\ 304 & 1420 & \mathrm{H} & 1170 & & 2 & \mathrm{~N} & \mathrm{~L} \\ 316 & 1370 & \mathrm{H}_{2} & 1170 & & 2 & \mathrm{NR} & \mathrm{B} \\ 347 & 1390 & \mathrm{H}_{2} & 1170 & & 2 & \mathrm{NR} & \mathrm{B} \\ \text { Inconel } & 1395 & \mathrm{H}_{2} & 1170 & & 2 & \mathrm{NR} & \mathrm{B} \\ 302 \mathrm{~B} & 1420 & \mathrm{Ar} & 1325 & & 2 & \mathrm{R} & \mathrm{L}\end{array}$

Figure 20

\section{METAL-PUO 2 COMPATIBILITY}

\begin{tabular}{|c|c|c|c|c|c|c|}
\hline \multirow[b]{2}{*}{$w$} & $M P{ }^{\circ} \mathrm{C}$ & ATM & TEMP ${ }^{\circ} \mathrm{C}$ & DURATION, H & OBS. & REF \\
\hline & 3370 & Ar & $>2250$ & $<1$. & $\mathbf{R}$ & H \\
\hline \multicolumn{2}{|c|}{; } & $\mathrm{H}_{2}$ & 1400 & 20 & $\mathbf{R}$ & B \\
\hline To & 2996 & Vac & 1500 & 4 & $\mathbf{R}$ & $\mathrm{B}, \mathrm{N}$ \\
\hline \multirow[t]{4}{*}{ Mo } & $2620^{\prime}$ & Ar & $>2200$ & $\ll 1$ & $\mathrm{R}$ & $\mathrm{H}$ \\
\hline & & Ar & 1750 & 3 & $N R$ & L \\
\hline & & $\mathrm{N}_{2}-\mathrm{H}_{2}$ & 1700 & 16 & NR & $N$ \\
\hline & & $\mathrm{H}_{2}$ & $1400^{\circ}$ & 20 & NR & B \\
\hline N b & 2415 & Ar & 1600 & 4 & NR & B \\
\hline$T i$ & 1820 & Ar: & 1600 & 4 & $\mathbf{R}$ & $B$ \\
\hline $2 r-2$ & 1810 & Ar & 1100 & 2 & $\mathrm{R}$ & 8 \\
\hline$V$ & 1710 & Ar & 1600 & 4 & NB & 8 \\
\hline
\end{tabular}

Figure 21

Metal - $\mathrm{PuO}_{2}$. Compatibility 
$\mathrm{UO}_{2}-\mathrm{PuO}_{2}$ pellets at $\mathrm{PuO}_{2}$ concentrations of $5,20,35$ and 80 percent using $\mathrm{UO}_{2}$ and $\mathrm{PuO}_{2}$ control pellets with each sample. No interaction has been seen in any two-hour exposure at $1100^{\circ} \mathrm{C}$. The compatibility of refractory metals with $\mathrm{PuO}_{2}$ is unsatisfactory for zircaloy-2, titanium and tantalum. Niobium, vanadium, molybdenum and probably tungsten would be compatible in inert atmospheres up to $1600-1700^{\circ} \mathrm{C}$, thus permitting fabrication. Compatibility can be expected to improve with mixed U-Pu oxides due to a lesser tendency to lose oxygen. At high temperatures, above $2200_{-}^{\circ} \mathrm{C}$, although $\mathrm{UO}_{2}$ will not interact with tungsten, $\mathrm{PuO}_{2}$ and $\mathrm{PuO}_{2}-\mathrm{ZrO}_{2}$ will. Tungsten ribbon filaments can be used to melt $\mathrm{PuO}_{2}$ but long term containment is limited due to oxygen release from the $\mathrm{PuO}_{2}$. The tendency for oxygen release is lessened with $\beta \mathrm{Pu}_{2} \mathrm{O}_{3}$ and would probably be lower with $\mathrm{PuO}_{2}$ diluted with $\mathrm{UO}_{2}$. The plutonium-oxygen phase diagram, Figure 22, illustrates the complexity of the problem encountered with the system.

\section{CONCLUSIONS}

Based on experience in making plutonium oxides; and related uranium experiences with spherical particles, a suitable method exists for spheroidizing or cuating most $\mathrm{Pu}$ or U-Pu compounds. Close control of preparation methods is essential, but the means are available. More experience with high-strength alloy and modified ceramic coating is needed. Most needed, at present, is more long-term compatibility data with as-applied coatings and matrices on a wide range of U-Pu compositions where purity, structure and contacting method is well known for all materials of the composite. This data 
should provide limits of compatibility under simulated thermal and irradiation conditions. There is reason to be confident that plutonium, with its unique reactor physics advantages, can be matched with the cellular fuel particle concept to give more freedom to the fuel designer.

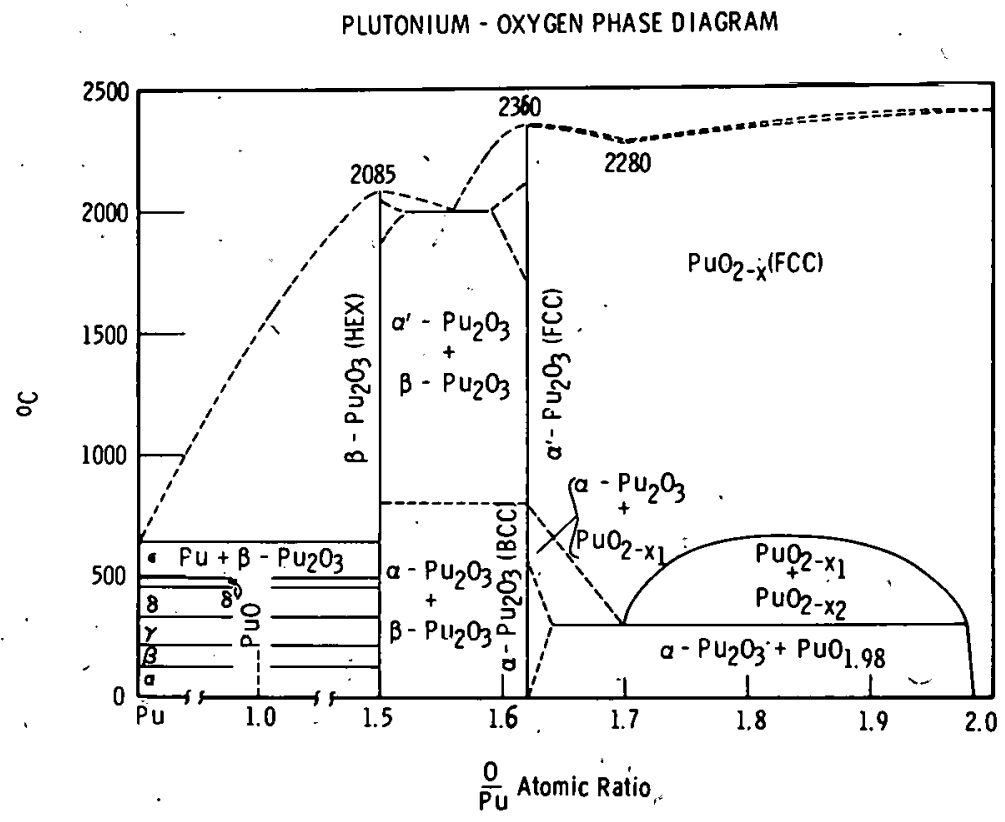

Figure 22 -

Plutonium-Oxygen Phase Diagram 


\section{REFERENCES}

1. Forscher, F., Cain, F. M., and Vondra, B. L., "Coated Fuel Particles", International Atomic Energy Symposium on "Fuel Element Fabrication with Special Emphasis on Cladding Materials", Vienna, Austria, May 13, 1960.

2. Pepkowitz, L. P., Vondra, B. L., and Shipko, F., "Development of Protective Metal Coatings for $\mathrm{UO}_{2}$ and U Particles", USAEC-ORNL Second:Conference on Nuclear Reactor Chemistry, Gatlinburg, Tennessee, 1961, TID-7622 (1962). 


$$
\text { CONF }-117-43
$$

THE PROCESSING, PHYSICAL PROPERTIES AND PERFORMANCE

OF PYROLYTIC GRAPHITE COATED $\mathrm{UC}_{2}$

by

R. L. Finicle and S. A. Taylor
Union Carbide Corporation
Carbon Products Division

ABSTRACT

Correlation of éxisting data has provided sufficient information to postulate a mechanism of deposition for the coating of a particle system with pyrolytic graphite. The fundamental difference between the massive substrate and particle systems is geometric. In the massive substrate system under a given set of conditions the substrate encounters essentially a constant atmosphere while in the particle system a definite atmospheric gradient is experienced by the particles. This gradient actually results in a two phase atmosphere and the condition ot these phases greatly influences the microstructure and physical properties of the deposit. Data from past experience and the 1iterature concerning the deposition of pyrolytic carbon and graphite on massive substrates.is presented which influenced the selection of initial operating conditions and/or serves as an aid in explaining the deposition mechanism.

The processing of two basic coating types are discussed including. some physical properties and performance data. Included also is the argument used in the justification and design of the duplex coating. 
Introduction:

Although the advantages gained by coating nuclear fuel particles with pyrolytic carbon are well known to those familiar with the art, they are listed below because of their influence on the direction of this work.

1. To retain fission products and prevent radioactive contamination of the coolant stream.

2. To retard thermal migration of fuel into the matrix.

3. To prevent hydrolysis and oxidation of carbide fuels.

The specifications for coated particle fuels first established by Sanderson-Porter were originally adopted by Union Carbide's Carbon Products Division as a guide for the coating development work. The specifications directly affecting the coating work were as follows:

1. Fùel Material

- 175 to 250 micron diameter uranium dicarbide spheroidś.

2. Coating Material - pyrolytically deposited carbon.

3. Coating. Thickness - 80 micron average, 50 micrón minimum.

4. Thermal Stability - must withstand 3 cycles from 200 to $2000^{\circ} \mathrm{C}$.

5. Surface Uranium Contamination - $\leqslant 1 \times 1.0^{-3} \%$ of contained uranium.

The above functions and specifications dictate a coating with low permeability and chemical reactivity, high strength, resistance to thermal shock and irradiation damage, and good uniformity. Extracting from the literature and an investigation by Union Carbide's Carbon Products Division on the conditions which affect the deposition rate and properties of pyrolytic graphite, it was possible to reduce the vast number of variables which influence the deposited material to those showing promise of producing coatings with the desired characteristics. 


\section{Deposition Conditions and Properties of Pyrolytic Graphite on}

Massive Substrates

Past studies of the deposition conditions and physical properties of pyrolytic graphite, as applied to massive substrates, served as a foundation for this work on coated particles: The following is a review of some of the more important factors which contributed toward establishing operating conditions and explaining the deposition mechanism for the particle system.

The apparatus used in a rate and properties study conducted by Union Carbide's Carbon Products Division, consisted of a water-cooled stainless steel vacuum chamber containing appropriate observation windows, gas ports, and water-cooled electrodes, a gas handling manifold, power supply and vacuum system. Figure l. shows a schematic diagram of the deposition chamber.

The gas manifold was designed as a gas mixing system so that various combinations of gases could be admitted to the deposition chamber under known conditions of partial pressure and flow rate. The total pressure was monitored by a mercury manometer and held constant with a Cartesian manostat. Gas flows were determined by rotameters and the gas mixtures were diffused upon entering the system by a multiple jet nozzle and further mixed by a magnetically driven fan located in series with the nozzle.

The substrate material consisted of graphite strips $1.0 \mathrm{~cm} x$ $0.5 \mathrm{~cm} \times 11.5 \mathrm{~cm}$ and were supported in a horizontal position by water-cooled copper electrodes. The samples were resistance heated and temperature was read with an optical pyrometer. The temperature drift caused by increasing sample cross -section, was compensated by simultaneously reading the temperature and adjusting the auto-transformer. No measurable temperature gradient was found over the central $8 \mathrm{~cm}$ of the sample.

The rate of deposition was studied as a function of temperature, total pressure, hydrocarbon partial pressure, hydrocarb on flux and diluent gas with the following general results.

The rate of deposition:

1. is a sharply increasing function of temperature from $1600^{\circ} \mathrm{C}$ to $2000^{\circ} \mathrm{C}$ and approaches a constant value

above $2000^{\circ} \mathrm{C}$

2. increases with pressure, but reaches a constant value at a total pressure which is dependent on other param-

eters; 
3. increases with hydrocarbon flux, but reaches a saturation value for a given set of conditions;

4. increases with increasing hydrocarbon partial pressure;

5. is independent of the thermal and physical properties of the diluent, but is substantially reduced by a chemically active diluent such as hydrogen.

The general shape of the rate curves is shown in Fugures II-V.

Density and metallographic appearance were found to be strongly temperature dependent although a range of densities and variations in microstructure can be produced at any given temperature depending on the conditions of the gas phase, i. e., amount of soot. For instance, a range of $1.77 \mathrm{gm} / \mathrm{cc}$ to $2.24 \mathrm{gm} / \mathrm{cc}$ was produced at $2000^{\circ} \mathrm{C}$ showing blocky cone growths to fine needle-like structures. This fact suggests the importance of gas phase reactions on the physical properties and microstructural appearance of the deposit. Of the diluent gases studied the degree of soot formation was greatest for argon and least for hydrogen.

Recent work done at Union Carbide's Carbon Products Division Advanced Materials Laboratory (7.), showed that system geometry was also very important. The variation of surface appearance, microstructure and deposition rate was investigated as a function of the distance between the gas inlet nozzle and substrate. It was found that the deposition rate decreased and the microstructure varied from a fine needle structure to large cone growths and finally to soot with increasing distances. The following explanation was given. As the carbonaceous gas enters the deposition chamber its temperature increases rapidly and upon becoming superheated with respect to the temperature of thermodynamic equilibrium carbon nuclei appear in fine dispersions. As these nuclei travel toward increasingly higher temperatures they begin to grow due to collisions with carbonaceous, gas molecules. Consequently the concentration of carbonaceous gas molecules decreases in this direction. Therefore, substrates placed at various points of the gas path encounter substantially different conditions. The layer of hydrogen which is formed on the substrate surface by the thermal decomposition of the hydrocarbon acts as a diffusion barrier to soot particles and decreases with increasing distances from the inlet because of the decrease in carbonaceous gas concentration. Grisdale, Pfister and van Roosbroeck (2) observed a similar fog-free region around the substrate and attributed it to the zone in which the transfer of heat from the surface to the gas occurs by conduction rather than convection. They feel that because of the high temperature gradient and the associated viscosity gradient, the heavier particles of soot tend to diffuse away from the surface. 
Flexural strength measurements parallel to the layer planes have indicated an increasing strength with decreasing grain size. (8) (9) Pyrolytic graphite deposited between $1600^{\circ} \mathrm{C}$ and $1900^{\circ} \mathrm{C}$ was found to be extremely hard and brittle while high density material deposited above $2000^{\circ} \mathrm{C}$ appeared to be soft and elastic.

The ability of pyrolytic graphite to serve as a coating at high temperatures was also known to be related to the deposition-temperature and the thermal expansion coefficients of the substrate and coating.

From these data and the literature,- the area of investigation became limited to those conditions which should produce a highly graphitic coating at a high rate of deposition. Helium and methane were selected as the diluent and carbonaceous gas respectively and operation was to be at atmospheric pressure. Because of the high coefficient of thermal expansion of $\mathrm{UC}_{2}$ as compared to pyrolytic graphite and the desire to obtain a high deposition rate the area of investigation was limited to temperatures above $1600^{\circ} \mathrm{C}$.

\section{Preparation of Coated Particle Fuels}

Early experimentation with a rotating bed coating reactor proved difficult because of apparatus mechanical problems and coating non-uniformity and wa's soon abandoned in favor of the vertical fluidized bed. A schematic of the original fluidized bed furnace is shown in Figure VI. The reactor was a cylindrical l" ID graphite vessel with a removable conical shaped inlet nozzle and an expanded top section. The reactor was surrounded by a graphite sleeve and a slip fit was maintained to allow for positioning and removal of the reactor. This was then encased in carbon felt insulation and a fused silica outer jacket. The orifice was water-cooled to prevent deposition and high frequency induction supplied the thermal energy.

For coating 175-250 micron uranium dicarbide spheroids at high temperatures a thin layer of pyrolytic carbon was applied at a temperature about $50^{\circ} \mathrm{C}$ below the agglomeration point of the particles. This "surface sintering" is a well-known phenomenon of metal powders and the sintering temperature is dependent on particle size for a given material.

Early experimentation using methane partial pressures as low as 0.1 atmospherés (low enough to produce a high density fine grain structure deposit on a massive substrate) yielded low density coatings which did not exhibit birefringence when viewed under polarized light, indicating its poor degree of crystal ordering. This was later verified by $x$-ray diffraction. This type of coating will be referred to as "non-crystalline" or "less crystalline" in this paper. 
Along with the effort to produce a high density columnar deposit evolved the concept of a dual láyered coating. Simple reasoning dictated a sacrificial inner layer to cushion the effects of inner mechanical and thermal stresses and fission product damage and an outer layer to act as a containment vessel: The inner layer ideally should be characterized by some degree of porosity to provide a volume for fission gases. The outer layer should be applied at a higher temperature than both the inner layer and the fuel temperature during reactor operation and possess a lower thermal expansion coefficient. This would allow a fissure to exist between the layers at reactor fuel temperature, thereby serving as an obstruction to crack propagation. The inner layer should also be as thick as the carbon range of the most penetrating fission products or about 25 microns. These characteristics were all satisfied by a low density, less crystalline inner laminar layer and a high density more highly crystalline outer columnar layer.

Further investigation revealed that pyrolytic graphite displaying the characteristic conical structure and possessing a high density could be deposited on uranium dicarbide spheroids by a further reduction in methane partial pressure. It was also found that the microstructure and surface texture of the columnar coating were dependent upon the dynamics of the particle bed as well as methane concentration. This structure variation could be closely controlled and was reproducible.

\section{Appearance, Properties and Performance of Coated Particles}

Microstructure

The general appearance of the external surface and microstructure of the less crystalline type coating is illustrated in Figures VII and VIII respectively. The surface appearance is smooth, black and generally possesses a high luster while the microstructure appears almost completely amorphous even using polarized light. The variations in surface texture of the columnar type coating can be seen in Figures IX-XI, which are in order of decreasing grain size. The difference in microstructure is best illustrated with polarized light, by Figures XII and XUI which show a cross-section of samples possessing large and small grain sizes respectively. The surface texture appears to be a function of grain size.

\section{Density of the Coating}

The densities of the coatings were found by crushing coated particles such that they would pass through a 100 mesh screen, leaching in hot $\mathrm{HNO}_{3}$ to remove all heavy metal and measuring in a Beckman Purgeable Comparison Pycnometer using helium. 
Densities of up to $2.20 \mathrm{gm} / \mathrm{cc}$ have been found for the columnar coating, depending on the deposition conditions. Within the accuracy of the measurement no correlation has been found between density and grain size.

To illustrate the low densities of the less crystalline type coating, and the higher densities of the columnar type, the density as a function of deposition temperature for both the particle coatings and the deposit formed on a massive substrate is plotted in Figure XIV.

\section{Mechanical Strength of Coated Particles}

Measurements were made of the crushing strength of individual coated particles of various types. The equipment consisted of an Instron Tensile Testing Machine, a compression load cell with a 1 to 50 pound range and a chart recorder. The load rate was 0.002 inches per minute.

The duplex-columnar type coatings were found to possess a higher crushing strength than the less crystalline coatings. Also within the duplexcolumnar types the strength increased markedly with surface smoothness, i. e., decreasing grain size. This apparent increase in strength could be attributed to either a point (for rough surface) vs. larger area (for 's mooth surface) loading, the smaller grain size, or both. Table I summarizes this data.

\section{Surface Contamination}

Contamination of the coated particles, by uranium at or near the surface was estimated by proportional counting of alpha-radiation,employing a $2 \pi$ flow proportional counter and P-10 gas. The flat source efficiency was found to be 50 per cent. The particles were placed as a monolayer in an aluminum planchet. The observed counting rate above background was corrected for geometry, and from the uranium content of the coated particles converted to percentage of total uranium at or near the surface. Inasmuch as the range of 4.2 to $4.75 \mathrm{mev}$ alpha particles in carbon is about 25 microns, the alpha count rates can be described as a minimum contamination level in the outer spherical shell of the coating of thickness equal to 25 microns.

Typical data for coated uranium dicarbide particles are given in

Table II.

Coating Thickness Variation

Coating thicknesses are measured by an $\mathrm{x}$-ray technique using a Picket "Hotshot" $50 \mathrm{KVP}$ Soft Radiation $\mathrm{x}$-ray unit with a $0.25 \mathrm{~mm}$ Be window and a $0.5 \mathrm{~mm}$ focal spot. Particles ere selected with the aid of a microriffle. 
Standard deviations of coating thicknesses for 200 micron diameter particles with a 100 micron coating are normally less than 8 microns and for 100 micron diameter particles. with a 25 micron coating are less than 4 microns.

\section{Irradiation Tests on Duplex-Columnar Coated Particles}

Extensive irradiation studies at Oak-Ridge National Laboratories have shown a quite satisfactory degree of fission product retention by the duplex-columnar structure. Typically the $\mathrm{R} / \mathrm{B}$ ratio for $\mathrm{Kr}^{88}$ at $600-1200^{\circ} \mathrm{C}$ and after ápproximately $30 \%$ burnup has been found to be 10-5. Figure XV is a cross-section of duplex-columnar coated particles after 5 atom per cent burn-up at $2000^{\circ} \mathrm{F}$ exhibiting the confinement of damage to the inner coating layer.

Remarks on the Mechanism of Deposition of Pyrolytic Carbon on the Particle System

It was indicated earlier that in the particle system a low density carbon of poor crystallinity is formed under the same conditions, neglecting geometry, that a high density well-oriented pyrolytic graphite would be formed on a substrate in a conventional system. The importance of geometry on the degree of gas phase reactions and subsequent effect on physical properties and microstructure was also pointed out. Based on the above considerations and the physical property data, it can then be proposed that the less crystalline carbon deposit is a form of carbon produced when gas phase reactions are extensive and no barrier to soot occlusions exists. The following argument is presented as a possible explanation to the deposition mechanism of pyrolytic carbon on the particle system.

If a carbonaceous gas is allowed to pass into a vertical tube at high temperature through an orifice the gas will begin to decompose after it has obtained sufficient thermal energy by radiation and convection from the hot walls. The exact point, i. e., heighth, which this occurs is, of course, peculiar to the geometry of the tube and inlet nozzle as well as gas composition, velocity and temperature. If particles are then added to this system and are allowed to occupy the volume below this decomposition height, the net effect is to lower this level because the particles act, in effect, as a heat exchanger. If the gas above this decomposition level is carbon rich and particles are permitted to cycle into this volume the condition for serious coating degradation by soot occlusions becomes quite probable. This condition is further enhanced by the lack of any diffusion barrier because of the turbulent nature of the particle system.

Very high efficiencies are realized in the columnar deposition process, sufficiently high that the carbon concentration in the gas stream can 
be effectively reduced to zero below the gas phase decomposition level. As the particles cycle between the carbon rich and carbon deficient regions in the furnace minute soot occlusions and/or interruptions in the coating process give rise to successive nucleation resulting in a regenerative conical microstructure. This depletion of carbon is brought about by a reduction in the methane concentration or by adjusting the operating parameters such that a greater deposition efficiency is obtained in the volume below the gas phase decomposition level. The coating thickness has been found to be a nearly linear function of time in the particle system. Although the linear deposition rate, i.e., thickness per unit time, is generally higher for the less crystalline coating, the absence or presence of columnar structure is not dependent upon this linear rate of growth. This is demonstrated by FigureXVIshowing a plot of thickness versus time for several particle coating experiments and a typical massive substrate experiment. The conditions for both coating types are shown schematically in Figure XVII.

The extent. to which growth is permitted from each nucleation point yields the varying structure shown in Figures IX-XIII and is dependent apon methane concentration, and the dynamic properties of the particle bed. The bed dynamics being, of course, affected by furnace geometry, gas velocities, temperature and the particle size,shape and density. Figure XVIII shows the variation in the average cone length as a function of the particle surface area per unit volume of carbon rich zone for a given set of coating conditions.

Studies of particle fluidization $(10,11,12)$ by others have shown that at high gas velocities an increase in bed slugging, leading to particle spouting, accompanies an increase in particle diameter. An increasing tendency to elutriate also accompanies a decrease in particle density. Both spouting and the tendency to elutriate increase in magnitude with time in a given coating run as the particles increase in diameter and decrease in density. The net effect then is a decrease in the dwell time per particle in the carbon rich zone and subsequent decrease in cone length with time in the coating run. Coatings have, in fact, been produced displaying large cone growths at the coating $-\mathrm{UC}_{2}$ interface and very fine structure at the coating extremity.

\section{Summary:}

The geometry of any system designed to produce pyrolytic graphite plays a very important part in the integrity of the product by exerting a marked effect on the rate of gas phase decomposition and subsequent formation of carbon nuclei. Degradation of the deposit by soot occlusions can be partially offset by the natural formation of a diffusion barrier around the substrate material. 
Deposition of high grade pyrolytic graphite in a fluidized particle system is more difficult because of the lack of a diffusion barrier and the extreme inherent geometry conditions imposed by such a system.

The application of a high density layer of pyrolytic graphite over a less crystalline pyrolytic carbon first layer on uranium dicarbide fuel particles has proven to be an efficient means of fission product retention. 
Table I

Crushing Strength of Pyrolytic Carbon Coated $\mathrm{UC}_{2}$ Spheroids

Coating Type

Non-crystalline

Non-črystalline

Non-crystalline

$\stackrel{\leftarrow}{\omega}$

Duplex-Columnar

Duplex-Columnar

Duplex-Columnar

- Duplex-Còlumnar

Duplex-Columnar

Average Total

$\underline{\text { Surface Texture }}$ Diameter-Microns

smooth-high gloss

415

485

330

370

393

381

wrinkled

smooth-dull

s mooth-semi-gloss
Average Coating

Thickness-Microns

96

120

90

90

95

95

95

95
Average Yield

Force-Lbs.

2. 3

1.5

1.6

3.67

4. 20

4. 77

5. 71

6.85 
Table II

\begin{tabular}{|c|c|c|c|c|}
\hline Coating Type & $\frac{\mathrm{UC}_{2} \text { Diameter }}{\text { microns }}$ & $\frac{\text { Total Coating }}{\text { Thickness-microns }}$ & $\frac{\text { Alpha Count }}{\text { Gpm/gm }}$ & $\frac{\text { Uranium Cont }}{\% \text { of Total }}$ \\
\hline n-crystalline & 200 & 100 & 2 & $0.6 \times 10^{-3}$ \\
\hline $\begin{array}{l}\text { plex-Columnar } \\
\text { low temperature }\end{array}$ & 200 & 92 & 2.5 & $0.7 \times 10^{-3}$ \\
\hline $\begin{array}{l}\text { plex-Columnar } \\
\text { high temperature }\end{array}$ & 200 & 100 & 11.1 & $3.3 \times 10^{-3}$ \\
\hline plex-Columnar & 100 & 35 & 24 & $6 \times 10^{-3}$ \\
\hline
\end{tabular}


Fig. I

Pyrolytic Graphite Deposition Chamber

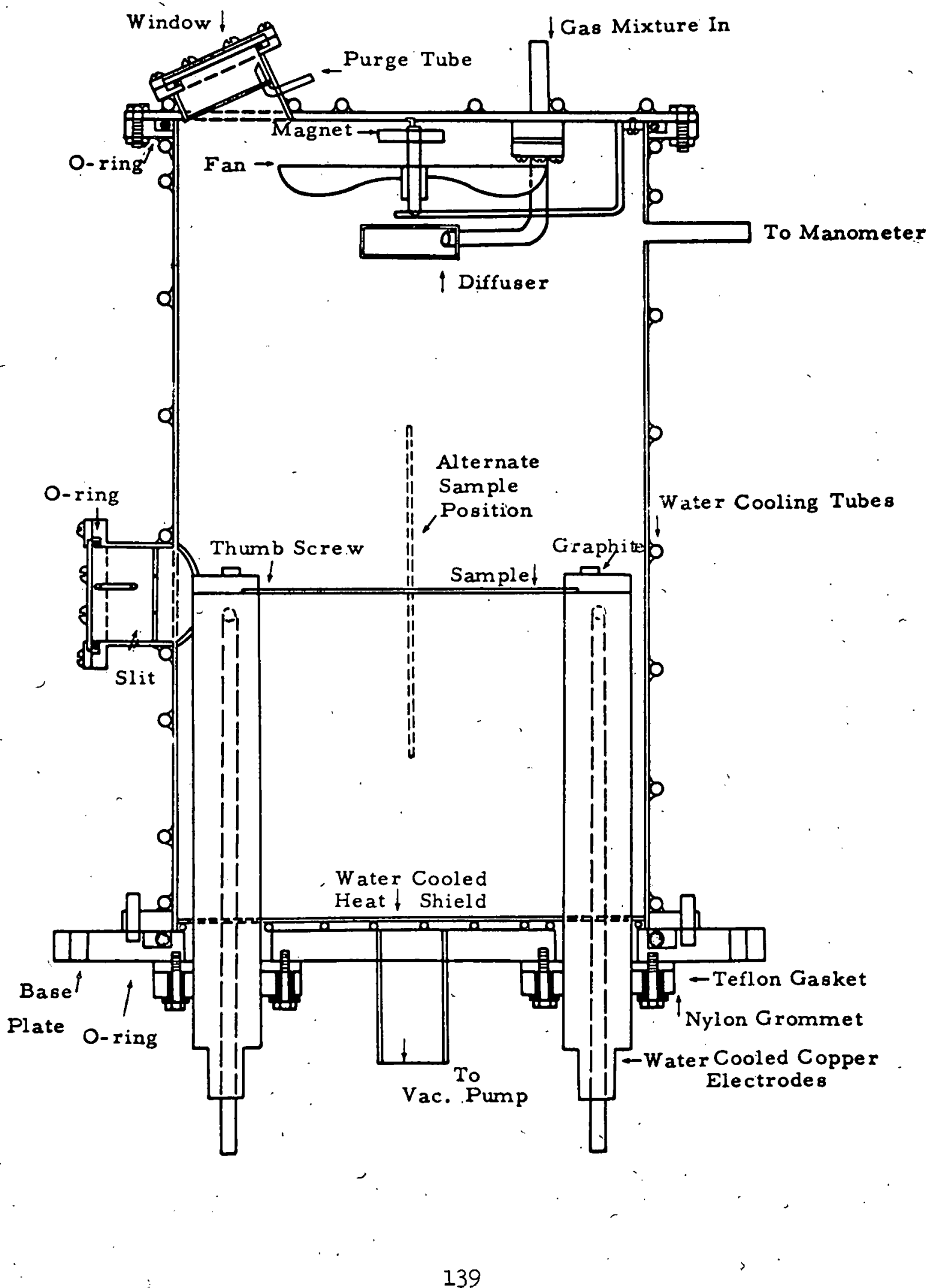


Fig. II

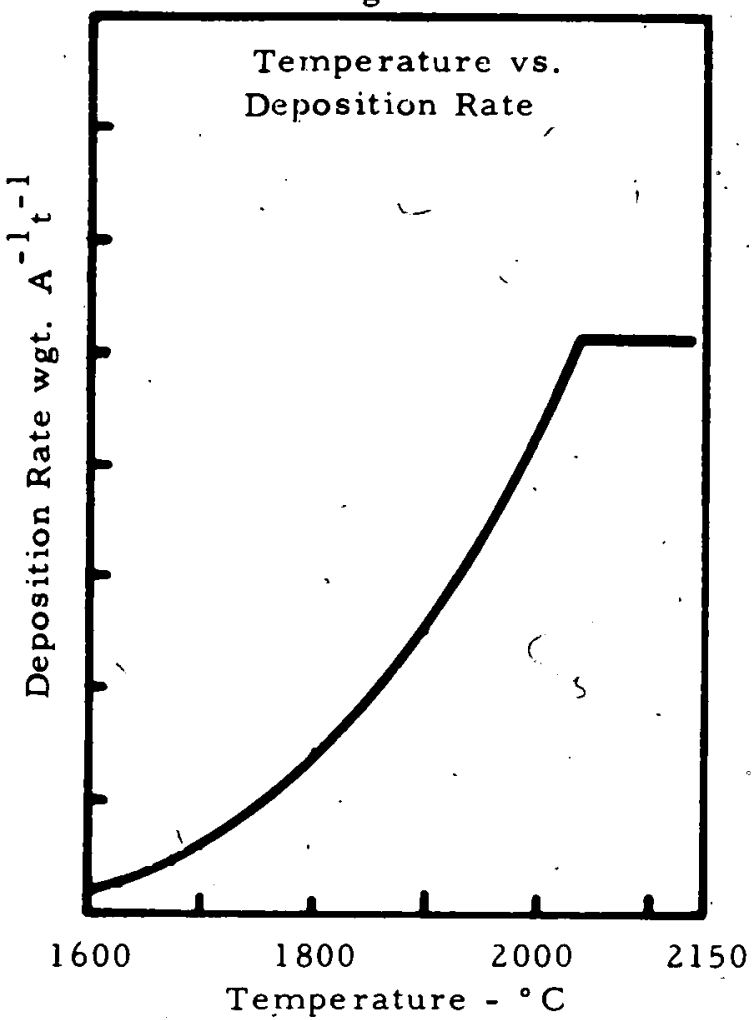

Fig. IV

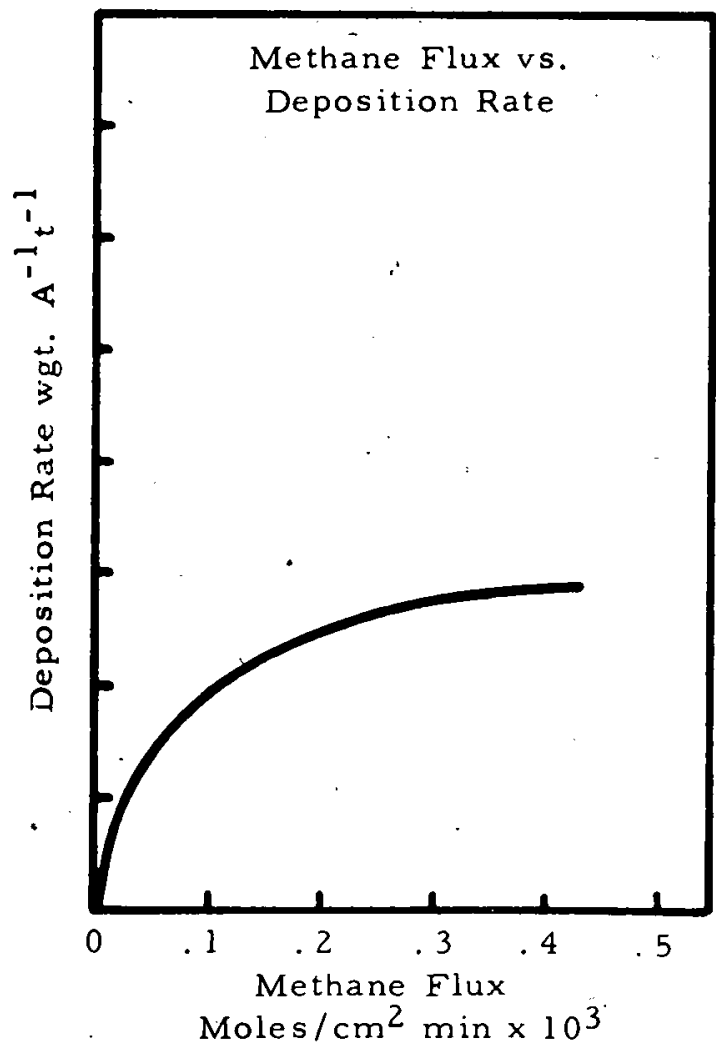

Fig. III

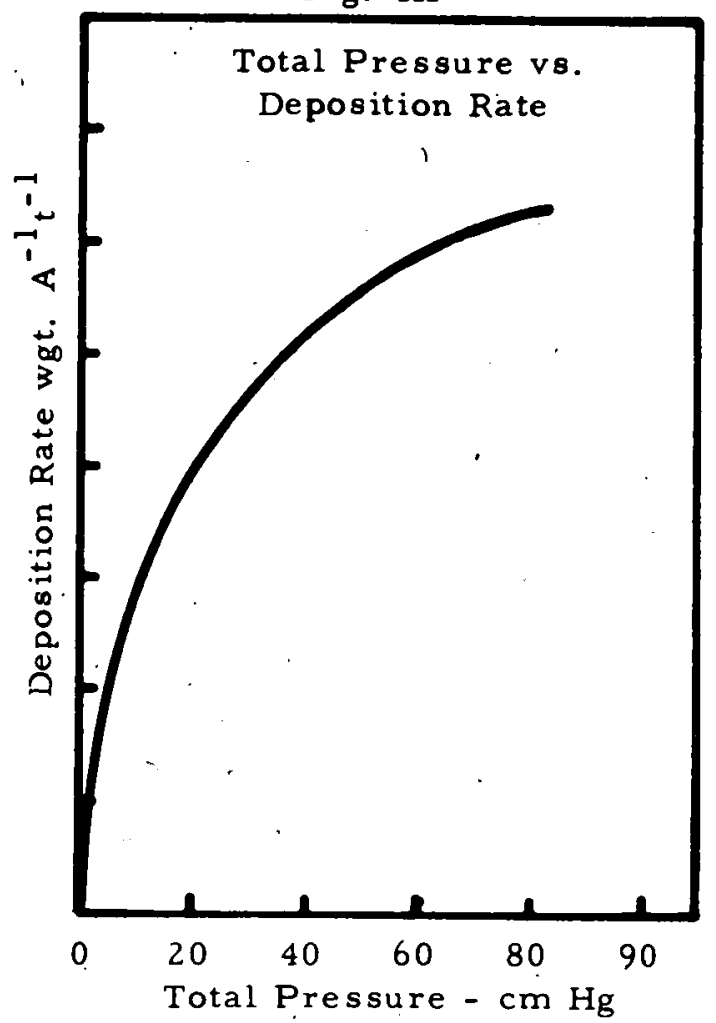

Fig. V

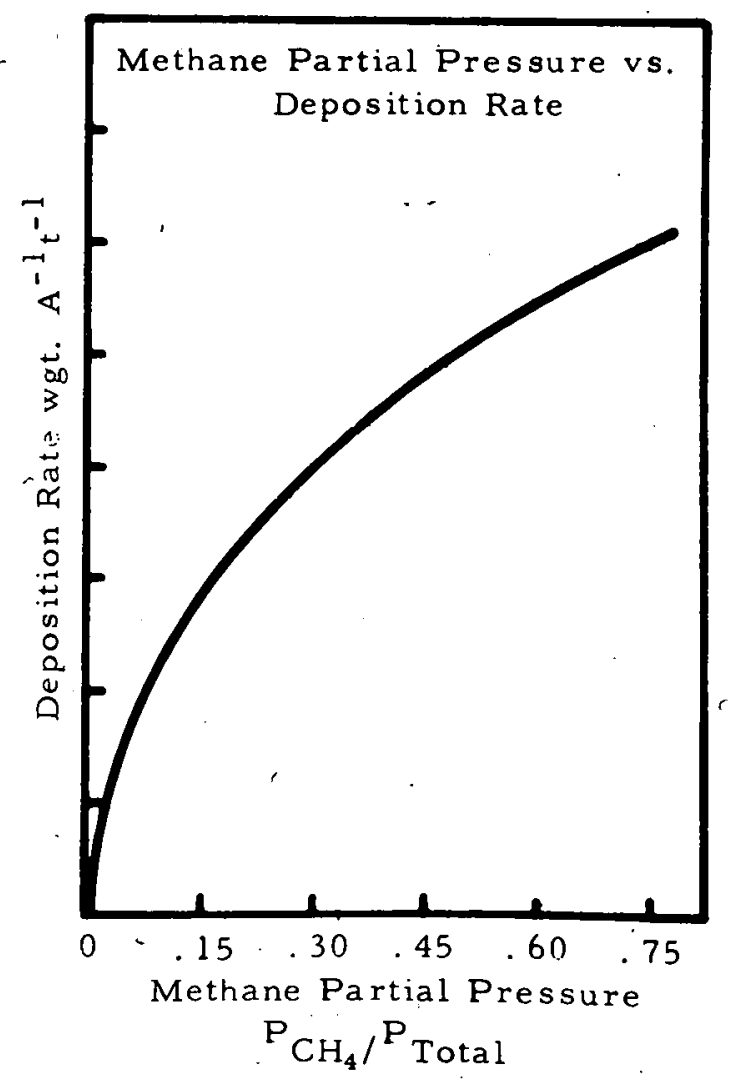


Fig. VI

Fluidized Bed Furnace

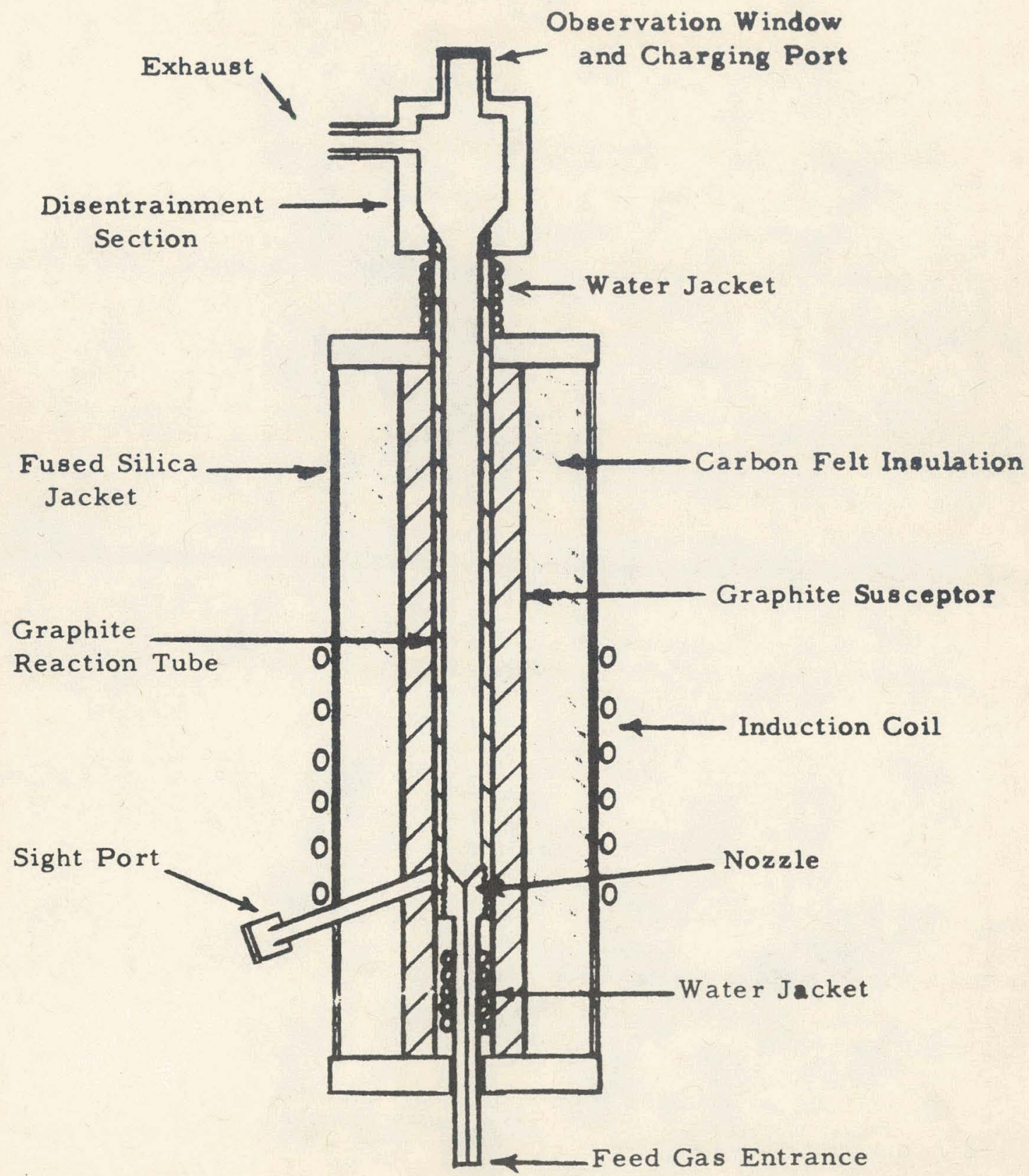




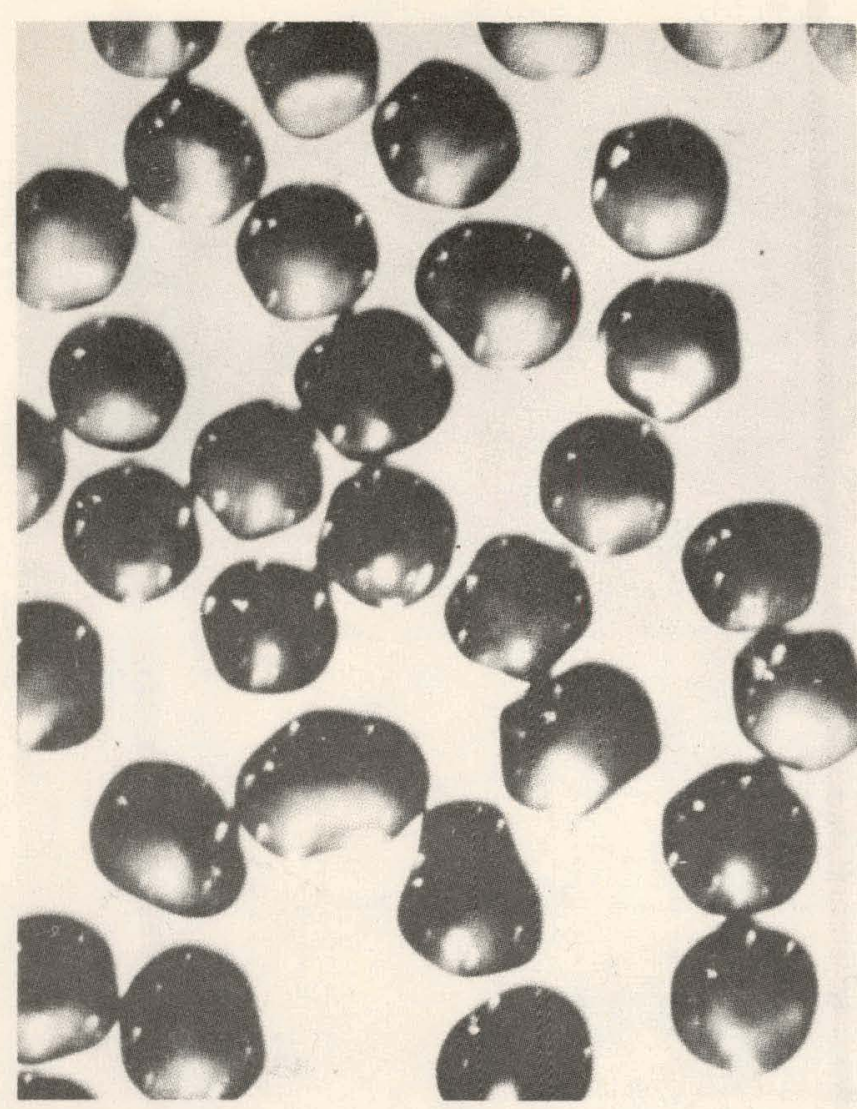

Fig. VII

Typical Non-crystalline Pyrolytic Carbon Coating on $\mathrm{UC}_{2}$ Spheroids

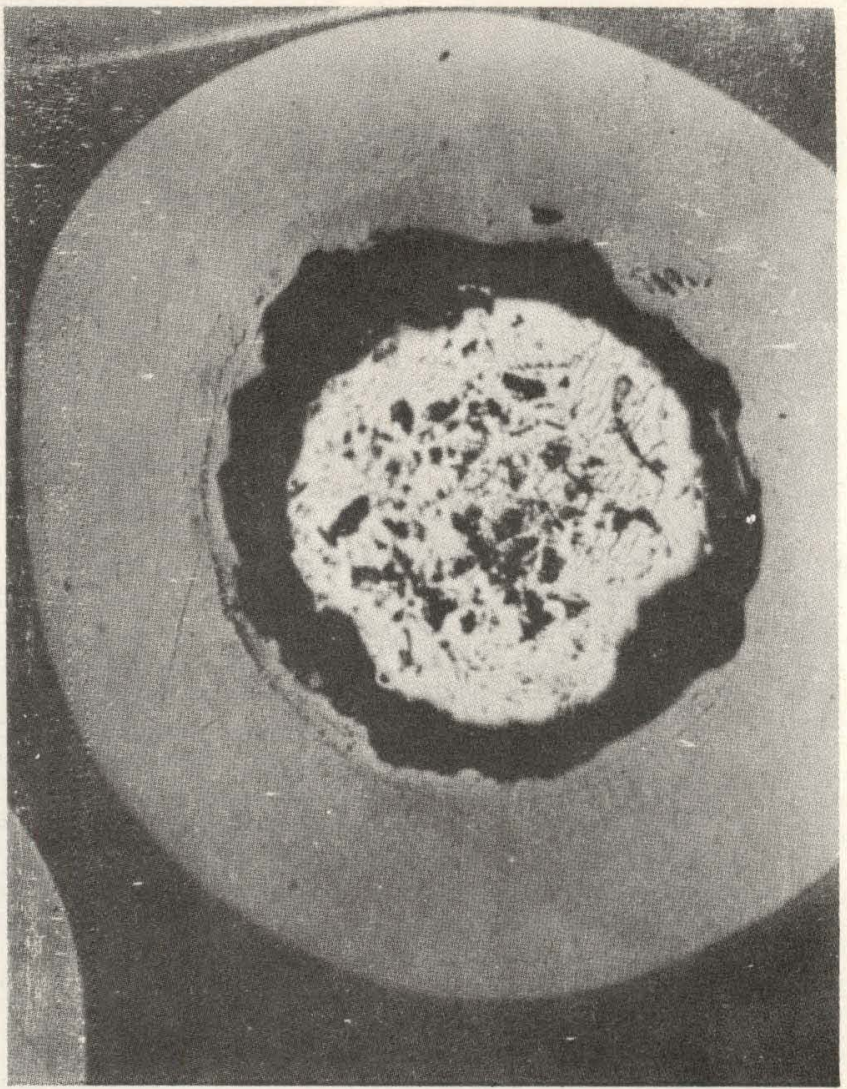

Fig. VIII

Typical Microstructure of Non-crystalline Pyrolytic Carbon Coating on $\mathrm{UC}_{2}$ Spheroids $200 \mathrm{X}$ 


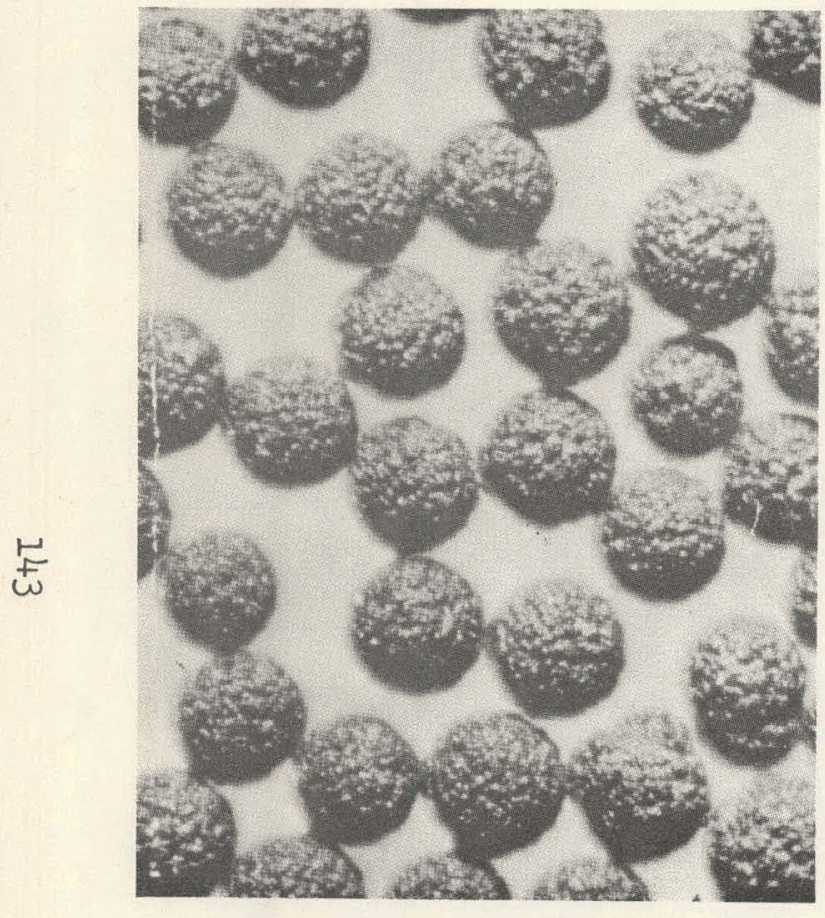

Fig. IX

Pyrolytic Graphite Coated $\mathrm{UC}_{2}$ Spheroids

Large Grain Size $30 \mathrm{X}$

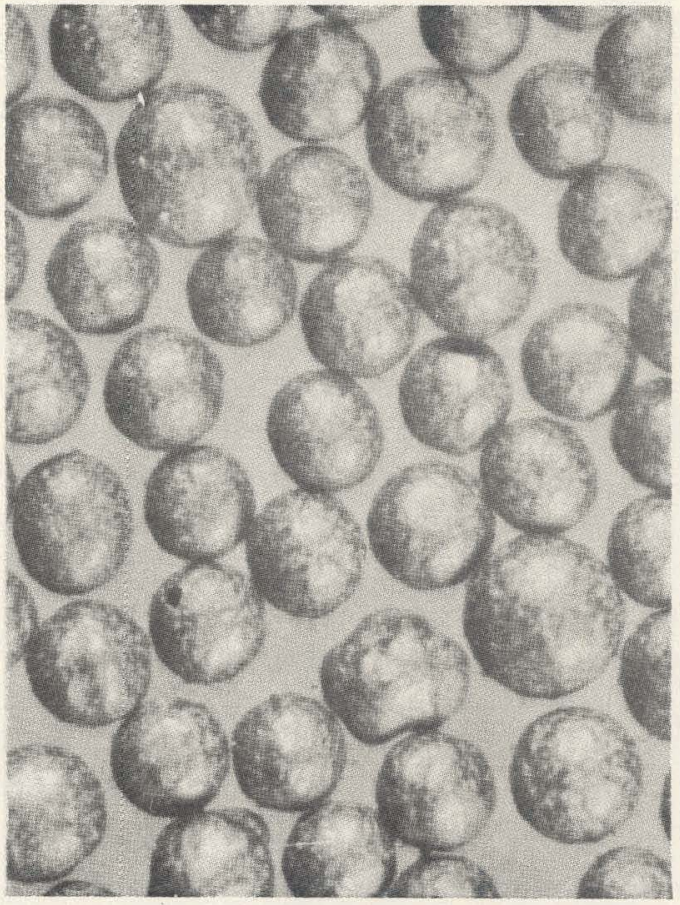

Fig. $\mathrm{X}$

Pyrolytic Graphite Coated $\mathrm{UC}_{2}$ Spheroids

Intermediate Grain Size $30 \mathrm{X}$

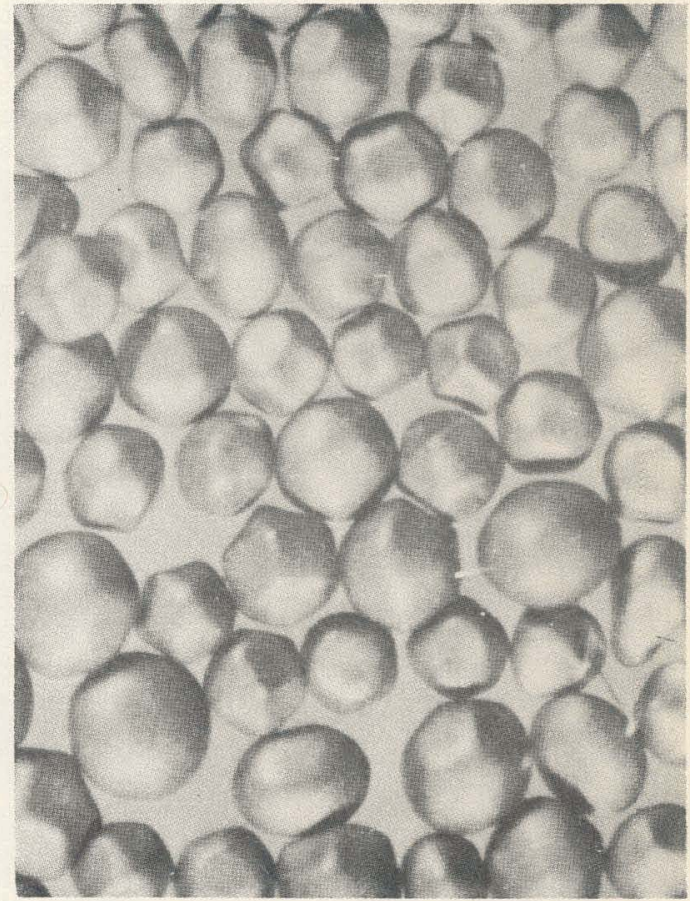

Fig. XI

Pyrolytic Graphite Coated $\mathrm{UC}_{2}$ Spheroids

Small Grain Size $30 \mathrm{X}$ 


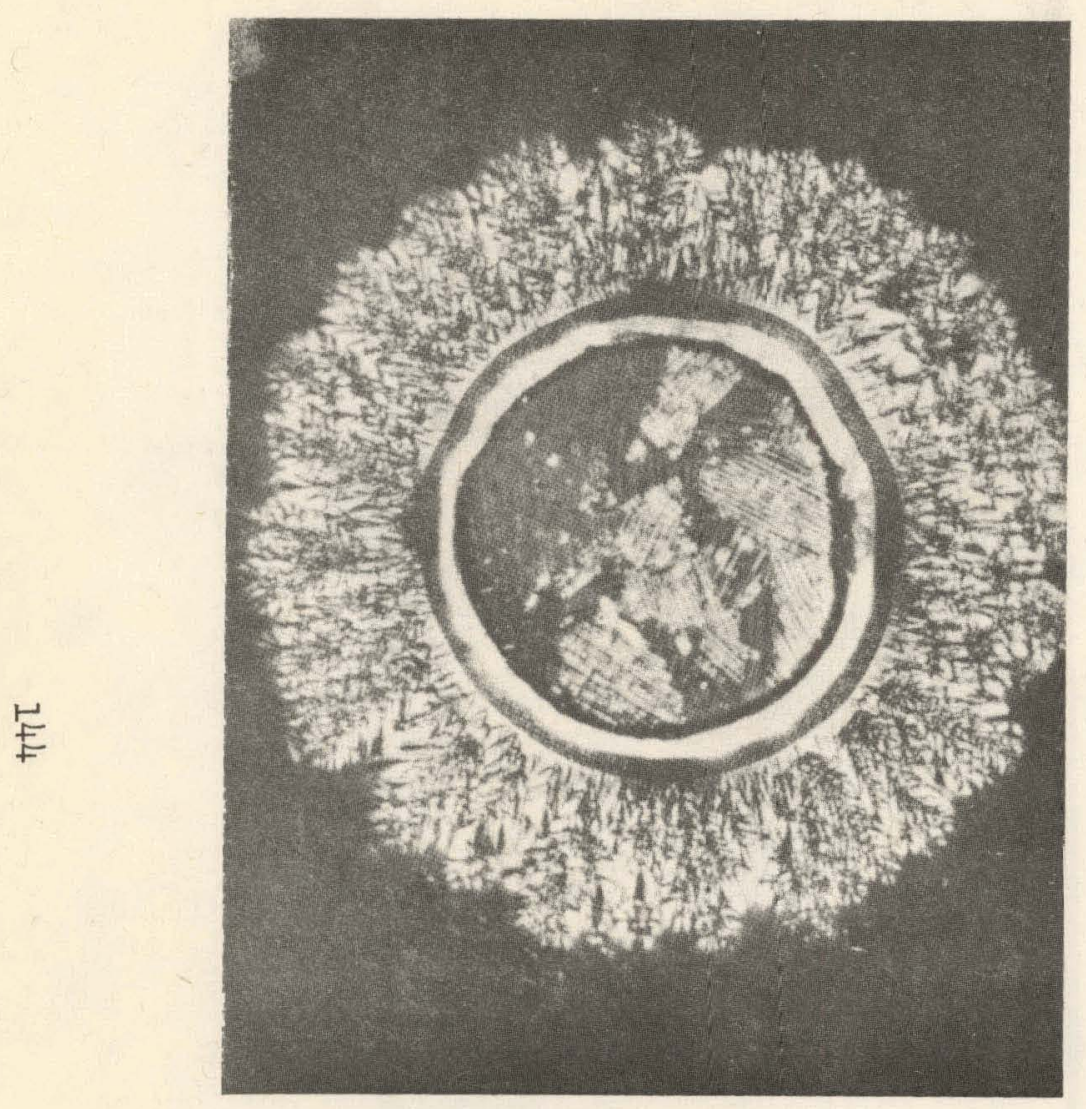

Fig. XII

Typical Microstructure of

Duplex-Columnar Pyrolytic

Graphite Coating on $\mathrm{UC}_{2}$ Spheroids Large Grain Size

$200 x$

Polarized Light

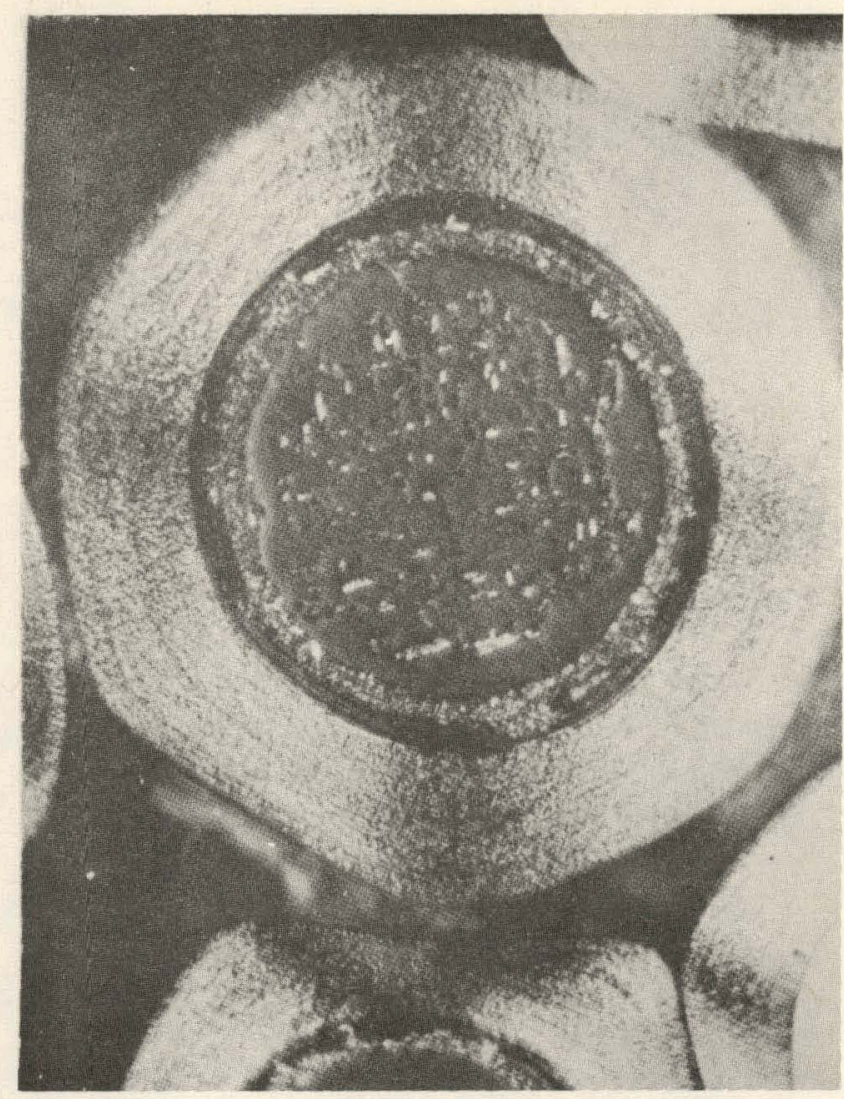

Fig. XIII

Typical Microstructure of

Duplex-Columnar Pyrolytic Graphite Coating on $\mathrm{UC}_{2}$ Spheroids Small Grain Size

$200 x$ Polarized Light 
Fig. XIV

Deposition Temperature Vs. Density
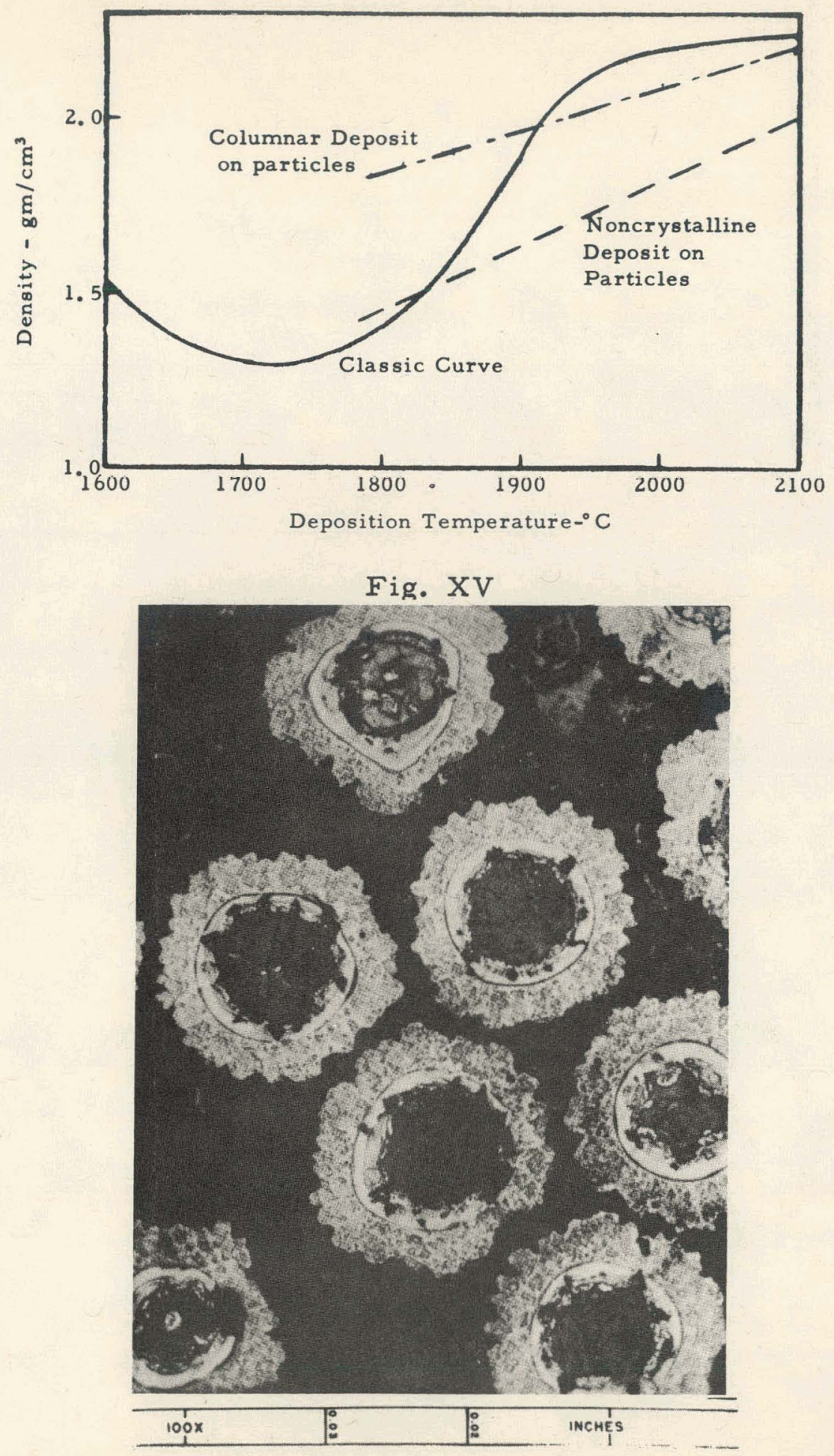

Duplex Columnar Coated $\mathrm{UC}_{2}$ after 5 Atom Per Cent Burnup at $2000^{\circ} \mathrm{F}$ 
Fig. XVI

Coating Time Vs. Coating Thickness

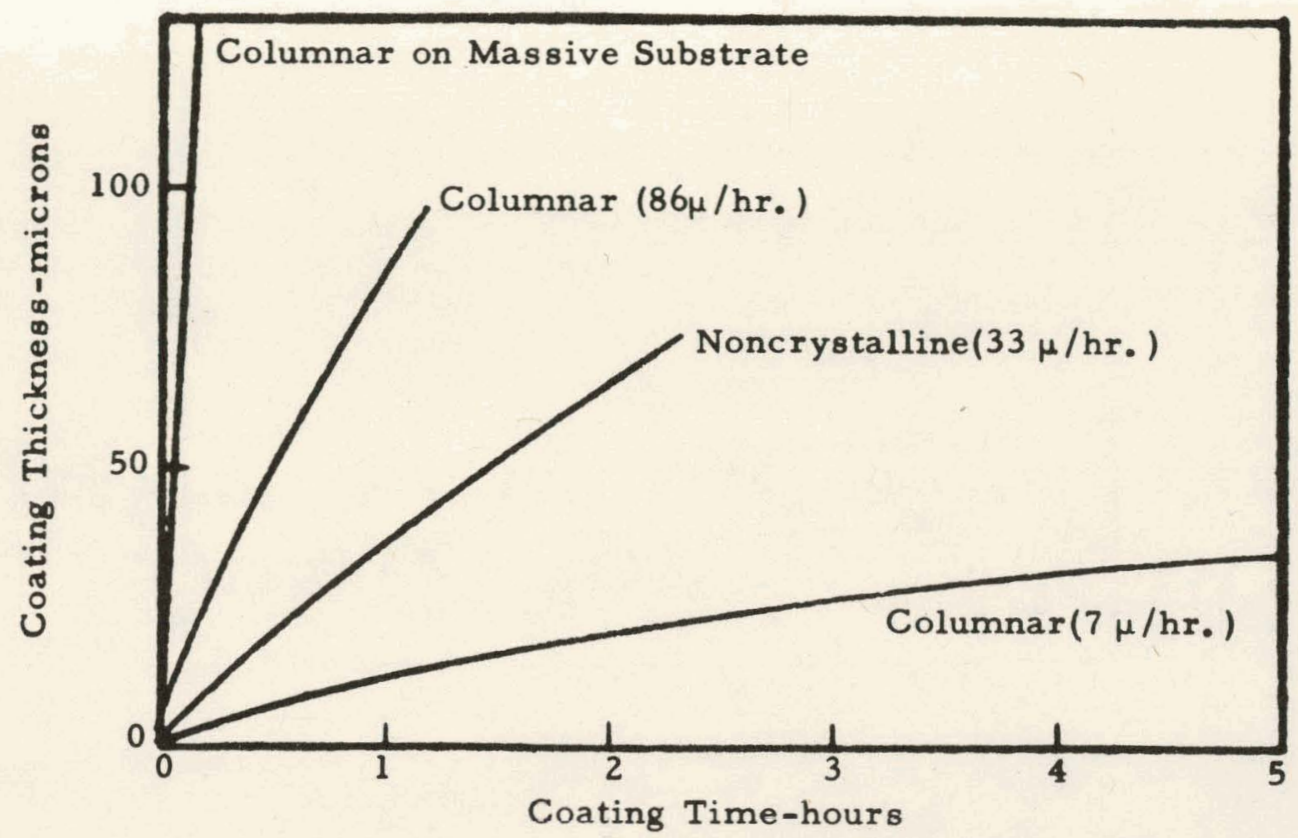

Fig. XVII

Atmosphere Conditions

for Less Crystalline

Coating

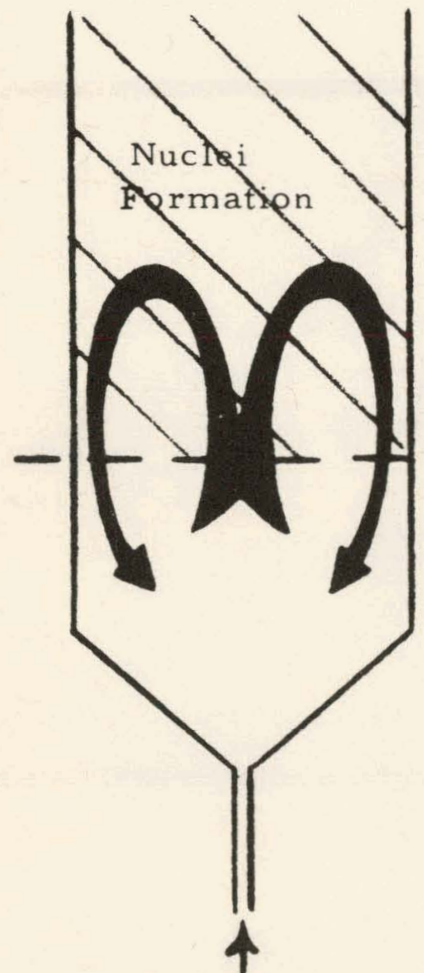

$\mathrm{High} \mathrm{CH}_{4}$

Concentration
Atmosphere Conditions for Highly Crystalline Coating
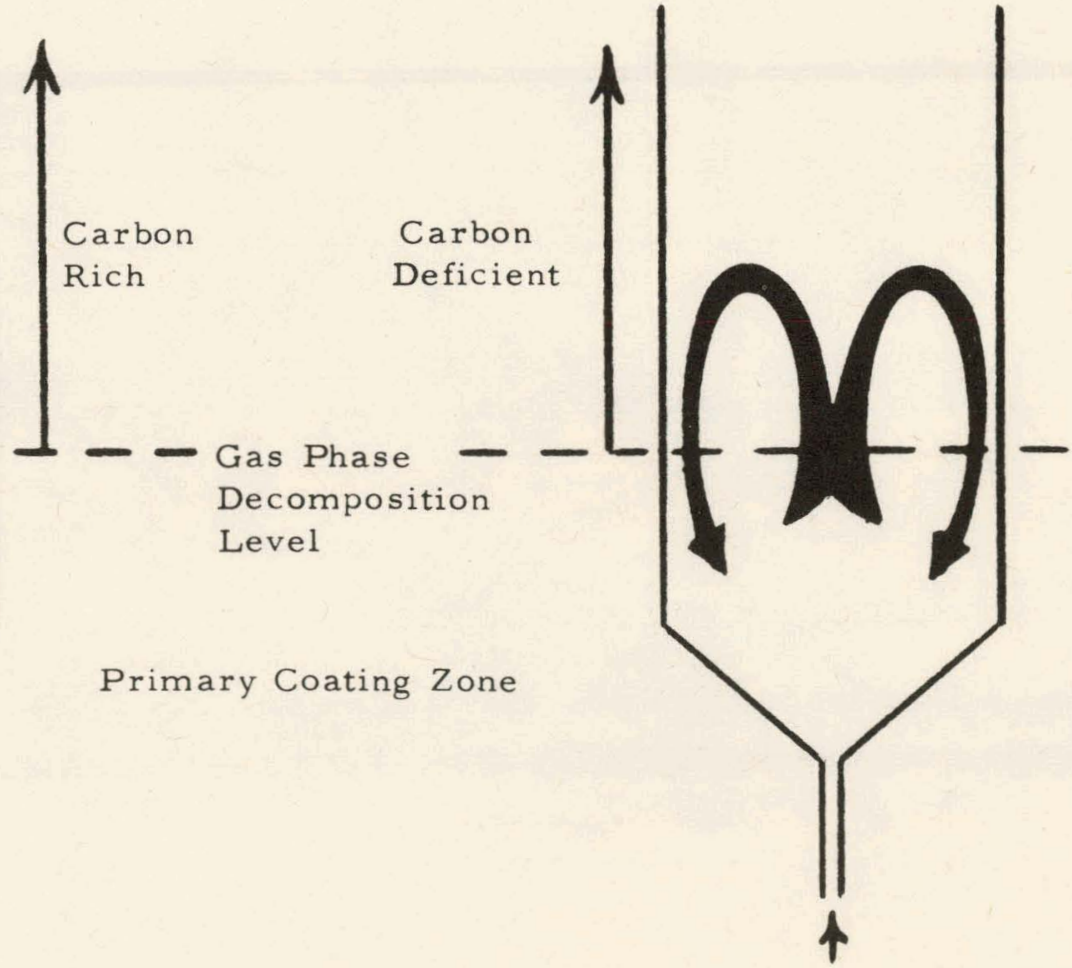

Low $\mathrm{CH}_{4}$

Concentration 
Fig. XVIII

Particle Surface Area Vs. Cone Length

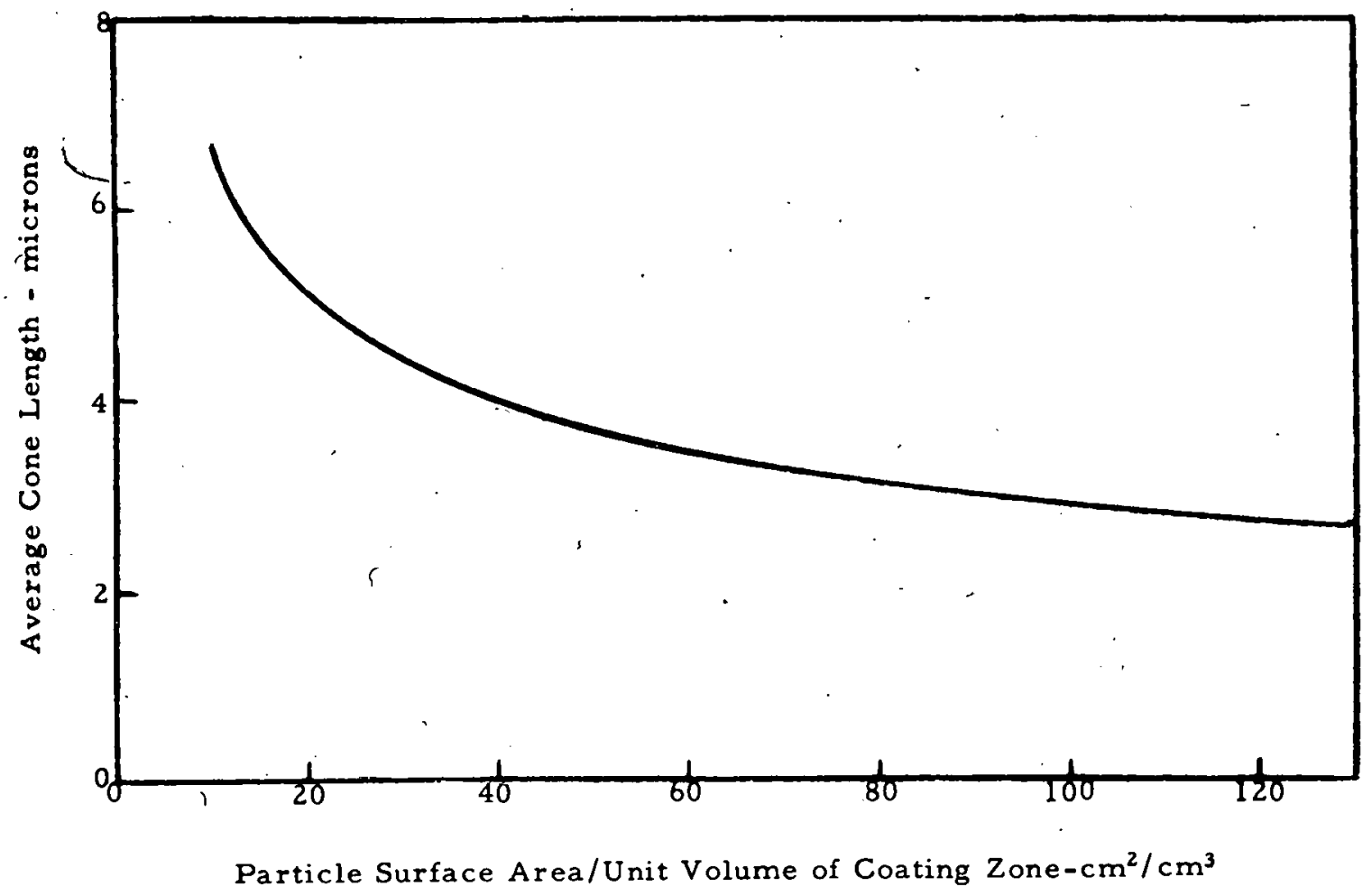




\section{References}

1) A. G. R. Brown and W. Watt, "The Preparation and Properties of High-Temperature Pyrolytic Carbon, "Conf. on Industrial Carbon and Graphite, Soc. Chem. Ind., London (Sept. 1957)

2) R. O. Grisdale, A. C. Pfister and W. van Roosbroeck, "Pyrolytic Film Resistors: Carbon and Borocarbon," Bell System Technical Journal 30:271-314 (April 1951)

3) L. Meyer and R. Gomer, "Energy Exchange between Cold Gas Molecules and a Hot Graphite Surface," J. Chem. Phys. Vol. 28, No. 4, 617-622 (April 1958)

4) A. G. R. Brown, P. Clark, J. Eastabrook, "Some Interésting Properties of Pyrolitic Carbon," J. Less-Common Metals, 1, 94-100 (1959)

5) R. J. Diefendorf, "The Deposition of Pyrolytic Graphite," Tenth Annual Reunion of the Societe de Chimie Physique, Paris, (June 1960)

6) R. O. Grisdale, "The Formation of Black Carbon," J. Applied Phys. Vol: 24, No. 9 (Sept. 1953)

7) P. H. Higgs, R. L. Finicle, R. J. Bobka, E. J. Seldin, and K. J. Zeitsch, "Studies of Graphite Deposited by Pyrolytic Processes," Technical Report Number WADD TR 61-72 Vol. XXXVII, 3-13, (July 1963) To be issued

8) W. W. Lozier and M. B. Manofsky; "Properties and Performance of Pyrolytic Graphite," Conf. on Mechanical Properties of Engineering Ceramics, North Carolina State College, Raleigh, (March 1960)

9) J. Pappis, "The Mechanical Properties of Pyrographite, "Conf. on Mechanical Properties of Engineering Ceramics, North Carolina State College, Raleigh (March 1960)

10) G. L. Matheson, W. A. Herbst and P. H. Holt, 2nd, "Characteristics of Fluid-Solid Systems, "Industrial and Engineering Chemistry, Vol. 41, (1949)

11) F. A. Zenz and D. F. Othmer, "Fluidization and Fluid-Particle Systems," Reinhold Publishing Corporation, 1960

12) S. A. Taylor, "Fluidization Studies of $\mathrm{UC}_{2}$ Spheroids, "Internal Report Parma Research Center, Carbon Products Division 
PREPARATION AND EVALUATION OF CARBON-COATED FUEL PARTICLES

by

M. F. Browning, A. C. Secrest, V. M. Secrest, R. B. Landrigan, and J. M. Blocher, Jr.*

\section{ABSTRACT}

The preparation, characterization, and performance of various types of pyrolytic carbon (PyC)-coated fuel particles are discussed. Most of the coatings studied have been deposited by pyrolysis of either methane or acetylene in a fluidized bed of the fuel particles at temperatures between 950 and $2000^{\circ} \mathrm{C}$. However, the preparation of coatings by pyrolysis of other carbon. compounds is also reported. Three types of coatings have been prepared: (1) monolithic - all PyC, (2) duplex-layers of porous and dense PyC, and (3) composite - layers of PyC and other materials. The outof-pile characterization of these materials is presented along with a brief summary of their in-pile performance. All three types of coating have shown good out-of-pile integrity, but the duplex and composite coatings have given superior in-pile performance. The coating procedures are described, and process variables are correlated with deposition rate and coating properties.

Battelle Memorial Institute, Columbus 1, Ohio 
Pyrolytic carbon is potentially the most useful coating for nuclear fuel particles. The value of its use as a reaction barrier has been already demonstrated in permitting the handling of mixed thoriumuranium carbide particles in the atmosphere without danger of hydrolysis. $(1,2)$ The requirements for its use to retain fission products are now being worked out, and indications point to ultimate widespread adoption of pyrolytic carbon coatings for this purpose.

Pyrolytic carbon can be easily applied by pyrolysis of hydrocarbons in a fluidized bed of the nuclear fuel particles. The coating is thus inexpensive and, at the same time, constitutes a moderating material compatible with the graphite matrix common to many current gas-cooled reactor designs.

In the work to be described here ${ }^{(3)}$, both uranium dicàrbide and uranium dioxide particles in the range of 50 to $350 \mu$ in diameter have been coated. Although $\mathrm{UO}_{2}$ in contact with graphite normally starts to react to release carbon monoxide at temperatures of about 1200 to $1300^{\circ} \mathrm{C}$, encapsulation of the particles in pyrolytic carbon prevents escape of the carbon monoxide, and no reaction occurs. The pressure of carbon monoxide in equilibrium with $\mathrm{UO}_{2}, \mathrm{UC}_{2}$, and carbon does not reach one atmosphere until about $1900^{\circ} \mathrm{C}$, and coatings of nominal thickness may even be expected to withstand the 10-atm. pressure calculated to be developed around $2200^{\circ} \mathrm{C}$. The fluidized-bed approach was used in this work because it has been found to be ideally suited to the uniform coating of small particles, for example less than $400 \mu$, by chemical vapor-deposition reactions: 
Several reactions for the vapor deposition of PyC have been investigated to varying extents. These are the pyrolysis of benzene, toluene, propane, carbon tetrachloride, hexachlorobenzene, acetone, methane, and acetylene. Coatings deposited from the hydrocarbons of this group were. similar in most respects. However, coatings obtained from the halides were porous over the limited range of conditions explored. Methane and acetylene were selected as the reactants for most of the present work because they could be conveniently metered as gases, they pyrolyzed readily at conveniently low temperatures, and they produced coatings with good integrity. Acetylene is pyrolyzed more rapidly than methane below $1500^{\circ} \mathrm{C}$. Consequently, acetylene was generally used to deposit coatings below this temperature. Methane was used above $1500^{\circ} \mathrm{C}$. because it had less tendency to decompose prematurely and plug the gas inlet of the coating reactor. The equipment used to coat nuclear fuel particles with PyC at temperatures up to $1500^{\circ} \mathrm{C}$. is shown in Figure 1 . The fluidized-bed reactor consists of a one-inch-I.D. mullite tube with an alumina-cement conical bed support. The fluidizing gas, helium, containing the hydrocarbon is introduced into the reactor chamber through a $3 / 64-$ inch hole in the center of the support cone. The cone angle has been varied considerably during this work, but not optimized for each type of bed and set of operation conditions. However, a cone with a relatively sharp angle, $37^{\circ}$, appears to. perform satisfactorily over a wide range of particle characteristics and coating conditions.

The fluidized-bed temperature was controlled in the low-temperature unit by reference to a thermocouple located in contact with the outer reactor wà11. 
Figure 2 shows the equipment used for experimental coating of nuclear fuel particles with PyC at temperatures above $1500^{\circ} \mathrm{C}$. by thermal decomposition of methane. The reactor consisted of a $40^{\circ}$ cone-bottomed 3/.4-inch-I.D. graphite tube which was enclosed in a 5-inch-I.D. Vycor. envelope and insulated with carbon black (Spheron $6 \mathrm{MPC}$ ). To prevent oxidation of the carbon black and graphite reactor, the annulus between the reactor and envelope was purged with helium. The graphite reactor was heated inductively and bed temperatures were measured optically through the $t c_{2}$ of the reactor with the hydrocarbon flow interrupted to avoid soot formation.

Uranium contamination was found to be a problem in pyrolytic carbon coatings prepared at $1600^{\circ} \mathrm{C}$. and above, in spite of the fact that coatings were deposited in two steps with an intermediate clean-up of the reactor. Coated particles prepared at $1600^{\circ} \mathrm{C}$. and above on $\mathrm{UC}_{2}$ invariably showed relatively high $\alpha$-emission which was not significantly reduced by an acid leach, indicating that the uranium was contained in the coating in a form which could not be leached. This factor accounts for the emphasis on coatings prepared below $1500^{\circ} \mathrm{C}$. It is interesting to note that contamination appeared to be considerably greater when $\mathrm{UC}_{2}$ was used as substrate material than when $\mathrm{UO}_{2}$ was used.

At deposition temperatures of 1100 to $1400^{\circ} \mathrm{C}$., soot was deposited on the reactor walls above the fluidized bed. This soot problem was sufficiently severe at times to cause plugging and run termination at $1400^{\circ} \mathrm{C}$. and at growth rates of about $50 \mu$ per hour. Another disadvantage was the tendency of the soot to feed back into the bed during deposition where it could be incorporated in the coatings. The extent to which soot particles 
from the wall have been included in the coatings prepared to date is open to question, and the effects of such inclusions are not completely understood.

A procedure to minimize deposition of soot was preliminarily tested. This consisted of introducing an auxiliary hydrogen stream $(\sim 21 . / \mathrm{min}$.$) into the top of the reactor in the zone where the soot$ collected. This technique has the value of lowering the gas temperature in this zone, regasifying the soot, reducing the partial pressure of the hydrocarbons, and promoting the removal of entrained materials. This procedure successfully minimized the soot deposits.

In the equipment used to deposit coatings above $1500^{\circ} \mathrm{C}$. by the decomposition of methane, plugging of the reactor with soot was less severe than with acetylene. However, considerable care must be taken to hold the vapor inlet to about $900^{\circ} \mathrm{C}$. or below to prevent plugging by premature pyrolysis.

The deposition efficiency of carbon on the particles of the bed is a complex function of a number of variables. Typically, 50 to 70 per cent of the available carbon was deposited on the particles.

- The deposition rate of carbon from acetylene was found to have the dependence on temperature below $1100^{\circ} \mathrm{C}$. expected from a prévious kinetics study by J. H. Oxley and others ${ }^{(4)}$. However, at a coating temperature of $1400^{\circ} \mathrm{C}$, the deposition rate was not as high as would be expected from an extrapolation of the rate data obtained at lower temperature. This suggests that the deposition rate at $1400^{\circ} \mathrm{C}$. was no longer limited by surface kinetics but by depletion of the reactants, a less effective flow pattern, and an increase in soot formation. The $\checkmark$ activation energy calculated from the data of lots prepared at 850 and 
$1100^{\circ} \mathrm{C}$. was $48.5 \mathrm{kcal} . / \mathrm{g}$. mole, which is essentially equal to the value $(51.0 \pm 1.8 \mathrm{kcal}$.$) obtained in the earlier work in the temperature range$ 850 to $1095^{\circ}$ C.

Carbon-coated particles presently being evaluated can be divided into the four types shown in Figures 3 through 6 .

1. Monolithic - coatings consisting of a single type of pyrolytic carbon.

2. Duplex - coatings consisting of alternate layers of dense and porous pyroIytic carbon.

3. Composite - coatings consisting of two or more layers of dissimilar materials.

4. Void - a type of composite coating containing an annular void as one of the components.

The particles with monolithic coatings were prepared to evaluate the different types of PyC deposits characteristic of various coating parameters and reactants.

The purpose of duplex, composite, and void-coatings is the provision of coating structures more resistant than monolithic coatings to fission-fragment damage and/or to substrate swelling. This was to be accomplished by (1) using an inner layer inherently more resistant to fission-recoil damage than the bulk of the coatings, (2) providing a means to prevent stress propagation from recoil damage through the entire coating, and/or (3) providing, by means of a void in the coating or a 
porous substrate, for swelling of the substrate and/or areas damaged by fission fragments without cracking the outer she11.

Microscopic examination of sectioned PyC coatings revealed two major types of structure termed "laminar" and "columnar". Examples of these are shown in Figures 4 and 7 . In several coatings no structure is clearly discernible, and in others a mixture of columnar and laminar structure can be seen. It should be noted that the units of columnar structure, some extending throughout the coating thickness, are not single grains as they might seem. As pointed out by Coffin (5), the "growth cones" of pyrolytic carbon are the result of the intersection of uniform and uninterrupted growth around adjacent surface asperities.

When acetylene was used as the source of carbon, no predominately columnar or laminar coatings were obtained at deposition temperatures between 1100 and $1300^{\circ} \mathrm{C}$. in the range of deposition rates explored. No sharp transition is apparent between the columnar and laminar structures at a precise deposition rate, but at $1400^{\circ} \mathrm{C}$. predóminately laminar coatings were obtained at rates greater than about $40 \mu$ per hour, and predominately columnar coatings were obtained at rates of less than about $10 \mu$ per hour.

The mechanism by which columnar and laminar structures are formed is not completely understood. However, it has been observed that the return of loose soot to the bed by artificial means made the laminar structure more predominant. This suggests that the laminar deposits are formed as a result of cycling of individual particles from top to bottom of the reactor. This would lead to periodic interruptions in the over-all growth pattern by accretion of soot, either fed back from the reactor walls, 
or generated in the upper section of the fluidized bed by homogeneous gas-phase nucleation. Another factor which may contribute to periodic interruption of the growth process and thus to lamination is the temperature cycle that individual particles experience in contacting the cooler gas at the base of the reaction zone. The significance of this second factor has not yet been determined. The columnar and laminar structures obtained in PyC coatings prepared from methane were much less clearly defined than were those of coatings deposited from acetylene at $1400^{\circ} \mathrm{C}$.

The various PyC coaling structures inentioned above have been studied only briefly by electron microscopy. E'lectron micrographs of selected specimens are hown in Figures 8, 9, and 10. Figures 8 and 9 show typical $1400^{\circ}$ C. columnar and laminar coatings, respectively, and Figure 10 shows a coating deposited at $1650^{\circ} \mathrm{C}$. from methane at its junction with a $1400^{\circ} \mathrm{C}$. structureless coating from the same reactant. The electron micrographs are of as-produced materials which were sectioned and polished before replication.

Electron micrographs of the columnar coating (e.g., Figure 8) did not show a definite structure as did the photomicrograph of this coating at a much lower magnification. This is because the growth pattern of columnar coatings, observable with a light microscope, is of a longer range nature than would be detectable at these high magnifications. The coatings appeared to be relatively free of voids. This would indicate that lessthan-theoretical densities (e.g., $1.7 \mathrm{~g} . / \mathrm{cc}$. in this case), must be accounted for by the uniform dispersion of low-density inclusions or voids, less than about 0.05 micron in size. 
The structural features of laminar coatings observable by light microscopy are also detectable in the electron'micrograph, Figure 9. The relatively coarse laminations noted at lower magnification appear to consist of groups of finer laminations, possibly less than $0.1 \mu$ in thickness. If such coatings are composed of alternate layers of a hard dense material and a softer more porous material, the polishing operation would be expected to develop the observed structure by abrading away more rapidly the softer layer. The lower density of this coating ( $\left.1.5 \mathrm{g.} / \mathrm{cc}_{.}\right)$ relative to the, columnar type, indicates that the softer material composing the laminations must be of even lower density.

The electron micrograph of the coating prepared at $1650^{\circ} \mathrm{C}$. (Figure 10), which shows many discontinuities in the surface, is consistent with the expected presence of larger soot particles in the deposited material. A more comprehensive study of, the PyC coatings, both as-polished and after etching, w111 be required before a-detailed inter= pretation of these electronmicrographs can be made.

Limited data on the relationship of coating temperature and coating density are presented in Figure 11. The density of laminar PyC coatings appears to reach a minimum of about 1.50 between 1400 and $1500^{\circ} \mathrm{C}$. Columnar coatings applied at a lower rate are relatively more dense. This is consistent with the data of Diefendorf ${ }^{(6)}$ for pyrolytic carbon deposited on extended surfaces at varying rates, and the postulate that soot inclusions lead to low density.

Highly porous coatings have been prepared, but techniques of measuring their bulk density have not yet been developed. Consequently, their porosity is best approximated by calculations from coating thickness 
and weight increase. For example, a coating prépared from $0.5 \mathrm{~atm}$. acetylene in helium at a rate of about $500 \mu / \mathrm{hr}$. at $1400^{\circ} \mathrm{C}$. was calculated to have a density of $0.99 \mathrm{~g} . / \mathrm{cm}^{3}$.

A method has been devised to determine relative hardness of PyC coatings. In general, it consists of determining the penetration of a pyramidal knoop indenter under a 10-gram load. Since deformation is within the elastic limit of the material, and the indenter does not leave a permanent impression in the coating, the equivalent elastic hardness was determined from the dimension of an impression left in a thin film of soot applied to the particle surface. For convenience, penetrations are reported as equivalent Knoop hardness numbers. It can be noted in Figure 12 that the hardness decreases with coating temperature. This is taken to indicate an increase in the long-range ordering of the deposits with an increase in coating temperature. This is further indicated by the hardness of the .

TABLE 1. TYPICAL HARDNESS OF PyC COATINGS

\begin{tabular}{|c|c|}
\hline Type of Coating & $\begin{array}{c}\text { Equivalent } \mathrm{KHN}, \\
(10-\mathrm{g} \cdot 1 \text { oad })\end{array}$ \\
\hline Laminar coatings from $\mathrm{C}_{2} \mathrm{H}_{2}$ at $1400^{\circ} \mathrm{C}$. & 142 \\
\hline Columnar coatings from $\mathrm{C}_{2} \mathrm{H}_{2}$ at $1400^{\circ} \mathrm{C}$. & 106 \\
\hline Coatings from $\mathrm{CCl}_{4}$ at $1400^{\circ} \mathrm{C}$. & 62 \\
\hline Columnar coatings from $\mathrm{CH}_{4}$ at $1400^{\circ} \mathrm{C}$. & 101 \\
\hline Laminar coatings from $\mathrm{C}_{2} \mathrm{H}_{2}$ at $1400^{\circ} \mathrm{C}$. & 112 \\
\hline Coatings from $\mathrm{C}_{2} \mathrm{H}_{2}$ at $950^{\circ} \mathrm{C}$. & 231 \\
\hline Coatings from $\mathrm{C}_{2} \mathrm{H}_{2}$ at $1100^{\circ} \mathrm{C}$. & 215 \\
\hline Coatings from $\mathrm{CH}_{4}$ at $1600^{\circ} \mathrm{C}$. & 87 \\
\hline
\end{tabular}


laminar coatings as compared to the more ordered columnar structure. The hardness of coatings prepared from various carbon sources were similar except for the deposit from $\mathrm{CCl}_{4}$ which appeared to be porous.

The hardness data on coated particles are as yet very limited, so the ultimate value of hardness measurements to obtain useful and unequivocal information has yet to be realized.

We shall now return to the question of coating integrity and the potential of these coatings for fission-gas retention.

Prior to in-pile study, individual lots of coated particles are subjected to a series of out-of-pile screening tests to ascertain the coating integrity. These include mićroscopic examination, acid leach, heat treatment, alpha emission, and $\mathrm{Xe}^{133}$ release on postirradiation heating. In addition, the coatings are usually characterized as to physical properties.

In genera1, less than $10 \mathrm{ppm}$. of the contained uranium is removed from a sample in an 8-hour leach in $8 \mathrm{~N} \mathrm{HNO}_{3}$ at $90^{\circ} \mathrm{C}$. The acid-leach resistance of PyC coatings was generally not affected by a heat treatment at $1250^{\circ} \mathrm{C}$. in helium for 48 hours.

In general, the alpha emission of PyC-coated particles indicated less than $2 \mathrm{ppm}$. of the contained uranium homogeneously distributed in the coating.

After the various lots have satisfactorily passed the out-ofpile screening tests, they are submitted for a determination of their Xenon $^{133}$ release in postirradiation heating at $1300^{\circ} \mathrm{C}$ : after an integrated exposure of $1.8 \times 10^{15}$ nvt. The releases have been typically less than 1 ppm. Results of this kind give assurance that the results of extended radiation will not be clouded by the presence of as-produced cracks or uranium contamination in the coating. 
Carbon-coated particles have been studied in-pile in both static and sweep-gas systems. Results of this continuing program have been reported recent $1 y$ (7).

In general, the in-pile results have indicated that specimens with monolithic pyrolytic carbon coatings fail relatively rapidly in

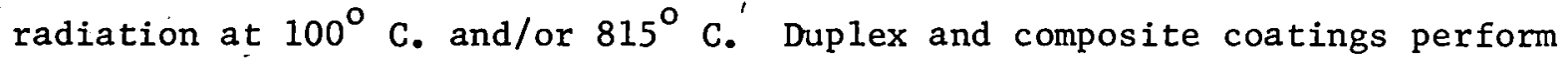
much more satisfactorily at both temperatures, and, at present, specimens with duplex coatings consisting of laminar. PyC overlaid with columnar $\mathrm{PyC}$ and composite coatings containing $\mathrm{PyC}$ and $\mathrm{Al}_{2} \mathrm{O}_{3}$ have undergone a burn-up of about 4 per cent with a Xenon ${ }^{133}$ release of less than $10^{-8}$ ppm. of that generated. Workers at $\mathrm{ORNL}^{(8)}$ have taken duplex coatings to 24 per cent burn-up at 1500 to $1700^{\circ} \mathrm{F}$ with marked fission-gas retention.

On the basis of this work and research now in progress in other laboratories, it is certain that pyrolytic carbon-coated nuclear fuel particles will constitute an important segment of future nuclear fuel technology. Coating configurations will vary with individual nuclear reactor design, particularly with the optimization of fuel loading, which limits the permissible coating thickness. Coatings will have to be designed to accomodate differential thermal expansion and differential radiation damage within the permissible coating thickness. Although more,work must be done, it is now clear that durable coating configurations will be permitted within practical limits of reactor design.

The authors gratefully acknowledge the help and advice of many others of the Battelle staff in the progress of this work, and the support of the United States Atomic Energy Commission under Contract No. W7405-Eng-92. 


\section{REFERENCES}

(1) R. W. Dayton, J. H. Oxley, and C. W. Townley, "Battelle Studies of CeramicCoated Particle Fuels", Ceramic Matrix Fuels Containing Coated Particles (Proceedings of a symposium held at Battel le Memorial Institute, November 5 and 6,1962 ), USAEC TID-7654, $\mathrm{p} 10$.

(2) W. V. Goeddel, "Pyrolytic Carbon - Coated Carbide Fuel Particles and Their Use in Graphite Matrix Fuel Elements", Ibid, p 142.

(3) M. F. Browning, et. al, "Coating Fuel Particles with Pyrolytic Carbon", USAEC Report BMI 1643 (August 16, 1963).

(4) J. H. Oxley, Arthur C.' Secrest, Neil D. Veigel, and John M. Blocher, Jr., "Kinetics of Carbon Deposition in a Fluidized Bed", A.I.Ch.E. Journa1, $\underline{7}$ [3], 498-501 (1961).

(5) L. F. Coffin, Jr., "A Note on the Structure-Property Relationships of Pyrolytic Grahpite", paper presented at AIAA Launch and Space-Vehicle Shell Structures Conference, Palm Springs, Calif., April 1-3, 1963.

(6) R. J. Diefendorf, J. Chem. Phys., 57, 815 (1960).

(7) R. J. Burian, N. E. Miller, R. L. Ritzman, and C. W. Townley, "Initial Irradiation Evaluation of Experimenta1 Pyrolytic-Carbon-Coated $\mathrm{UC}_{2}$ and $\mathrm{UO}_{2}$ Fuel Particles", BMI-1628 (April 25, 1963).

(8) W. O. Harris, et. al., "Coated-Particle Fuel Development at Oak Ridge National Laboratory", . Ceramic Matrix Fuels Containing Coated Particles (Proceedings of a Symposium held at Battelle Memorial Institute, November 5 and 6, 1962), USAEC TID-7654. [See also R. L. Finicle and S. A. Taylor, "The Processing Physical Properties and Performance of Pyrolytic Graphite Coated UC2" (this volume)] 


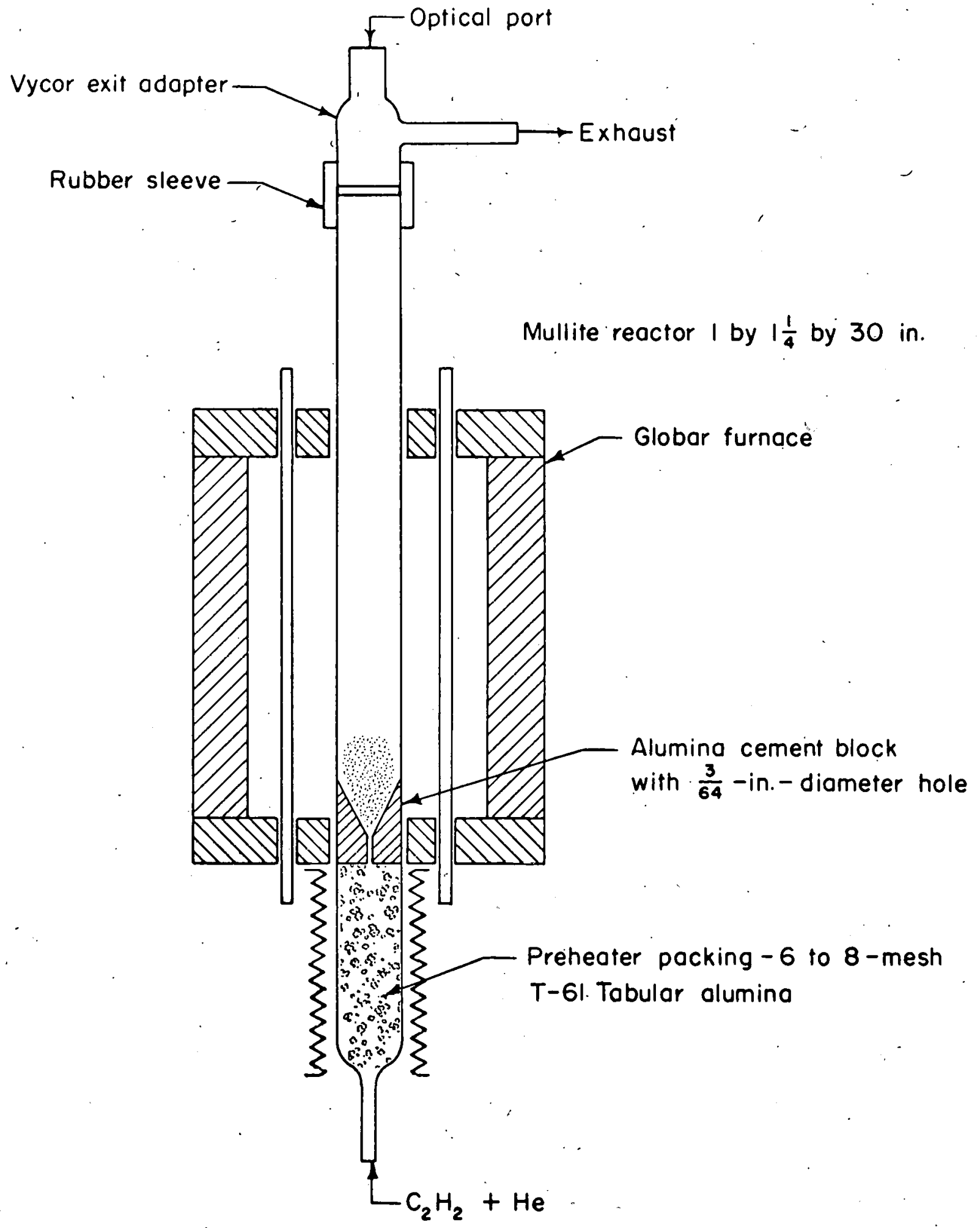

Figure 1. FLUIDIZED-BED REACTOR FOR PYROLYTIC CARBON COATING $<1500^{\circ} \mathrm{C}$, (A 45405). 


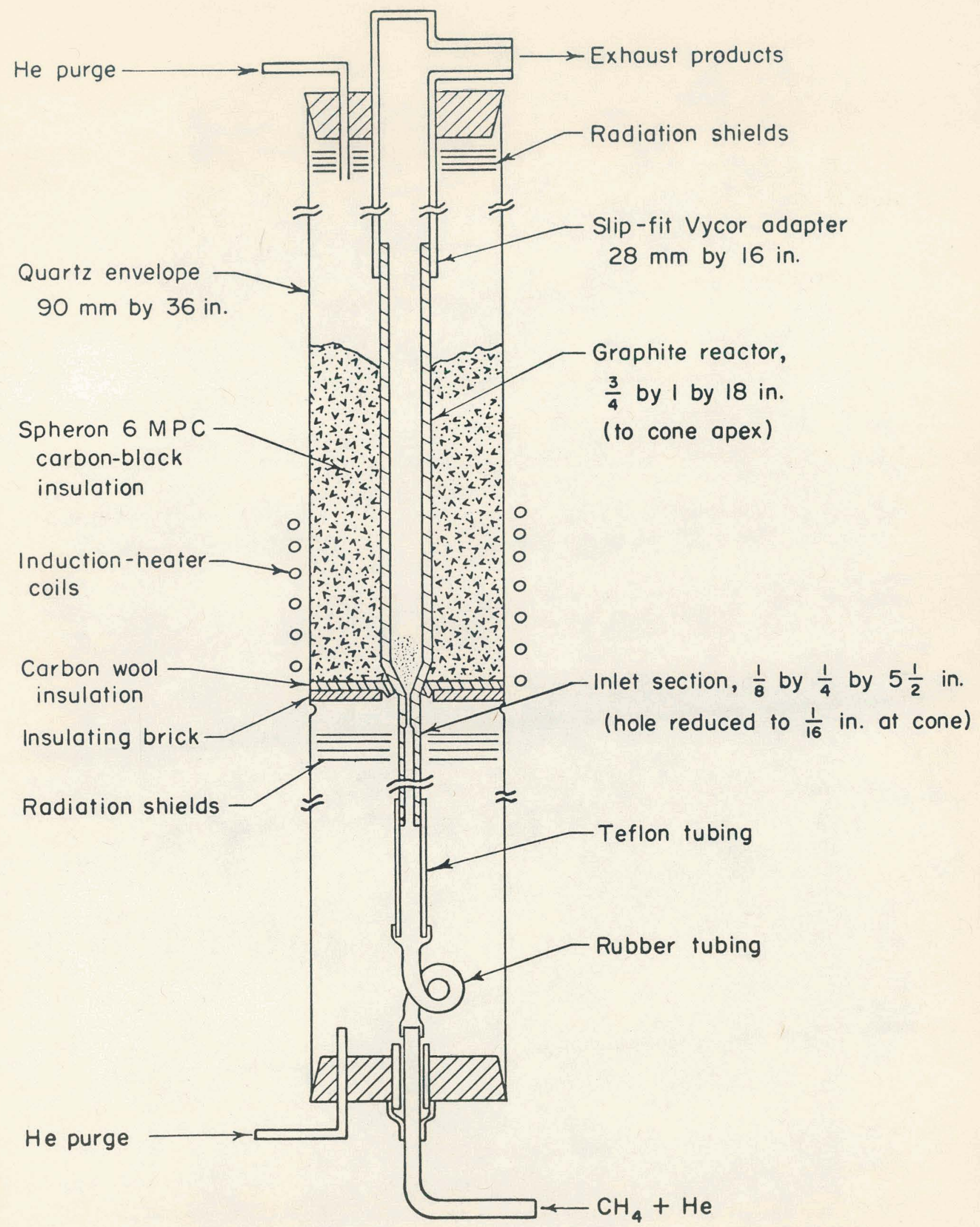

Figure 2. FLUIDIZED-BED REACTOR FOR PYROLYTIC CARBON COATING $>1500^{\circ} \mathrm{C}$, (A45406). 


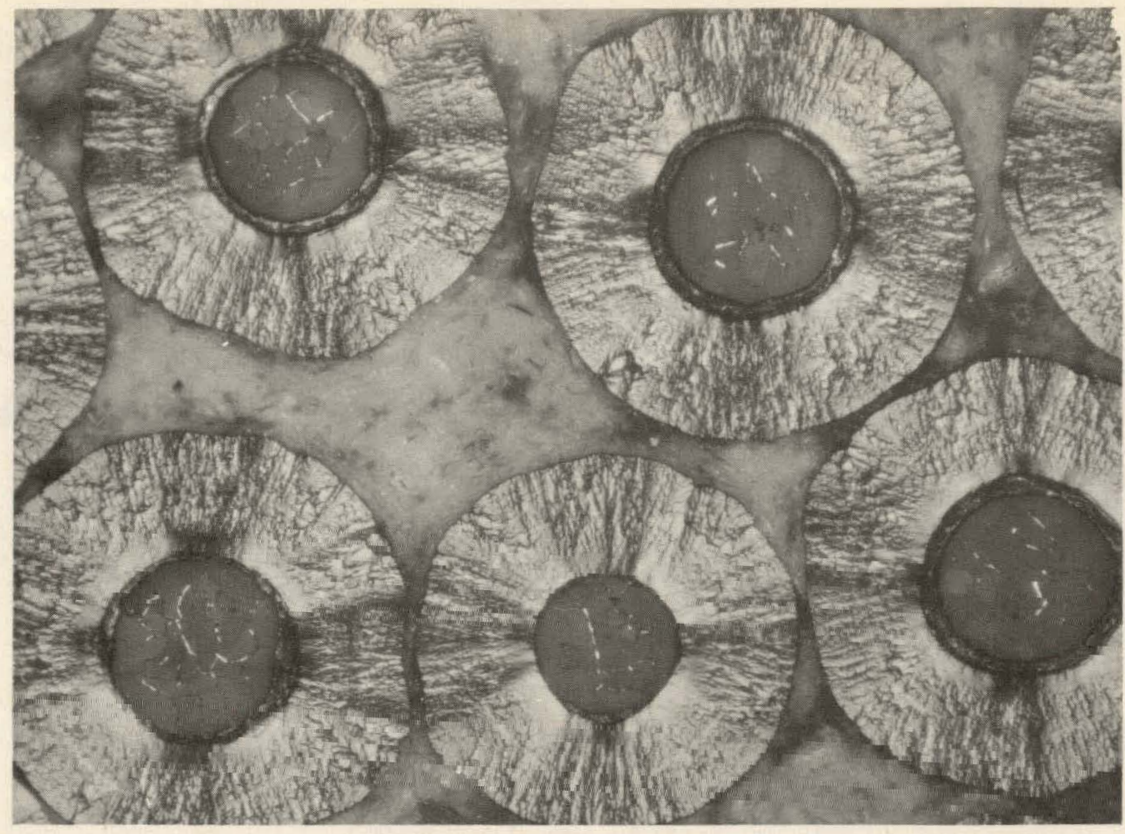

Figure 3. 200- $\mu$ ENRICHED UC COATED WITH $113 \mu$ OF COLUMNAR PYROLYTIC CARBON, POLARIZED LIGHT. (N95511).

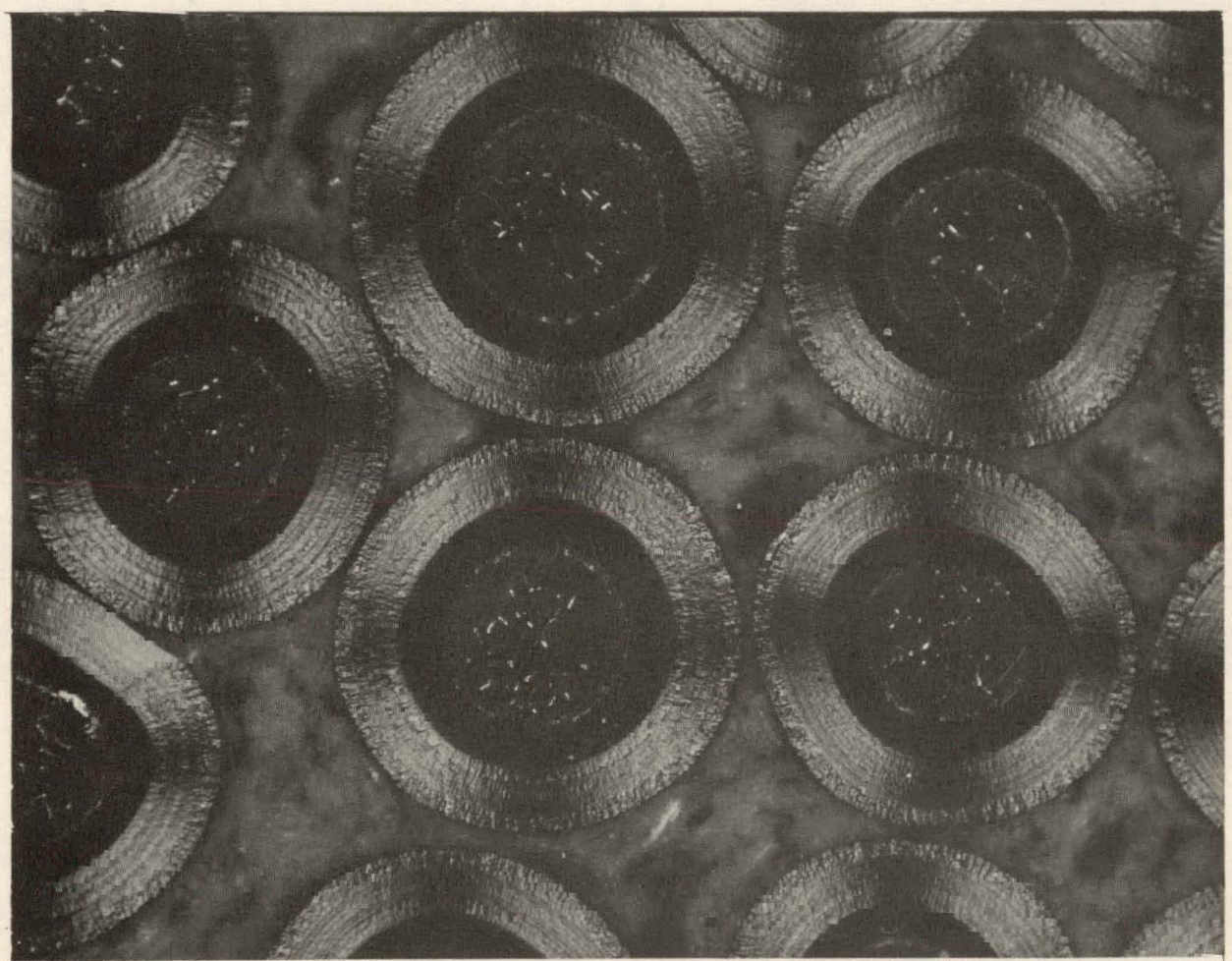

Figure 4. 200- $\mu$ ENRICHED UC COATED WITH 38 , OF POROUS PYROLYTIC CARBON AND $68 \mu$ OF COLUMKAR PYROLYTIC CARBON: POLARIZED LIGHT (N96239). 


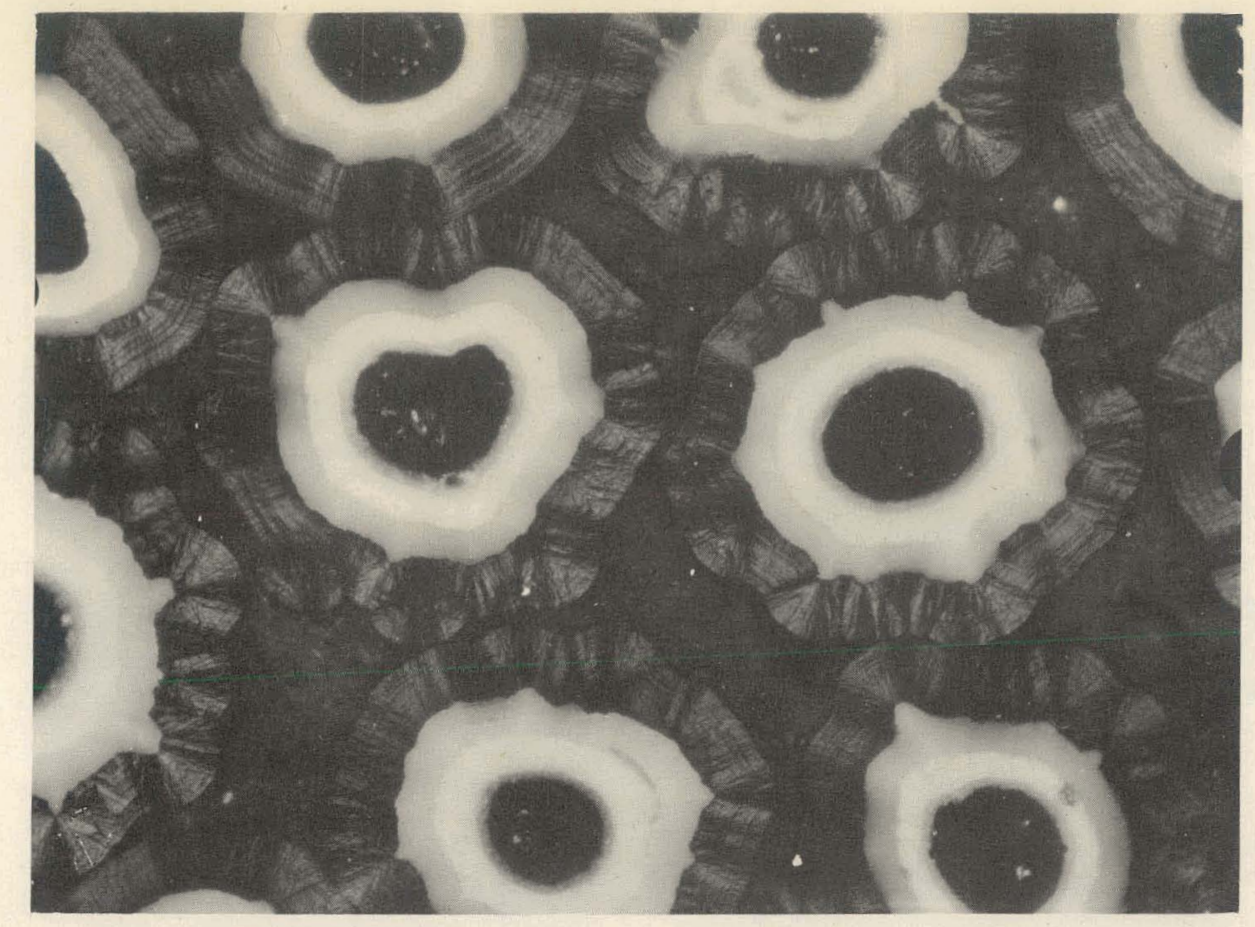

Figure 5. $127 \mu$ ENRICHED UO COATED WITH $8 \mu$ of DENSE ALUMINA, $18 \mu$ OF POROUS ALUMINA, $28 \mu$ OF DENSE ALUMINA, AND $65 \mu$ OF LAMINARCOLUMNAR PYROLYTIC CARBON: POLARIZED LIGHT (N81848).

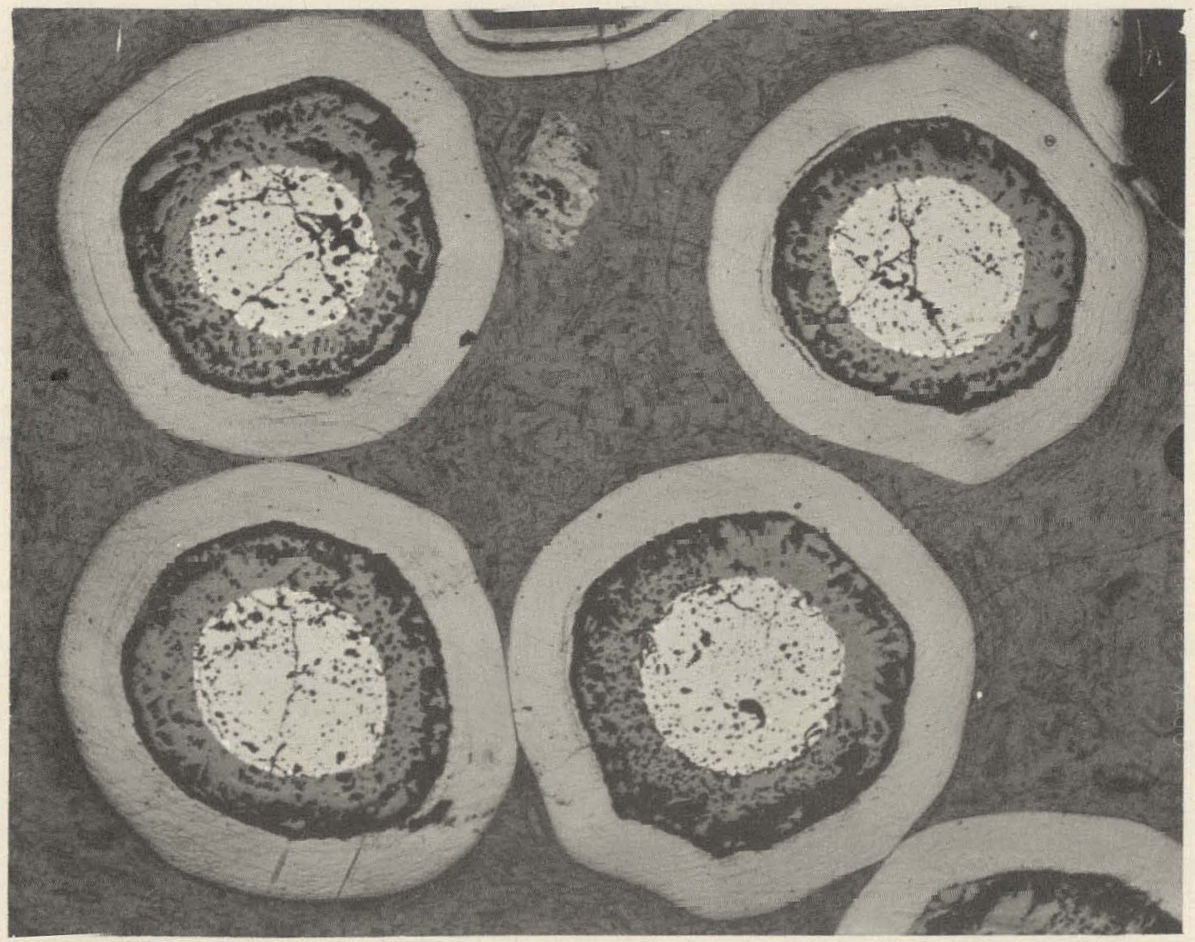

Figure 6. ANNULAR VOID FORMED BY HEAT TREATING TO SHRINK $30 \mu$ OF POROUS $\mathrm{Al}_{2} \mathrm{O}_{3}$ UNDER $42 \mu$ OF PYROLYTIC CARBON (N93515). 


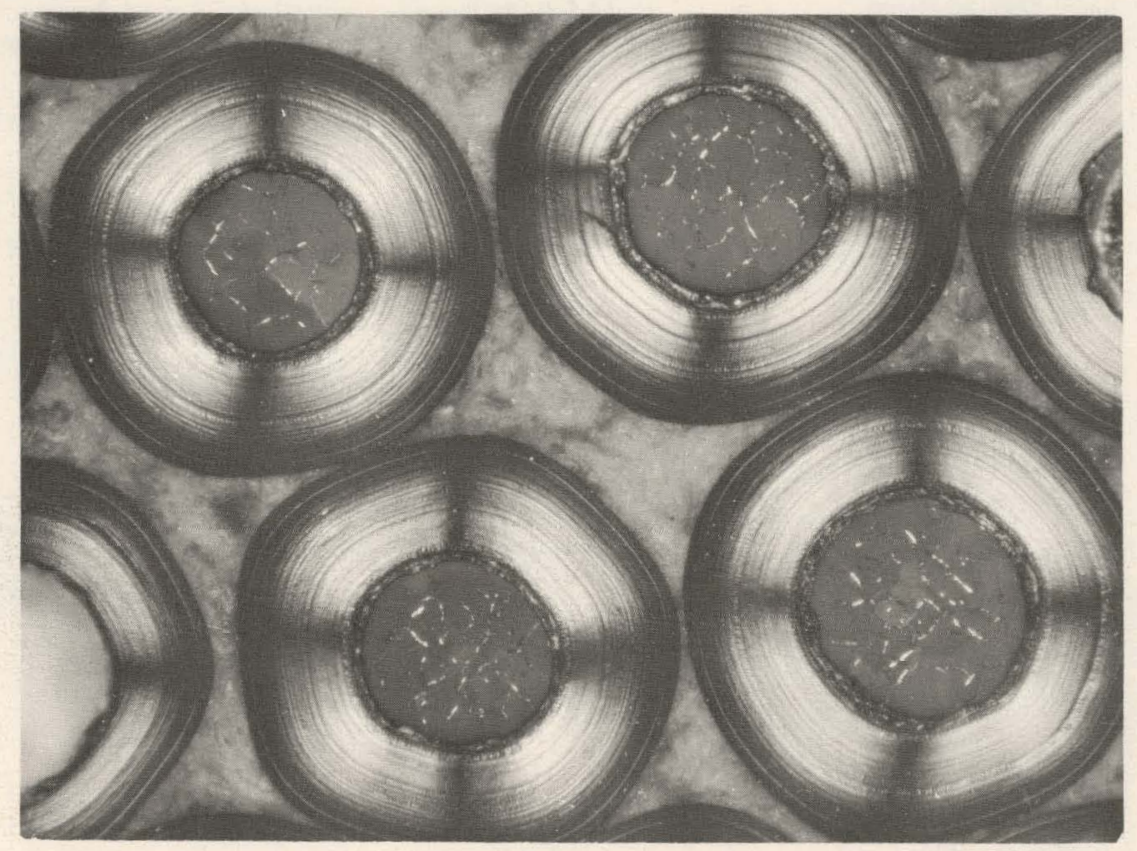

Figure 7. 200- $\mu$ ENRICHED UC COATED WITH $118 \mu$ OF LAMINAR PYROLYTIC CARBON: POLARIZED LIGHT (N95513). 


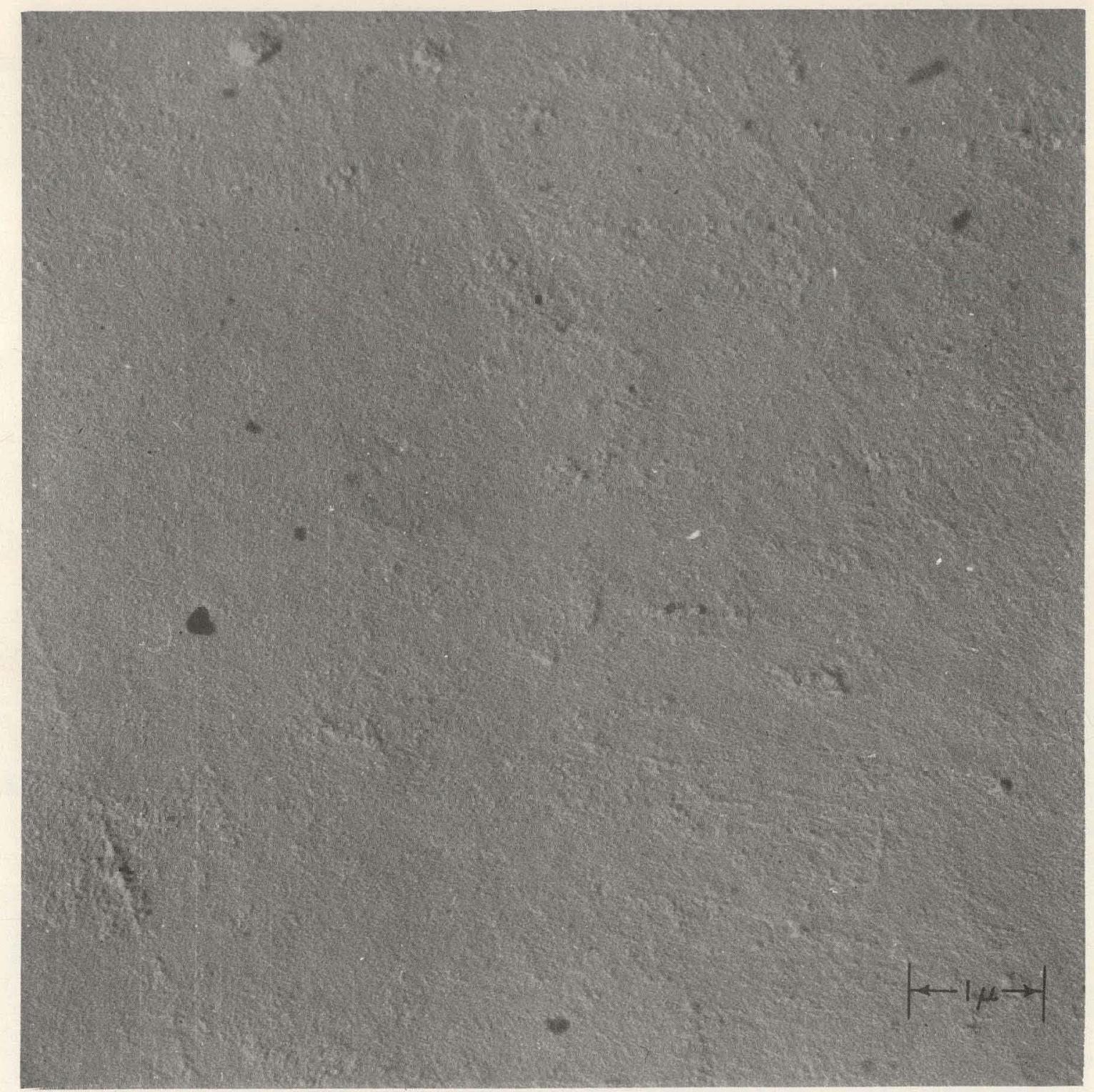

Figure 8. ELECTRON MICROGRAPH OF COLUMNAR PYROLYTIC CARBON COATING PREPARED AT $1400^{\circ} \mathrm{C}$ FROM $\mathrm{C}_{2} \mathrm{H}_{2}$ (NE7300C). 


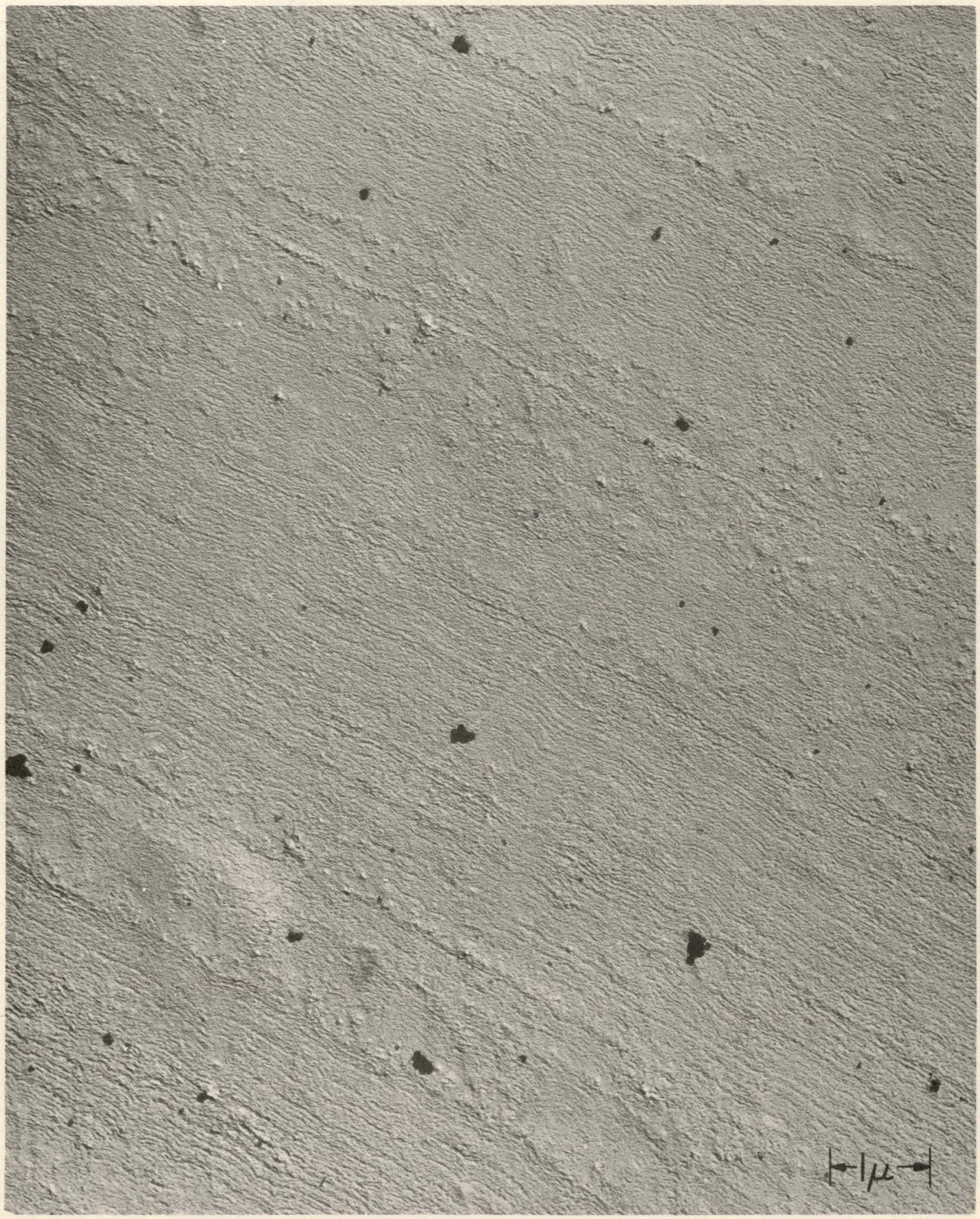

Figure 9. ELECTRON MICROGRAPH OF LAMINAR PYROLYTIC CARBON COATING PREPARED AT $1400^{\circ} \mathrm{C}$ FROM $\mathrm{C}_{2} \mathrm{H}_{2}$ (J8241). 


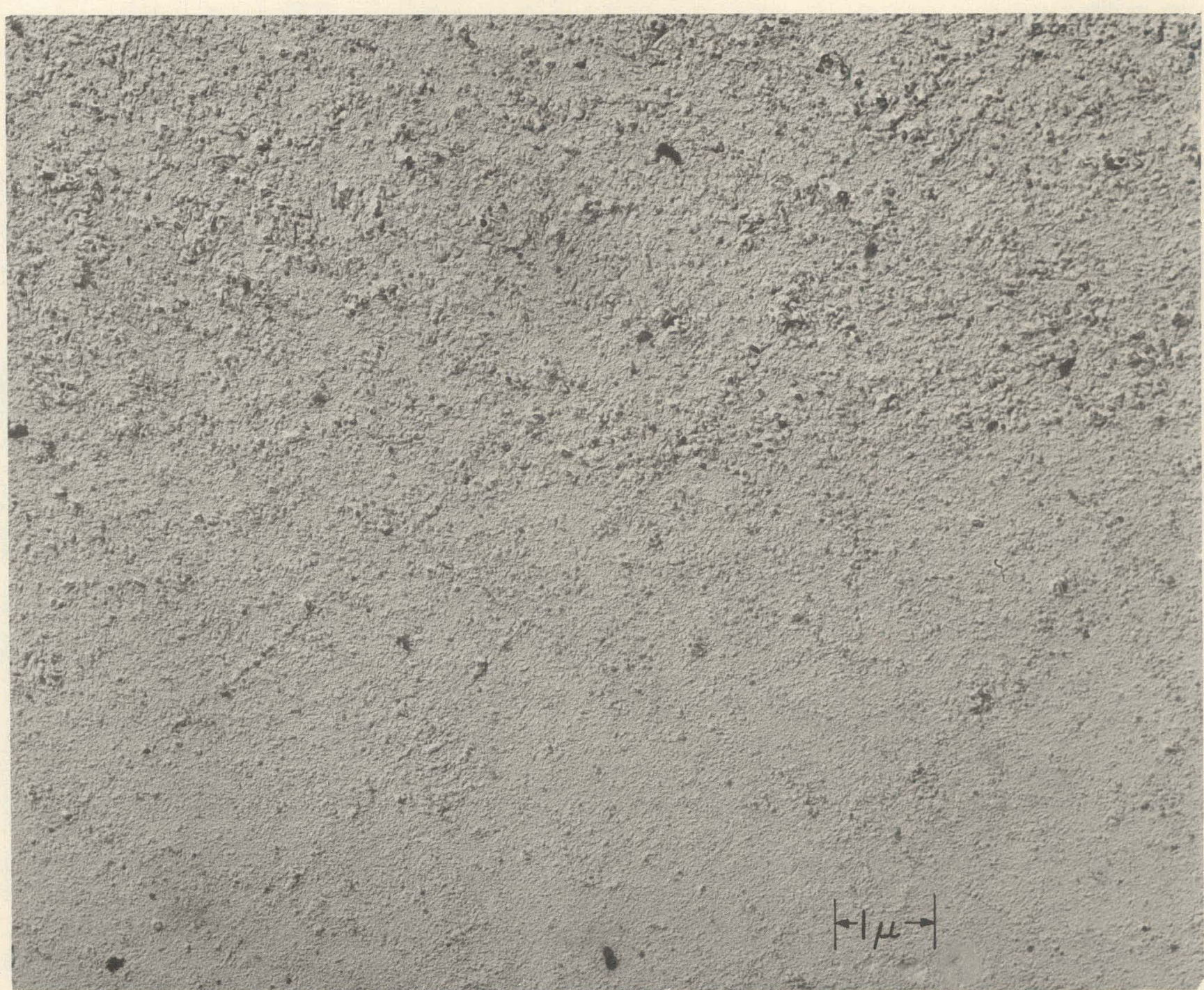

Figure 10. ELECTRON MICROGRAPH OF PYROLYTIC CARBON COATINGS PREPARED FROM METHANE PYROLYTIC AT $1400 \mathrm{C}$ (lower portion) AND $1650 \mathrm{C}$ (upper portion). (J8435). 


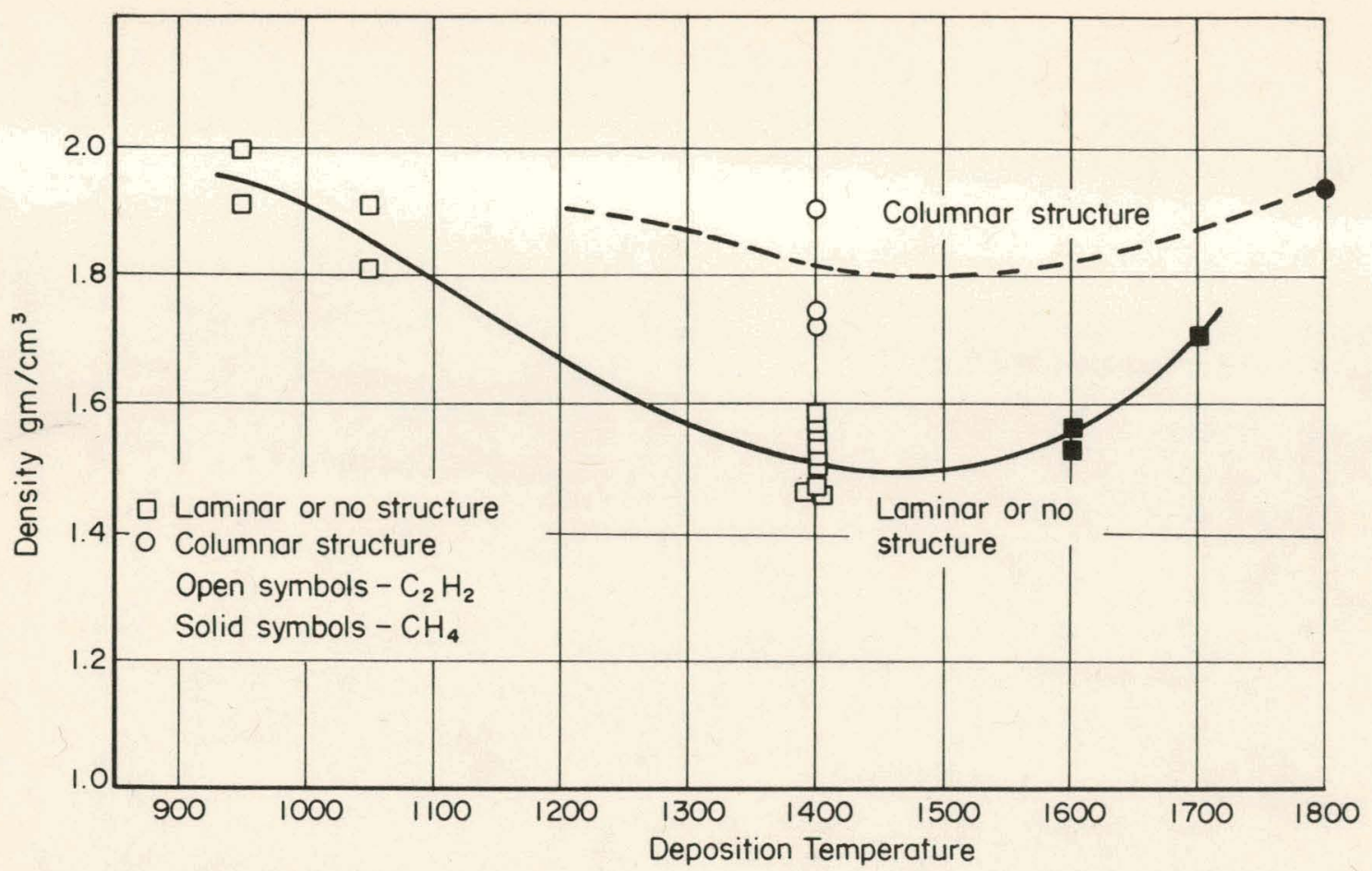

Figure 11. PYROLYTIC CARBON DENSITY AS A FUNCTION OF DEPOSITION TEMPERATURE (A45411).

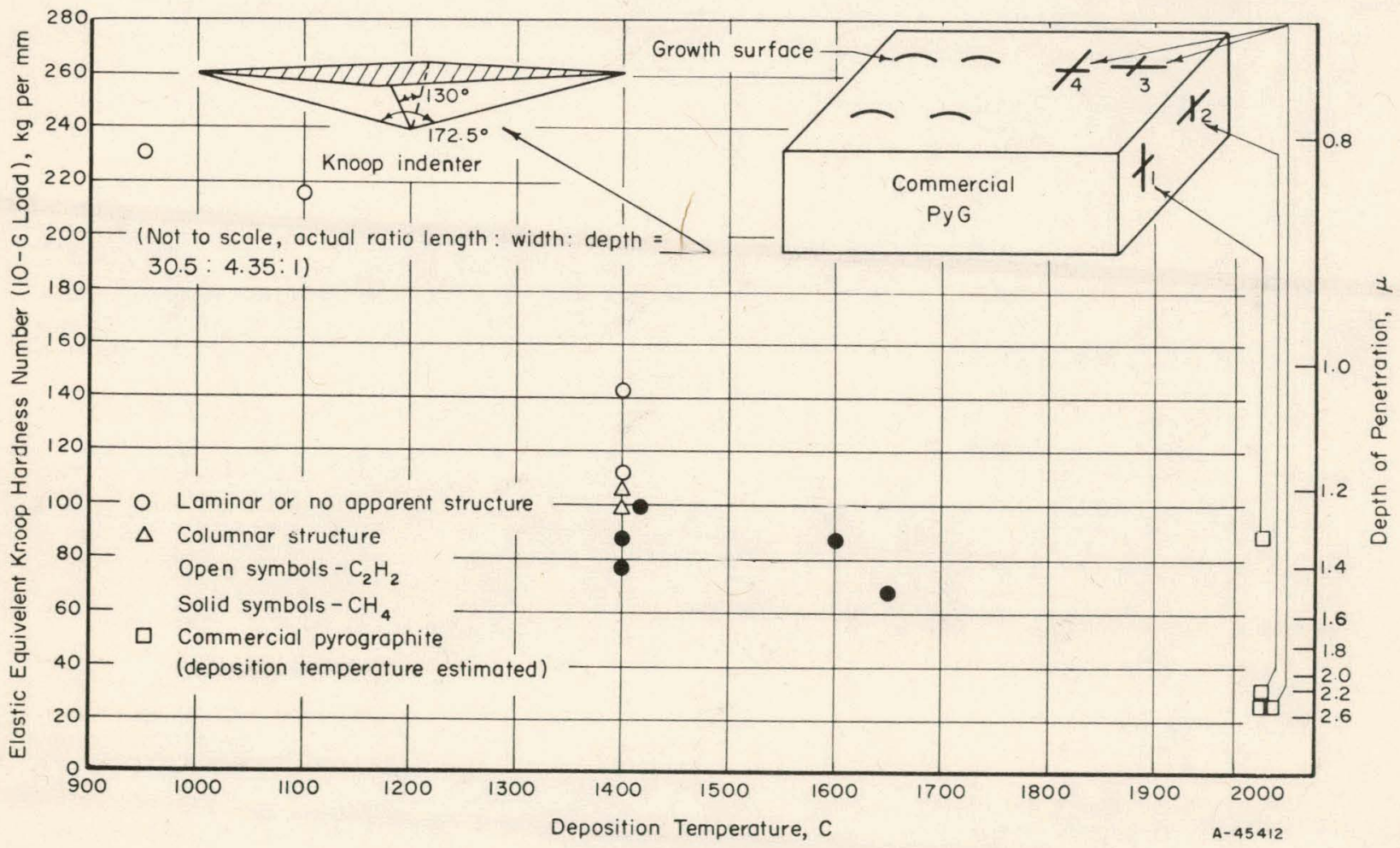

Figure 12. HARDNESS OF PYROLYTIC CARBON COATINGS AS A FUNCTION OF DEPOSITION TEMPERATURE (A45412). 


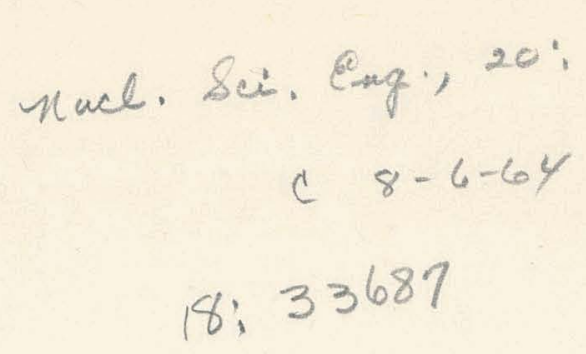

\title{
Processing of Graphite Reactor Fuels Containing Coated Particles and Ceramics*
}

\author{
R. E. Blanco, G. I. Cathers, L. M. Ferris, T. A. Gens, R. W. Horton and E. L. Nicholson \\ Chemical Technology Division, Oak Ridge National Laboratory, Oak Ridge, Tennessee** \\ Revised April 28, 1964
}

\begin{abstract}
Potential processing methods for graphite-matrix nuclear reactor fuels which contain coated particles and/or ceramics are discussed. Both nonaqueous and aqueous processing methods are being developed. Fuels containing either uncoated or carbon-coated particles generally are first burned in oxygen at 800-1200 $\mathrm{C}$ to eliminate the graphite as $\mathrm{CO}_{2}$ and convert the uranium, thorium and other metallic constituents of the fuel to their respective oxides. The combustion ash (oxides) can then either be treated by a nonaqueous volatility method or be dissolved or leached in a suitable aqueous reagent in preparation for decontamination and recovery of the fuel by solvent extraction. In the Fluoride Volatility and Chloride Volatility methods, the constituents of the ash are converted to the respective halides; decontamination and recovery is then achieved by selective volatilization in the fluoride volatility method and, possibly, with chloride volatility. The chlorides can also be dissolved in water in preparation for solvent extraction. Fuel particles coated with such materials as $\mathrm{Al}_{2} \mathrm{O}_{3}, \mathrm{BeO}$ and $\mathrm{SiC}$ can be separated from the graphite matrix by a variety of methods other than burning; for example, disintegration of the fuel in boiling $90 \% \mathrm{HNO}_{3}$ or anodic disintegration in dilute nitric acid. Special methods are then required for recovery of the fuel.
\end{abstract}

\section{INTRODUCTION}

Potential processing methods being developed at Oak Ridge National Laboratory (ORNL) for graphite-base advanced gas-cooled reactor fuel elements containing coated particles and/or ceramics are summarized in this paper. Early fuel types $^{1}$ (dispersion-type fuels) were made by blending graphite flour with uranium and thorium oxide powders, pressing the desired configuration, and graphitizing at 2200 to $2800 \mathrm{C}$ to form the final element. However, hydrolysis of the uranium and thorium carbides formed during fuel manufacture caused disintegration of the elements during storage. To circumvent this and to provide

*Reprinted from Nuclear Science and Engineering: 20, 13-22 (1964) with permission.

**Research sponsored by the U. S. Atomic Energy Commission under contract with the Union Carbide Corporation.

${ }^{1}$ Gas-Cooled Reactors, J. Franklin Institute Monograph No. 7, Franklin Institute, Lancaster, Pa., (1960). better fission-gas retention during reactor operation, the newer graphite fuels (called coatedparticle or beaded fuels) will contain carbide or oxide fuel particles coated with pyrolytic carbon, $\mathrm{Al}_{2} \mathrm{O}_{3}, \mathrm{SiC}$ or similar materials prior to their inclusion into the matrix. Other materials such as $\mathrm{Al}_{2} \mathrm{O}_{3}, \mathrm{BeO}$ and $\mathrm{SiC}$ can be used as the matrix, but, at present, most of the fuel-development work is centered around graphite. Although the first coated-particle fuels, for the High Temperature Graphite Reactor (HTGR) ${ }^{2}$ and the West German Pebble Bed Reactor (AVR) ${ }^{3}$, will contain pyrolyticcarbon-coated $\mathrm{ThC}_{2} / \mathrm{UC}_{2}$ particles (Table I), it is possible that the particles in future reactors such as Dragon will be stabilized with a refractory

${ }^{2}$ W. V. GOEDDEL, "The Development and Evaluation of Graphite-Matrix Fuel Compacts for the HTGR," GA-2289 (Aug. 8, 1961).

${ }^{3}$ W. O. HARMS, ORNL Metals and Ceramics Division, personal communication, (Feb. 14, 1963).

'J. BLOMSTRAND, L. MASSIMO, J. SCHLOSSER and E. SCHRODER, "The Dragon Core," paper presented at the Thorium Fuel Cycle Symposium, Gatlinburg, Tennessee, (Dec. 5-7, 1962). 
TABLE I

Description and Compositions of Typical Graphite-Matrix Coated-Particle Fuels

\begin{tabular}{|c|c|c|}
\hline Fuel Type & Description & $\begin{array}{c}\text { Composition } \\
\text { (wt \%) }\end{array}$ \\
\hline HTGR (Peach Bottom Reactor) & C-coated $\mathrm{ThC}_{2} / \mathrm{UC}_{2}$ particles in a graphite matrix & $\begin{array}{l}\text { Th }-21.2 \\
U=2.1 \\
C-76.9\end{array}$ \\
\hline AVR (West German Pebble-Bed Reactor) & C-coated $\mathrm{ThC}_{2} / \mathrm{UC}_{2}$ particles in a graphite matrix & $\begin{array}{l}T h=4.4 \\
U=0.6 \\
C=95.0\end{array}$ \\
\hline \multirow[t]{4}{*}{ Dragon reactor } & 3-region graphite-matrix & \\
\hline & $\begin{array}{l}\frac{\text { Inner Region }}{\mathrm{ThC}_{2} / \mathrm{UC}_{2}} \text { particles with triplex coating of carbon } \\
\text { and } \mathrm{SiC}\end{array}$ & $\begin{array}{l}\text { Th }=15.0 \\
U=1.0 \\
S i=5.0\end{array}$ \\
\hline & $\begin{array}{l}\frac{\text { Intermediate Region ( } 32 \text { wt } \% \text { of core): }}{\mathrm{ThC}_{2} / \mathrm{UC}_{2} / \mathrm{ZrC} \text { particles with triplex coating of }} \\
\text { carbon and } \mathrm{SiC}\end{array}$ & $\begin{array}{l}\text { Th }=3.0 \\
\mathrm{U}-1.2 \\
\mathrm{Zr}-\mathbf{2 5 . 0} \\
\mathrm{Si}-\mathbf{5 . 0}\end{array}$ \\
\hline & $\begin{array}{l}\text { Outer Region ( } 49 \text { wt } \% \text { of core): } \\
\mathrm{ThC}_{2} / \mathrm{UC}_{2} / \mathrm{ZrC} \text { particles with triplex coating of } \\
\text { carbon and } \mathrm{SiC}\end{array}$ & $\begin{array}{l}\text { Th }=3.0 \\
\text { U }=0.9 \\
\text { Zr }-23.0 \\
\text { Si }-5.0\end{array}$ \\
\hline Experimental fuel & BeO-coated $\mathrm{ThO}_{2} / \mathrm{UO}_{2}$ particles in a graphite matrix & $\begin{array}{l}\text { Th }-9.0 \\
U=1.0 \\
\text { Be }-10.0\end{array}$ \\
\hline Experimental fuel & $\mathrm{Al}_{2} \mathrm{O}_{3}$-coated $\mathrm{ThO}_{2} / \mathrm{UO}_{2}$ particles in a graphite matrix & $\begin{array}{l}\text { Th }=9.0 \\
\text { U }=1.0 \\
\text { Al }=20.0\end{array}$ \\
\hline
\end{tabular}

${ }^{2}$ Reference 4. However, the Dragon core may be a two-region reactor: inner region, $\mathrm{ThC}_{3} / \mathrm{UC}_{2}$ particles with triplex coating; outer region, $\mathrm{ZrC} / \mathrm{UC}$ particles coated with pyrolytic carbon (Personal communication from G. W. Horsley and F. C. Wood, Dragon Project, Winfrith, England, September 26, 1963).

carbide such as $\mathrm{ZrC}$. Pyrolytic carbon and $\mathrm{SiC}$ have also been considered as coatings for the entire fuel element ${ }^{5}$.

The wide variety of possible fuels makes processing studies difficult. To keep pace with the ever expanding fuel development technology, several alternative methods for processing graphite-base coated-particle fuels are being studied. In one general approach, the fuel is first burned in oxygen to convert the graphite to volatile $\mathrm{CO}$ and $\mathrm{CO}_{2}$, and the uranium, thorium and other materials to their respective oxides. The oxide combustion ash can then be treated by either volatility or aqueous methods. In other alternatives, (1) the fuel could be ground fine enough to break the coated particles and the fissionable and fertile materials recovered by leaching with nitric acid; or (2) the graphite matrix could be disintegrated by $90 \% \mathrm{HNO}_{3}$ or by anodic electrolysis. The coated particles could then be separated from the graphite slurry and treated separately.

\footnotetext{
s"Fuel Element Development Program for the Pebble Bed Reactor," NYO-9064 (April 30. 1961).
}

In this paper, the status of ORNL development of a variety of potential processing methods for graphite-base fuels is discussed. In addition, combustion is discussed in a separate section, since it is such a vital step in many of the process alternatives. At this stage, critical comparison of the various alternative processes is impossible, from both the standpoints of engineering feasibility and economics.

\section{COMBUSTION OF GRAPHITE FUELS}

Combustion is a step common to several of the potential processes to be discussed; it therefore seems logical to review it at this point. Engineering-scale studies of the fixed-bed burning of graphite-base fuels have been conducted at $\mathrm{ORNL}^{6-8}$. The major objective of these studies was the development of equipment in which the graphite fuels could be burned rapidly and completely

${ }^{\circ} \mathrm{C}$. D. SCOTT, L. E. McNEESE and J. C. SUDDATH, "Processing of Graphite Fuels for Uranium Recovery by Oxidation and Fluorination," ORNL-TM-185 (March 20, 1962). 
but still achieve high oxygen utilization and a minimum production of $\mathrm{CO}$, which is a potential explosion hazard, in the off-gas. The burning technique used should also avoid the formation of high centerline temperatures in the fuel bed that could result in a sintered, unreactive ash. Sintering (clinkering) is deleterious not only because it diminishes the chemical reactivity of the ash but also because, in several potential processes, the ash must be transferred to a separate vessel for further chemical treatment. Filtration systems capable of removing small amounts of extremely fine oxide particles from the combustion off-gas were also tested.

The ORNL fixed-bed burning studies were conducted in a variety of stainless steel and nickel vessels varying in diameter from 2 to 5 inches.

${ }^{7}$ L. E. MCNEESE and C. D. SCOTT, "Recovery of Uranium from Graphite Fuels by Oxidation and Fluorination. I. Design and Initial Operation of an Engineering-Scale Facility,"' ORNL-3434 (1963)(Classified).

${ }^{8}$ C. D. SCOTT, "Recovery of Uranium from Graphite Fuels by Oxidation and Fluorination. II. Use of Mathematical Analysis of the Oxidation Process in Fixed Beds to Predict Process Conditions," ORNL-3456 (1963) (Classified).
In tests with a 2.5-inch-diameter downflow reactor, complete combustion of the graphite in pure oxygen was achieved in $3 \mathrm{~h}$ or less. The off-gas contained less than $3.5 \%$ CO while the overall oxygen utilization was greater than or equal to $50 \%$. Wall heat-transfer fluxes ranged from 20000 to $80000 \mathrm{Btu} \mathrm{h}^{-1} \mathrm{ft}^{-2}$. On occasion, the centerline temperature of the burning bed rose high enough to cause sintering of the ash to a friable solid, as shown in Figure 1. These ash lumps were accompanied by some smaller granular material and a very small amount of coarse dust. This reactor was enclosed in a furnace to heat it to the graphite ignition temperature of 650 to $700 \mathrm{C}$. An external coil was provided for spray cooling with a compressed-air/water mixture.

Use of a 5-in.-diameter upflow reactor (Figure 2), fitted for multiple-zone oxygen injection and cooling, resulted in high average burning rates without the excessive local cooling loads that resulted in the single-zone burner. The fuel was supported on an alumina ceramic plate to prevent grate burnout. Burning rates as high as $4 \mathrm{~g}$-moles of carbon per minute, with wall heat fluxes of about $40000 \mathrm{Btu} \mathrm{h} \mathrm{h}^{-1} \mathrm{ft}^{-2}$, were obtained with pure oxygen without excessive sintering of the ash.

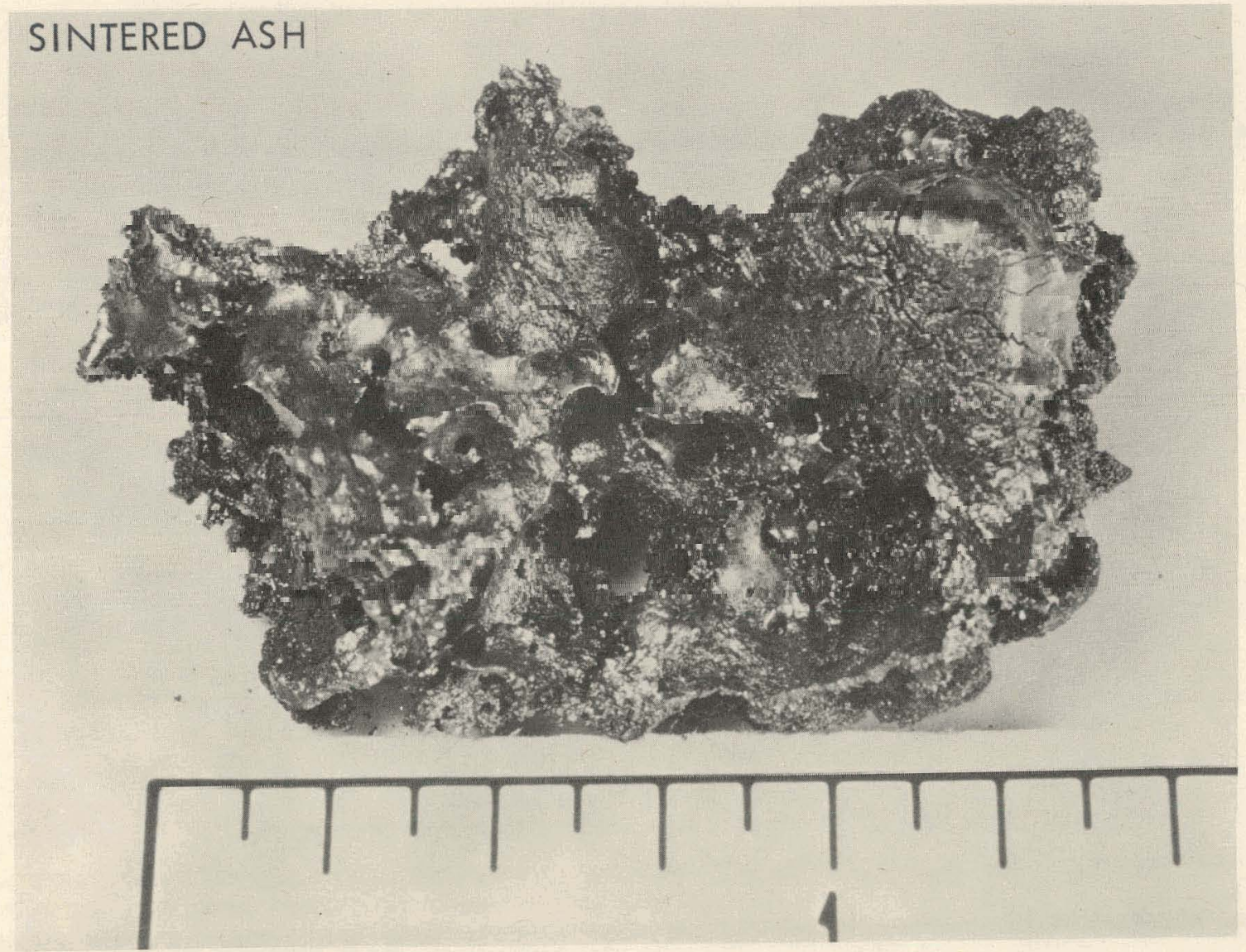

Fig. 1. Sintered ash from combustion of a uranium containing graphite matrix fuel. 


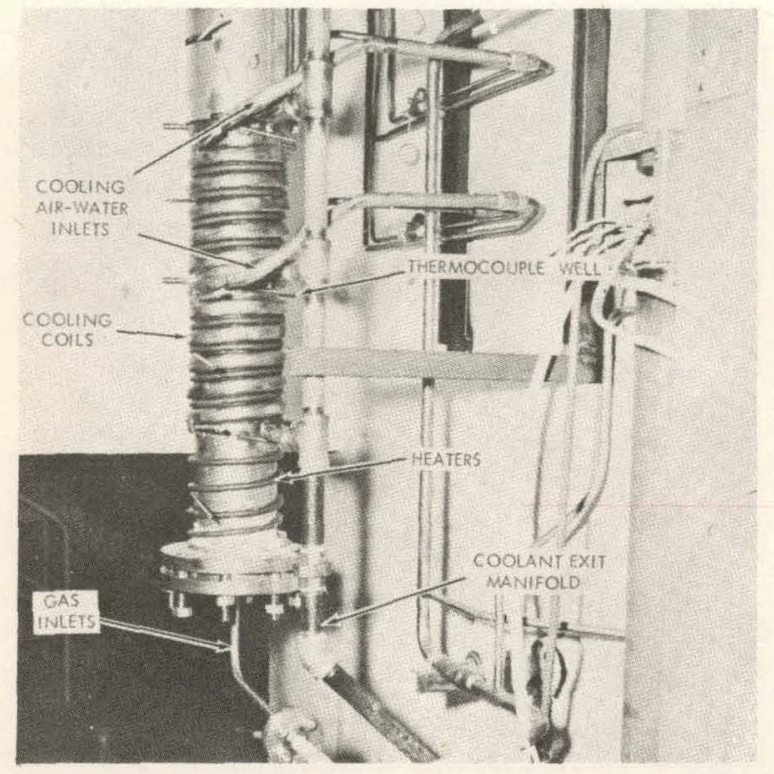

Fig. 2. Experimental graphite fuel combustionfluorination reactor; 5-in.-diameter.

However, burner control at these high rates was difficult. Operation of the burner was satisfactory using a $50 \%$ air $/ 50 \%$ oxygen mixture to burn at a rate of $2.5 \mathrm{~g}$-moles of carbon per min (with an initial bed volume of approximately $0.5 \mathrm{cu} \mathrm{ft}$.).

Combustion off-gases from the 5-in. reactor were cooled before passage through sintered metal mesh or porous metallic filters (25-40 $\mu$ range). Cooling of the off-gas helped prolong the life of the filter unit. The $\mathrm{CO}$ content of the off-gas was monitored continuously. With the 5 -in. reactor, it was difficult to maintain the $\mathrm{CO}$ at a low concentration, but explosion hazards were minimized by off-gas dilution during the occasional periods when the $\mathrm{CO}$ concentration was high. Solids collected from the off-gas by the filter unit had size distributions similar to that shown in Figure 3. High filtration efficiency depended on filtration through the solids cake rather than the mesh filters alone. The uranium contained in the solids collected by the filter was less than $0.2 \%$ of the uranium charged to the reactor. The amount of uranium escaping through the filter unit was less than $0.002 \%$.

Although satisfactory burning of typical graphite-base fuel was achieved in the 5 -in.-diameter burner, other techniques must be evaluated before the optimum burner design is selected. Graphitebase fuels generally contain enriched uranium; consequentiy, the critical geometry of the combustion reactors must be considered. Several parallel combustion units would be required to

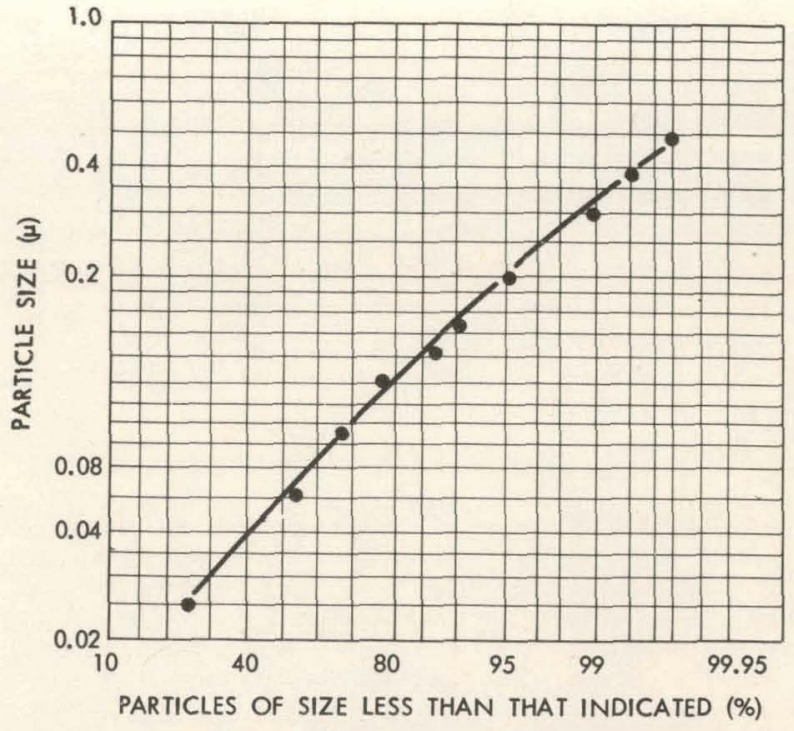

Fig. 3. Particle-size distribution of solids in offgas from combustion of a uranium containing-graphite matrix fuel. Distribution obtained by physical sizing and from counts from electron micrographs.

achieve acceptably high capacities if geometrically critically safe 5 -in.-diameter units were used. This problem may be overcome by use of a slabshape burner which is now being tested at ORNL (Figure 4). This reactor is expected to achieve high capacity with low fuel-bed centerline temperatures, improved cooling system control and improved gas distribution. Another technique, combustion of the fuel in a bed of fluidized alumina, has received study at Brookhaven $\mathrm{Na}$ tional Laboratory?

Extensive volatilization of ruthenium and cesium occurred in initial small-scale combustion studies with irradiated graphite fuels. In tests ${ }^{10}$ with a fuel containing only uranium dicarbide dispersed in the graphite matrix (burnup, $0.1 \%$ of the uranium), greater than $40 \%$ of the ruthenium was volatilized at $800 \mathrm{C}$. With HTGR fuel samples ${ }^{11}$

'L. P. HATCH, R. JOHNSON, J. J. REILLY, S. J. WACHTEL and E. WIRSING, "Progress on Individual Activities, November-December, 1963," BNL-Log. No. C-11355 (Jan. 1964) (Classified).

${ }^{10}$ L. M. FERRIS, A. H. KIBBEY and M. J. BRADLEY, "Processes for Recovery of Uranium and Thorium from Graphite-base Fuel Elements. Part II.," ORNL-3186 (Nov. 16, 1961).

${ }^{11}$ L. M. FERRIS, K. S. WARREN, and J. W. ULLMANN, "Combustion-Dissolution Experiments with Irradiated Graphite-base Reactor Fuel Containing Carbon-Coated Thorium-Uranium Dicarbide Particles," ORNL-TM-688 (Sept. 20, 1963). 


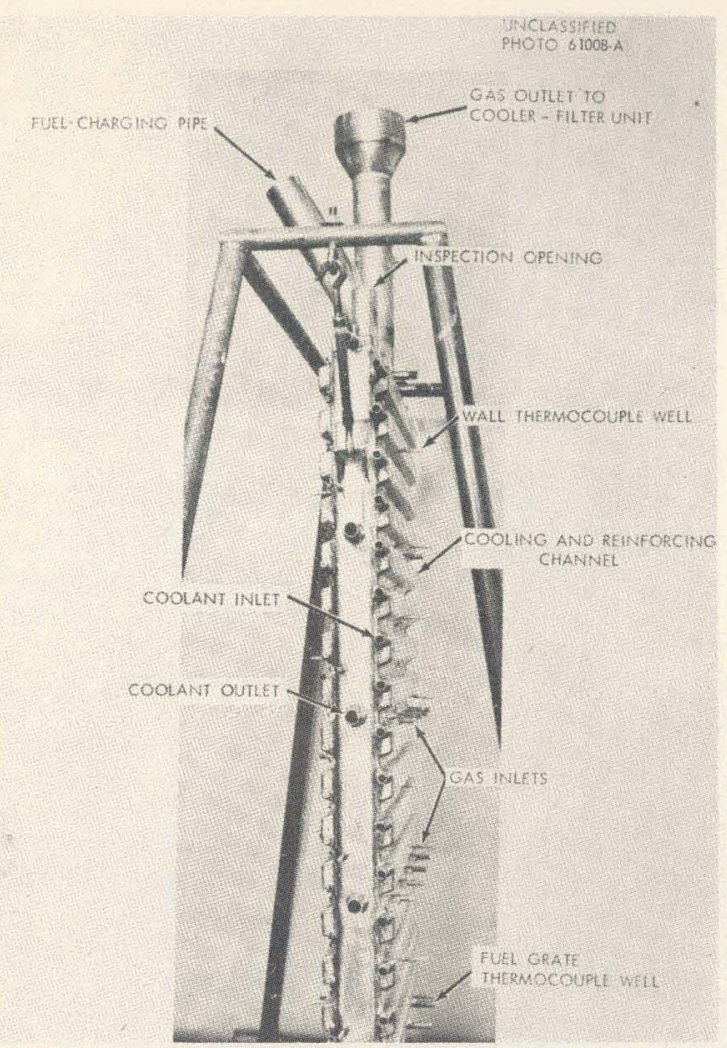

Fig. 4. Mark II combustion-fluorination reactor. End view of the 2.5-in.-thick slab reactor.

irradiated to about $10000 \mathrm{MWd} /$ metric ton of $\mathrm{U}+$ Th, 6-h combustions in oxygen produced the results shown in Table II. Decontamination factors of greater than $10^{4}$ for ruthenium and cesium in the off-gas were obtained by passage of the gas at room temperature through a 40 -micron-porosity sintered nickel filter and a paper millipore filter.

TABLE II

Volatilization of Fission Products During 6-h Combustions of HTGR Fuel Irradiated to about $10000 \mathrm{MWd} / \mathrm{T}(\mathrm{U}+\mathrm{Th})$

\begin{tabular}{c|c|c|c|c|c}
\hline \multirow{2}{*}{$\begin{array}{c}\text { Test } \\
\text { No. }\end{array}$} & \multirow{2}{*}{$\begin{array}{c}\text { Temp: } \\
\left({ }^{\circ} \mathrm{C}\right)\end{array}$} & \multicolumn{4}{|c}{ Amount of Fission Product Volatilized } \\
\cline { 3 - 6 } & & $\mathrm{Ru}$ & $\mathrm{Cs}$ & $\mathrm{Zr}$ & Rare Earths \\
\cline { 3 - 6 } & 800 & 78 & 24 & 0.008 & 0.02 \\
\hline 1 & 800 & 96 & 35 & 0.07 & 0.1 \\
3 & 1200 & 97 & 67 & 0.04 & 0.06 \\
4 & 1200 & 99 & 88 & 0.02 & 0.01 \\
\hline
\end{tabular}

\section{FLUORIDE VOLATILITY PROCESSES}

Fluoride volatility processing technology has progressed to the point where it can be considered as an alternative to solvent extraction ${ }^{12}$. Combination of the two nonaqueous processes, combustion and fluorination, appears inherently advantageous since both steps could be carried out in the same equipment. Two alternatives exist: to fluorinate the combustion ash directly as shown in Figure 5, or to transfer the ash to a second, fused-salt, fluorinator reactor by air blast, screw feed or gravity drop (Figure 6). An advantage of fluoride volatility systems is the ease of waste disposal. In the first alternative, residual fission and corrosion products after fluorination must be removed periodically from a fixed-bed reactor with an aqueous reagent or from a fluidized-bed reactor by ejecting the bed with an air lift. In the second alternative, the fission products remain in the fused salt, which is drained to a waste container. Thorium cannot be recovered by either fluoride volatility procedure; however, this may be no disadvantage since, in the present economy, the recovery of thorium may not be necessary.

\section{Combustion/Fluorination Process}

The ease with which $\mathrm{U}_{3} \mathrm{O}_{8}, \mathrm{UO}_{2}$ and $\mathrm{UO}_{3}$ can be fluorinated with elemental fluorine at high temperatures is well known ${ }^{23}$. Combustion/fluorination experiments (Figure 5) were conducted with a fuel that did not contain thorium in both the 2.5in.- and 5-in.-diameter reactors described in the previous section. After combustion in the 2.5-in. reactor, greater than $99 \%$ of the uranium was generally recovered by fluorination at 400 to $500 \mathrm{C}$ for 2 to $3.5 \mathrm{~h}$ except where a fuel-support grate or filter failed. Fluorine utilization ranged from 14 to $60 \%$. Massive, dense, sinters were successfully fluorinated, although at a reduced rate. After combustion in the 5-in. reactor, the ash was fluorinated with pure fluorine flowing at a rate of 20 to 30 liters (STP) per minute. Uranium recoveries were equal to or greater than $98 \%$; the fluorine utilization was about $50 \%$. Higher recoveries probably could be achieved with better gas distribution through the alumina support plate. Preliminary corrosion studies at Battelle Memorial Institute have indicated that either " $\mathrm{L}$ " nickel or INOR-8 will be a suitable material of

\footnotetext{
${ }^{12}$ R. K. STEUNENBERG and R. C. VOGEL, Reactor Handbook, 2nd Edition, Vol. II, Interscience Publishers, (1961), chapter 6 .

${ }^{13}$ F. R. BRUCE, J. M. FLETCHER and H. H. HYMAN, editors, Process Chemistry, Vol. 2, Pergamon Press, New York, (1958), pp. 106-209.
} 


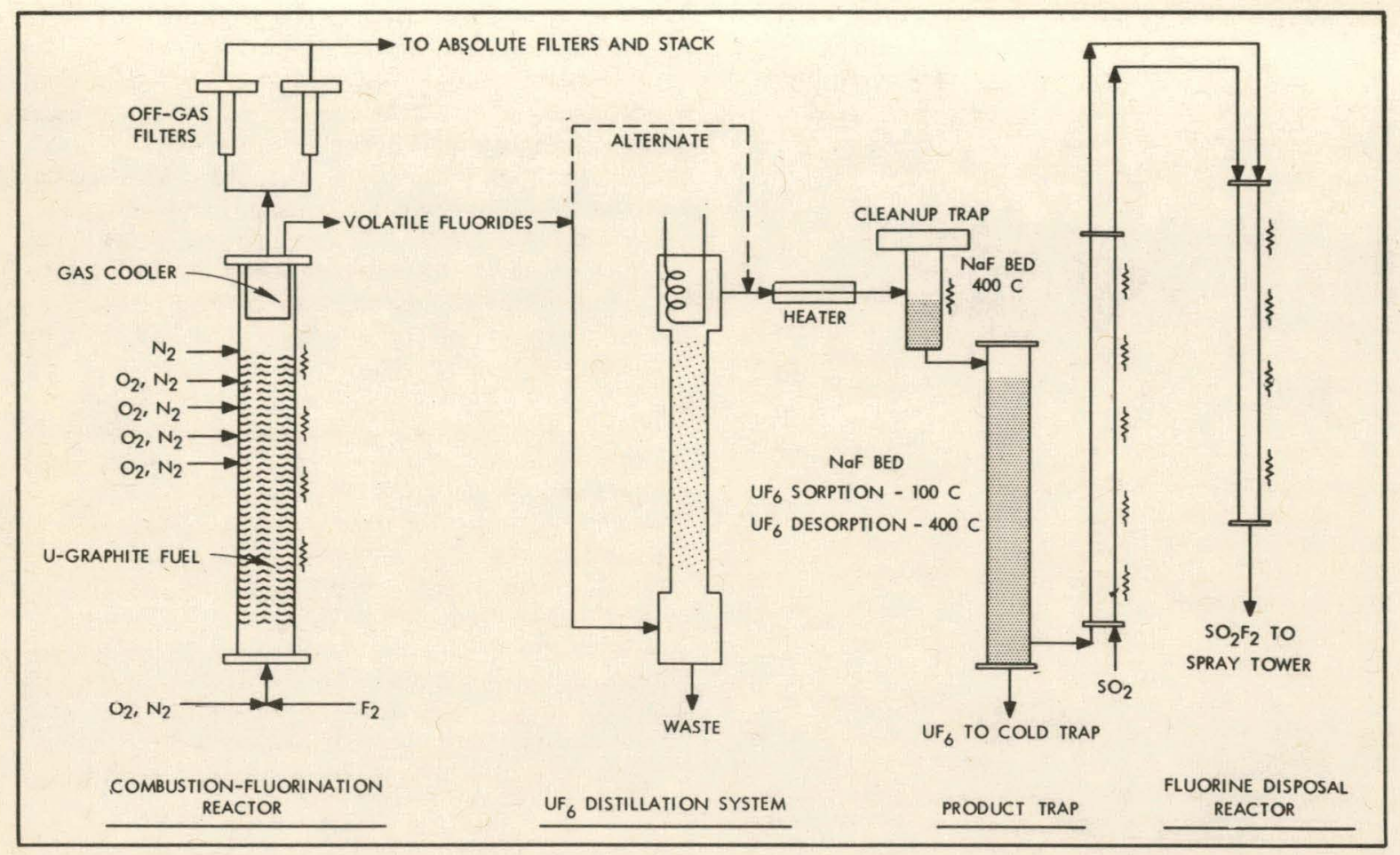

Fig. 5. Combustion-volatility flowsheet.

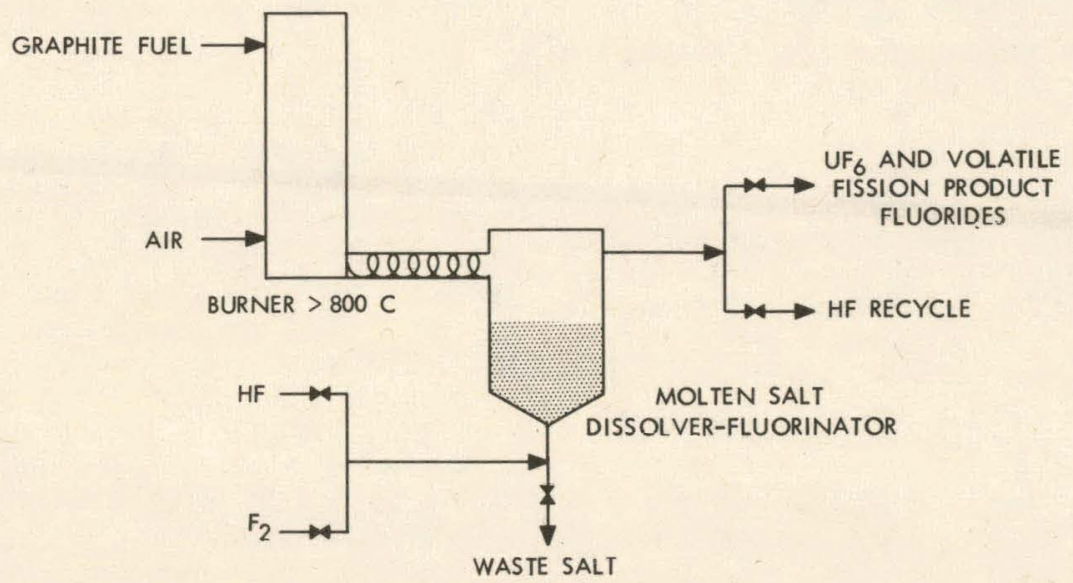

Fig. 6. Combustion-fused salt fluoride volatility process for graphite fuels.

construction for a combustion-fluorination reactor $^{14}$. Corrosion rates of 0.007-0.010 in. per month are anticipated.

${ }^{14}$ P. D. MILLER, E. F. STEPHAN, W. N. STIEGELMEYER and F. W. FINK, "Corrosion During Oxidation-Fluorination Processing," BMI-X-209 (Oct. 19, 1962).
Either sintering or the presence of large amounts of nonvolatile fluorides hinders complete uranium recovery due to the formation of solid solutions and to slow gas diffusion. For example, in a small-scale combustion/fluorination experiment with HTGR fuel, only $93 \%$ of the uranium was recovered in $45 \mathrm{~min}$ of fluorirfation at 420 to $520 \mathrm{C}$. 
The mottled appearance of the residue indicated that the uranium was occluded in the $\mathrm{ThO}_{2}$. Complete uranium recovery can probably be achieved with long fluorination times.

\section{Fused-Salt Volatility Process}

Dissolution of the combustion residues in a fused salt (Figure 6) is an effective method for treating many refractory materials that may be impossible or extremely difficult to process by aqueous methods. These materials include alumina, thoria, beryllia and zirconia. Solution in a fused salt also eliminates solid-solution problems and ensures contact between fluorine and uranium. Laboratory studies have shown the feasibility of dissolving refractory materials such as $\mathrm{ZrO}_{2}$, $\mathrm{ThO}_{2}$ and $\mathrm{BeO}$ in fused fluoride melt.s (Table III). Fluorination tests with melts of these types have indicated no difficulty in rolatilizing the uranium (as $\mathrm{UF}_{6}$ ) from an initial uranium concentration of about 1000 parts $/ 10^{6}$ down to less than 5 parts $/ 10^{6}$. The major disadvantages of the fused salt process for graphite fuels are transfer of the ash to the salt and the corrosiveness of the fused salt.

An important factor to consider is the salt composition to be used with a specific fuel. For example, with HTGR fuel a salt with a high compatibility for $\mathrm{ThF}_{4}$ is required. The LiF-BeF and $\mathrm{NaF}-\mathrm{LiF}-\mathrm{ZrF}_{4}$ systems are typical of those that might be suitable ${ }^{15}$. Further work on development of specific salt mixtures and flowsheets is needed.

\section{Purification of $U F_{\mathrm{B}}$ by Fluoride Volatility}

Extensive development work has been carried out on two methods of achieving complete decon-

${ }^{19}$ R. E. THOMA, "Phase Diagrams of Nuclear Reactor Materials," ORNL-2548 (Nov. 6, 1959). tamination of the $U F_{B}$ product (Figure 5). One is based on distillation to separate the volatile flourides from $U F_{B}$. The second method ${ }^{16}$ employs sorption of NaF. Both methods have been used successfully in pilot-plant operations ${ }^{12},{ }^{17}, 18$. In pilot-plant tests at ORNL with the NaF method, uranium was successfully recovered from irradiated zirconium-uranium fuel cooled 13 months, with gross beta and gamma decontamination factors of $1 \times 10^{8}$ and $5 \times 10^{8}$, respectively ${ }^{18}$.

\section{CHLORIDE VOLATILITY PROCESSES}

Chloride volatility processes ${ }^{19-22}$ for treating the combustion ash from graphite fuels are also being investigated on a laboratory scale. Chlorination of the ash can probably be carried out in the combustion reactor without excessive corrosion and the resultant chlorides processed by volatility methods or by aqueous dissolution and solvent extraction. Treatment of fuels containing particles coated with beryllia or alumina has been considered, but does not appear promising.

\footnotetext{
${ }^{10}$ G. I. CATHERS, R. L. JOLLEY and E. C. MONCRIEF Nucl. Sci. Eng., 13, 391 (1962).

${ }^{17}$ F. L. CULLER, et al., "Chemical Technology Division Annual Progress Report for Period Ending June 30. 1962," ORNL-3314, pp. 33-57 (1962).

${ }^{10} F$. L. CULLER et al., "Chemical Technology Division Annual Progress Report for Period Ending June 30, 1963," ORNL-3452 (1963).

${ }^{10}$ T. A. GENS, "Laboratory Development of Chloride Volatility Processes for the Recovery of Uranium Directly from Spent Rover Fuel or from Its Combustion Ash," ORNL-3376 (May 31, 1963) (Classified).

${ }^{20} \mathrm{P}$. SPEECKAERT, "Processing of Irradiated Uranium by Sublimation of the Chlorides," CEN-R-1915 (Sentember, 1960); CEN-R-1730 (July, 1959).

${ }^{21}$ D. NAUMANN, Kernenergie, 5, 118 (1962).

${ }^{22} \mathrm{~T}$. ISHIHARA, K. HIRANO and T. HONDA, J. Atomic Energy Soc. Japan, 4, 231 (1962).
}

TABLE III

Dissolution of Oxides by Hydrofluorination in Fused Salt

HF Flow Rate: 16-21 mole $\mathrm{h}^{-1} \mathrm{ft}^{-2}$ in 2-in.-diam. reactor

\begin{tabular}{|c|c|c|c|}
\hline - Material $^{\mathrm{a}}$ & $\begin{array}{l}\text { Salt Composition } \\
\text { (mole \%) }\end{array}$ & $\begin{array}{l}\text { Temp. } \\
\left({ }^{\circ} \mathrm{C}\right)\end{array}$ & $\begin{array}{l}\text { Dissolution Rate } \\
\left(\mathrm{mg} \mathrm{min} \mathrm{min}^{-1} \mathrm{~cm}^{-2}\right)\end{array}$ \\
\hline $\mathrm{ZrO}_{2}$ & $31 \mathrm{LiF}-24 \mathrm{NaF}-45 \mathrm{ZrF}_{4}$ & 650 & $1.1,1.4$ \\
\hline $36 \% \mathrm{UO}_{2}-64 \% \mathrm{ZrO}_{2}$ & $31 \mathrm{LiF}-24 \mathrm{NaF}-45 \mathrm{ZrF}_{4}$ & 650 & $1.0,1.2$ \\
\hline $\mathrm{UO}_{2}$ & $31 \mathrm{LiF}-24 \mathrm{NaF}-45 \mathrm{ZrF}_{4}$ & 650 & 11.5 \\
\hline $\mathrm{BeO}$ & $49 \mathrm{NaF}-40 \mathrm{LiF}-11 \mathrm{BeF}_{2}$ & 600 & $0.60,0.56,0.62$ \\
\hline $\mathrm{ThO}_{2}$ & \multicolumn{2}{|c|}{$\begin{array}{l}\text { Much faster in } 31 \mathrm{LiF}-24 \mathrm{NaF}-45 \mathrm{ZrF}_{4} \text { than in } \\
\text { any of above due to methathesis with } \mathrm{ZrF}_{4} ; \text { spe- } \\
\text { cific rates difficult to obtain. }\end{array}$} & \\
\hline
\end{tabular}

all materials were either pressed and sintered or fused. 


\section{Aqueous Purification}

The $\mathrm{ThO}_{2} / \mathrm{U}_{3} \mathrm{O}_{8}$ combustion ash from HTGR fuel chlorinated rapidly with phosgene gas or with chlorine gas presaturated at room temperature with carbon tetrachloride vapor (Table IV). Chlorination was complete in $2 \mathrm{~h}$ at $500 \mathrm{C}$ with either reagent. The nonvolatile uranium and thorium tetrachloride products, as well as the uranium penta and hexachlorides that volatilized during chlorination, were all completely water soluble. Short-term corrosion tests indicated that nickelbase alloys would corrode at less than 0.0005 in. per month during the combustion and chlorination steps. The brief period for dissolution of the chloride products in cold water in the combustion reactor should not cause excessive corrosion. The major advantage in this procedure is that a mechanical transfer of the combustion ash to a second vessel for dissolution is not necessary.

Several solvent-extraction methods are available for recovery of the uranium and thorium from aqueous chloride solutions. These elements can be extracted directly with tributyl phosphate (in a kerosene solution) in either zirconium or Hastelloy equipment or in titanium equipment if a small amount of nitric acid is present. However, the chloride must be removed from the solution prior to extraction in stainless steel equipment. The Darex process ${ }^{23}$, in which chloride is oxidized to chlorine gas with nitric acid, is particularly suited for this purpose.

\section{TABLE IV}

Combustion-Chlorination of HTGR Fuel

Samples: $10 \mathrm{~g} ; 1.5 \% \mathrm{U}, 7 \% \mathrm{Th}, 91.5 \% \mathrm{C}$ Combustion: $2.5 \mathrm{~h}, 800 \mathrm{C}, 1$ liter of $\mathrm{O}_{2}$ per $\mathrm{min}$ Chlorination: $2 \mathrm{~h}, 300 \mathrm{~cm}^{3}$ per min

\begin{tabular}{|c|l|c|c|}
\hline Run & \multicolumn{1}{|c|}{ Reagent } & $\begin{array}{c}\text { Temp. } \\
\left({ }^{\circ} \mathrm{C}\right)\end{array}$ & $\begin{array}{c}\text { Uranium } \\
\text { Volatilized } \\
(\%)\end{array}$ \\
\hline 1 & $85 \% \mathrm{Cl}_{2}-15 \% \mathrm{CCl}_{4}$ & 500 & 74.5 \\
2 & $85 \% \mathrm{Cl}_{2}-15 \% \mathrm{CCl}_{4}$ & 550 & 83.6 \\
3 & $\mathrm{COCl}_{2}$ & 500 & 63.6 \\
\hline
\end{tabular}

\section{Purification by Chloride Volatility}

In experiments with HTGR ash, over half the uranium chlorides volatilized using either $\mathrm{COCl}_{2}$ or $\mathrm{Cl}_{2} / \mathrm{CCl}_{4}$ at $500 \mathrm{C}$ and was collected on the cool exit of the reaction tube (Table IV). The thorium

${ }^{20}$ F. G. KTTTS and W. E. CLARK, "The Darex Process: The Treatment of Stainless Steel Reactor Fuels with Dilute Aqua Regla," ORNL-2712 (May 23, 1962). remained as a nonvolatile residue. At $550 \mathrm{C}$ in $\mathrm{Cl}_{2} / \mathrm{CCl}_{4}$, about $10 \%$ more of the uranium volatilized than at $500 \mathrm{C}$. To achieve a complete separation of the uranium and thorium, volatilization of both the uranium and thorium chlorides at 700 to $900 \mathrm{C}$ and selective condensation of the thorium chloride at about $650 \mathrm{C}$ would probably be necessary. The uranium chloride could be collected at a much lower temperature. Although the $\mathrm{ThO}_{2}$ component of the combustion ash chlorinated rapidly at $500 \mathrm{C}$, sintered $\mathrm{ThO}_{2}$ can be chlorinated only at temperatures of $900 \mathrm{C}$ or higher. Since corrosion rates of nickel-base alloys in chlorine and $\mathrm{CCl}_{4}$ are excessively high at temperatures above $600 \mathrm{C}^{24}$, decontamination and separation of uranium and thorium by chloride volatility methods appears less attractive than by solvent extraction from aqueous solution. However, suitable materials of construction for high-temperature chlorination are being sought.

Chlorination of beryllia or alumina with carbon tetrachloride vapor is possible, but the temperatures required are too high for containment of the $\mathrm{CCl}_{4}$ vapor in metal. Temperatures of about $900 \mathrm{C}$ are needed for the chlorination of beryllia that has been sintered at high temperatures ${ }^{25}$.

\section{AQUEOUS PROCESSES INVOLVING COMBUSTION}

Since combustion in oxygen converts the constituents of the fuel to their respective oxides, the combustion/dissolution method ${ }^{10},{ }^{28}$ is potentially applicable to both dispersion and coated-particle fuels containing $\mathrm{ThC}_{2}, \mathrm{UC}_{2}, \mathrm{SiC}$ and $\mathrm{BeO}$, but probably cannot be used with fuels containing $\mathrm{Al}_{2} \mathrm{O}_{3}$ or $\mathrm{ZrC}$. Both sintered $\mathrm{Al}_{2} \mathrm{O}_{3}$ and $\mathrm{ZrO}_{2}$ are extremely inert to aqueous reagents. If the burner is constructed of a nickel-base alloy, which cannot be used to contain nitric acid, the oxide combustion ash will probably have to be transferred to a separate stainless steel vessel for dissolution. However, if the wall temperatures of the burner can be controlled below $1000 \mathrm{C}$, combustion and dissolution could possibly be carried out in the same stainless steel vessel.

Laboratory-scale experiments show ed ${ }^{10,11,27}$ that $\mathrm{ThO}_{2} / \mathrm{U}_{3} \mathrm{O}_{8}$ ash produced by combustion of fuel

${ }^{24}$ M. H. BROWN, W. D. DeLONG and J. R. AULD, ind. Eng. Chem., 38, 839 (1947).

${ }^{35} \mathrm{~A}$. V. NOVOSELOVA and K. N. SEMENENKO, Russian J. morg. Chem., 3, 2213 (1938); see translation AERE-tr$11 / 3 / 5 \% 1180$.

${ }^{20}$ D. J. O'CONNOR and K. R. HYDE, "Summary of Processing Studies on HUGO Fuels. Part I. Oxidation and Acid Leaching," H.T.G.C./F.P.W.P./P.5 (May 15, 1957).

${ }^{27}$ L. M. FERRIS, "Chemical Processing of .Coated Par ticle Fuels," ORNL-TM-193 (April 3, 1962). 
samples at 800 to $1200 \mathrm{C}$ dissolved readily in a $200 \%$ excess of boiling $13 \mathrm{M} \mathrm{HNO}_{3} / 0.04 \underline{\mathrm{M}} \mathrm{HF} / 0.1$ M $\mathrm{Al}\left(\mathrm{NO}_{3}\right)_{3}$ (Table $\mathrm{V}$ ). The ash from HTGR fuel irradiated to about $10000 \mathrm{MWd} / \mathrm{T}(\mathrm{U}+\mathrm{Th})$ also dissolved readily in this reagent ${ }^{11}$. Fuels containing $\mathrm{SiC}$ will require more stringent treatment since the $\mathrm{SiO}_{2}$ formed (which does not dissolve in nitric acid) traps 0.5 to $3 \%$ of the uranium (Table v). Although not yet tested, it is possible that the $\mathrm{SiO}_{2}$ can be dissolved in concentrated $\mathrm{NaOH}$ solution prior to the dissolution of the uranium and thorium oxides in fluoride-catalyzed nitric acid. Combustion of fuel samples containing $\mathrm{Al}_{2} \mathrm{O}_{3}-$ coated particles left the particles virtually unaffected, and hence less than $10 \%$ of the uranium was recovered in the subsequent nitric acid leach of the particles (Table V). Iron, which may be an undesired impurity in the graphite matrix, forms a nitric-acid-insoluble oxide on combustion, and can trap a significant amount of uranium (TableV).

Uranium and thorium oxides tend to form solid solutions with zirconium oxide which cannot be dissolved readily in aqueous reagents. Fuels containing $\mathrm{ZrC}$ will, therefore, probably have to be processed by one of the combustion/volatility methods.

\section{AQUEOUS PROCESSES NOT} INVOLVING COMBUSTION

\section{Grind-Leach Process}

An alternative aqueous process for coatedparticle fuels that does not involve combustion of the fuel as the first step is mechanical grinding followed by acid leaching of the finely powdered material ${ }^{10}, 28-91$. Obviously, the fuel must be ground fine enough to ensure rupture of all the fuel particles, about 200 mesh for 100 -micron particles. In laboratory tests of this method, recoveries were greater than $99 \%$ from both carbon- and $\mathrm{Al}_{2} \mathrm{O}_{3}$-coated fuels. However, the grind-leach method is plagued with engineering problems. Grinding a highly radioactive material to a fine powder, and centrifugation or filtration operations with the finely powdered graphite are difficult. Colloidal-size particles either plugged the filters or could not be removed by centrifuging. However, some encouraging studies have shown that uranium and thorium can be recovered by solvent extraction directly from a nitric-acid/graphite slurry. Preliminary studies ${ }^{32,39}$ showed that organic compounds formed in the dissolution of uranium and thorium carbides in nitric acid caused emulsifica-

${ }^{28}$ M. J. BRADLEY and L. M. FERRIS, Nucl. Sci. Eng., 8, 432 (1960):

29M. J. BRADLEY and L. M. FERRIS, "Recovery of Uranium and Thorium from Graphite-Fuels. I. Laboratory Development of a Grind-Leach Process," ORNL-2761 (March 17, 1960).

${ }^{{ }^{\circ}}$ K. R. HYDE and D. J. O'CONNOR, "Processing Studies on H.T.G.C. Fuels," AERE C/R 2321 (September 1957).

${ }^{31}$ W. B. TARPLEY and R. S. WINCHESTER, "Ultrasonic Leaching of Urania-impregnated Graphite Fuels," NYO9581 (April 1961).

${ }^{32}$ A. M. SIMPSON and B. A. HEATH, "Products of the Reaction Uranium Monocarbide-Nitric Acid,' IG Memorandum 464 (D), (June 1959).

${ }^{3}$ R. E. BLANCO, "Quarterly Progress Report for Chemlcal Development Section B, July-September 1962," ORNL-TM-403 (Feb. 7, 1963).

TABLE V

Uranium and Thorium Recoveries from Graphite Fuels by the Combustion/Dissolution Process Fuel Burned in Oxygen at 800-1200 C; Ash Leached 6-10 h in Boiling Reagent

\begin{tabular}{|c|c|c|c|c|c|c|c|}
\hline \multirow[t]{2}{*}{ Types of Particle in Fuel } & \multicolumn{4}{|c|}{ Fuel Comp. (\%) } & \multirow[t]{2}{*}{$\begin{array}{c}\text { Leachant } \\
\text { (Moles/liter) }\end{array}$} & \multicolumn{2}{|c|}{$\begin{array}{l}\text { Amount } \\
\text { Unleached } \\
(\%)\end{array}$} \\
\hline & $\mathbf{U}$ & Th & Si & $\mathrm{Fe}$ & & $\mathrm{U}$ & Th \\
\hline Uncoated $\mathrm{ThC}_{2}-\mathrm{UC}_{2}$ & 1.7 & 8.0 & - & - & $\begin{array}{l}13 \mathrm{HNO} / 0.04 \\
\mathrm{HF} / 0.1 \mathrm{Al}\left(\mathrm{NO}_{3}\right)_{3}\end{array}$ & 0 & 0 \\
\hline Pyrolytic carbon-coated $\mathrm{ThC}_{2}-\mathrm{UC}_{2}$ & 9.9 & 33.0 & - & - & $\begin{array}{l}13 \mathrm{HNO} / \mathrm{s} / 0.04 \\
\mathrm{HF} / 0.1 \mathrm{Al}\left(\mathrm{NO}_{\mathrm{s}}\right)_{\mathrm{s}}\end{array}$ & 0 & 0 \\
\hline $\mathrm{Al}_{2} \mathrm{O}_{3}$-coated $\mathrm{UO}_{2}$ & 8.0 & - & $-\cdot$ & - & $10 \mathrm{HNO}_{3}$ & 90.1 & - \\
\hline Uncoated $\mathrm{UC}_{2}$ & 3.7 & - & - & 0.1 & $10 \mathrm{HNO}_{3}$ & 0.2 & - \\
\hline Uncoated $\mathrm{UC}_{2}$ & 0.7 & - & - & 0.4 & $10 \mathrm{HNO}$, & 2.0 & - \\
\hline Uncoated $\mathrm{UO}_{2}$ & 7.0 & - & 2.0 & - & $10 \mathrm{HNO}_{3}$ & 0.4 & - \\
\hline Uncoated UO, & 6.8 & - & 20.3 & - & $10 \mathrm{HNO}_{3}$ & 2.4 & - \\
\hline
\end{tabular}


TABLE VI

Uranium and Thorium Recoveries from Graphite Matrix Fuels by the 90\% HNO, Process

Conditions: Fuel samples simultaneously disintegrated and leached in boiling 21.5 $\mathrm{M}$ HNO, for two 4-h periods; the residue was then water-. washed.

\begin{tabular}{|c|c|c|c|c|}
\hline \multirow{2}{*}{$\begin{array}{l}\text { Fuel Dispersed in } \\
\text { Graphite Matrix }\end{array}$} & \multicolumn{2}{|c|}{ Fuel Comp. (\%) } & \multicolumn{2}{|c|}{ Amount Unleached (\%) } \\
\hline & $\mathbf{U}$ & Th & $\mathrm{U}$ & Th \\
\hline Uncoated $\mathrm{UO}_{2}$ & 7.1 & 0 & 0.1 & - \\
\hline Uncoated $\mathrm{UC}_{2}$ & 3.0 & 0 & 0.62 & -- \\
\hline Uncoated $\mathrm{UC}_{2}$ & 13.7 & 0 & 0.07 & -- \\
\hline Uncoated ThC-UC ${ }^{a}$ & 1.5 & $7.2{ }^{`}$ & 0.06 & 0.25 \\
\hline Uncoated ThC-UC & 1.3 & 15.0 & 0.10 & 0.16 \\
\hline $\mathrm{C}$-coated $\mathrm{ThC}_{2}-\mathrm{UC}_{2}$ & 9.7 & 33.5 & 93.1 & 95.1 \\
\hline $\mathrm{Al}_{3} \mathrm{O}_{3}$-coated $\mathrm{UO}_{2}$ & 8.0 & 0 & 99.2 & -- \\
\hline C-coated $U^{2} C_{2} b$ & 8.0 & 0 & 98.0 & -- \\
\hline
\end{tabular}

a Three $4 \mathrm{~h}$ leaches.

${ }^{b}$ Disintegrated anodically in $15.8 \mathrm{M} \mathrm{HNO}_{3}$ at $95 \mathrm{C}$, then leached twice for $4 \mathrm{~h}$ in boiling $15.8 \mathrm{M} \mathrm{HNO}_{3}$.

tion during solvent extraction of the uranium under normal Purex conditions. However, the emulsioncausing compounds can be partially degraded to inactive species by treatment with permanganate.

Even though the grind-leach process may be proven applicable for other types of fuels, it is doubtful that the method can be used with a $\mathrm{ZrC}$ bearing fuel such as proposed for the Dragon reactor, particularly if the $\mathrm{ZrC}$ concentration in the fuel particle is high. High-density zirconium carbide is inert to most boiling acids, including nitric, and dissolves rapidly only in $\mathrm{HNO}_{3} / \mathrm{HF}$ mixtures when the $\mathrm{HF}$ concentration is higher than about $1 \mathrm{M}$. Such $\mathrm{HNO}_{3} / \mathrm{HF}$ solutions cannot be contained in most metals and alloys, so their use as process reagents is precluded except where fuel irradiation levels are low enough to permit the use of acid-resistant plastic equipment.

Possibly a grind-leach process can be applied to $\mathrm{Al}_{2} \mathrm{O}_{3}$ - or $\mathrm{BeO}$-coated particles after the graphite matrix has been removed by combustion or electrolysis. In this way, the amount of material to be ground is reduced about tenfold.

\section{0\% $\mathrm{HNO}_{3}$ and Anodic Disintegration Processes}

Several relatively simple aqueous processing approaches were developed for dispersion-type fuel before the advent of coated-particle fuels. Simultaneous disintegration and leaching ${ }^{10},{ }^{34}$ (two $4-\mathrm{h}$ leaches) in boiling $90 \% \mathrm{HNO}_{3}$ resulted in uranium and thorium recoveries of at least $99.5 \%$ from typical fuel samples (Table VI). The nitric

S4M. J. BRADLEY and L. M. FERRIS, Ind. Eng. Chem., 53, 279 (1961). acid leach liquor, after appropriate concentration adjustment, was suitable as a feed for decontamination and recovery of the uranium and thorium by solvent extraction with tributyl phosphate. Another effective method tested was anodic disintegration and leaching ${ }^{35},{ }^{36}$ of the fuel in 4 to $10 \mathrm{M} \mathrm{HNO}_{3}$. Unfortunately, these techniques were not applicable to coated-particle fuels, the recoveries being generally less than 5\% (Table VI). It should be noted, however, that the anodic disintegration procedure has found wide application in evaluating the integrity of coated particles in unirradiated and irradiated graphite fuel compacts ${ }^{37}, 38$. A suitable method for separating the heavy coated particles from the graphite slurry remains to be developed.

\section{ACKNOWLEDGMENT}

This paper presents the work of many people in the Chemical Technology Division, Oak Ridge National Laboratory, including M. R. Bennett, M. J. Bradley, B. A. Hannaford, S. Katz, A. H. Kibbey, F. G. Kitts, R. S. Lowrle, L. E. McNeese, R. H. Rainey, C. E. Schilling, C. D. Scott, J. W. Ullmann, K. S. Warren, and C. D. Watson.

${ }^{\text {s5 }}$ L. M. FROMM, "Recovery of Uranium from Graphite Shapes by Electrolytic Disintegration in Nitric Acid," ORNL-238 (Feb. 24, 1949).

${ }^{30}$ K. R. HYDE, D. J. O'CONNOR and J. L. WOODHEAD, "Acid Leaching and Anode Dissolution of Graphite-moderated Fuels," Australian Atomic Energy Symposium, Melbourne University Press, Melbourne, Australia, p. 420 (1958).

${ }^{37}$ R. A. EWING, T. S. ELLEMAN and R. B. PRICE, Trans. Am. Nucl. Soc., 4 (i) , 152 (1961).

38،"Gas-Cooled Reactor Program Semi-Annual Progress Report for Period Ending March 31, 1963," ORNL-3445, p. 132 (1963): 


$$
\text { BNW-7352 CONF - } \mid 17-21
$$

RECOVERY OF URANIUM FROM PYROLYTIC CARBON-COATED

$\mathrm{UC}_{2}$ SPHEROIDS

by

'H. Katz and J. Wagner

Brookhaven National Laboratory

Upton, L. I., N. Y.

\section{ABSTRACI}

$100 \%$ recovery of uranium from pyrolytic carbon-coated spheroids of uranium dicarbide has been accomplished by an aqueous electrolytic process at the small scale laboratory level. This result was obtained in a system which circulated 1-molar nitric acid through a thin bed of the spheres. The bed was supported between a glass frit and the anode, with which the bed was in contact. The anode was a spiral of platinum wire; the cathode was a grid of tantalum wire. Current density was about $0.2 \mathrm{amp} / \mathrm{cm}^{2}$ based on geometric surface area calculated from the javerage particle size of 150 microns. Initial flow rate was about $1.3 \mathrm{ml} / \mathrm{cm}^{2} / \mathrm{sec}$. Reaction temperature was $72-82^{\circ} \mathrm{C}$; time was 15 hours.

At $1 / 5$ the above current density and at the same temperature, recovery was smaller and was independent of concentration of nitric acid over the range $1-4$ molar; also recovery in 1-molar ammonium nitrate was about the same as in 1 -molar $\mathrm{HNO}_{3}$.

About a 100-fold increase in recovery was obtained by going from a convection-stirred cell at $90^{\circ} \mathrm{C}$ to the pumped type of cell at $54^{\circ} \mathrm{C}$ using ammonium nitrate as the electrolyte.

$$
181-93
$$




\section{INTRODUCTION}

Various schemes for the recovery of uranium from nuclear fuels have been reported (1-6). Schweitzer, et al (7) detected uranium in solution following electrolysis of coated $\mathrm{UC}_{2}$ particles in a static type cell, like our type II cell, Figure 4. In the present work, pyrolytic carbon-coated $\mathrm{UC}_{2}$ spheroids were electrolyzed in aqueous 1-molar $\mathrm{HNO}_{3}$ to yield 100 per cent recovery.

\section{RESULTS}

\section{Recovery of Uranium as a Function of}

Current Density and Temperature

In Figure 1, uranium recovery is plotted against reaction time. One hundred per cent recovery was obtained in 15 hours. The electrolyte was 1-molar $\mathrm{HNO}_{3}$; current density was about $0.2 \mathrm{amp} / \mathrm{cm}^{2}$; temperature was $72-82^{\circ} \mathrm{C}$; initial flow rate was about $1.3 \mathrm{ml} / \mathrm{cm}^{2} / \mathrm{sec}$. The other data suggest that higher current densitities and temperatures improve recovery. For example, at a current density of $0.04 \mathrm{amp} / \mathrm{cm}^{2}$ and $49^{\circ} \mathrm{C}$, about $30 \%$ recovery was obtained. This is compared with $70-86 \%$ recovery at the higher current density and temperatures. At zero current density.a recovery of $0.9 \%$ was obtained in 18 hours. It also appears that there may be an optimum temperature since our results at $80^{\circ}$ were better than at $90^{\circ}$ and $64^{\circ}$. The two crosses $(+)$ show the result of using $2-\mathrm{M}$ and $4-\mathrm{M}$ $\mathrm{HNO}_{3}$ at $85^{\circ}$ and $93^{\circ}$ respectively, current density $0.04 \mathrm{amp} / \mathrm{cm}^{2}$. 


\section{EXPERIMENTAL}

These results were obtained in a system which circulated the electrolyte through a thin bed of the $\mathrm{UC}_{2}$ particles supported on a pyrex frit. Figure 2 is a sketch of the electrolytic cell. The anode, which pressed the particles against the frit, was a flat spiral of $40 \mathrm{mil}$ p.latinum wire. The cathode was a grid of $40 \mathrm{mil}$ tantalum wire. Initial flow rate through the frit was about $1.3 \mathrm{ml} / \mathrm{cm}^{2} / \mathrm{sec}$. Gas pressure above the anode ranged from 8.5 to 11.5 psig. The frit was standard Pyrex, coarse pore size: The area used to calculate current density was obtained by adding the total wetted surface area of the anode to the geometric surface area of the $\mathrm{UC}_{2}$ particles, assuming a uniform size distribution of spheres. The direction of flow across the bed was chosen so as to hold the particles against the frit and in contact with the anode. Earlier work had shown that contact with the anode was essential.

\section{Earlier Experiments}

Some of our earlier runs were made using 1 -molar $\mathrm{NH}_{4} \mathrm{NO}_{3}$ as the electrolyte. In Figure 3 we have plotted the results on the same scale as the nitric acid data and compared them with these data. The solid lines are the nitric acid data. The triangles show results in $\mathrm{NH}_{4} \mathrm{NO}_{3}$ obtained at $76^{\circ} \mathrm{C}$. The solid black triangle was run at a current density of 0.02 to $0.03 \mathrm{amp} / \mathrm{cm}^{2}$; the open triangles at $0.01 \mathrm{amp} / \mathrm{cm}^{2}$. The circles show results at $54^{\circ} \mathrm{C}$; solid circle at a current density of $0.02-0.03$ amp $/ \mathrm{cm}^{2}$; open circles at $0.01 \mathrm{amp} / \mathrm{cm}^{2}$. 
The square data points were run at $91^{\circ} \mathrm{C}$, current density 0.02$0.03 \mathrm{amp} / \mathrm{cm}^{2}$, but differed from the other points in that they were obtained in the cell shown in Figure 4. In this cell, only force of gravity was used to keep the particles touching the anode, and the anode gas pressure was atmospheric. Going back to Figure 3, one solid line shows the nitric acid data at $49^{\circ} \mathrm{C}, \mathrm{CD}=0.04 \mathrm{amp} / \mathrm{cm}^{2}$; and the other, the best nitric acid data. The results in $\mathrm{NH}_{4} \mathrm{NO}_{3}$ suggest that recovery is about the same as in $\mathrm{HNO}_{3}$; Also, that the type of cell is very important. In the cell giving $100 \%$ recovery, the particles were pressed between the frit and the anode.

\section{Discussion}

Figure 5 is a photograph of the particles showing their appearance before reaction. Note the uniform size distribution. Figure 6 shows the particles after reaction in the Type I cell. Some have split open. One hollow fragment has a wall thickness about $1 / 4$ of i.ts diameter, essentially that before reaction.

To get some idea of the current density required to rapidly rupture pyrolytic carbon, a flat specimen, prepared at Brookhaven National Laboratory, was mounted in silicone rubber so that edges and back were masked. It was placed in 1-molar $\mathrm{HNO}_{3}$ and a current density of 3 amp $6 \mathrm{~cm}^{2}$ applied. Within two minutes, swelling and flaking occurred. The current density was then reduced to $1 \mathrm{amp} / \mathrm{cm}^{2}$. Flaking continued but at a slower rate. These results suggest again that it may be possible to reduce reaction time by increasing the current density. 
- Figure 7 is a comparison of the particle size distribution before and after reaction, plotted on log-normal probability scales. Note that after reaction and $58 \%$ recovery, the average particle diameter was about $16 \%$ greater than that of the unreacted material. Also, the maximum diameter of the particles was greater than that before reaction, and the proportion of both very large and very small particles was greater. The increase in the proportion of small particles is attributed to flaking and that of the large particles to swelling.

At $100 \%$ recovery, the average particle diameter was about the same as that before reaction; maximum particle size was greater than before reaction; but less than at $58 \%$ recovery. The proportion of very smal1 particles increased considerably.

In earlier work done by Schweitzer, et al. (7), carbonate was deţected in an $\mathrm{NH}_{4} \mathrm{NO}_{3}$ system, which, of course, suggests oxidation. If a surface oxidation were the only process, a parallel shift in particle size distribution toward smaller diameters would be expected. since oúr data do not show this, we conclude that it is a mixed process of oxidation and swelling. This conclusion is also supported by the appearance of the particles after reaction.

A major problem was plugging of the glass fit. We have delayed plugging by placing a fine frit before the cell inlet.

Why is there an apparent temperature maximum for recovery? At $90^{\circ} \mathrm{C}$, gas bubbles larger than at the other temperatures were observed at the anode. These large bubbles may have blocked the current more than smaller bubbles so that the effective current density may have been less than calculated. 
In summary, we have described a method for $100 \%$ recovery of uranium from pyrolytic carbon-coated $\mathrm{UC}_{2}$ spheroids by electrolysis in an aqueous solution. This was done in a system which circulated the electrolyte through a thin bed of the particles. The bed was pressed between a porous glass frit and the anode.

\section{Acknowledgement}

Use of the Zeiss particle size analyzer was obtained through the kindness of Dr. E. P. Cronkite, Brookhaven National Laboratory. C. H. Brewster was very helpful with execution of the experiments. S. J. Tassinari, D. Leahy, P. Klotz, R. Schwartz, and.J. Murphy contributed the uranium analyses.

This research was sponsored by the U. S. Atomic Energy Commission.

\section{Literature Cited}

(1) Fromm, L. W., Jr. (to U. S. Atomic Energy Commission), U. S. Patent $2,903,402$ (8 September 1959).

(2) Ferris, L. M., ORNL-TM-193 (3 April 1962).

(3) Oak Ridge National Laboratory, p 1-57, ORNL-3314 (21 September 1962).

(4) Hyde, K. R. and O'Connor, D. J., AERE-R4107 (August 1962).

(5) Kibbey, A. H. and Ferris, L. M., ORNL-TM-384 (26 September 1962).

(6) Slansky, C. M., Roberts, M. W., and Rohde, K. L., Nuclear Science and Engineering, 12, 33-38 (1962).

(7) Schweitzer, D. G., Singer, R. M., and Hrabak, G., Brookhaven National Laboratory, private communication, 1962. 


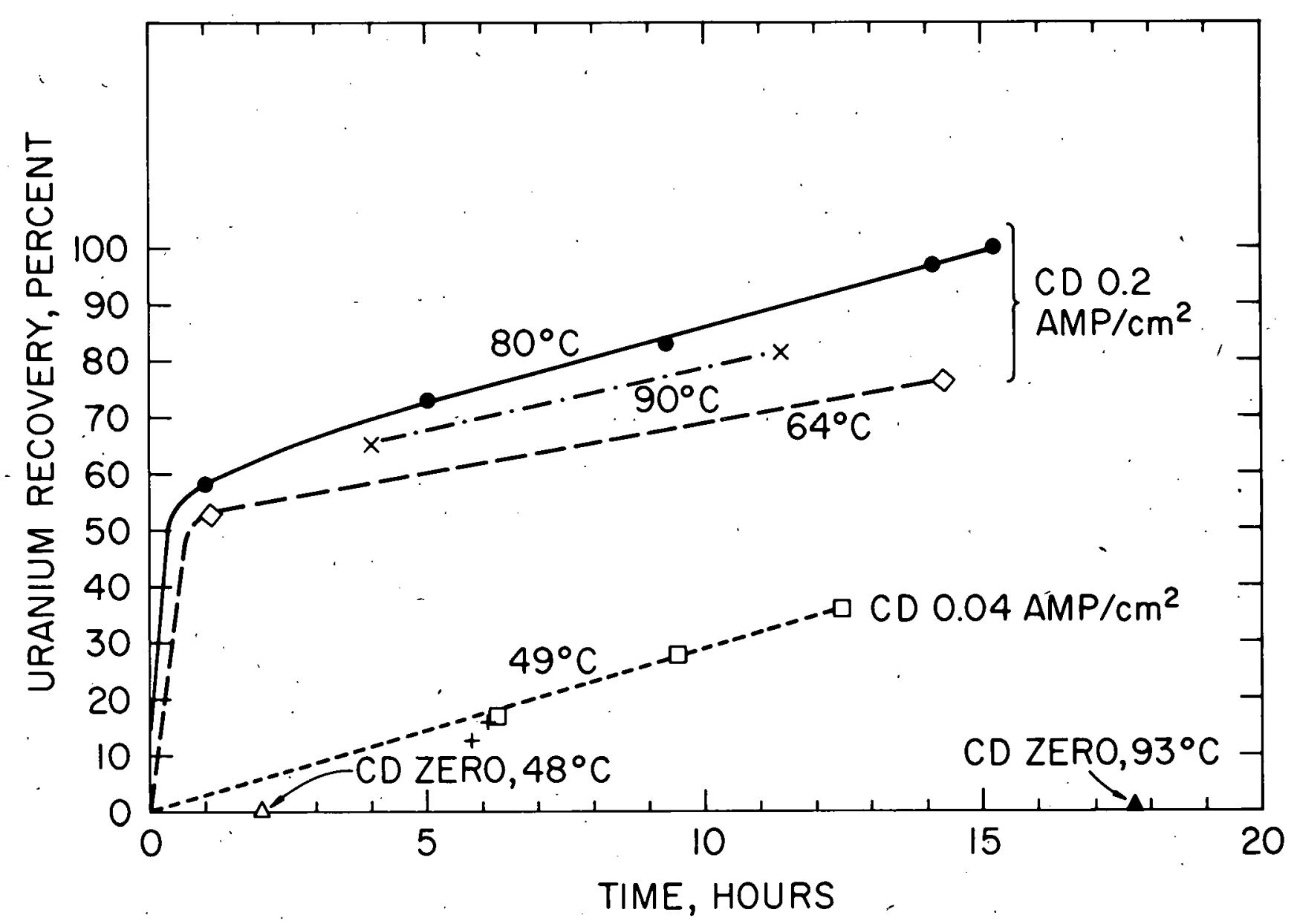

Figure 1. Higher Current Densities and Temperature Improve Recovéry in 1-Molar $\mathrm{HNO}_{3}$. 


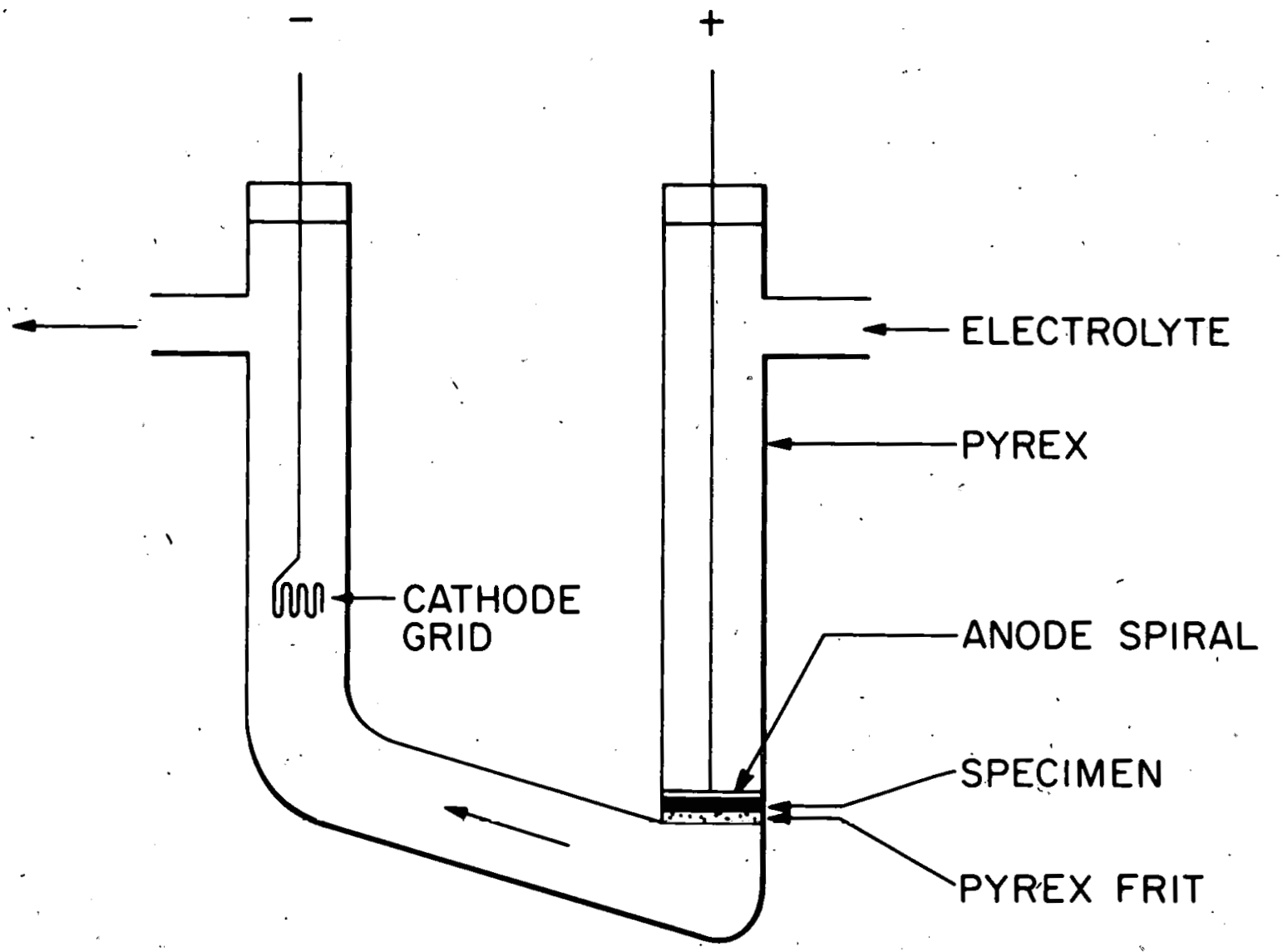

Figure 2. Electrólytic Ce11, Type I. 


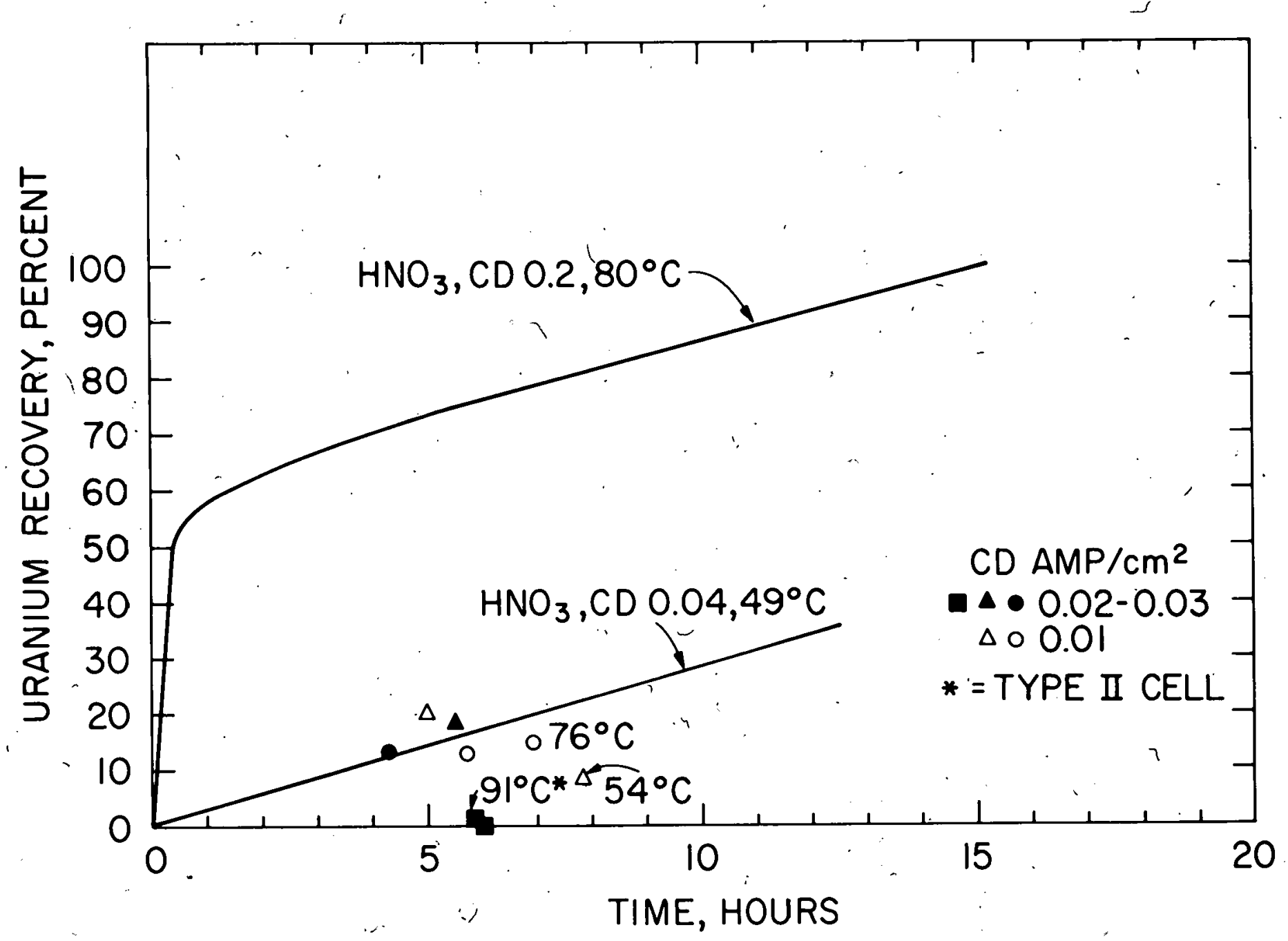

Figure 3. Uranium Rećovery in 1- Molar $\mathrm{NH}_{4} \mathrm{NO}_{3}$. 


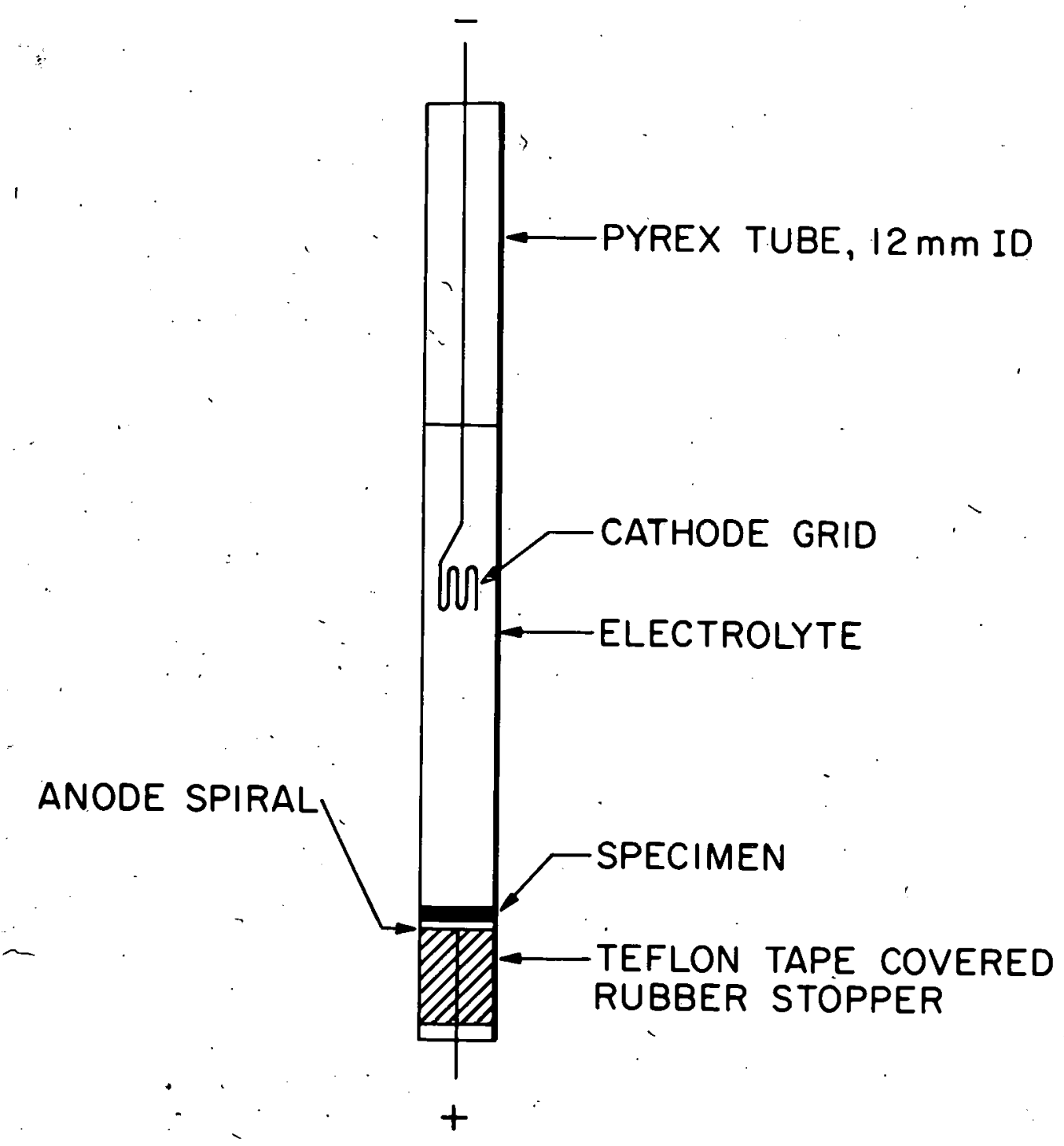

Figure 4. Electrolytic Cell, Type II. 


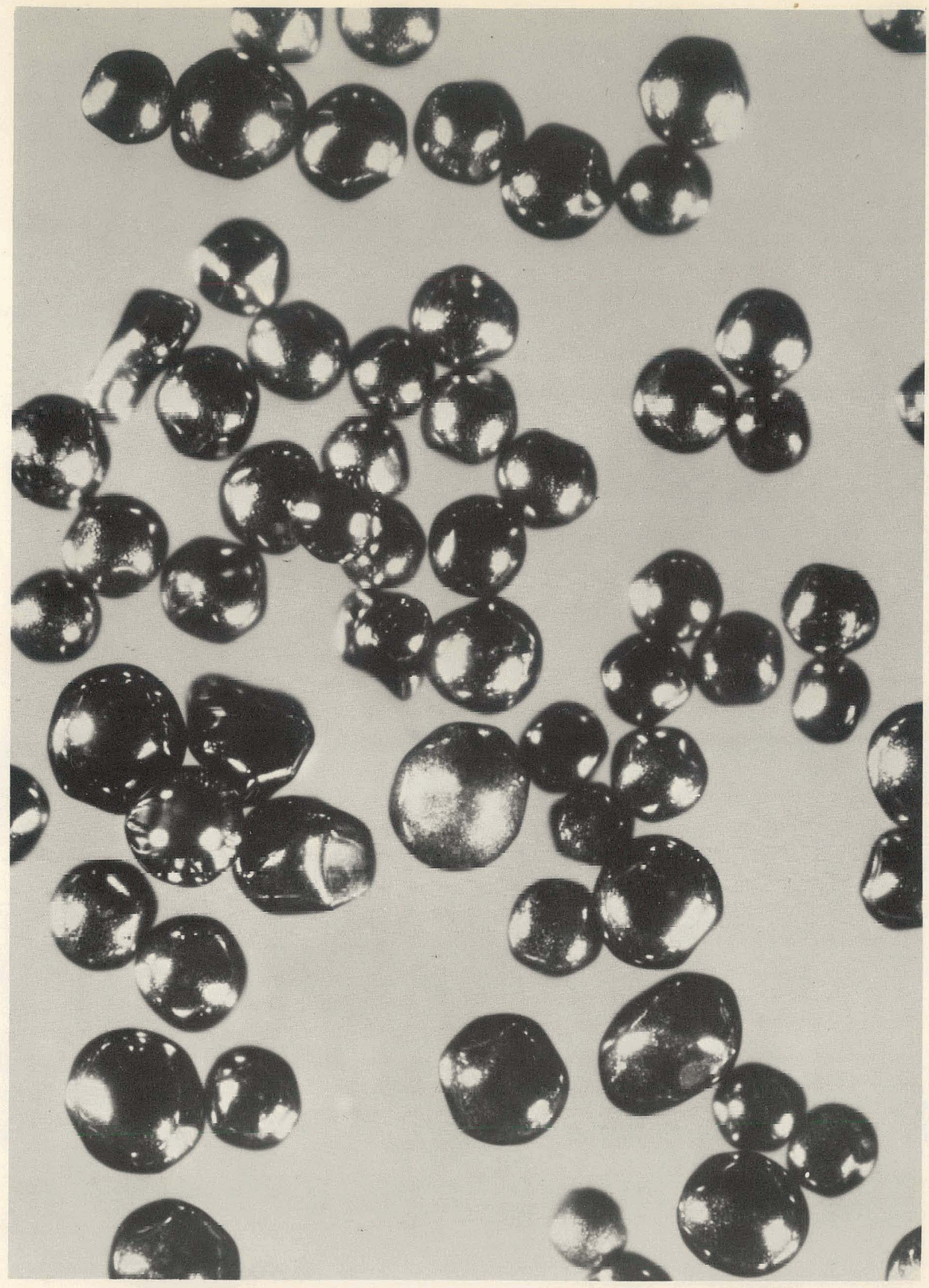

Figure 5. Particles Before Reaction. 

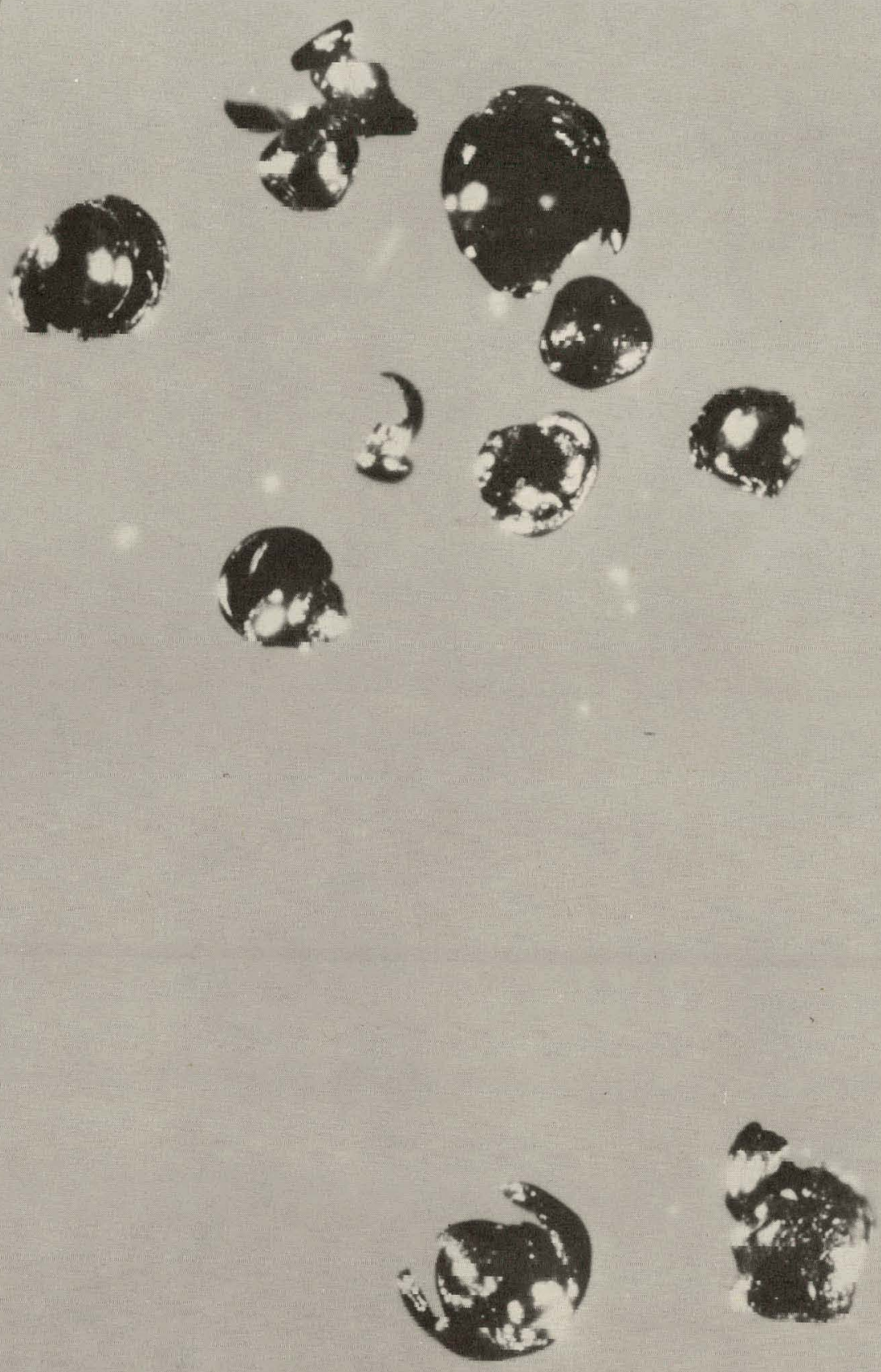

Figure 6. Particles After Reaction. 


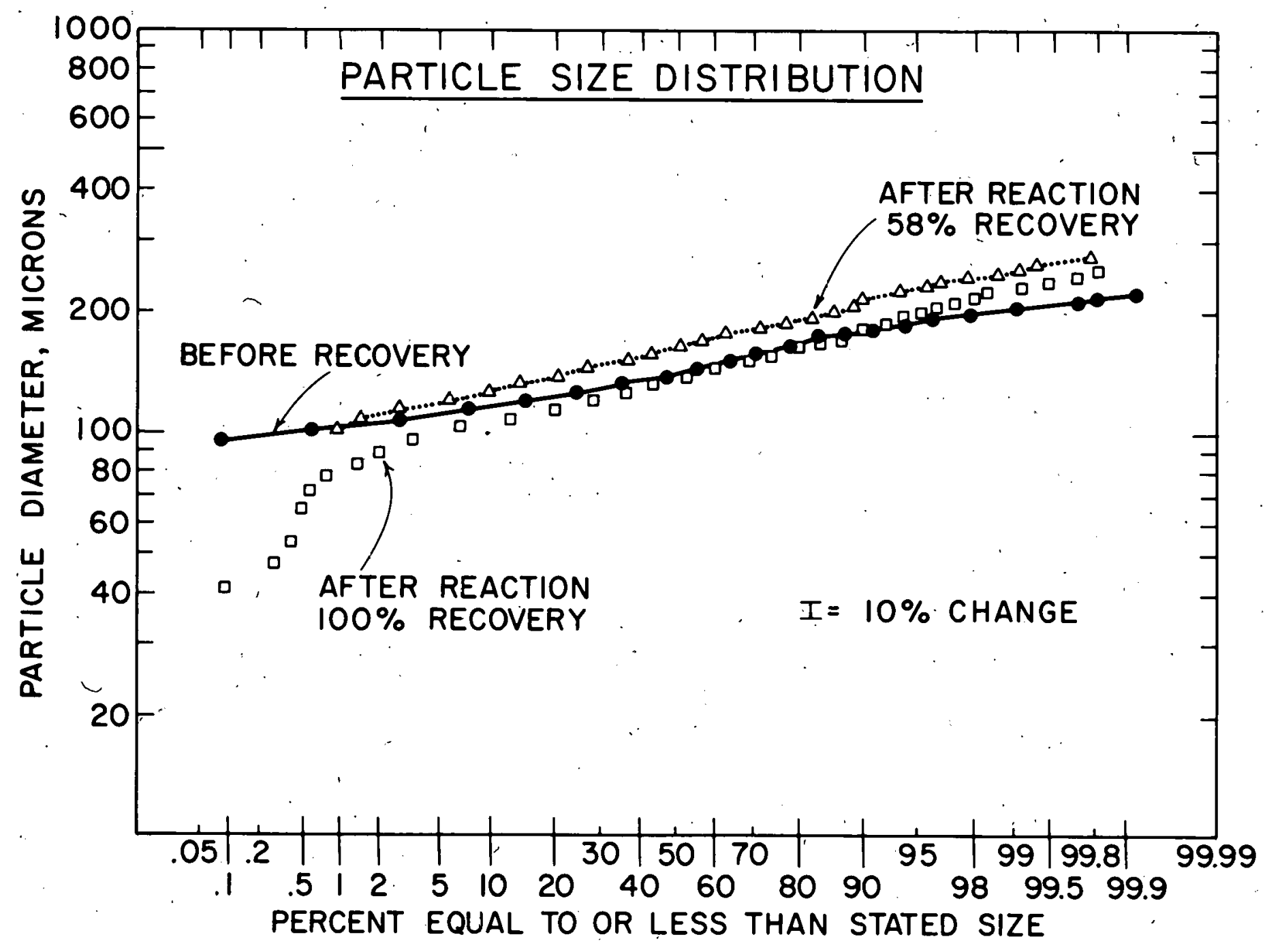

Figure 7. Particle Size Distribution. 